Florida International University

FIU Digital Commons

5-14-2019

\title{
Phenolate Derivatives of Octanuclear Iron-Oxo-Pyrazolato Complexes; Enantiomeric Resolution of T-Symmetry Species
}

Konstantinos Lazarou

Florida International University, klaza005@fiu.edu

Follow this and additional works at: https://digitalcommons.fiu.edu/etd

Part of the Inorganic Chemistry Commons

\section{Recommended Citation}

Lazarou, Konstantinos, "Phenolate Derivatives of Octanuclear Iron-Oxo-Pyrazolato Complexes;

Enantiomeric Resolution of T-Symmetry Species" (2019). FIU Electronic Theses and Dissertations. 4272. https://digitalcommons.fiu.edu/etd/4272

This work is brought to you for free and open access by the University Graduate School at FIU Digital Commons. It has been accepted for inclusion in FIU Electronic Theses and Dissertations by an authorized administrator of FIU Digital Commons. For more information, please contact dcc@fiu.edu. 


\title{
FLORIDA INTERNATIONAL UNIVERSITY
}

\author{
Miami, Florida
}

\section{PHENOLATE DERIVATIVES OF OCTANUCLEAR IRON-OXO-PYRAZOLATO COMPLEXES; ENANTIOMERIC RESOLUSION OF T-SYMMETRY SPECIES}

A dissertation submitted in partial fulfillment of the

requirements for the degree of

DOCTOR IN PHILOSOPHY

in

CHEMISTRY

by

Konstantinos Lazarou 
To: Dean Michael R. Heithaus

College of Arts, Sciences and Education

This dissertation, written by Konstantinos Lazarou, and entitled Phenolate Derivatives of Octanuclear Iron-Oxo-Pyrazolato Complexes; Enantiomeric Resolusion of T-Symmetry Species, having been approved in respect to style and intellectual content, is referred to you for judgment.

We have read this dissertation and recommend that it be approved.

Kostantinos Kavallieratos

Kathleen Rein

David Chatfield

Daniela Radu

Raphael G. Raptis, Major Professor

Date of Defense: May 14, 2019

The dissertation of Konstantinos Lazarou is approved.

Dean Michael R. Heithaus

College of Arts, Sciences and Education

Andrés G. Gil

Vice President of Research and Economic Development and Dean of the University Graduate School

Florida International University, 2019 
(C) Copyright 2019 by Konstantinos Lazarou

All rights reserved. 


\section{DEDICATION}

I dedicate this work to all the people who supported me during a difficult period

of my life and gave me the motivation to stand back on my feet and keep pursuing my dreams. 


\section{ACKNOWLEDGMENTS}

First, I would like to thank my advisor Professor Raphael G. Raptis for his trust that made me part of his group. His continuous support and guidance was decisive for the completion of this work. I learned a lot next to him and matured as a chemist, as a scientist overall. I feel lucky and honored having worked with him and being supervised by him.

I would also like to thank the members of my committee: Prof. Konstantinos Kavallieratos, Prof. Kathleen Rein, Prof. David Chatfield and Prof. Daniela Radu for their advice, support and feedback during these years.

I would like to thank our collaborators and technical staff that promoted this work: Prof. Karilys Gonzalez-Nieves (University of Puerto Rico, Carolina, PR), Dr. Yiannis Sanakis (National Center for Scientific Research "Demokritos”, Athens, Greece; EPR and ${ }^{57} \mathrm{Fe}-$ Mössbauer measurements), and Dr. Ya Li Hsu (Florida International University, USA; NMR and IR measurements). I would also like to thank Dr. Evgen Govor for providing crystallographic and electrochemical data for some of the $\mathrm{Fe}_{8}$ compounds with phenolates, as well instructing me with the synthesis of these complexes.

I would like to thank Professor Raptis' research group, for their invaluable support, help and patience: Dr. Loguesh Mathivathanan, Dr. Indranil Chakraborty, Dr. Alan Rodriguez, Dr. Kaige Shi, Dr. Shambhu Kandel, Dr. Jessica M. Lopez-Pla and David Kreiger. Thank you for sharing your experiences, expertise and friendship. 
ABSTRACT OF THE DISSERTATION

PHENOLATE DERIVATIVES OF OCTANUCLEAR IRON-OXO-PYRAZOLATO

COMPLEXES; ENANTIOMERIC RESOLUSION OF T-SYMMETRY SPECIES

\author{
by
}

Konstantinos Lazarou

Florida International University, 2019

Miami, Florida

Professor Raphael G. Raptis, Major Professor

Octanuclear ferric complexes involving achiral phenolates of the general formula $\left[\mathrm{Fe}_{8}\left(\mu_{4}-\mathrm{O}\right)_{4}(\mu-\mathrm{pz})_{12}\left(\mathrm{R}-\mathrm{C}_{6} \mathrm{H}_{4} \mathrm{O}\right)_{4}\right],\left(\mathrm{R}=4-\mathrm{NO}_{2}, 4-\mathrm{CN}, 4-\mathrm{F}, 4-\mathrm{Cl}, 4-\mathrm{I}, 4-\mathrm{CH}_{3} \mathrm{O}\right.$, and 3- $\left.\mathrm{NO}_{3}\right)$, where synthesized and characterized by single crystal X-ray crystallography, elemental analysis, ${ }^{1} \mathrm{H}-\mathrm{NMR}$, UV-Vis, IR, ${ }^{57} \mathrm{Fe}$ Mössbauer spectroscopy and electrochemical methods (cyclic and differential pulse voltammetry). Results indicate that the nature of the phenolate substituents allows the fine tuning of the spectroscopic data of the compounds.

Subsequently, this project focused on the resolution of the racemic octanuclear iron-oxo-pyrazolato complex $\left[\mathrm{Fe}^{\mathrm{III}}{ }_{8}\left(\mu_{4}-\mathrm{O}\right)_{4}(\mu-4-\mathrm{R}-\mathrm{pz})_{12} \mathrm{Cl}_{4}\right],\left[\mathrm{Fe}_{8}\right],(\mathrm{R}=\mathrm{H}, \mathrm{Me}, \mathrm{Cl})$ to its $P$ and $M$ enantiomers. The strategy employed towards that goal was the diastereomer formation via substitution of the terminal chloride ligands with the chiral $(R, S)$ 4-secbutylphenol. Substitution with rac-4-sec-butylphenol reveals selectivity of the $\mathrm{Fe}_{8} P$ and $M$ enantiomers for the phenolate $R$ and $S$ enantiomers, respectively. In the case of the 4$\mathrm{H}-\mathrm{pz}$ and 4- $\mathrm{CH}_{3}-\mathrm{pz}$ derivatives, this selectivity is manifested in their X-ray structures and ${ }^{1} \mathrm{H}-\mathrm{NMR}$ spectra. However it does not result in resolution, as the enantiomers 
cocrystallize as racemates. In contrast, the 4-Cl-pz derivative crystallized in a noncentrosymmetric (chiral) space group, as determined by single crystal X-ray structure determination. The enantiomeric relationship of the $P / R$ and $M / S$ species was further established by Circular Dichroism experiments. These enantiomers are stable towards racemization. Re-introduction of the terminal chloride ligands was achieved via reaction of the $P / R$ and $M / S$ with $\mathrm{HCl}$, and the Circular Dichroism spectra of the products showed the presence of the $P$ and $M$ enantiomers in solution with their absolute configuration persisting.

The selective coordination of the $R$ and $S$ phenolates to the $P$ and $M$ complexes constitutes an unprecedented example of enantiomeric recognition in a non-biological system resulting in spontaneous resolution upon crystallization by employing only racemic reagents and media. 


\section{TABLE OF CONTENTS}

CHAPTER

PAGE

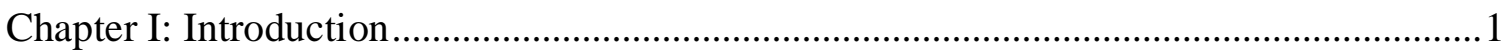

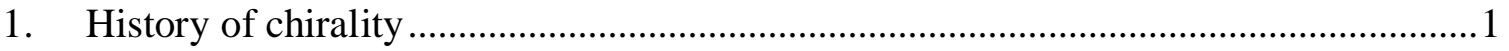

1.1. Chirality: Definition..................................................................................

1.2. Absolute configuration determination by physical methods .................................

1.2.1. Circular Dichroism ..................................................................................

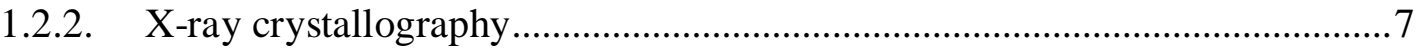

1.3. The necessity for enantiopure compounds ……………..................................

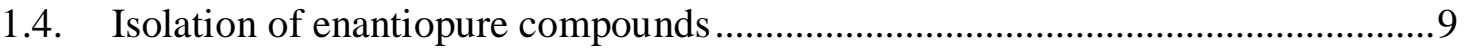

1.4.1. Enantiopure inorganic compounds .............................................................. 11

1.4.1.1. Inorganic asymmetric synthesis ......................................................... 11

1.4.1.2. Direct resolution: Chromatography ………………................................. 16

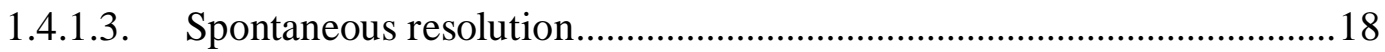

1.4.1.4. Indirect resolution: Diastereomer formation ........................................21

1.5. The octanuclear iron-oxo-pyrazolato complex ……...........................................2

Chapter II: Synthesis and characterization of $\mathrm{Fe}_{8}$ complexes terminated with phenolates

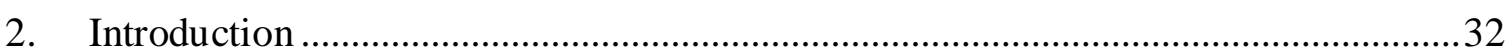

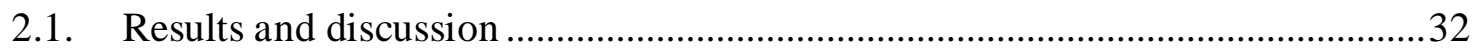

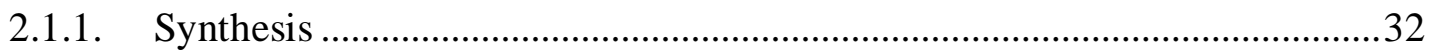

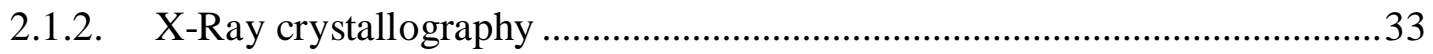

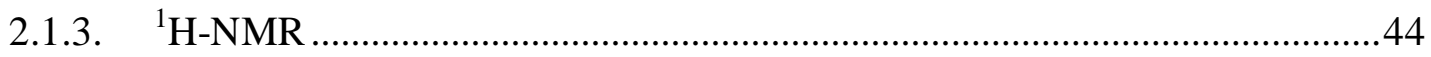

2.1.4. UV-Visible Spectroscopy ………………………...................................

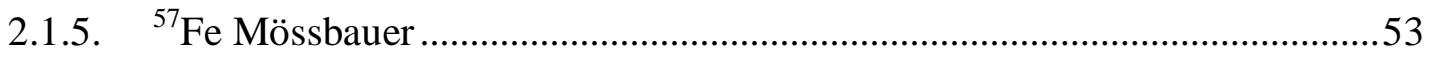

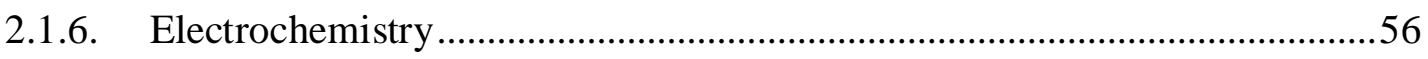

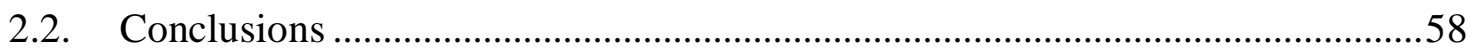

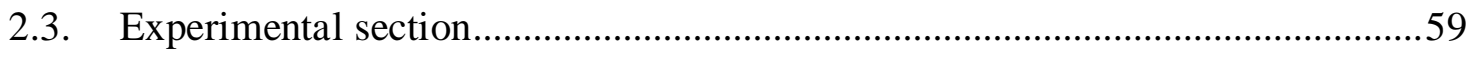

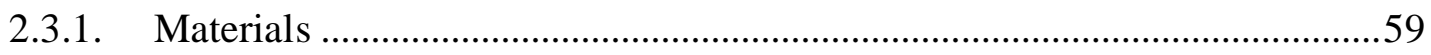

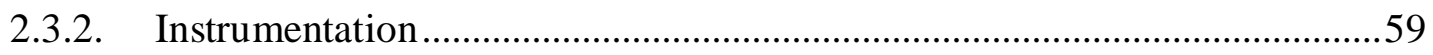




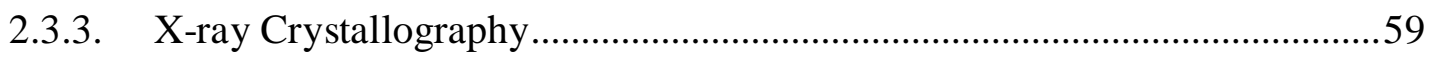

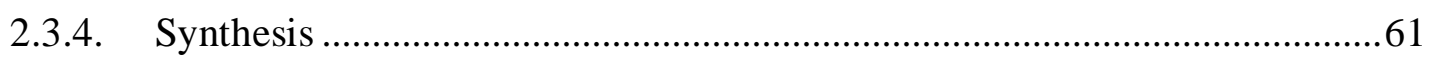

Chapter III: Resolution of $\mathrm{Fe}_{8}$ via diastereomer formation with chiral phenols ................65

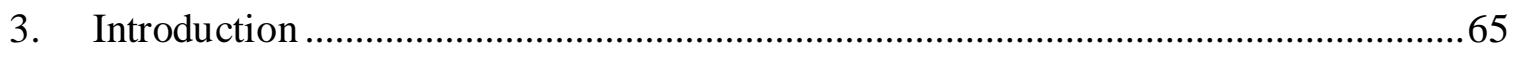

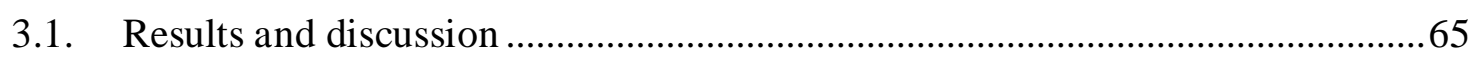

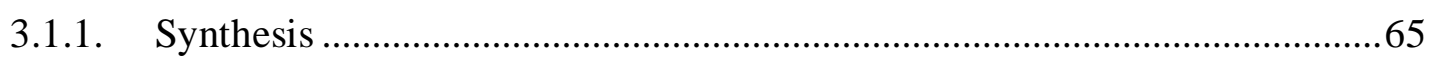

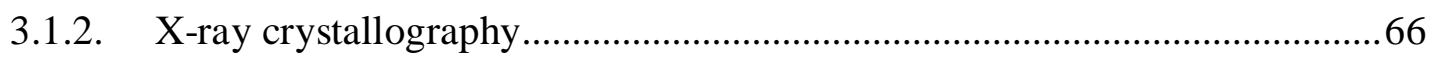

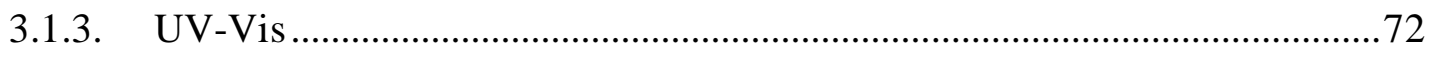

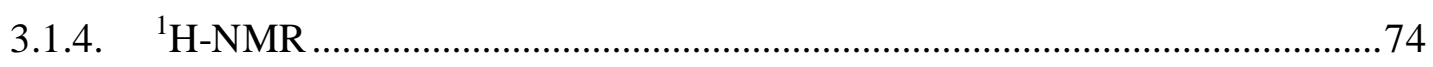

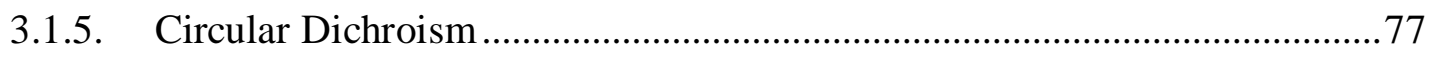

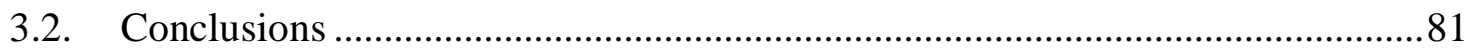

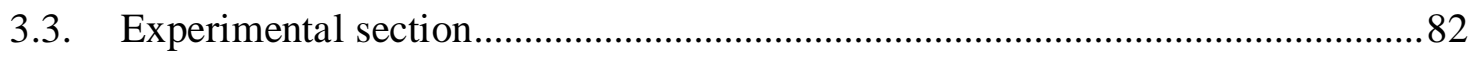

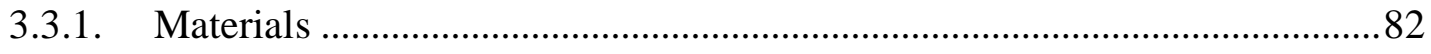

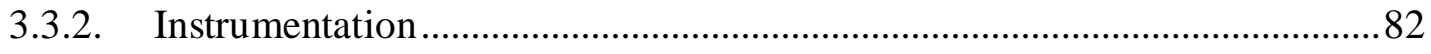

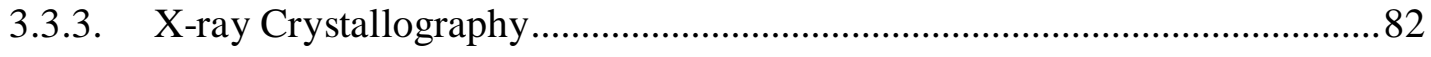

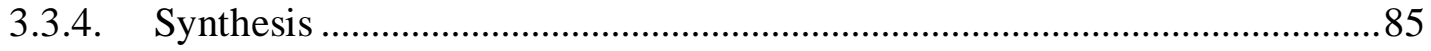

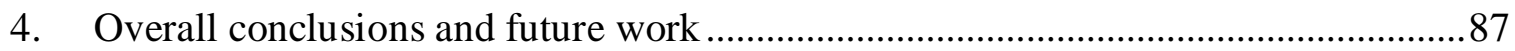

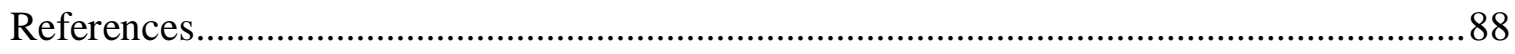

Appendix

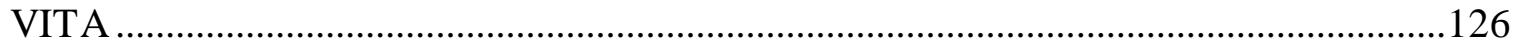




\section{LIST OF TABLES}

TABLE

PAGE

Table 1. Selected bond distances $(\AA)$ and interatomic angles $\left(^{\circ}\right)$ for $1-5$.

Table 2. Selected bond distances $(\AA)$ and interatomic angles $\left(^{\circ}\right)$ for $6-9$

Table 3. Structure refinement parameters for complexes $2-5$.

Table 4. Structure refinement parameters for complexes $6-9$.

Table 5. $\mathrm{T}_{1}$ and $\mathrm{T}_{2}{ }^{*}$ values for ${ }^{\mathrm{a}} \mathrm{H}$ and ${ }^{\mathrm{b}} \mathrm{H}$ protons of compounds 2,4 , and 7.

Table 6. Chemical shifts $\delta$ (ppm) for compounds 2-7 and 9.

Table 7. Magnitude of the chemical shifts of protons ( $\mathrm{ppm}$ ) of 3 with decreasing temperature.

Table 8. LMCT bands maxima of compounds 2-9.

Table 9. ${ }^{57} \mathrm{Fe}$ Mössbauer parameters of compounds $2-9$.

Table 10. Redox potentials $\left(\mathrm{E}_{1 / 2}\right.$ in $\left.\mathrm{V}\right)$ and separation $(\Delta \mathrm{V})$ between consecutive redox processes of compounds $2-9$.

Table 11. Selected bond lengths $(\AA)$ and interatomic angles $\left(^{\circ}\right)$ for compounds 8,12 , $13 \mathrm{a}$ and $13 \mathrm{~b}$.

Table 12. Structure refinement parameters for complexes 8, 12, 13a, and 13b.

Table 13. Chemical shifts $\delta$ (ppm) for compounds 8, 12 and 13. 


\section{LIST OF FIGURES}

FIGURE

PAGE

Figure 1. Analysis of chiral compound with Circular Dichroism Spectroscopy. 2

Figure 2. $\Delta$ and $\Lambda$ configuration of $\left[\mathrm{Co}(\mathrm{en})_{3}\right]^{3+}$. 3

Figure 3. a) $P$ and $M$ heptahelicene; b) Helical structure of bisdipyrrin dinuclear complex.

Figure 4. CD spectrum of $P$ (peak A) and $M$ (peak B) enantiomers of a tungsten biscorrole complex with formula $\mathrm{W}[\mathrm{T} p \mathrm{MePC}]_{2}$. Reprinted with permission from Schies, et al. Metallocorroles as Inherently Chiral Chromophores: Resolution and Electronic Circular Dichroism Spectroscopy of a Tungsten Biscorrole. Chem. Commun. 2017, 53 (45), 6121-6124. Copyright (2017) Royal Society of Chemistry

Figure 5. $S$-(-)-thalidomide, and $R$-(+)-thalidomide 8

Figure 6. $[\mathrm{Rh}(R, R \text {-DIPAMP })(\mathrm{COD})]^{+}$catalyst for the enantioselective hydrogenation of alkenes.

Figure 7. L-3,4-dihydroxyphenylalanine or L-DOPA, a drug for Parkinson's disease treatment.

Figure 8 . Chirality induction by the $(S)$-salicyloxazoline and formation of $\Lambda$ enantiomer with two bipyridine ligands L1 and L2.

Figure 9. Substitution of $(S)$-salicyloxazoline by bipyridine to yield the final $\Lambda$ trisheteroleptic polypiridyl ruthenium complex $\Lambda_{\mathrm{Ru}}$.

Figure 10. Diastereoselective conversion of prochiral trans-[Ru-(bpy $\left.)_{2}(\mathrm{MeCN})_{2}\right]^{2+} 1$ into chiral $c i s-\Delta-\left[\mathrm{Ru}(\text { bpy })_{2}\{(S)-\mathrm{SO}\}\right]^{+}$, where $\mathrm{SO}=(S)$-(isopropylsulfinyl)phenol....... 13

Figure 11. Acid-induced substitution of the chiral ligand $(S)$-SO for bpy to yield the $\Delta$ homoleptic ruthenium bipyridine complex.

Figure 12. $(R)$-salicylaldimine ligand promotes $\Lambda$ configuration on a tetrahedral zinc complex, whereas $(S)$-salicylaldimine promotes the $\Delta$ one. 
Figure 13. Top and side views of sigmoidal and reverse-sigmoidal arrangement of gold atoms, and amine ligands (one enantiomer shown). Adapted with permission from $\mathrm{He}$ et al. Structurally Well-Defined Sigmoidal Gold Clusters: Probing the Correlation between Metal Atom Arrangement and Chiroptical Response. J. Am. Chem. Soc. 2016, 138 (17), 5634-5643. Copyright (2016) American Chemical Society.

Figure 14 . Whelk-O ${ }^{\circledR} 1$ chiral stationary phase.

Figure 15. Carbamate-modified amylose CSP in the Chiralpak ${ }^{\circledR}$ AD column.

Figure 16. Circular dichroism spectra of pair of enantiomers of $\mathrm{Fe}_{4} \mathrm{~S}_{4}$-thiolate-cubanetype clusters with $(R R R R)$ blue line and $(S S S S)$ red line. (modified from reference 86)...19

Figure 17. La (III) coordination sphere in (a) $\Lambda$ and (b) $\Delta$ MOF's with dihydroxymalonate.

Figure 18. Chiral anionic resolving agents.

Figure 19. Chiral cationic resolving agents

Figure 20. $\mathrm{M}_{4} \mathrm{~L}_{6}$ type cages, where $\mathrm{H}_{4} \mathrm{~L}^{1}=N, N^{\prime}$-bis(2,3-dihydroxybenzoyl)-1,5diaminonaphthalene (left), and $\mathrm{H}_{4} \mathrm{~L}^{2}=N, N^{\prime}$-dihydroxy- $N, N^{\prime}$-di-p-tolylisophthalamide (right). $\mathrm{M}=\mathrm{Ga}(\mathrm{III}), \mathrm{Fe}(\mathrm{III}), \mathrm{Al}(\mathrm{III})$.

Figure 21. Structures of the $\left[\mathrm{Au}_{102}(p-\mathrm{MBA})_{44}\right]$ cluster (left) and $p$-MBA ligand (right). Reprinted with permission from Knoppe et al. Chiral Phase Transfer and Enantioenrichment of Thiolate-Protected Au102 Clusters. J. Am. Chem. Soc. 2014, 136 (11), 4129-4132. Copyright (2014) American Chemical Society....

Figure 22. Resolution of Rh complex with tripodal tetradentate ligand. $(S)$ phenylglycinate used as chiral auxiliary.

Figure 23. Face-specific coordination of the 1-Me-3PhCp ligand.

Figure 24. Synthesis and resolution of chiral $\mathrm{Ru}\left(\mathrm{PPh}_{3}\right)_{2} \mathrm{Cl}(1-\mathrm{Me}-3-\mathrm{PhCp})$ complex. (modified from reference 103)

Figure 25. Ball-and-stick diagram of the $\left[\mathrm{Fe}_{8}\right]$ complex. Hydrogen atoms omitted for clarity Color codes: gold, Fe; red, O; blue, N; green Cl; black, C. ${ }^{106}$ 
Figure 26. The propeller twist of $M$ (anti-clockwise) and $P$ (clockwise) $\mathrm{Fe}_{8}$. Only three of the twelve pyrazolate ligands are shown.

Figure 27. Cyclic voltammogram of $\left[\mathrm{Fe}^{\mathrm{III}}{ }_{8}\left(\mu_{4}-\mathrm{O}\right)_{4}(\mu-\mathrm{pz})_{12} \mathrm{Br}_{4}\right], v s . \mathrm{Fc}^{+} / \mathrm{Fc}$. Reprinted with permission from Baran et al. Synthesis, Characterization, and Study of Octanuclear Iron-Oxo Clusters Containing a Redox-Active Fe4O4-Cubane Core. Inorg. Chem. 2008, 47 (2), 645-655. Copyright (2008) American Chemical Society.

Figure 28. Ball-and-stick diagram of $\left[\mathrm{Fe}_{8}\left(\mu_{4}-\mathrm{O}\right)_{4}(\mu-\mathrm{pz})_{12}\left(4-\mathrm{NO}_{2}-\mathrm{C}_{6} \mathrm{H}_{4} \mathrm{O}\right)_{4}\right](2)$.

Hydrogen atoms omitted for clarity. Color codes: gold, Fe; red, O; blue, N; black, C. ....34

Figure 29. Ball-and-stick diagram of $\left[\mathrm{Fe}_{8}\left(\mu_{4}-\mathrm{O}\right)_{4}(\mu-\mathrm{pz})_{12}\left(4-\mathrm{NC}-\mathrm{C}_{6} \mathrm{H}_{4} \mathrm{O}\right)_{4}\right](3)$.

Hydrogen atoms omitted for clarity. Color codes: gold, Fe; red, O; blue, N; black, C.....34

Figure 30. Ball-and-stick diagram of $\left[\mathrm{Fe}_{8}\left(\mu_{4}-\mathrm{O}\right)_{4}(\mu-\mathrm{pz})_{12}\left(4-\mathrm{F}-\mathrm{C}_{6} \mathrm{H}_{4} \mathrm{O}\right)_{4}\right](4)$. Hydrogen atoms omitted for clarity. Color codes: gold, Fe; red, O; blue, N; F, olive; black, C.

Figure 31. Ball-and-stick diagram of $\left[\mathrm{Fe}_{8}\left(\mu_{4}-\mathrm{O}\right)_{4}(\mu-\mathrm{pz})_{12}\left(4-\mathrm{Cl}-\mathrm{C}_{6} \mathrm{H}_{4} \mathrm{O}\right)_{4}\right](5)$. Hydrogen atoms omitted for clarity. Color codes: gold, Fe; red, O; blue, N; green, $\mathrm{Cl}$; black, C. ....35

Figure 32. Ball-and-stick diagram of $\left[\mathrm{Fe}_{8}\left(\mu_{4}-\mathrm{O}\right)_{4}(\mu-\mathrm{pz})_{12}\left(4-\mathrm{I}-\mathrm{C}_{6} \mathrm{H}_{4} \mathrm{O}\right)_{4}\right](6)$. Hydrogen atoms omitted for clarity. Color codes: gold, Fe; red, O; blue, N; purple, I; black, C. .....36

Figure 33. Ball-and-stick diagram of $\left[\mathrm{Fe}_{8}\left(\mu_{4}-\mathrm{O}\right)_{4}(\mu-\mathrm{pz})_{12}\left(4-\mathrm{CH}_{3} \mathrm{O}-\mathrm{C}_{6} \mathrm{H}_{4} \mathrm{O}\right)_{4}\right](7)$.

Hydrogen atoms omitted for clarity. Color codes: gold, Fe; red, O; blue, N; black, C. ....36

Figure 34. Ball-and-stick diagram of $\left[\mathrm{Fe}_{8}\left(\mu_{4}-\mathrm{O}\right)_{4}(\mu-\mathrm{pz})_{12}\left(3-\mathrm{NO}_{2}-\mathrm{C}_{6} \mathrm{H}_{4} \mathrm{O}\right)_{4}\right](9)$. Hydrogen atoms omitted for clarity. Color codes: gold, Fe; red, O; blue, N; black, C. ....37

Figure 35. Bis(imino)pyridine iron(III) bis(aryloxide).

Figure 36. ${ }^{1} \mathrm{H}-\mathrm{NMR}$ of $\left[\mathrm{Fe}_{8}\left(\mu_{4}-\mathrm{O}\right)_{4}(\mu-\mathrm{pz})_{12} \mathrm{Cl}_{4}\right]$ (1) in $\mathrm{CD}_{2} \mathrm{Cl}_{2}$. Solvents denoted with asterisk.

Figure 37. ${ }^{1} \mathrm{H}-\mathrm{NMR}$ of $\left[\mathrm{Fe}_{8}\left(\mu_{4}-\mathrm{O}\right)_{4}(\mu-\mathrm{pz})_{12}\left(4-\mathrm{F}-\mathrm{C}_{6} \mathrm{H}_{4} \mathrm{O}\right)_{4}\right]$ (4) in $\mathrm{CDCl}_{3}$. Solvents denoted with asterisk.

Figure 38. Spin distribution on the $\mathrm{Fe}_{\mathrm{o}}-\mathrm{OAr}$ moiety

Figure 39. Chemical shift of protons ${ }^{4} \mathrm{H}$ and ${ }^{\mathrm{b}} \mathrm{H}$ of $\left[\mathrm{Fe}_{8}\left(\mu_{4}-\mathrm{O}\right)_{4}(\mu-\mathrm{pz})_{12}\left(4-\mathrm{NC}-\mathrm{C}_{6} \mathrm{H}_{4} \mathrm{O}\right)_{4}\right]$

(3) with decreasing temperature. 
Figure 40. Chemical shift of protons ${ }^{3} \mathrm{H}$ and ${ }^{5} \mathrm{H}$ of $\left[\mathrm{Fe}_{8}\left(\mu_{4}-\mathrm{O}\right)_{4}(\mu-\mathrm{pz})_{12}\left(4-\mathrm{NC}-\mathrm{C}_{6} \mathrm{H}_{4} \mathrm{O}\right)_{4}\right]$ (3) with decreasing temperature.

Figure 41. Chemical shift of protons ${ }^{\mathrm{a}} \mathrm{H}$ of $\left[\mathrm{Fe}_{8}\left(\mu_{4}-\mathrm{O}\right)_{4}(\mu-\mathrm{pz})_{12}\left(4-\mathrm{NC}-\mathrm{C}_{6} \mathrm{H}_{4} \mathrm{O}\right)_{4}\right]$ (3) with decreasing temperature.

Figure 42. UV-Vis spectrum of $\left[\mathrm{Fe}_{8}\left(\mu_{4}-\mathrm{O}\right)_{4}(\mu-\mathrm{pz})_{12}\left(4-\mathrm{I}-\mathrm{C}_{6} \mathrm{H}_{4} \mathrm{O}\right)_{4}\right](6)$ in $\mathrm{CH}_{2} \mathrm{Cl}_{2}$.

Figure 43. ${ }^{57} \mathrm{Fe}$ Mössbauer of $\left[\mathrm{Fe}_{8}\left(\mu_{4}-\mathrm{O}\right)_{4}(\mu-4-\mathrm{Ph}-\mathrm{pz})_{12} \mathrm{Cl}_{4}\right]$ at $80 \mathrm{~K}\left(\mathrm{Fe}_{\mathrm{c}}\right.$ blue trace, $\mathrm{Fe}_{\mathrm{o}}$ red trace).

Figure 44. ${ }^{57} \mathrm{Fe}$ Mössbauer of $\left[\mathrm{Fe}_{8}\left(\mu_{4}-\mathrm{O}\right)_{4}(\mu-\mathrm{pz})_{12}\left(4-\mathrm{I}_{-} \mathrm{C}_{6} \mathrm{H}_{4} \mathrm{O}\right)_{4}\right](6)$ at $80 \mathrm{~K}\left(\mathrm{Fe}_{\mathrm{c}}\right.$ blue trace, $\mathrm{Fe}_{\mathrm{o}}$ red trace).

Figure 45. Cyclic voltammogram (solid line) and differential pulse voltammogram (dashed line) of $\left[\mathrm{Fe}_{8}\left(\mu_{4}-\mathrm{O}\right)_{4}(\mu-\mathrm{pz})_{12}\left(4-\mathrm{NO}_{2}-\mathrm{C}_{6} \mathrm{H}_{4} \mathrm{O}\right)_{4}\right]$ (2) in $0.5 \mathrm{M} \mathrm{Bu}_{4} \mathrm{NPF}_{6} / \mathrm{CH}_{2} \mathrm{Cl}_{2}$, vs $\mathrm{Fc}^{+} / \mathrm{Fc}$.

Figure 46. Ball-and-stick diagram of $\left[\mathrm{Fe}_{8}\left(\mu_{4}-\mathrm{O}\right)_{4}(\mu-\mathrm{pz})_{12}\left(r a c-4-{ }^{\mathrm{s}} \mathrm{Bu}-\mathrm{C}_{6} \mathrm{H}_{4} \mathrm{O}\right)_{4}\right]$ (8): Gold, Fe; red, O; blue, N; black, C. Only hydrogen atoms on the stereocenters are shown. ......67

Figure 47. Ball-and-stick diagram of $\left[\mathrm{Fe}_{8}\left(\mu_{4}-\mathrm{O}\right)_{4}\left(\mu-4-\mathrm{CH}_{3}-\mathrm{pz}\right)_{12}\left(\mathrm{rac}-4-{ }^{\mathrm{s}} \mathrm{Bu}^{-\mathrm{C}_{6}} \mathrm{H}_{4} \mathrm{O}\right)_{4}\right]$ (12): Gold, Fe; red, O; blue, N; black, C. Hydrogen atoms omitted for clarity.

Figure 48. Ball-and-stick diagrams of $13 \mathrm{a}(P / R$ enantiomer, up and left), and $13 \mathrm{~b}(M / S$ enantiomer, up and right). View parallel to one of the $C_{3}$ axes of $13 \mathrm{a}$ (down and left), and $13 \mathrm{~b}$ (down and right). Three of the twelve pyrazolates and three of the four phenolates are shown: Gold, Fe; red, O; blue, N; green, $\mathrm{Cl}$; black, C. Only hydrogen atoms on the stereocenters are shown.

Figure 49. UV-Vis spectrum of $\left[\mathrm{Fe}_{8}\left(\mu_{4}-\mathrm{O}\right)_{4}(\mu-\mathrm{pz})_{12}\left(4-{ }^{\mathrm{s}} \mathrm{Bu}-\mathrm{C}_{6} \mathrm{H}_{4} \mathrm{O}\right)_{4}\right]$, (8), recorded at $295 \mathrm{~K}$ in $\mathrm{CH}_{2} \mathrm{Cl}_{2}$.

Figure 50. UV-Vis spectrum of $\left[\mathrm{Fe}_{8}\left(\mu_{4}-\mathrm{O}\right)_{4}\left(\mu-4-\mathrm{CH}_{3}-\mathrm{pz}\right)_{12}\left(4-{ }^{\mathrm{s}} \mathrm{Bu}-\mathrm{C}_{6} \mathrm{H}_{4} \mathrm{O}\right)_{4}\right]$, (12), recorded at $295 \mathrm{~K}$ in $\mathrm{CH}_{2} \mathrm{Cl}_{2}$.

Figure 51. UV-Vis spectrum of $\left[\mathrm{Fe}_{8}\left(\mu_{4}-\mathrm{O}\right)_{4}(\mu-4-\mathrm{Cl}-\mathrm{pz})_{12}\left(4-{ }^{\mathrm{s}} \mathrm{Bu}-\mathrm{C}_{6} \mathrm{H}_{4} \mathrm{O}\right)_{4}\right]$, (13), recorded at $295 \mathrm{~K}$ in $\mathrm{CH}_{2} \mathrm{Cl}_{2}$.

Figure 52. ${ }^{1} \mathrm{H}-\mathrm{NMR}$ spectrum of $8,400 \mathrm{MHz}, \mathrm{CDCl}_{3}$. Solvents denoted with asterisk, phenol impurities with cross. 
Figure 53. ${ }^{1} \mathrm{H}-\mathrm{NMR}$ spectrum of $12,400 \mathrm{MHz}, \mathrm{CD}_{2} \mathrm{Cl}_{2}$. Solvents denoted with asterisk.

Figure 54. ${ }^{1} \mathrm{H}-\mathrm{NMR}$ spectrum of $13,400 \mathrm{MHz}, \mathrm{CDCl}_{3}$. Solvents denoted with asterisk, phenol impurities with cross.

Figure 55. CD spectra of $M(S)$ (red) and $P(R)$ (blue) diastereomers of $\left[\mathrm{Fe}_{8}\left(\mu_{4}-\mathrm{O}\right)_{4}(\mu-4\right.$ $\mathrm{Cl}-\mathrm{pz})_{12}\left(4-{ }^{\mathrm{s}} \mathrm{Bu}-\mathrm{C}_{6} \mathrm{H}_{4} \mathrm{O}\right)_{4}$ ] (13b and 13a) in $\mathrm{CH}_{2} \mathrm{Cl}_{2}$ at $295 \mathrm{~K}$.

Figure 56. CD spectra of $M$ (red) and $P$ (blue) enantiomers of $\left[\mathrm{Fe}_{8}\left(\mu_{4}-\mathrm{O}\right)_{4}(\mu-4-\mathrm{Cl}-\right.$ pz) $\left.{ }_{12} \mathrm{Cl}_{4}\right],(11)$, in $\mathrm{CH}_{2} \mathrm{Cl}_{2}$ at $295 \mathrm{~K}$.

Figure 57. UV-vis spectrum of a solution of 13 after addition of $\mathrm{HCl} 0.06 \mathrm{M}$ recorded at $295 \mathrm{~K}$ in $\mathrm{CH}_{2} \mathrm{Cl}_{2}$.

Figure 58. UV-vis spectrum of $\left[\mathrm{Fe}_{8}\left(\mu_{4}-\mathrm{O}\right)_{4}(\mu-4-\mathrm{Cl}-\mathrm{pz})_{12} \mathrm{Cl}_{4}\right](11)$, recorded at $295 \mathrm{~K}$ in

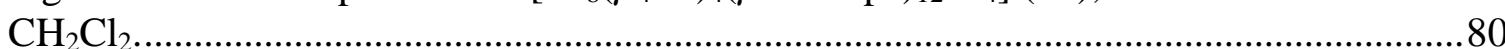

Figure 59. Subtraction of the UV-Vis spectra depicted on Figure 56 and Figure 57. The resulting graph matches the $\mathrm{UV}-\mathrm{Vis}$ spectrum of $4-{ }^{\mathrm{s}} \mathrm{Bu}-\mathrm{C}_{6} \mathrm{H}_{4} \mathrm{OH}$ recorded in $\mathrm{CH}_{2} \mathrm{Cl}_{2} \ldots 81$ 


\section{ABBREVIATION OR ACRONYMS}

\begin{tabular}{|c|c|}
\hline $\mathrm{CD}$ & Circular Dichroism \\
\hline $\mathrm{Cp}$ & Cyclopentadienyl \\
\hline CSP & Chiral Stationary Phase \\
\hline $\mathrm{CV}$ & Cyclic Voltammetry \\
\hline DCM & Dichloromethane \\
\hline DIPAMP & 1,2-bis[(2-methoxyphenyl)(phenylphosphino)]ethane \\
\hline DPV & Differential Pulse Voltammetry \\
\hline ee & Enantiomeric excess \\
\hline en & ethylenediamine \\
\hline $\mathrm{Fc}^{+} / \mathrm{Fc}$ & Ferricenium/Ferrocene \\
\hline FT-IR & Fourier Transformation-Infrared \\
\hline HPLC & High Pressure Liquid Chromatography \\
\hline IVCT & Intravalence-Charge-Transfer \\
\hline L-DOPA & L-3,4-dihydroxyphenylalanine \\
\hline LMCT & Ligand-to-Metal Charge Transfer \\
\hline $\mathrm{MeCN}$ & Acetonitrile \\
\hline $\mathrm{MeOH}$ & Methanol \\
\hline MOF & Metal-Organic-Framework \\
\hline NMR & Nuclear Magnetic Resonance \\
\hline OR & Optical Rotation \\
\hline $\mathrm{pz}$ & Pyrazolate \\
\hline $\mathrm{pzH}$ & Pyrazole \\
\hline rac & racemic \\
\hline${ }^{\mathrm{s}} \mathrm{Bu}$ & sec-butyl \\
\hline TBA & Tetrabutylammonium \\
\hline $\mathrm{THF}$ & Tetrahydrofuran \\
\hline UV-Vis-NIR & Ultraviolet-Visible-Near Infrared \\
\hline VCD & Vibrational Circular Dichroism \\
\hline
\end{tabular}




\section{LIST OF COMPOUNDS}

\section{Chapter II}

$\left[\mathrm{Fe}_{8}\left(\mu_{4}-\mathrm{O}\right)_{4}(\mu-\mathrm{pz})_{12} \mathrm{Cl}_{4}\right]$ or $\left[\mathrm{Fe}_{8}\right]$

$\left[\mathrm{Fe}_{8}\left(\mu_{4}-\mathrm{O}\right)_{4}(\mu-\mathrm{pz})_{12}\left(4-\mathrm{NO}_{2}-\mathrm{C}_{6} \mathrm{H}_{4} \mathrm{O}\right)_{4}\right]$

$\left[\mathrm{Fe}_{8}\left(\mu_{4}-\mathrm{O}\right)_{4}(\mu-\mathrm{pz})_{12}\left(4-\mathrm{NC}-\mathrm{C}_{6} \mathrm{H}_{4} \mathrm{O}\right)_{4}\right]$

$\left[\mathrm{Fe}_{8}\left(\mu_{4}-\mathrm{O}\right)_{4}(\mu-\mathrm{pz})_{12}\left(4-\mathrm{F}-\mathrm{C}_{6} \mathrm{H}_{4} \mathrm{O}\right)_{4}\right]$

$\left[\mathrm{Fe}_{8}\left(\mu_{4}-\mathrm{O}\right)_{4}(\mu-\mathrm{pz})_{12}\left(4-\mathrm{Cl}-\mathrm{C}_{6} \mathrm{H}_{4} \mathrm{O}\right)_{4}\right]$

$\left[\mathrm{Fe}_{8}\left(\mu_{4}-\mathrm{O}\right)_{4}(\mu-\mathrm{pz})_{12}\left(4-\mathrm{I}-\mathrm{C}_{6} \mathrm{H}_{4} \mathrm{O}\right)_{4}\right]$

$\left[\mathrm{Fe}_{8}\left(\mu_{4}-\mathrm{O}\right)_{4}(\mu-\mathrm{pz})_{12}\left(4-\mathrm{CH}_{3} \mathrm{O}-\mathrm{C}_{6} \mathrm{H}_{4} \mathrm{O}\right)_{4}\right]$

$\left[\mathrm{Fe}_{8}\left(\mu_{4}-\mathrm{O}\right)_{4}(\mu-\mathrm{pz})_{12}\left(4-{ }^{\mathrm{s}} \mathrm{Bu}-\mathrm{C}_{6} \mathrm{H}_{4} \mathrm{O}\right)_{4}\right]$

$\left[\mathrm{Fe}_{8}\left(\mu_{4}-\mathrm{O}\right)_{4}(\mu-\mathrm{pz})_{12}\left(3-\mathrm{NO}_{2}-\mathrm{C}_{6} \mathrm{H}_{4} \mathrm{O}\right)_{4}\right]$

\section{Chapter III}

$\left[\mathrm{Fe}_{8}\left(\mu_{4}-\mathrm{O}\right)_{4}\left(\mu-4-\mathrm{CH}_{3}-\mathrm{pz}\right)_{12} \mathrm{Cl}_{4}\right]$

$\left[\mathrm{Fe}_{8}\left(\mu_{4}-\mathrm{O}\right)_{4}(\mu-4-\mathrm{Cl}-\mathrm{pz})_{12} \mathrm{Cl}_{4}\right]$

$\left[\mathrm{Fe}_{8}\left(\mu_{4}-\mathrm{O}\right)_{4}\left(\mu-4-\mathrm{CH}_{3}-\mathrm{pz}\right)_{12}\left(4-{ }^{\mathrm{s}} \mathrm{Bu}-\mathrm{C}_{6} \mathrm{H}_{4} \mathrm{O}\right)_{4}\right]$

$\left[\mathrm{Fe}_{8}\left(\mu_{4}-\mathrm{O}\right)_{4}(\mu-4-\mathrm{Cl}-\mathrm{pz})_{12}\left(4-{ }^{\mathrm{s}} \mathrm{Bu}-\mathrm{C}_{6} \mathrm{H}_{4} \mathrm{O}\right)_{4}\right]$ 


\section{Chapter I: Introduction}

\section{History of chirality}

The rotation of plane polarized light by chiral compounds was first observed by JeanBaptiste Biot in 1815, whereas Luis Pasteur deduced the molecular basis of the phenomenon in 1848 by noticing the distinct behavior of ammonium sodium tartrate crystals under a microscope equipped with polarized light, achieving their separation manually with the use of tweezers. ${ }^{1}$ Chirality was initially thought to be a property solely of organic molecules; however, Alfred Werner proved this idea to be wrong by showing the resolution of a multinuclear cobalt compound, hexol, a purely inorganic compound

containing coordinated ammonia and hydroxo bridges. ${ }^{2}$ Since then, chirality has been a fascinating topic of focus in science, especially after the discovery that the building blocks of life like amino acids, sugars, and the DNA, are chiral.

\subsection{Chirality: Definition}

Chirality is a property of objects which are not superimposable to their mirror image. In symmetry terms, chiral objects lack an improper rotation axis $S_{n}$. The $S_{n}$ is an operation combining a rotation $C_{n}$ with a reflection through a $\sigma_{h}$ plane perpendicular to the $C_{n}$ axis, or $\mathrm{C}_{\mathrm{n}}$ followed by $\sigma_{\mathrm{h}}$. Chiral molecules exist in two enantiomeric forms, which rotate polarized light in opposite directions but in equal magnitude depending on the wavelength of the incident light. 


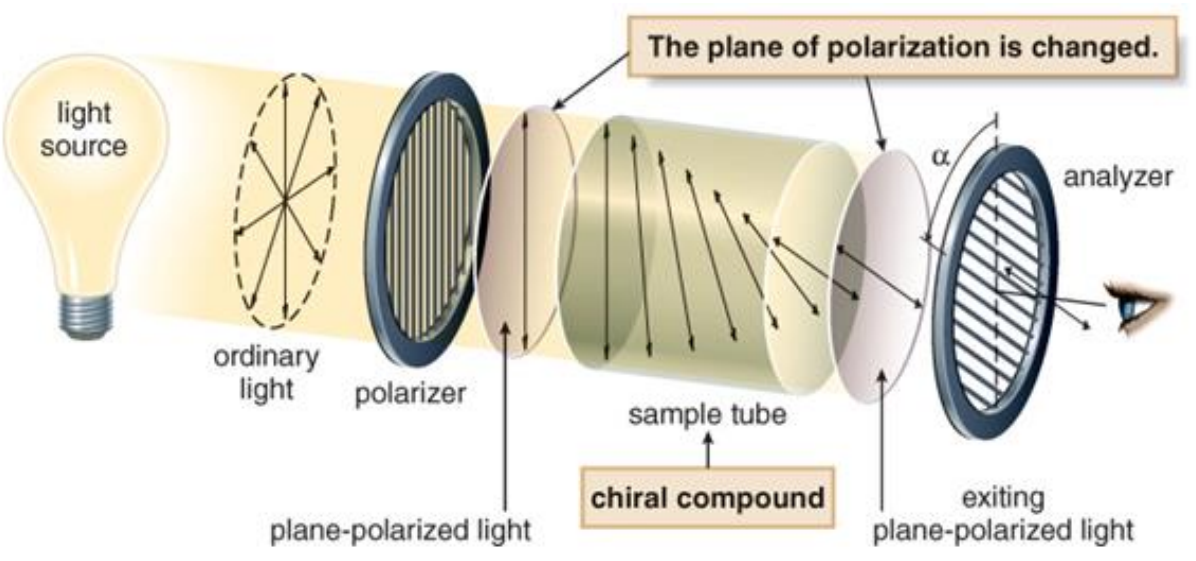

Figure 1. Analysis of chiral compound with Circular Dichroism Spectroscopy.

The most common type of chirality is observed in organic molecules where a carbon atom is surrounded by four different substituents. The nomenclature assigned to the two enantiomers is $R$ and $S$, according to the Cahn-Ingold-Prelog system. Chirality, however, can arise in the absence of a stereogenic center. Such cases exist when an axis of chirality is present: an axis about which a set of substituents is held in a spatial arrangement that is non-superimposable on its mirror image. For example, in coordination chemistry, $\Delta$ (delta, right-handedness) and $\Lambda$ (lambda, left-handedness) prefixes are used to describe the twist of the propeller formed by chelating ligands attached to the metal center. The $\Delta$ and $\Lambda$ prefixes are most commonly used for mononuclear complexes, such as one in octahedral arrangement with two or three equivalent bidentate ligands (e.g., $\Delta$ - and $\Lambda$ $\left[\mathrm{Co}(\mathrm{en})_{3}\right]^{3+}$, Figure 2). The $P$ (clockwise rotation) and $M$ (anticlockwise rotation) notation is also used to describe axial chirality and is preferable for molecules that resemble helices, such as helicenes or some polynuclear complexes (Figure 3 ). ${ }^{3}$ The DNA is another example of helical chirality. The significance of chirality can be perceived by its 
various implications in chemistry, ${ }^{4-6}$ materials science $^{7-10}$ medicine, ${ }^{11}$ pharmaceuticals, ${ }^{12-14}$, magnetism, ${ }^{15-21}$ non-linear optics, ${ }^{22-25}$ agriculture ${ }^{26}$ forensic analysis, ${ }^{27}$ and catalysis. ${ }^{28-37}$
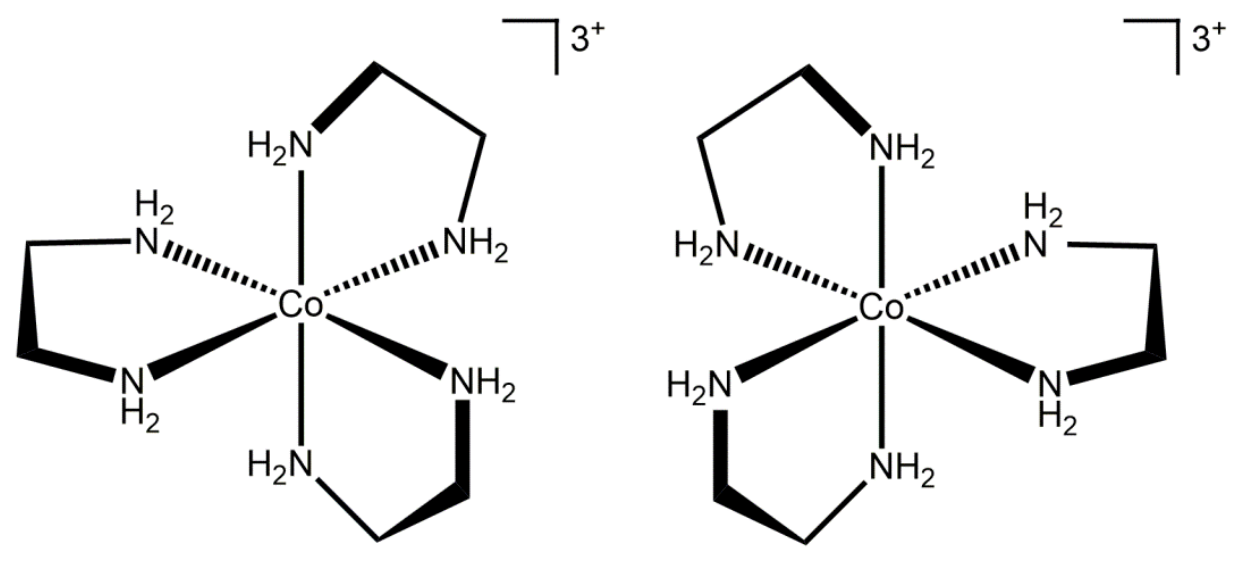

Figure 2. $\Delta$ and $\Lambda$ configuration of $\left[\mathrm{Co}(\mathrm{en})_{3}\right]^{3+}$.

a)

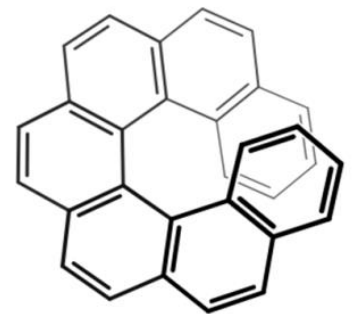

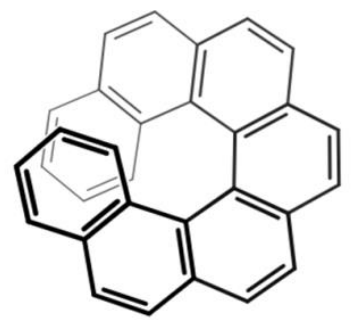

b)

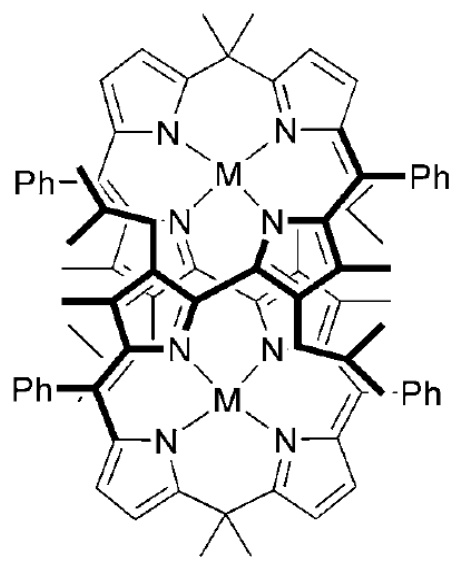

Figure 3. a) $P$ and $M$ heptahelicene; b) Helical structure of bisdipyrrin dinuclear complex. 


\subsection{Absolute configuration determination by physical methods}

The structural and spectroscopic study of chiral molecules, either in solution or solid state, is not a trivial task since their two enantiomeric forms exhibit identical physical and chemical properties in an achiral environment. Thus, a chiral medium is necessary to allow for observations regarding potential differences in the behavior of the two, which in many cases can be significant and have great consequences. Their aforementioned ability to rotate polarized light in opposite directions can be quantified by measurement of their optical rotation $(\mathrm{OR})$. The $\mathrm{OR}$ is measured with a polarimeter and the specific rotation, which is characteristic of the compound, can be calculated by the following equation:

$$
[\alpha]_{\bar{\lambda}}^{T}=\frac{\alpha}{l \times c}
$$

where $\alpha$ (degrees) is the optical rotation observed, 1 is the beam path length through the solution $(\mathrm{dm})$ and $\mathrm{c}$ is the concentration of the sample $\left(\right.$ in $\left.\mathrm{gcm}^{-3}\right)$, at temperature $\mathrm{T}\left({ }^{\circ} \mathrm{C}\right)$, and wavelength $\lambda(\mathrm{nm})$. In most cases light of $589 \mathrm{~nm}$ wavelength is used (the sodium D line) and $\lambda$ can be replaced by the symbol $\mathrm{D}$ in equation (1). ${ }^{38}$ The highest optical rotation value recorded to date is $[\alpha]_{\mathrm{D}}=-9620^{\circ}$ for $M-(-)-[13]$ helicene. ${ }^{39}$ The $(+)$ and (-) prefixes are used to describe the right (dextrorotary) and left (levorotary) rotation of the polarized light by an optically active molecule. However, the sign does not provide any information on the absolute configuration of a molecule. The method can be utilized for the calculation of the enantiomeric excess (ee), or optical purity of a sample, given that the specific rotation of its enantiopure form is known by the formula:

$$
e e(\%)=\frac{\alpha_{o b s}}{[\alpha]_{\bar{\lambda}}^{T}} \times 100
$$


However, in practice gas chromatography with a chiral stationary phase is a more suitable method for the determination of $e e$.

\subsubsection{Circular Dichroism}

Circular Dichroism (CD) is a powerful spectroscopic technique for the study of chirality defined as:

$$
C D=A^{l}-A^{r}
$$

where $\mathrm{A}^{1}$ and $\mathrm{A}^{\mathrm{r}}$ are the absorption of left and right circularly polarized light, respectively. Instrumentation for $\mathrm{CD}$, like UV-Vis, measures the ellipticity $\theta$ (mdeg) against the wavelength, and in analogy to Lambert-Beer law, the molar coefficient, or absorption coefficient is given by:

$$
\Delta \varepsilon=\varepsilon^{l}-\varepsilon^{r}=\frac{C D}{c \times b}
$$

where $\mathrm{c}$ is the concentration $(\mathrm{M})$ and $\mathrm{b}$ is the path length $(\mathrm{cm})$. Therefore, a CD signal can only be observed when the optically active molecule exhibits electronic transitions in UV-Vis spectrum. The CD signal is a signed quantity, and it has to be opposite for each enantiomer, while no signal is observed for racemic mixtures (i.e. equimolar mixtures of the two enantiomers). The technique's application in the configurational and conformational analysis of organic compounds, ${ }^{40}$ as well as transition metal compounds, ${ }^{41}$ has been unequivocally established. An example of a CD spectrum of two

enantiomers of a tungsten biscorrole complex is shown in Figure $4 .^{42}$ Like optical rotation, circular dichroism can provide information about the enantiopurity of the 
compound under study but additionally, in many cases, has the advantage of providing information about the absolute configuration when exciton coupling occurs. Exciton coupled CD results when two or more strongly absorbing chromophores are located near in space and have the appropriate orientation (asymmetrical). The intensity and the sign of the couplet (defined by the sign of its longer wavelength component) are related to the orientation, which depends on the molecular configuration and conformation. ${ }^{43}$
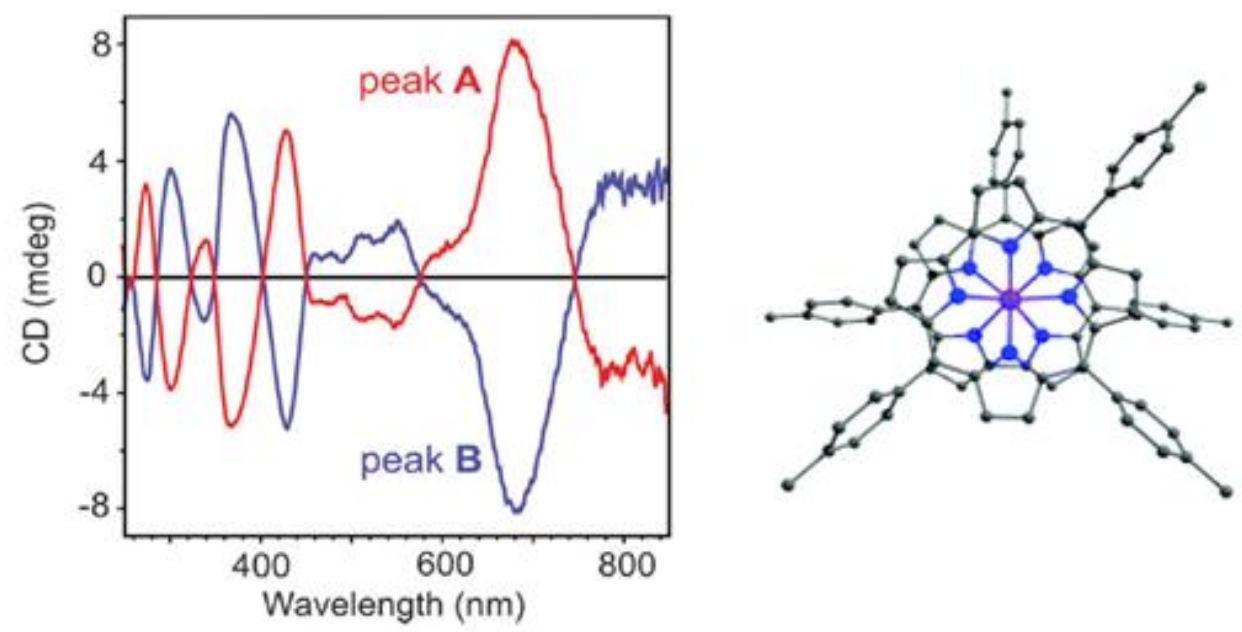

Figure 4. CD spectrum of $P$ (peak A) and $M$ (peak B) enantiomers of a tungsten biscorrole complex with formula $\mathrm{W}[\mathrm{T} p \mathrm{MePC}]_{2}$. Reprinted with permission from Schies, et al. Metallocorroles as Inherently Chiral Chromophores: Resolution and Electronic Circular Dichroism Spectroscopy of a Tungsten Biscorrole. Chem. Commun. 2017, 53 (45), 6121-6124. Copyright (2017) Royal Society of Chemistry.

Vibrational Circular Dichroism (VCD) is a similar spectroscopic technique that allows for absolute configuration and conformation determination by inspection of vibrational transitions occurring in the infrared (IR) and near-infrared (NIR) regions of the electromagnetic spectrum. ${ }^{44}$ The VCD analysis can also play an important complementary role to the X-ray crystallographic analysis. ${ }^{45}$ 


\subsubsection{X-ray crystallography}

X-ray crystallography is considered the most efficient solid state technique for the determination of structures and absolute configuration assignment of chiral molecules, which is based on the anomalous scattering of heavy elements $(Z>16$, for diffraction of Mo-K $\alpha$ radiation of $\lambda=0.71073 \AA$ ) and evaluated by the Flack parameter. ${ }^{46}$ Anomalous scattering or anomalous dispersion refers to a change in a diffracting X-ray's phase that occurs from specific atoms in a crystal due to X-ray absorbance. The heavier the atom, the higher the amount of energy it absorbs when close to the atom's absorption edge. For Mo-K $\alpha$ radiation, atoms heavier than sulfur are required for the phenomenon to be observable. For non-centrosymmetric structures that also exhibit anomalous scattering, a small but measurable difference between the intensities $\mathrm{I}_{(\mathrm{hkl})}$ of a reflection from a set of planes hkl and $\mathrm{I}_{(-\mathrm{h}-\mathrm{k}-\mathrm{l})}$ of a reflection from the inversion center-related -h-k-l planes can be observed. The difference between these pairs, known as Friedel or Bijvoet pairs, allows the solution of the phase problem for the diffraction data and the determination of absolute structure. ${ }^{47}$ The Flack parameter is determined by the following equation:

$$
I_{(h k l)}=(1-x)\left|F_{(h k l)}\right|^{2}+x\left|F_{(-h-k-l)}\right|^{2}
$$

where $I$ is the intensity of the diffracted beam, $\mathrm{x}$ is the Flack parameter, and $F$ is the calculated structure factor. The physically meaningful values of $\mathrm{x}$ are $0 \leq x \leq 1$, but as a result of statistical fluctuations and systematic errors, experimental values may lay a little outside of this range by a few estimated standard deviations (esd). The esd of the numerical value of the Flack parameter must be $u \leq 0.04$. A crystal of an enantiomerically pure compound in the correct absolute configuration has $\mathrm{x}=0$. When $\mathrm{x}$ 
$=1$, there is only one domain in the crystal, that of the inverted stereochemistry. A value of $\mathrm{x}$ near 0.5 corresponds to a racemic mixture. Values in between are possible when different proportions of each enantiomer are present.

\subsection{The necessity for enantiopure compounds}

The properties of the two enantiomers of a chiral compound vary when placed in a chiral environment. In some cases these properties are so different that one enantiomer can be a useful medicine able to treat health conditions, whereas the other one can be harmful, even lethal. One example is the infamous thalidomide case in the late 50's. Thalidomide (Figure 5) was a drug administered as a racemic mixture to pregnant women as sleepinginducing agent; however, a lot of children were later born with serious defects. It was later proven that the sleeping-inducing properties belonged to the $R$ enantiomer of thalidomide, whereas the $S$ one, being toxic and teratogenic, was responsible for this

unfortunate event. ${ }^{48}$ Another example of a pharmaceutical product is Naproxen ${ }^{\mathrm{TM}}$, the $S$ enantiomer of which alleviates arthritis pain, whereas its $R$ enantiomer can cause liver toxicity. ${ }^{49}$ These examples demonstrate the reason why isolation of the enantiomers of chiral molecules that possess desirable properties is crucial in fields such as the pharmaceutical industry.
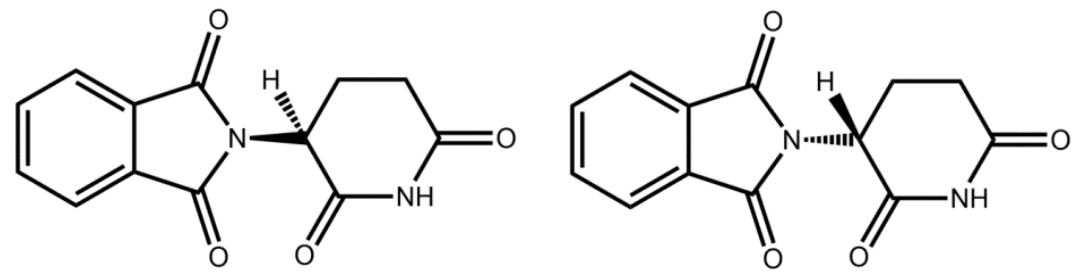

Figure 5. $S$-(-)-thalidomide, and $R$-(+)-thalidomide. 


\subsection{Isolation of enantiopure compounds}

One of the main routes towards enantiopure compounds (the other being chromatographic techniques) is asymmetric synthesis, the preferential synthesis of one of the two enantiomers, from prochiral precursors. Chiral catalysts play key role on the selectivity of these reactions and in most cases comprise transition metal complexes with chiral enantiopure ligands. One of the most characteristic examples was presented by the ingenious modification of Wilkinson's catalyst by William S. Knowles. The Wilkinson's catalyst, a square planar rhodium (I) complex with formula $\left[\mathrm{RhCl}\left(\mathrm{PPh}_{3}\right)_{3}\right]\left(\mathrm{PPh}_{3}=\right.$ triphenylphosphine), has been a successful catalyst for the hydrogenation of alkenes. Knowles expanded its use into their asymmetric analogues by substituting the achiral triphenylphospines with chiral ones. His most successful complex, $[\mathrm{Rh}(R, R-$ DIPAMP)(COD) $]^{+}$(Figure 6), was used for the enantioselective synthesis of L-DOPA, a drug used for Parkinson's disease treatment (Figure 7). ${ }^{50}$ His contribution to the field was very significant and, as a result, he, together with Ryoji Noyori and K. Barry Sharpless, were awarded with the 2001 Nobel in Chemistry for their contributions in chemical chirality-Knowles and Noyori for "chirally catalyzed hydrogen reactions", while Sharpless for "chirally catalyzed oxidation reactions", 51

Asymmetric catalysis, in which a coordination compound is typically involved, is a characteristic example where the isolation of an enantiomer of an organic compound depends on the availability of the appropriate enantiomer of an inorganic compound. In other words, enantiopure organic molecules require enantiopure inorganic ones. The principles that govern the chiral resolution of the former are essentially the same as the 
ones related to the latter. Thus, the methods and approaches used apply to both organic and inorganic. These include asymmetric synthesis, the direct synthesis of the desirable enantiomer from achiral precursors, and methods that deal with the resolution of racemic mixtures, such as spontaneous resolution by direct crystallization, ${ }^{52-54}$ analytical methods, like chromatography with chiral stationary phases, ${ }^{55,56}$ and diastereomer formation and resolution. ${ }^{57,58}$ A novel method that has been recently reported discusses the separation of enantiomers by their enantiospecific interaction with achiral magnetic substrates. ${ }^{59}$ Excellent reviews have been written on the topic of the separation of enantiomers. ${ }^{60,61}$

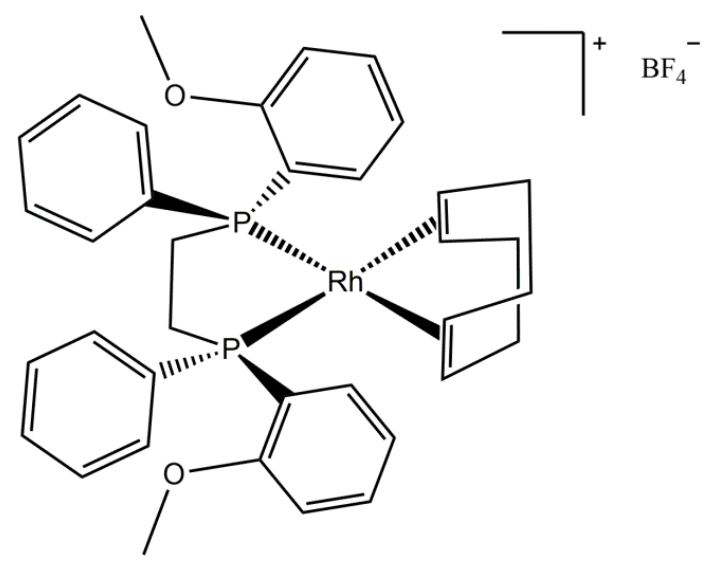

Figure 6. $[\mathrm{Rh}(R, R \text {-DIPAMP })(\mathrm{COD})]^{+}$catalyst for the enantioselective hydrogenation of alkenes.<smiles>N[C@@H](Cc1ccc(O)c(O)c1)C(=O)O</smiles>

Figure 7. L-3,4-dihydroxyphenylalanine or L-DOPA, a drug for Parkinson's disease treatment. 


\subsubsection{Enantiopure inorganic compounds}

\subsubsection{Inorganic asymmetric synthesis}

Stereoselective synthesis of coordination compounds can be achieved through enantiopure chiral ligands. Thus, the chirality of metal centers can be predetermined, yielding preferentially products of one absolute configuration. ${ }^{62}$ In other words, this method can be described as a transfer of the chiral information from the ligand or ligands, to the metal center. ${ }^{63}$ Meggers et al. demonstrated the synthesis of tris-heteroleptic ruthenium complexes with bipyridine based ligands using enantiopure salicyloxazoline as a temporary auxiliary ligand, which transferred its chirality to the intermediate complex and from it on to final complex containing only achiral bipyridines (Figure 8 and Figure 9). ${ }^{64}$ An analogous procedure was employed for the asymmetric synthesis of the $\Delta$ enantiomer of a homoleptic tris-bipyridine ruthenium complex, where the chiralityinducing ligand was (S)-(isopropylsulfinyl)phenol (Figure 10 and Figure 11). ${ }^{33}$ Bipyridine-based ligands have also been used for the diastereoselective synthesis of octahedral iron (II) complexes and silver (I) helicates. ${ }^{65-68}$ Janiak et al. showed that the same principle can be applied to tetrahedral zinc complexes with enantiopure Schiff base ligands. The absolute configuration of the ligand determines the absolute configuration of the final product (Figure 12). ${ }^{69}$ 


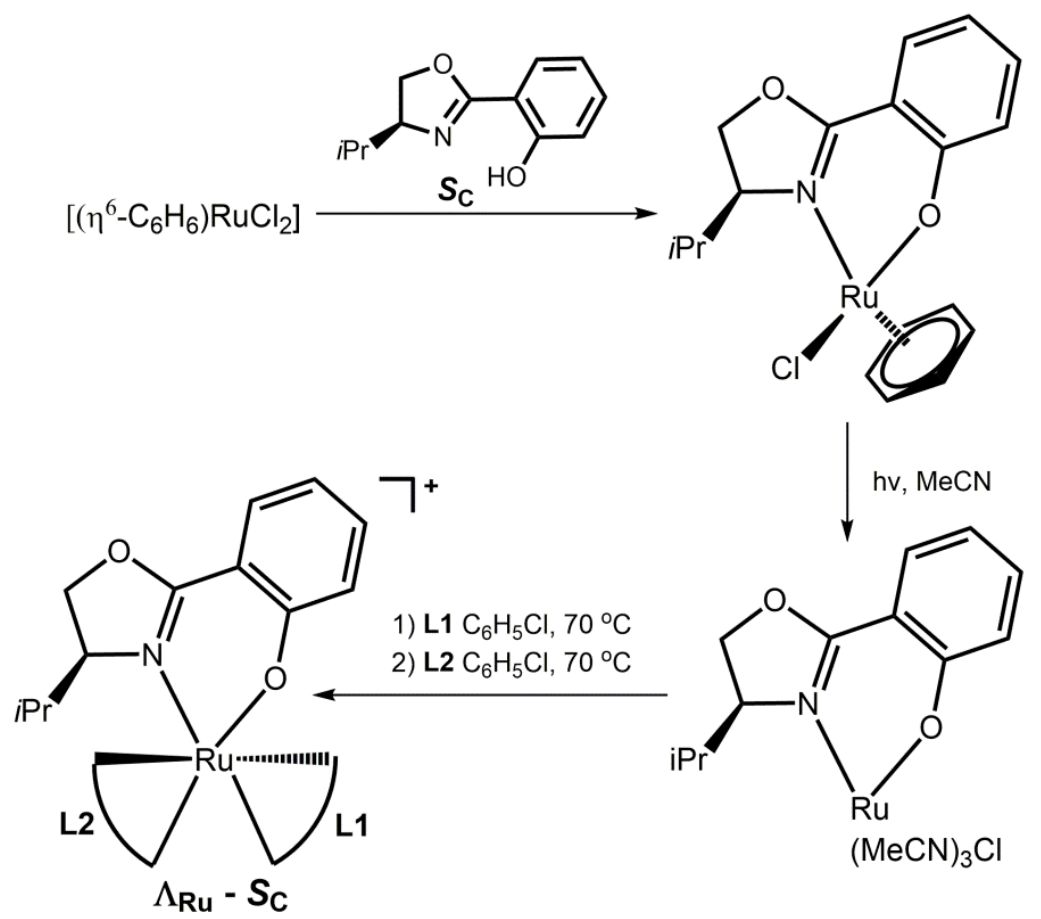

Figure 8. Chirality induction by the $(S)$-salicyloxazoline and formation of $\Lambda$ enantiomer with two bipyridine ligands L1 and L2.

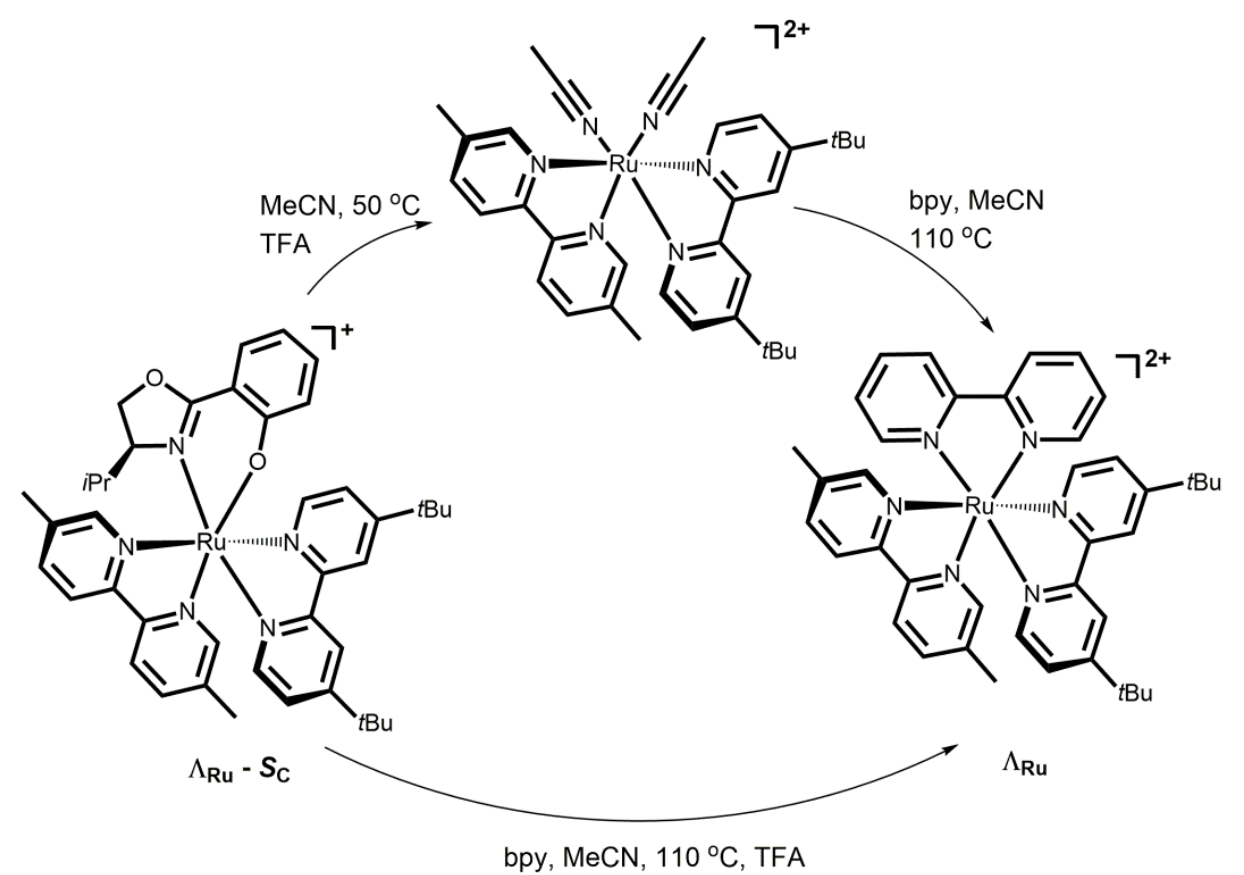

Figure 9. Substitution of $(S)$-salicyloxazoline by bipyridine to yield the final $\Lambda$ trisheteroleptic polypiridyl ruthenium complex $\Lambda_{\mathrm{Ru}}$. 


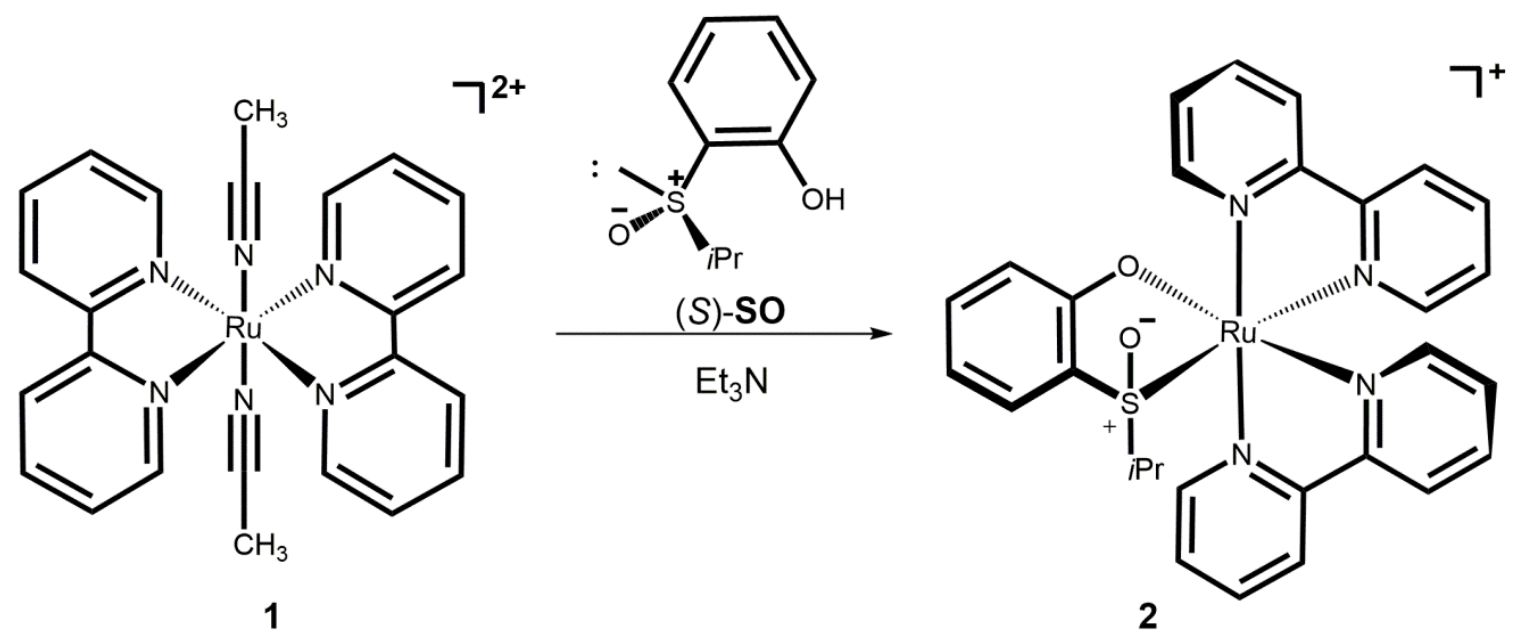

Figure 10. Diastereoselective conversion of prochiral trans-[Ru-(bpy $\left.)_{2}(\mathrm{MeCN})_{2}\right]^{2+} \mathbf{1}$ into chiral cis- $\Delta-\left[\mathrm{Ru}(\mathrm{bpy})_{2}\{(S)-\mathrm{SO}\}\right]^{+} \mathbf{2}$, where $\mathbf{S O}=(S)$-(isopropylsulfinyl)phenol.

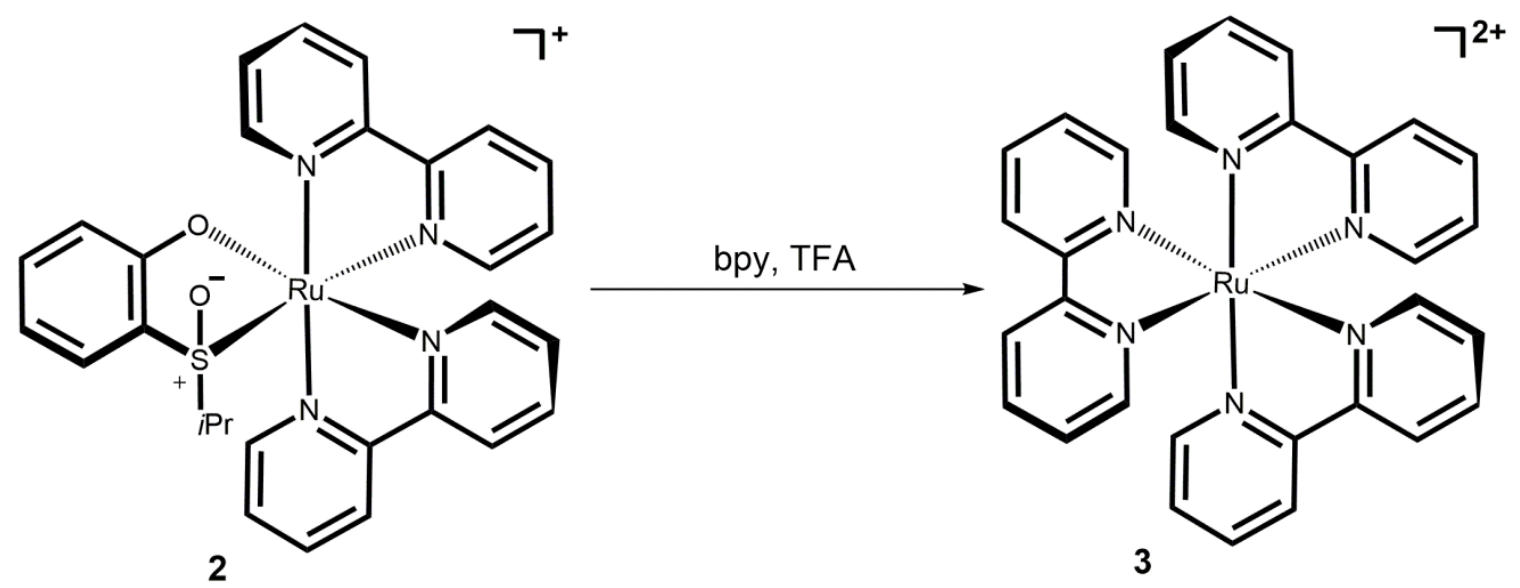

Figure 11. Acid-induced substitution of the chiral ligand $(S)$-SO for bpy to yield the $\Delta$ homoleptic ruthenium bipyridine complex. 


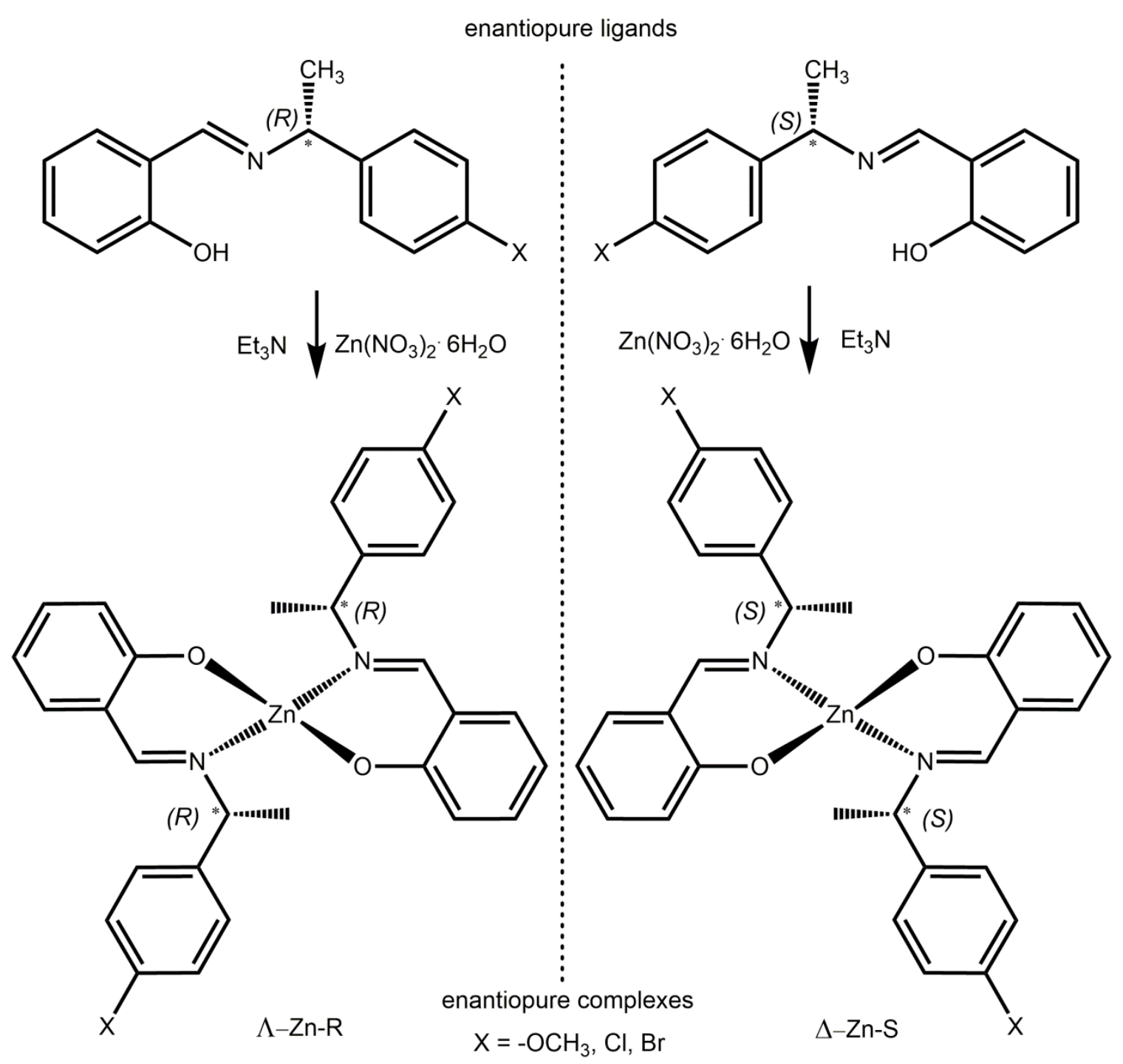

Figure 12. $(R)$-salicylaldimine ligand promotes $\Lambda$ configuration on a tetrahedral zinc complex, whereas $(S)$-salicylaldimine promotes the $\Delta$ one.

Configurational control can also be applied in organometallic compounds. As an example $\Lambda$ and $\Delta$ configurations of octahedral cationic iridium hydride complexes were isolated with the aid of chiral oxazoline-based ligands. ${ }^{70}$ Often, these complexes are generated in situ during catalytic tranformations. ${ }^{71}$ Asymmetric synthesis is not limited only to 
mononuclear metal complexes, such as those already mentioned, but examples of multinuclear homometallic or mixed-metal clusters exist also in the literature, albeit not as many. A pair of enantiopure $\mathrm{Cu}_{4} \mathrm{O}_{4}$ cubane-type clusters was constructed by $(R$ or $S)$ 2-[(2-hydroxy-1-phenylethylimino)methyl]phenol and $\mathrm{CuCl}_{2}$, and their magnetic properties were studied. ${ }^{72}$ Zhao et al. reported the synthesis of sigmoidal hexanuclear gold (I) clusters with enantiopure amine ligands and the study of the correlation between their metal atom arrangement and their chiroptical response (Figure 13). ${ }^{73}$
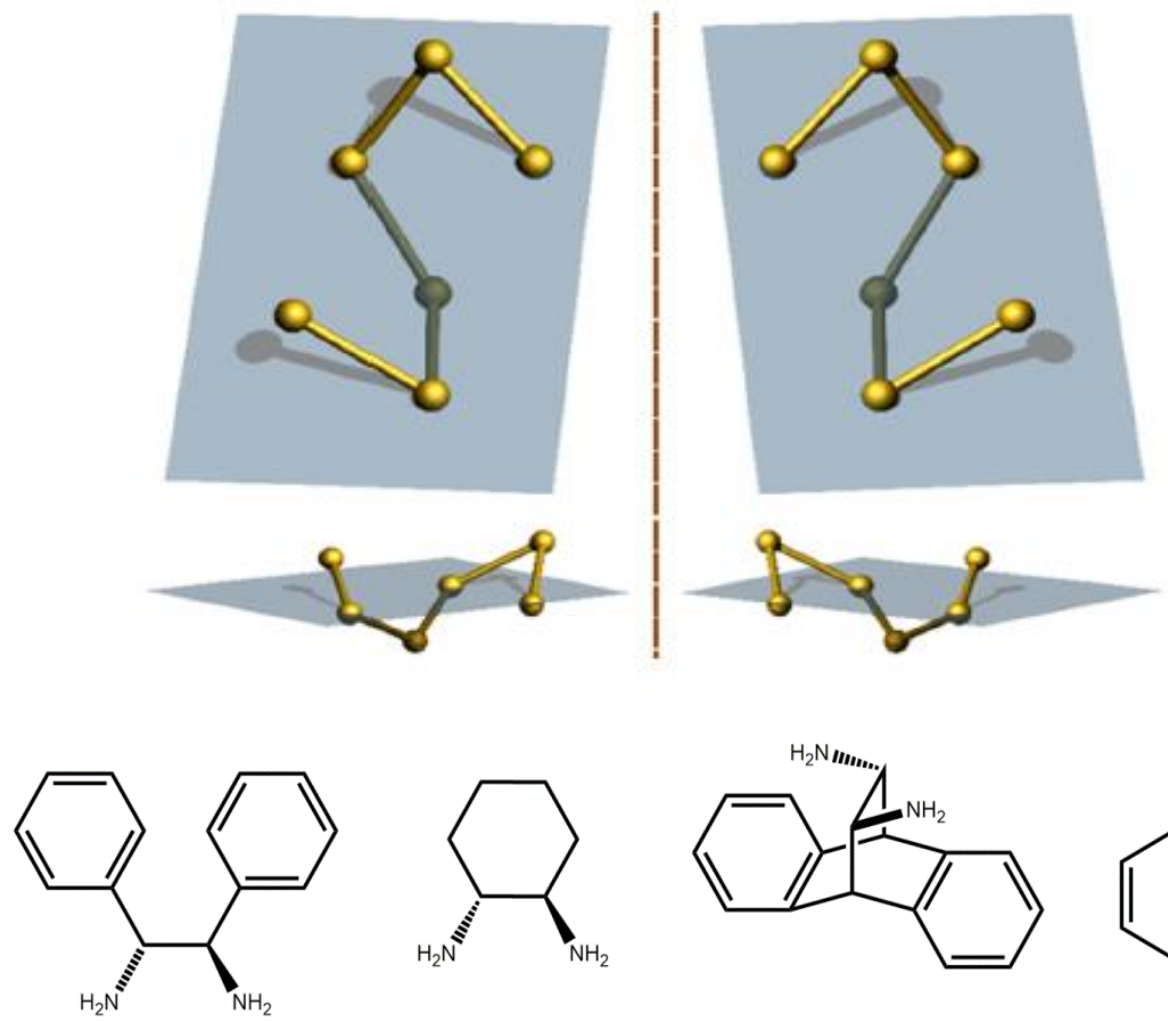<smiles>C[C@H](N)c1ccccc1</smiles>

Figure 13. Top and side views of sigmoidal and reverse-sigmoidal arrangement of gold atoms, and amine ligands (one enantiomer shown). Adapted with permission from He et al. Structurally Well-Defined Sigmoidal Gold Clusters: Probing the Correlation between Metal Atom Arrangement and Chiroptical Response. J. Am. Chem. Soc. 2016, 138 (17), 5634-5643. Copyright (2016) American Chemical Society. 
Pentanuclear mixed-metal and mixed-valent clusters of the general formula $\left[\mathrm{Mn}^{\mathrm{II}} \mathrm{Mn}_{3}{ }_{3}\right.$ $\mathrm{M}^{\prime}$ ], where $\mathrm{M}^{\prime}=\mathrm{Na}^{\mathrm{I}}, \mathrm{Ca}^{\mathrm{II}}, \mathrm{Mn}^{\mathrm{II}}$, as well as a nonanuclear one with formula $\left[\mathrm{Mn}^{\mathrm{II}} \mathrm{Mn}_{6}^{\mathrm{III}} \mathrm{Na}_{2}^{\mathrm{I}}\right]$, built from enantiomerically pure Schiff base $(R$ or $S$ )-phenylglysinol, were published by Escuer et al. $^{74}$ Probably the most prominent example of the asymmetric synthesis of enantiomerically pure polynuclear complexes is the construction of $\left\{\mathrm{Fe}_{28}\right\}$ wheels from the reaction of iron(III) nitrate and L-(+)- or D-(-)-tartaric acid in mildly acidic environment. ${ }^{75}$

\subsubsection{Direct resolution: Chromatography}

Chromatographic techniques, particularly HPLC, are being routinely used for the separation of a wide variety of organic molecules. The main advantage of the technique is the fact that it can be used in both analytical and preparative scale. The separation depends on the interactions between the analyte and a chiral selector, the nature of which can be of hydrogen bonding, dipole-dipole interactions, steric hindrance, $\pi-\pi$ interactions, and electrostatic or hydrophobic interactions. ${ }^{76}$ The columns used for these separations are typically equipped with a chiral stationary phase (CSP). Common commercial CSP's are classified as molecular or polymeric. Molecular CSP's, also called Pirkle-type, consist of small chiral molecules attached to a silica $\left(\mathrm{SiO}_{2}\right)$ surface. ${ }^{77}$ Among them, Whelk- $\mathrm{O}^{\circledR} 1$ is considered one of the most successful and versatile chiral stationary phases (Figure 14). ${ }^{78}$ 


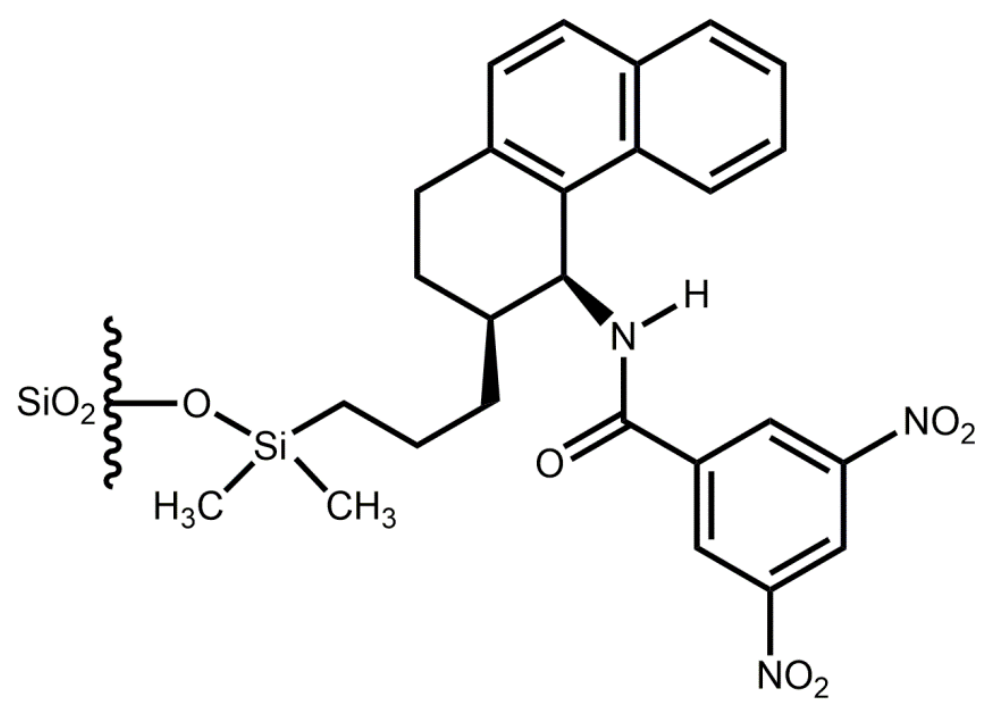

Figure 14 . Whelk-O ${ }^{\circledR} 1$ chiral stationary phase.

Polymeric CSP's mainly include modified polysaccharides like cellulose and amylose. One of the most efficient modifier is tris(3,5-dimethylphenylcarbamate), present in the commercially available columns Chiralpak $^{\circledR} \mathrm{AD}$ (amylose-derived, Figure 15) and Chiralcel ${ }^{\circledR} \mathrm{OD}$ (cellulose based). ${ }^{79}$

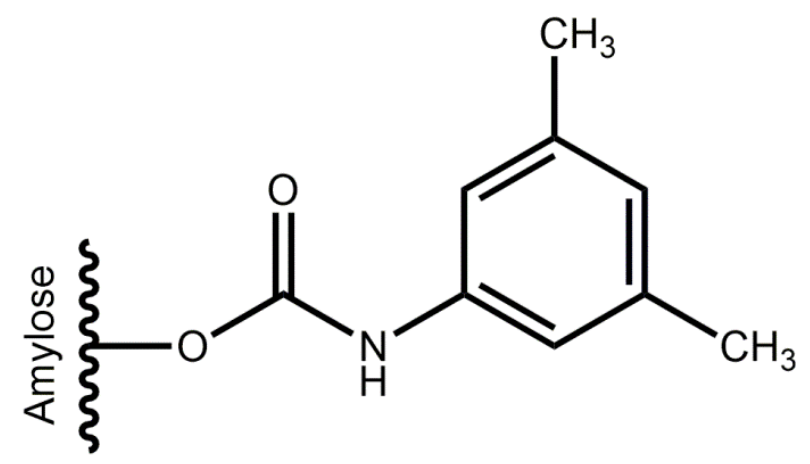

Figure 15. Carbamate-modified amylose CSP in the Chiralpak ${ }^{\circledR} \mathrm{AD}$ column. 
In contrast to the broad application of chromatography to the separation of organic molecules, examples of chromatographic separations of inorganic compounds are scarce in the literature. Chiralcel ${ }^{\circledR} \mathrm{OD}$ was successful in the separation of tetrahedral organometallic clusters of a variety of first- and second-row transition metals. ${ }^{80-82}$ Cellulose-derived CSP's, on the other hand, achieved the resolution of an iron(II) complex with formula $\left[\mathrm{Fe}_{2}\left(\mathrm{C}_{25} \mathrm{H}_{20} \mathrm{~N}_{4}\right)_{3}\right] \mathrm{Cl}_{4},{ }^{83}$ and the first enantioseparation and observation of circular dichroism of gold clusters protected by achiral thiolates with formula $\left[\mathrm{Au}_{38}\left(\mathrm{SCH}_{2} \mathrm{CH}_{2} \mathrm{Ph}\right)_{24}\right] .{ }^{84}$

\subsubsection{Spontaneous resolution}

Spontaneous resolution is defined as the segregation of enantiomers upon crystallization. Luis Pasteur was the first to report the resolution of ammonium tartrate crystals using this method. ${ }^{1}$ When mixtures of mirror-image configurations or conformations of a compound - a racemate-condense, they may do so in three general ways: (i) as a racemic compound in which both enantiomers are present in equal amounts in the condensate; (ii) as a conglomerate in which molecules form crystals comprised of only one enantiomer (homochiral) but where the sample as a whole is racemic because it contains equal amounts of enantiomorphic condensates; (iii) as a pseudoracemate, in which the condensates contain the two enantiomers in a non-ordered arrangement. Only the second category, the conglomerate, implies spontaneous resolution. ${ }^{53}$ In crystallographic terms, enantiopure compounds can only crystallize into one of the 65 chiral or Sohncke space groups (of the total 230 space groups). On the other hand, achiral compounds can crystallize in both chiral and achiral space groups. ${ }^{85}$ The observation of a 
chiral space group does not necessarily imply that crystals, as an entity, will be optically active since this activity can be a result of racemic twinning or lamellar epitaxy (where macroscopic layers of opposite enantiomers stack on top of each other). ${ }^{53}$ Although resolution via spontaneous crystallization is the most economical method, it is quite uncommon, and especially for metal-containing complexes, reports in the literature are few. Holm et al. reported the synthesis of a family of cubane-type clusters $\left[\mathrm{Fe}_{4} \mathrm{~S}_{4}\left(\mathrm{SR}^{*}\right)_{4}\right]^{2-}$ with several chiral racemic thiolate ligands, and from all possible diastereomers one pair of enantiomers was spontaneously resolved upon crystallization exhibiting mirror-imagerelated CD spectra (Figure 16). ${ }^{86}$

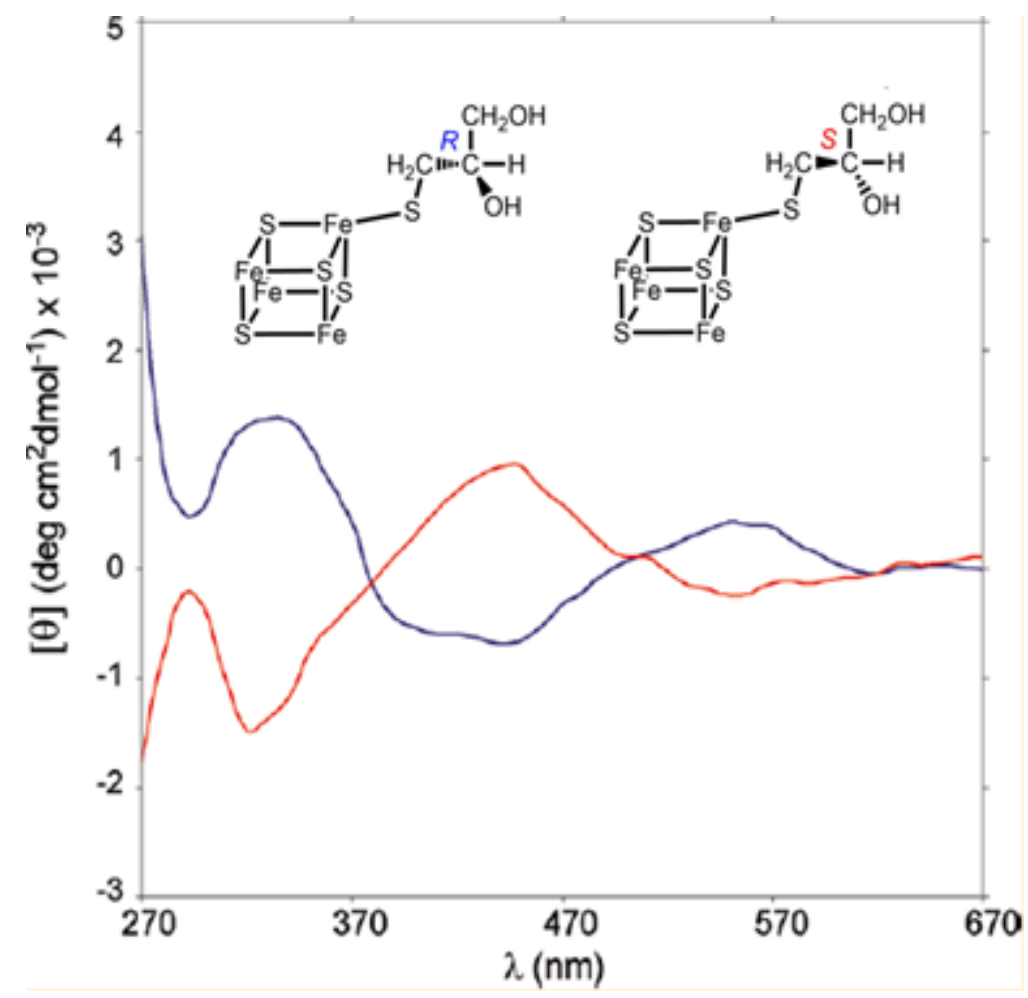

Figure 16. Circular dichroism spectra of pair of enantiomers of $\mathrm{Fe}_{4} \mathrm{~S}_{4}$-thiolate-cubanetype clusters with $(R R R R)$ blue line and $(S S S S)$ red line. (modified from reference 86$)$. 
The first example of a trinuclear triple helix constructed by an oligobipyridine ligand and $\mathrm{Ni}$ (II) ions was reported by Fisher et al. ${ }^{87} \mathrm{~A}$ rare example of a labile Fe (III) complex was published by Muziol et al. Spontaneous resolution upon crystallization occurred when $\left[\mathrm{Fe}(\text { oxalate })_{3}\right]^{3-}$ was mixed with $\left[\mathrm{Co}\left(\mathrm{NH}_{3}\right)_{4}\left(\mathrm{H}_{2} \mathrm{O}\right)_{2}\right]^{3+}$ yielding the heterometallic complex cis- $\left[\mathrm{Co}\left(\mathrm{NH}_{3}\right)_{4}\left(\mathrm{H}_{2} \mathrm{O}\right)_{2}\right] \quad\left[\mathrm{Fe}(\mathrm{ox})_{3}\right] \cdot 2 \mathrm{H}_{2} \mathrm{O}$, with the racemization process significantly obstructed by the extended H-bonding network developed in the crystal form. ${ }^{88} \mathrm{~A}$ case of two complexes of lanthanides has also been reported. Metal organic frameworks (MOF's) of $\mathrm{La}$ (III) and Gd (III) with dihydroxymalonate were spontaneously resolved upon crystallization (Figure 17). ${ }^{89}$

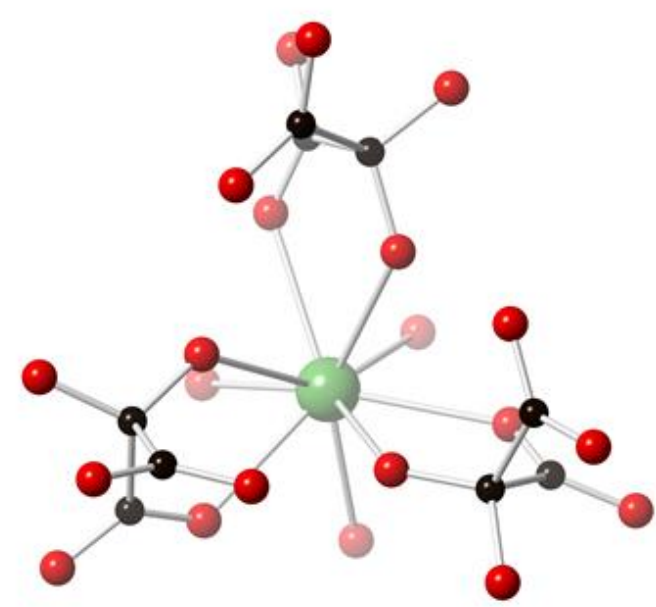

Figure 17. La (III) coordination sphere in (a) $\Lambda$ and (b) $\Delta$ MOF's with dihydroxymalonate.

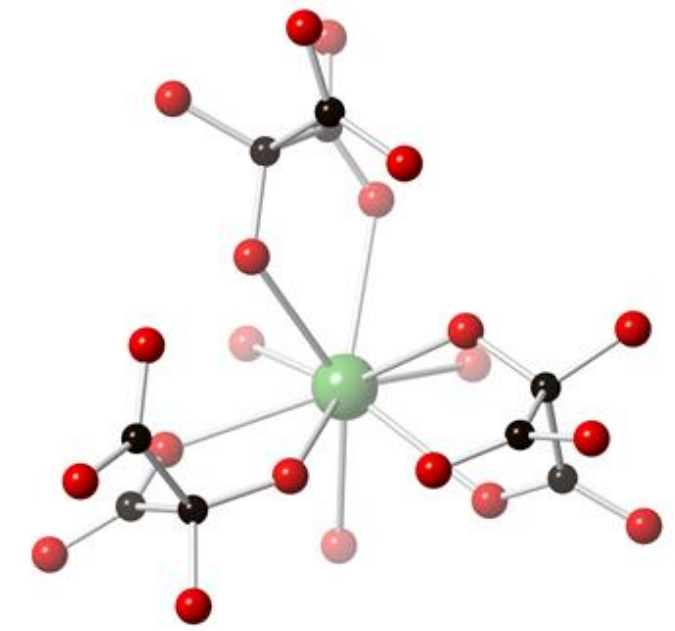




\subsubsection{Indirect resolution: Diastereomer formation}

Diastereomer formation is another approach for the resolution of racemic mixtures. Derivatization of the latter with other chiral moieties results in diastereomers, which by definition, exhibit different properties in achiral environments, in contrast to the enantiomers rendering their separation more feasible. The derivatization can take place either with the use of ionic species when the resolution target is ionic itself or by covalent bond formation between target and resolving agent when the starting racemate material is neutral. In both cases, the isolation of the diastereomers becomes simpler using conventional methods and can be achieved by solubility difference of solids, ${ }^{90,91}$ chromatography, ${ }^{92}$ or simply by kinetic resolution through crystallization. Some examples of anionic resolving agents, given in Figure $18,{ }^{57}$ include carboxylates (quinate, mandelate, entries $\mathbf{1}$ and $\mathbf{2}$ respectively), sulfonates (10-camforsulfonate, entry 3), and phosphonates $[(S)-(+)$-binaphthyl-2,2'-diyl-phosphate], (entry 4) and $\Delta$-tris(tetrachloro1,2-benzenediolato)phosphate(V), (entry 5) or $\triangle$-TRISPHAT. 4 -TRISPHAT was successful towards the resolution of a triangular host $[\mathrm{Cp} * \mathrm{Rh}(5$-chloro-2,3dioxopyridine) $]_{3}$ after its modification with $\mathrm{LiCl}$ and $\mathrm{AgOTf}$ (silver triflate). The diastereomers formed, $\quad\left[\mathrm{Li}(R, \quad R, \quad R)-\{\mathrm{Cp} * \mathrm{Rh}(5 \text {-chloro-2,3-dioxopyridine })\}_{3}\right][\Delta-$ TRISPHAT] and [Li( $S, S, S)-\left\{\mathrm{Cp}^{*} \mathrm{Rh}(5 \text {-chloro-2,3-dioxopyridine) }\}_{3}\right][\Delta$-TRISPHAT], were subsequently separated by fractional crystallization. ${ }^{93}$ Chiral cationic agents that have been employed for the resolution of anionic racemates are depicted in Figure $19 .{ }^{94}$ High levels of enantiomeric enrichment were achieved for dinuclear helicates of formula $\mathrm{K}_{6}\left[\mathrm{Ga}_{2} \mathbf{L}_{3}\right]\left[\mathrm{H}_{4} \mathbf{L}=1,4\right.$-bis(2',3'-dihydroxybenzamido)phenylene $]$ with the use of three 
different chiral cations, $N$-benzyl-quininium (quin), $N$-benzyl-cinchoninium (cinc), and $N$-methyl-s-nicotinium (s-nic). Raymond et al. also employed $N$-methyl-s-nicotinium for the resolution of tetrahedral supramolecular assemblies of the type $\mathrm{M}_{4} \mathrm{~L}_{6}^{1}$ and $\mathrm{M}_{4} \mathrm{~L}_{6}^{2}$, where $\mathrm{H}_{4} \mathrm{~L}^{1}=N, N^{\prime}$-bis(2,3-dihydroxybenzoyl)-1,5-diaminonaphthalene, $\mathrm{H}_{4} \mathrm{~L}^{2}=N, N^{\prime}-$ dihydroxy- $N, N^{\prime}$-di-p-tolylisophthalamide, and $\mathrm{M}=\mathrm{Ga}(\mathrm{III}), \mathrm{Fe}(\mathrm{III}), \mathrm{Al}(\mathrm{III})$. They then demonstrated the kinetic stability of these tetrahedral complexes towards racemization, a common problem with compounds bearing metal centers with no crystal field stabilization energy (CFSE). ${ }^{95,96}$<smiles>O=[14C][C@]1(O)C[C@@H](O)[C@H](O)[C@H](O)C1</smiles>

1<smiles>O=P1([O-])Oc2ccc3ccccc3c2-c2c(ccc3ccccc23)O1</smiles>

4

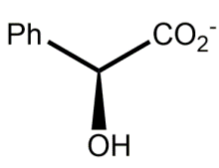

2

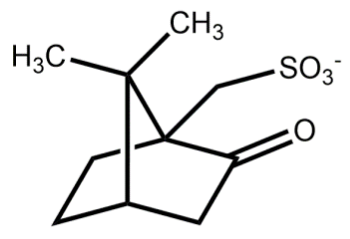

3<smiles>Clc1c(Cl)c(Cl)c2c(c1Cl)Oc1c(Cl)c(Cl)c(Cl)c(Cl)c1O[Pb]1(O2)Oc2c(Cl)c(Cl)c(Cl)c(Cl)c2O1</smiles>

Figure 18. Chiral anionic resolving agents. 


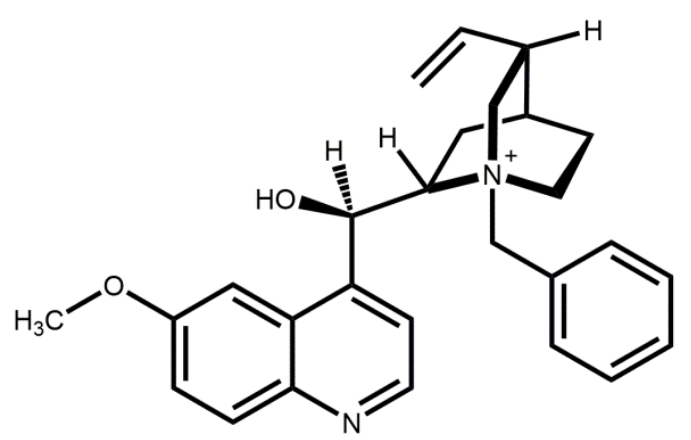

$N$-benzyl-quininium

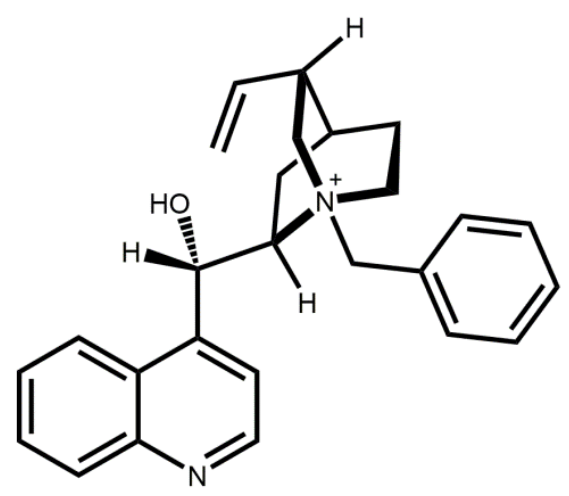

$N$-benzyl-cinchonidinium<smiles>CN1CCC[C@H]1c1ccc[n+](C)c1</smiles>

(S)-N-methyl-nicotinium

Figure 19. Chiral cationic resolving agents.
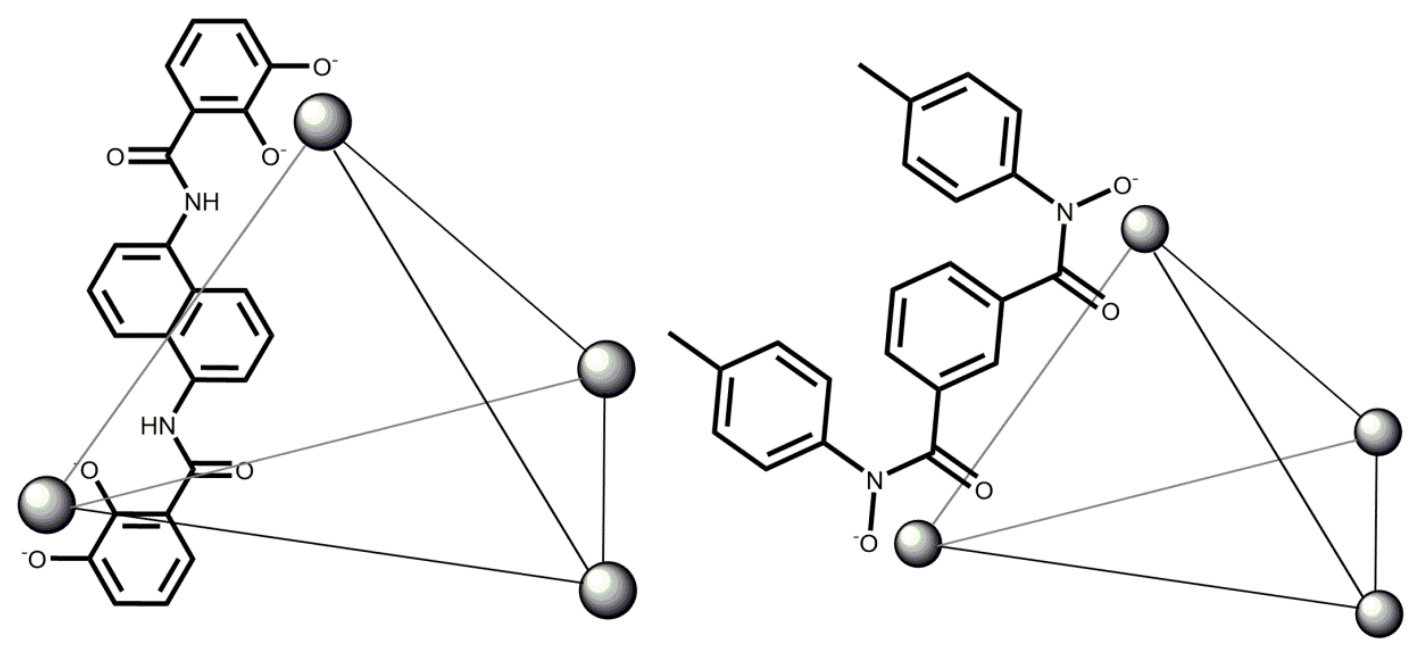

Figure 20. $\mathrm{M}_{4} \mathrm{~L}_{6}$ type cages, where $\mathrm{H}_{4} \mathrm{~L}^{1}=N, N^{\prime}$-bis(2,3-dihydroxybenzoyl)-1,5diaminonaphthalene (left), and $\mathrm{H}_{4} \mathrm{~L}^{2}=N, N^{\prime}$-dihydroxy- $N, N^{\prime}$-di-p-tolylisophthalamide (right). $\mathrm{M}=\mathrm{Ga}$ (III), $\mathrm{Fe}(\mathrm{III}), \mathrm{Al}(\mathrm{III})$. 
Extended metal atom chains (EMAC) consist of linearly bonded metal atoms surrounded by organic ligands, also known as molecular wires. A chiral analogue of this family, represented by a tricobalt chain with formula $\left[\mathrm{Co}_{3}(\mathrm{dpa})_{4}(\mathrm{MeCN})_{2}\right]^{2+}$, was resolved by anion exchange with the use of the chiral salt $\left.\left(\mathrm{NBu}_{4}\right)_{2}\left[\mathrm{As}_{2} \text { (tartrate }\right)_{2}\right]$ and selective crystallization. The $\Lambda$ enantiomer of the EMAC crystallized with the $\Delta$ enantiomer of the anionic part of the salt $\left[\mathrm{As}_{2}(\text { tartrate })_{2}\right]^{2-}$, whereas the $\Delta$ enantiomer of the EMAC crystallized with the $\Lambda$ enantiomer, both of them in the chiral $P 42{ }_{1} 2$ space group. ${ }^{97}$ One last example of the use of chiral anions comprises a unique polynuclear gold cluster with formula $\left[\mathrm{Au}_{102}(p-\mathrm{MBA})_{44}\right](p-\mathrm{MBA}=$ para-mercaptobenzoic acid $)$, resolved with the use of an ammonium salt of (-)- $1 R, 2 S-N$-dodecyl- $N$-methylephedrinium bromide by preferable transfer of one of the enantiomers of the $\left\{\mathrm{Au}_{102}\right\}$ cluster from water into chloroform organic phase. ${ }^{98}$ The crystal structure of the nanosize cluster is one of the few ever reported for nanometer-sized gold particles (Figure 21). ${ }^{99}$
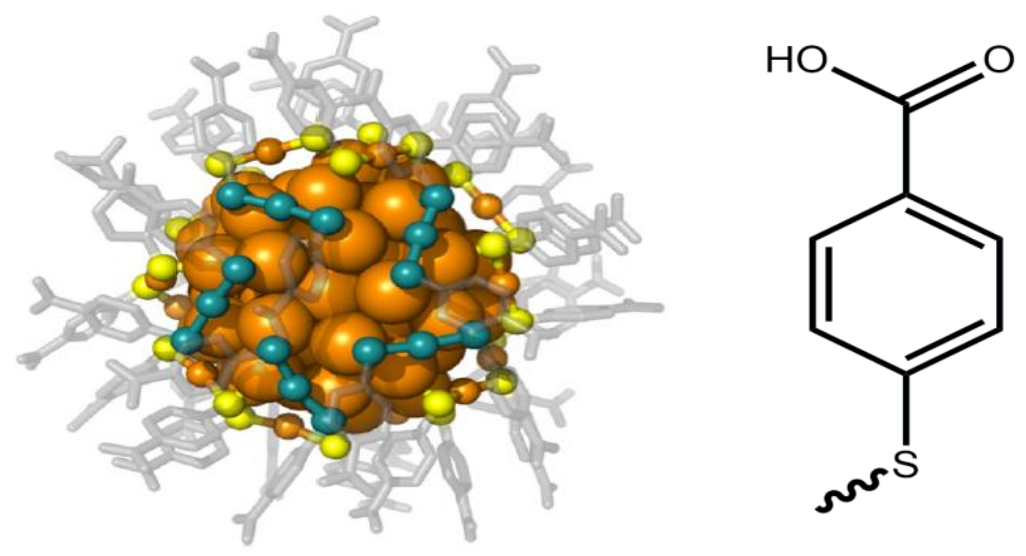

Figure 21. Structures of the $\left[\mathrm{Au}_{102}(p-\mathrm{MBA})_{44}\right]$ cluster (left) and $p$-MBA ligand (right). Reprinted with permission from Knoppe et al. Chiral Phase Transfer and Enantioenrichment of Thiolate-Protected Au102 Clusters. J. Am. Chem. Soc. 2014, 136 (11), 4129-4132. Copyright (2014) American Chemical Society. 
Diastereomer formation in the form of salts of ionic species is not the only possibility. Direct substitution reaction of one or more of the racemate's achiral ligands with chiral ones, either in racemic or in enantiopure form, can lead to the formation of diastereomers which can subsequently be separated with the same methods described previously. Carmona et al. described the resolution of rhodium complexes with a tripodal tetradentate ligand with the general formula $\left[\mathrm{Rh}\left(\kappa^{4} C, N, N^{\prime}, P-\mathbf{L}\right) \mathrm{AB}\right]\left[\mathrm{SbF}_{6}\right], \mathrm{A}, \mathrm{B}=\mathrm{Cl}$, $\mathrm{MeCN}, \quad \mathrm{H}_{2} \mathrm{O}, \quad \mathbf{L}=N$-benzyl- $N$-[2-(diphenylphosphanyl)benzyl]-1-(pyridine-2yl)methanamine (the synthesis was also reported by the same group) ${ }^{100}$ As depicted in Figure 22, reaction of the initial complex with $(S)$-phenylglycinate yields, by substitution of the coordinated $\mathrm{MeCN}$, two diastereomers $(A, S)$ and $(C, S)$ in ca. 1:1 ratio which were thereafter separated by silica gel chromatography. Further substitution of the chiral ligands with terminal $\mathrm{Cl}$ by addition of excess $\mathrm{HCl}$ yields the two enantiomers $A$ and $C$ with retention of the configuration. The enantiopure compounds readily catalyzed the Diels-Alder reaction of methacrolein and cyclopentadiene after the removal of $-\mathrm{Cl}$ ligands with $\mathrm{AgNO}_{3}$ with the open position temporarily occupied by $\mathrm{MeCN}$ or $\mathrm{H}_{2} \mathrm{O}$ molecules. ${ }^{101}$ It is noteworthy that chiral-at-metal complexes like this fulfill the requirements of optical resolution, high configurational stability and labile coordinate sites. Chiral-at-metal catalysts seem to be more efficient at accomplishing asymmetric induction because of the proximity of the chiral center and the substrate; such systems have not been explicitly documented so far. ${ }^{102}$ 

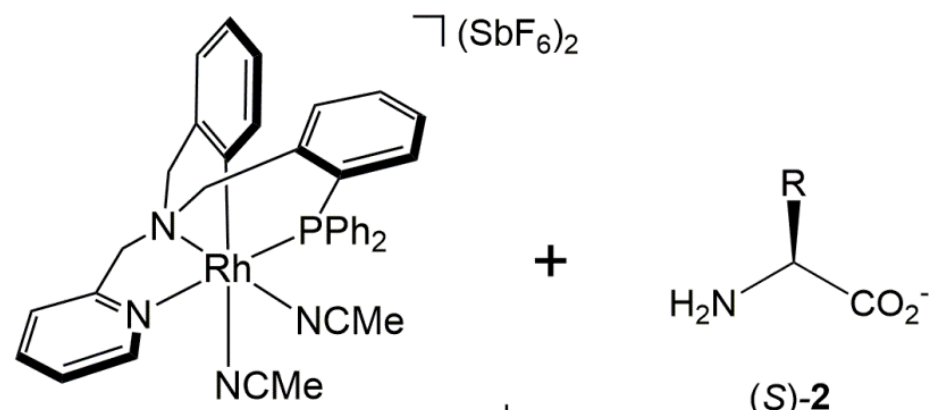

(S)-2

$\operatorname{rac}-1(A, C)$
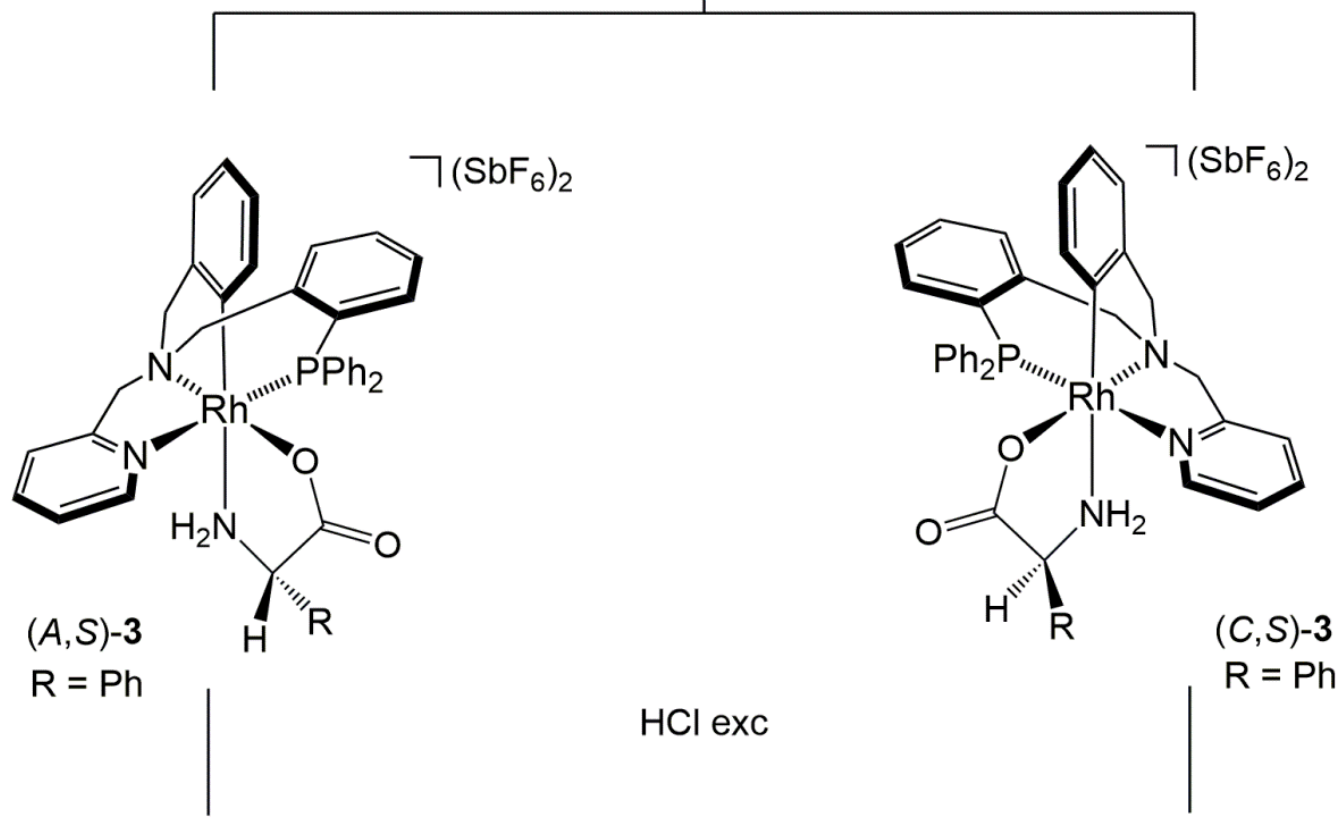

$\mathrm{HCl}$ exc

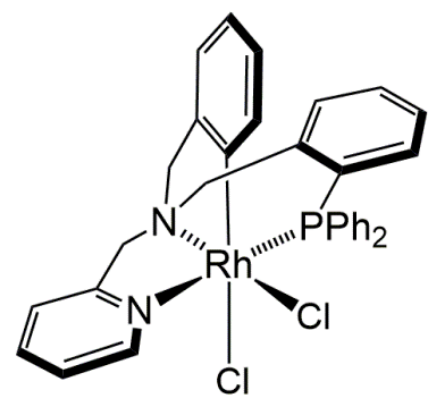

(A)-4
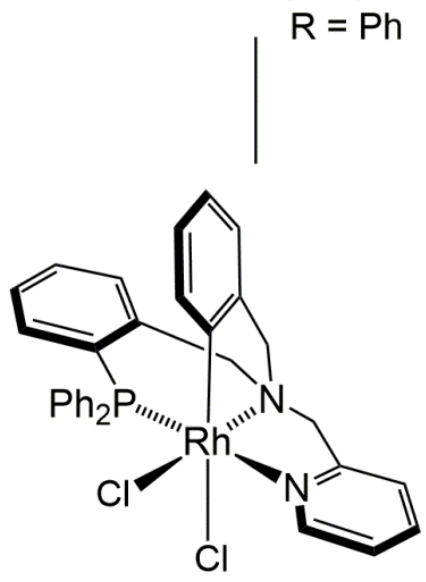

(C)-4

Figure 22. Resolution of $\mathrm{Rh}$ complex with tripodal tetradentate ligand. $(S)$ phenylglycinate used as chiral auxiliary. 
A similar approach was employed by Rong et al. for the resolution of a ruthenium chloride complex featuring chirality from the face-specific coordination of the 1-Me3PhCp ligand (Figure 23). ${ }^{103}$ Substitution of the chloro ligand by the enantiopure thiol,
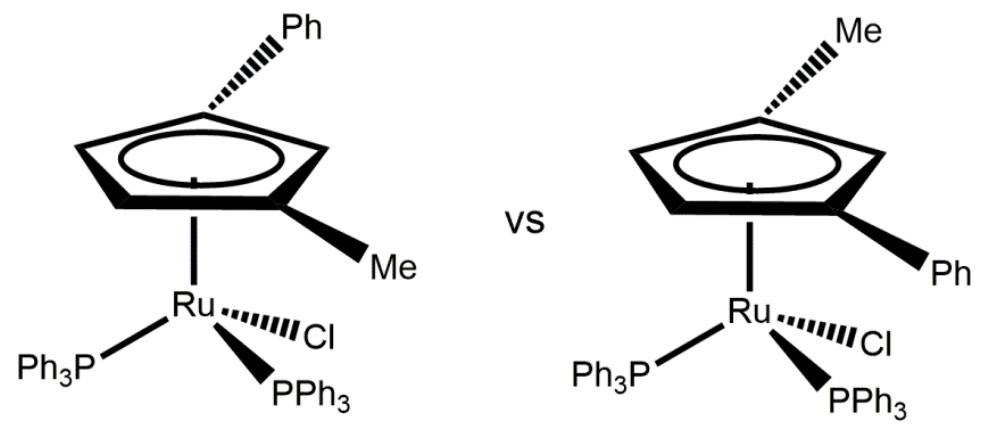

Figure 23. Face-specific coordination of the 1-Me-3PhCp ligand.

$(S)$ - $\alpha$-methyl-benzenemethanethiol yielded a 1:1 mixture of diastereomers, which were then separated by fractional crystallization to give $\left(S_{\mathrm{Cp}}, S\right)-\mathbf{1 1}$ and $\left(R_{\mathrm{Cp}}, S\right)$-11 (see Figure 24) in high diastereomeric ratios. Removal of the chiral thiolate ligand by complexation with $\mathrm{Hg}$, and re-introduction of chloride using excess of $\mathrm{LiCl}$ allows for the isolation of one of the enantiomers of the starting complex $\left(S_{\mathrm{Cp}}\right)-\mathbf{8}$ (Figure 24). Enantiopure ruthenium complexes like these are excellent candidates for asymmetric catalysis. A summary of the synthetic procedure and resolution is given in Figure 24. ${ }^{103}$ 

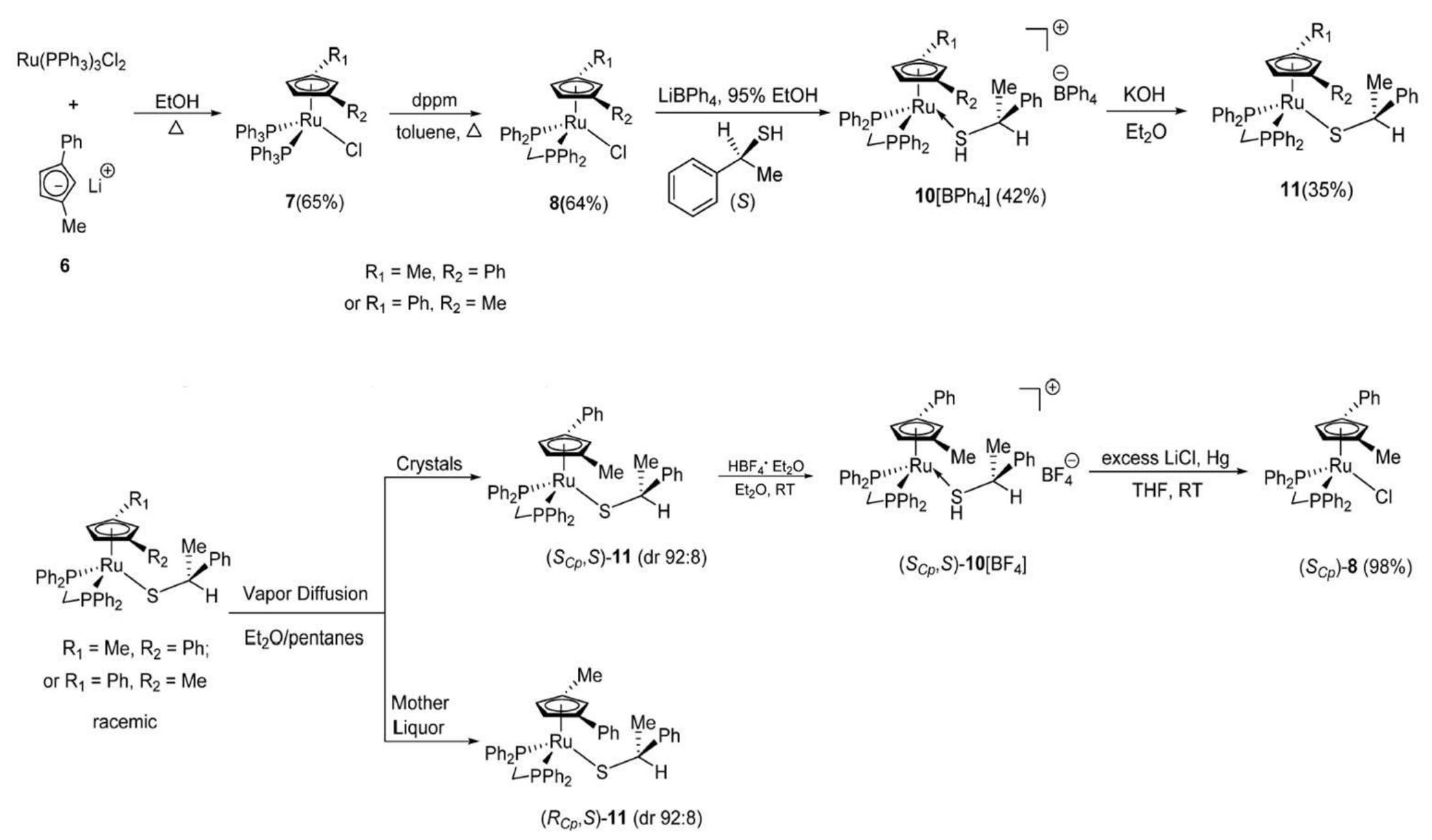

Figure 24. Synthesis and resolution of chiral $\mathrm{Ru}\left(\mathrm{PPh}_{3}\right)_{2} \mathrm{Cl}(1-\mathrm{Me}-3-\mathrm{PhCp})$ complex. (modified from reference 103) 


\subsection{The octanuclear iron-oxo-pyrazolato complex}

The octanuclear iron-oxo-pyrazolato complex $\left[\mathrm{Fe}^{\mathrm{III}}{ }_{8}\left(\mu_{4}-\mathrm{O}\right)_{4}(\mu-\mathrm{pz})_{12} \mathrm{Cl}_{4}\right]\left[\mathrm{Fe}_{8}\right]$, (Figure 25) has been reported and studied by Raptis' group since $1999 .{ }^{104}$ Chirality, in many cases, can arise from the self-assembly of achiral subcomponents in supramolecular structures. ${ }^{105}$ The $\mathrm{Fe}_{8}$ complex is one of those cases. It consists of a $\mathrm{Fe}_{4} \mathrm{O}_{4}$-cubane core inside a shell of four outer Fe-atoms, twelve bridging pyrazolates, and four terminal chloride ligands. The $\mathrm{Fe}_{4} \mathrm{O}_{4} \mathrm{Cl}_{4}$ moiety is in a tetrahedral arrangement, with each of the four $C_{3}$ axes running through $\mathrm{Cl}-\mathrm{Fe}-\mathrm{O} \cdots \mathrm{Fe}$ atoms. The twelve pyrazolate ligands wrap around the iron-oxide core with a propeller twist, eliminating the symmetry mirror planes and reducing the $T_{d}$ symmetry of the $\mathrm{Fe}_{4} \mathrm{O}_{4} \mathrm{Cl}_{4}$-core to that of the chiral $T$ point group. As a consequence, the molecule crystallizes as an $M / P$ racemic mixture.

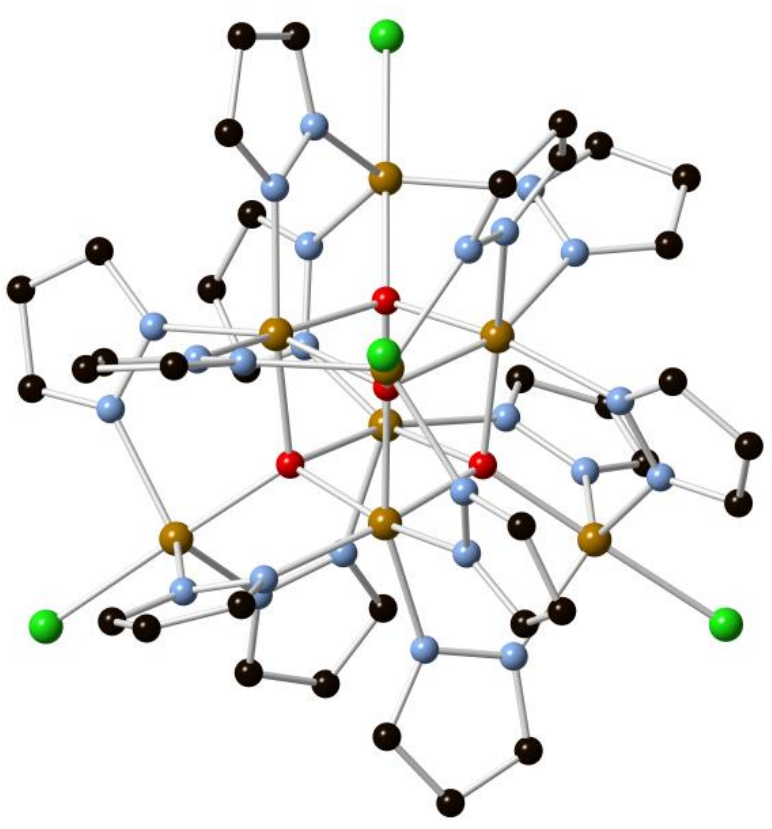

Figure 25. Ball-and-stick diagram of the $\left[\mathrm{Fe}_{8}\right]$ complex. Hydrogen atoms omitted for clarity Color codes: gold, $\mathrm{Fe}$; red, $\mathrm{O}$; blue, $\mathrm{N}$; green $\mathrm{Cl}$; black, $\mathrm{C}^{106}$ 

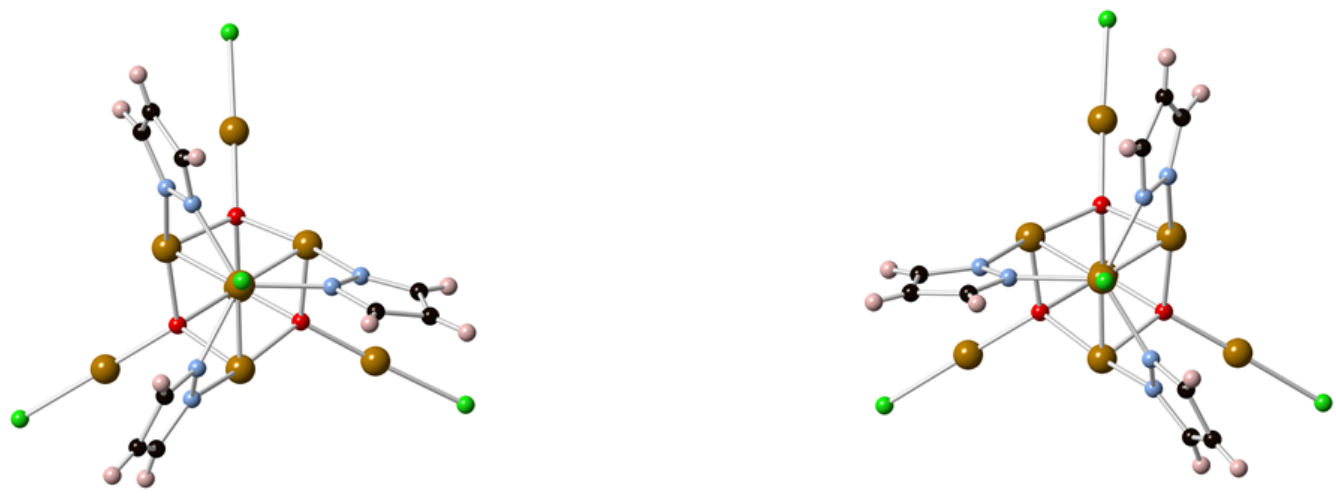

Figure 26. The propeller twist of $M$ (anti-clockwise) and $P$ (clockwise) $\mathrm{Fe}_{8}$. Only three of the twelve pyrazolate ligands are shown.

A variety of flavors of the general formula $\left[\mathrm{Fe}^{\mathrm{III}}{ }_{8}\left(\mu_{4}-\mathrm{O}\right)_{4}(\mu-4-\mathrm{R}-\mathrm{pz})_{12} \mathrm{X}_{4}\right]\left(\mathrm{R}=\mathrm{H}, \mathrm{Cl}, \mathrm{CH}_{3}\right.$, $\mathrm{CH}_{2} \mathrm{CH}_{2} \mathrm{Cl}, \mathrm{CH}_{2} \mathrm{CH}_{2} \mathrm{CH}_{2} \mathrm{Cl}, \mathrm{X}=\mathrm{Cl}, \mathrm{Br}, \mathrm{NSC}$ ) have been reported, as well as watersoluble derivatives $\left(\mathrm{R}=\mathrm{CH}_{2} \mathrm{CH}_{2} \mathrm{OH}, \mathrm{CH}_{2} \mathrm{CH}_{2} \mathrm{CH}_{2} \mathrm{OH}\right) .{ }^{106,107}$ The $\mathrm{Fe}_{8}$ exhibits reach electrochemistry, showing up to four reversible reduction processes which can be tuned by differentiation of the $\mathrm{R}$ or $\mathrm{X}$ substituents (Figure 27). Additionally, it structurally resembles the $\mathrm{Fe}_{4}\left(\mu_{4}-\mathrm{O}\right)_{4}$ motifs encountered in magnetite, ferrihydrite, and maghemite. The resolution of the $\mathrm{Fe}_{8}$ complex, or one of its derivatives, could render it an excellent candidate for enantioselective catalysis. Iron-based catalysts have been known for a long time and have implications in a great variety of organic transformations. ${ }^{108}$ During the last decade, in particular, iron catalysts have been developed to participate in more challenging reactions that were previously only possible via catalysis with second and third row transition metals. ${ }^{109-111}$ Furthermore, there is a great need for moving towards more sustainable chemistry and thus relying more on abundant, low-toxicity metals like iron. ${ }^{112}$ Asymmetric iron-based catalysis, on the other hand, is still a developing field. ${ }^{113}$ 
In recent years, an increasing number of iron(II) and iron(III) complexes have found catalytic applications in asymmetric reactions, where second and third row transition metals were dominating, like, for example, cross-coupling reaction for $\mathrm{C}-\mathrm{C}$ bond formation, C-H bond activation, epoxidations, etc. ${ }^{114-120}$ In addition to its potential application as an enantioselective catalyst, $\mathrm{Fe}_{8}$ could possibly exhibit specific interaction with biological substrates and its properties could be exploited, finding applications in the intriguing and emerging field of artificial metalloenzymes. ${ }^{121}$

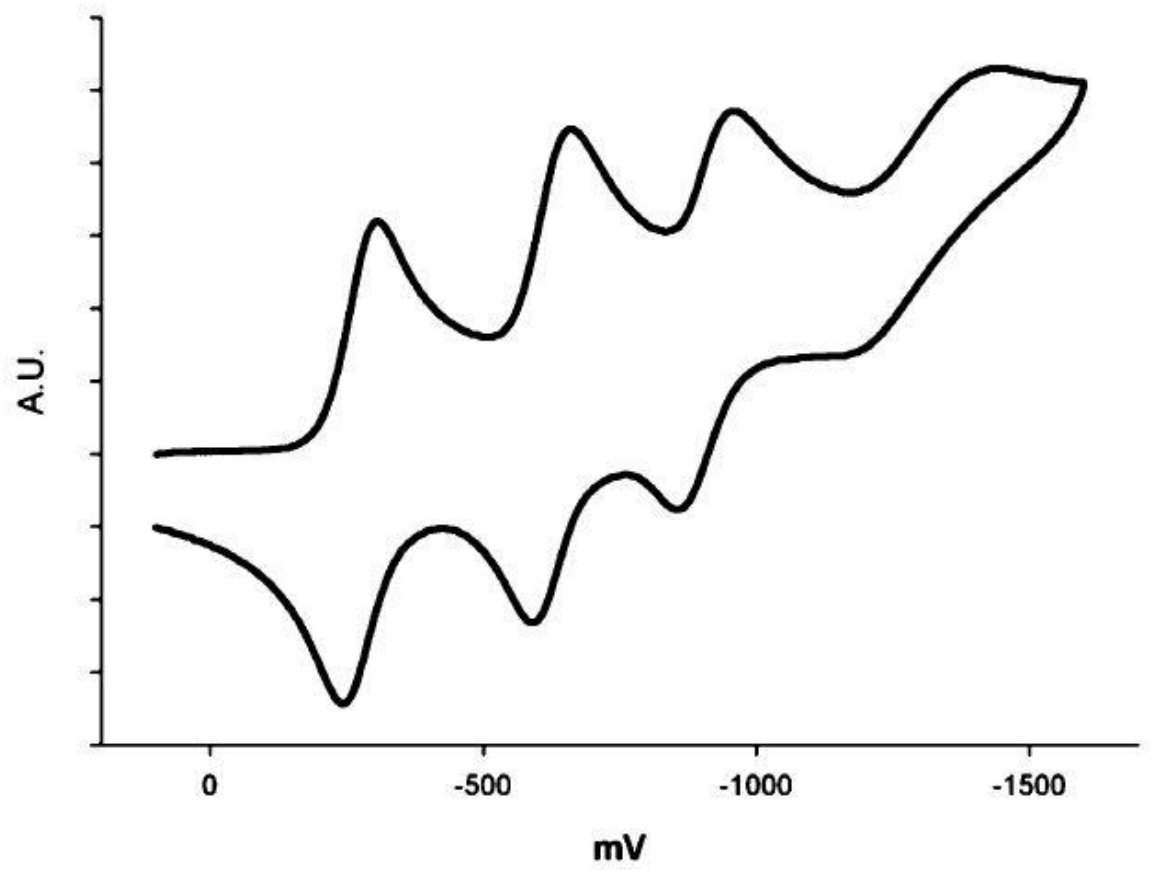

Figure 27. Cyclic voltammogram of $\left[\mathrm{Fe}^{\mathrm{IIII}}{ }_{8}\left(\mu_{4}-\mathrm{O}\right)_{4}(\mu-\mathrm{pz})_{12} \mathrm{Br}_{4}\right], v s . \mathrm{Fc}^{+} / \mathrm{Fc}$. Reprinted with permission from Baran et al. Synthesis, Characterization, and Study of Octanuclear IronOxo Clusters Containing a Redox-Active Fe4O4-Cubane Core. Inorg. Chem. 2008, 47 (2), 645-655. Copyright (2008) American Chemical Society. 


\section{Chapter II: Synthesis and characterization of $\mathrm{Fe}_{8}$ complexes terminated with \\ phenolates}

\section{Introduction}

The strategy towards the resolution of the racemic mixture of the $\left[\mathrm{Fe}_{8}\right]$ complex includes the substitution of the terminal $-\mathrm{Cl}$ ligands with chiral phenols, which are expected to yield pairs of diastereomers (for detailed description see chapter III). Upon deprotonation, phenols become phenolates, which are known to have great affinity for $\mathrm{Fe}$ (III) metal centers, in contrast to alcohols. In addition, the lower $\mathrm{pKa}$ of phenols, ranging from 7.1 to 10.3 for a variety of mono-substituted ones, ${ }^{122}$ renders them amenable to deprotonation by mild bases. Therefore, it is appropriate to first optimize the synthetic protocols and crystallization methods of $\mathrm{Fe}_{8}$-phenolates, as well as interpret their spectroscopic parameters, especially their ${ }^{1} \mathrm{H}-\mathrm{NMR}$. Towards that goal, seven achiral phenols and a chiral one were chosen, and their corresponding $\mathrm{Fe}_{8}$-phenolates were synthesized and studied in detail by structural and spectroscopic methods.

\subsection{Results and discussion}

\subsubsection{Synthesis}

Complex $\left[\mathrm{Fe}_{8}\left(\mu_{4}-\mathrm{O}\right)_{4}(\mu-\mathrm{pz})_{12} \mathrm{Cl}_{4}\right]$ (1) was prepared using a literature procedure. ${ }^{106}$ Complexes 2-10 were synthesized by addition of a 20-fold excess of the corresponding phenol and triethylamine, to a $\mathrm{CH}_{2} \mathrm{Cl}_{2}$ solution of $\mathbf{1}$. 


\subsubsection{X-Ray crystallography}

Crystallographic data and refinement parameters for complexes $\mathbf{2 - 5}$ are summarized in Table 3 and for complexes 6-9 in Table 4. Compounds 2, 3, and 9 crystallize in triclinic $P-1$ space group with one molecule per asymmetric unit for $\mathbf{2}$ and $\mathbf{3}$, and two molecules for 9 related by an inversion center. Compounds 4 and 7 crystallize in monoclinic $P{ }_{1} / c$ space group with a whole molecule per asymmetric unit, whereas $\mathbf{6}$ and $\mathbf{7}$ in monoclinic $C 2 / c$ with half molecule per asymmetric unit, the other half generated by the principal $C_{2}$ axis. Compound $\mathbf{8}$ crystallizes in $C 2 / c$, as well (for detailed crystallographic and structural description of $\mathbf{8}$ see Chapter III). All the compounds crystallize in centrosymmetric space groups as racemic mixtures. Two types of iron atoms are present in the structure. One is the cubane $\mathrm{Fe}_{\mathrm{c}}$, a six-coordinated distorted octahedral center surrounded by three $\mathrm{N}$ atoms from the pyrazolate ligands and three $\mathrm{O}$ atoms from the cubane $\left(\mathrm{O}_{\mathrm{c}}\right)$. The other is the outer $\mathrm{Fe}_{\mathrm{o}}$, a five-coordinated trigonal bipyramidal center surrounded by three $\mathrm{N}$ atoms from the pyrazolate ligands, one $\mathrm{O}$ from the cubane and a terminal ligand (- $\mathrm{Cl}$ in case of $\mathbf{1}$ and the $\mathrm{O}_{\mathrm{ph}}$ of the corresponding phenolate in case of $\mathbf{2}$ 9). 


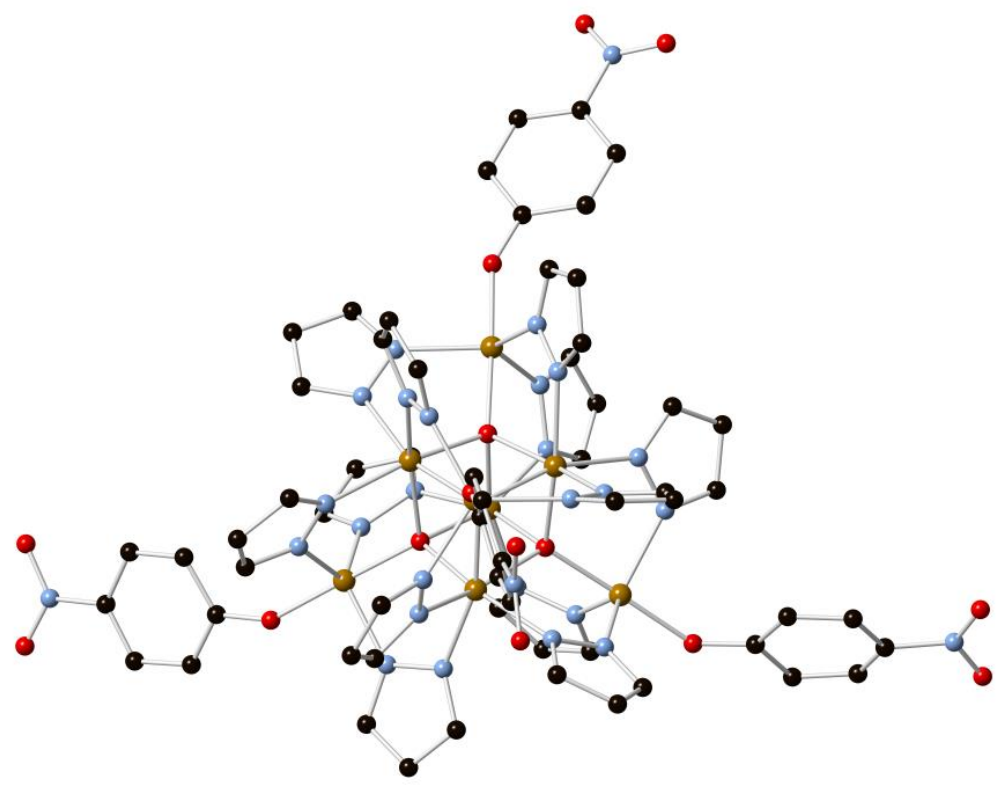

Figure 28. Ball-and-stick diagram of $\left[\mathrm{Fe}_{8}\left(\mu_{4}-\mathrm{O}\right)_{4}(\mu-\mathrm{pz})_{12}\left(4-\mathrm{NO}_{2}-\mathrm{C}_{6} \mathrm{H}_{4} \mathrm{O}\right)_{4}\right]$ (2). Hydrogen atoms omitted for clarity. Color codes: gold, Fe; red, O; blue, N; black, C.

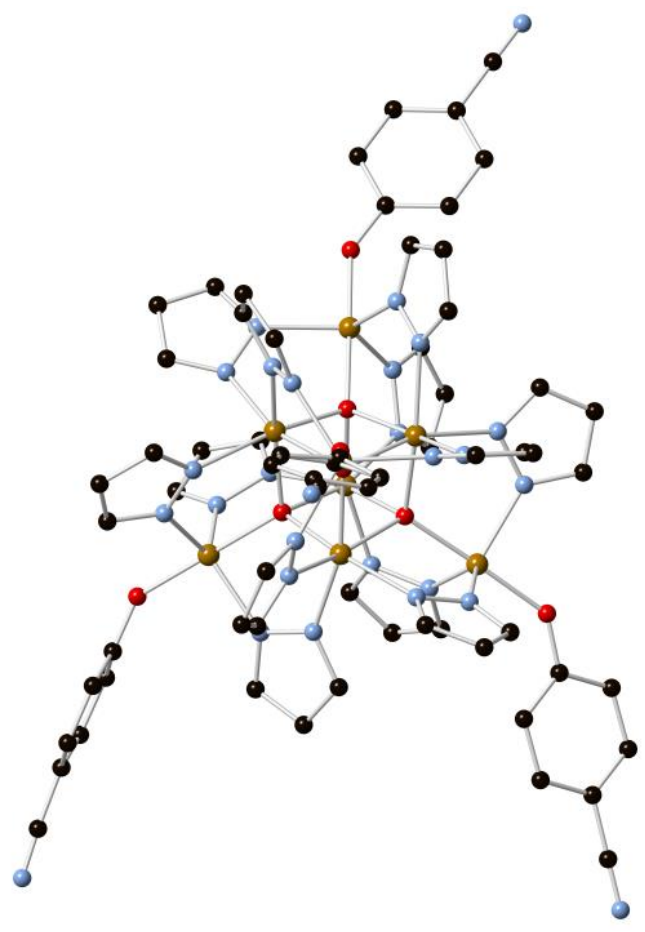

Figure 29. Ball-and-stick diagram of $\left[\mathrm{Fe}_{8}\left(\mu_{4}-\mathrm{O}\right)_{4}(\mu-\mathrm{pz})_{12}\left(4-\mathrm{NC}-\mathrm{C}_{6} \mathrm{H}_{4} \mathrm{O}\right)_{4}\right](3)$. Hydrogen atoms omitted for clarity. Color codes: gold, Fe; red, O; blue, N; black, C. 


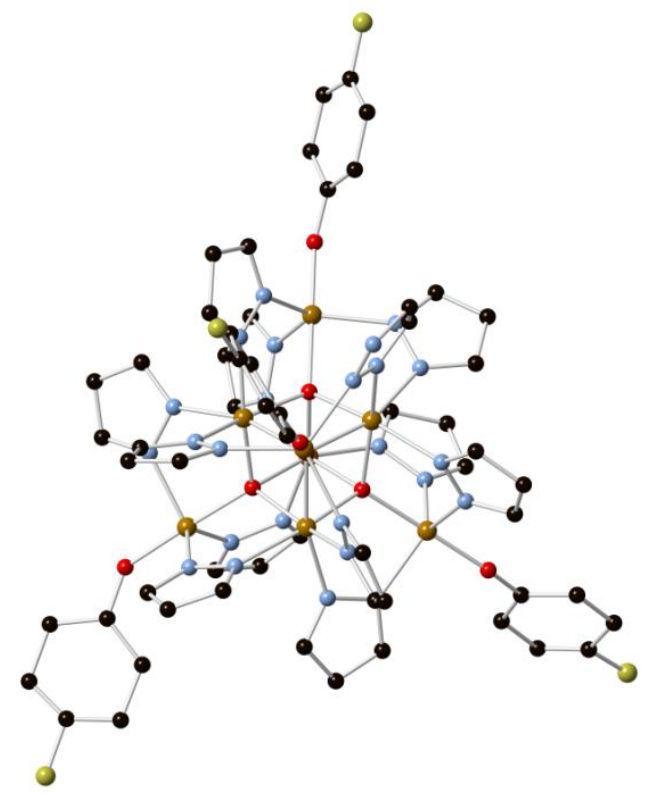

Figure 30. Ball-and-stick diagram of $\left[\mathrm{Fe}_{8}\left(\mu_{4}-\mathrm{O}\right)_{4}(\mu-\mathrm{pz})_{12}\left(4-\mathrm{F}-\mathrm{C}_{6} \mathrm{H}_{4} \mathrm{O}\right)_{4}\right]$ (4). Hydrogen atoms omitted for clarity. Color codes: gold, Fe; red, O; blue, N; F, olive; black, C.

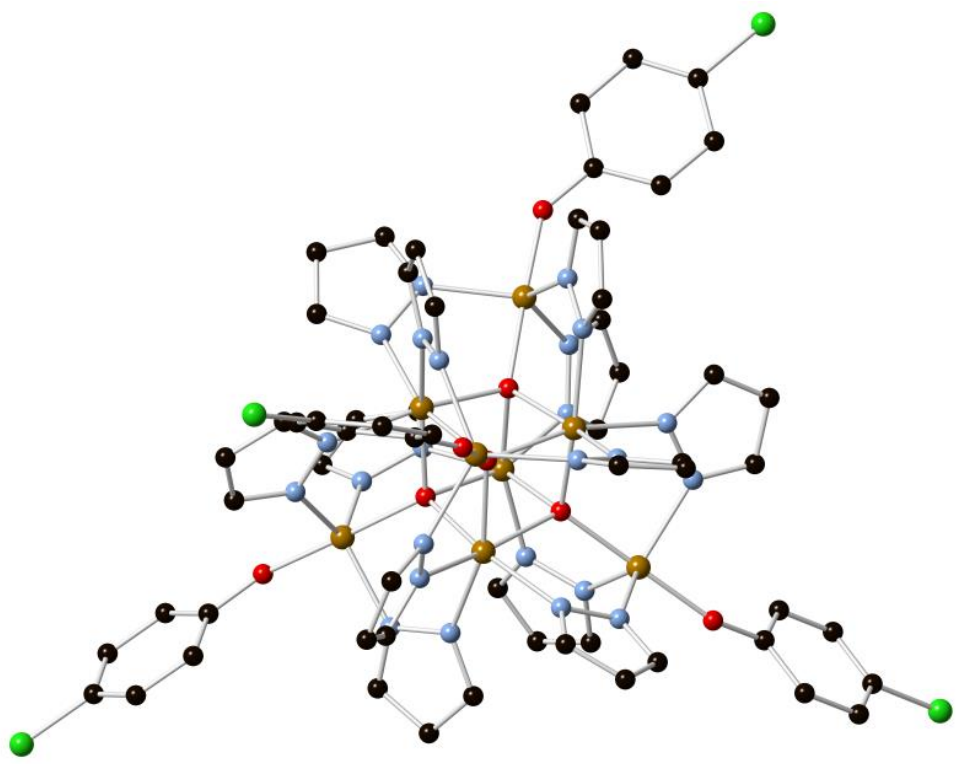

Figure 31. Ball-and-stick diagram of $\left[\mathrm{Fe}_{8}\left(\mu_{4}-\mathrm{O}\right)_{4}(\mu-\mathrm{pz})_{12}\left(4-\mathrm{Cl}-\mathrm{C}_{6} \mathrm{H}_{4} \mathrm{O}\right)_{4}\right](5)$. Hydrogen atoms omitted for clarity. Color codes: gold, Fe; red, O; blue, N; green, Cl; black, C. 


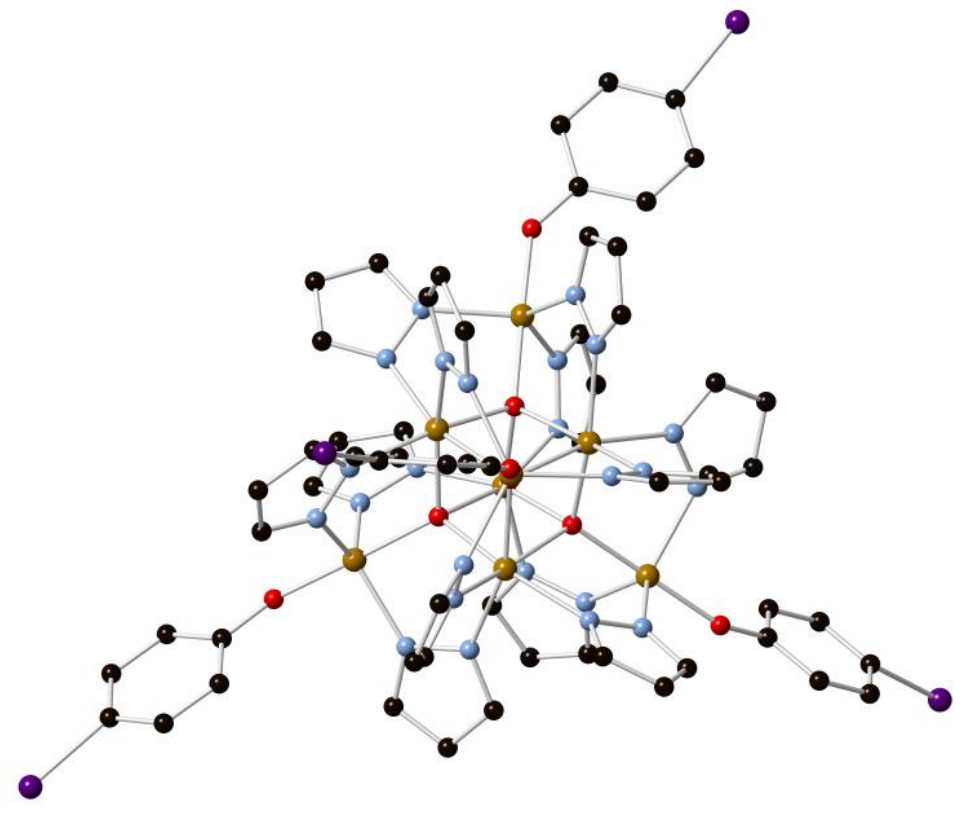

Figure 32. Ball-and-stick diagram of $\left[\mathrm{Fe}_{8}\left(\mu_{4}-\mathrm{O}\right)_{4}(\mu-\mathrm{pz})_{12}\left(4-\mathrm{I}_{-} \mathrm{C}_{6} \mathrm{H}_{4} \mathrm{O}\right)_{4}\right]$ (6). Hydrogen atoms omitted for clarity. Color codes: gold, Fe; red, O; blue, N; purple, I; black, C.

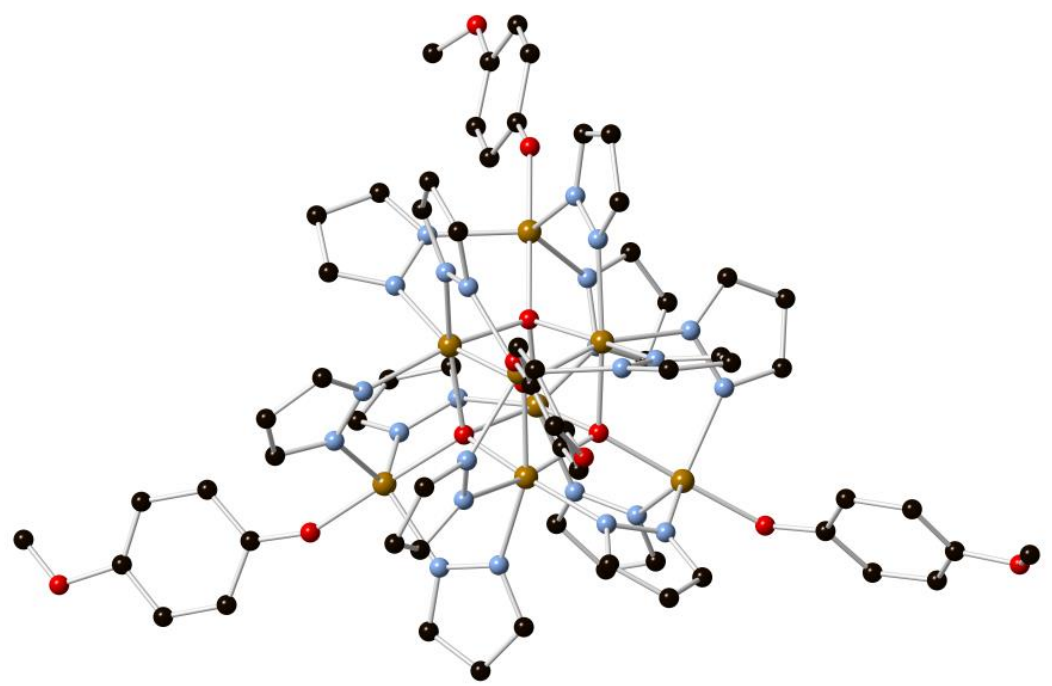

Figure 33. Ball-and-stick diagram of $\left[\mathrm{Fe}_{8}\left(\mu_{4}-\mathrm{O}\right)_{4}(\mu-\mathrm{pz})_{12}\left(4-\mathrm{CH}_{3} \mathrm{O}-\mathrm{C}_{6} \mathrm{H}_{4} \mathrm{O}\right)_{4}\right]$ (7). Hydrogen atoms omitted for clarity. Color codes: gold, Fe; red, O; blue, N; black, C. 


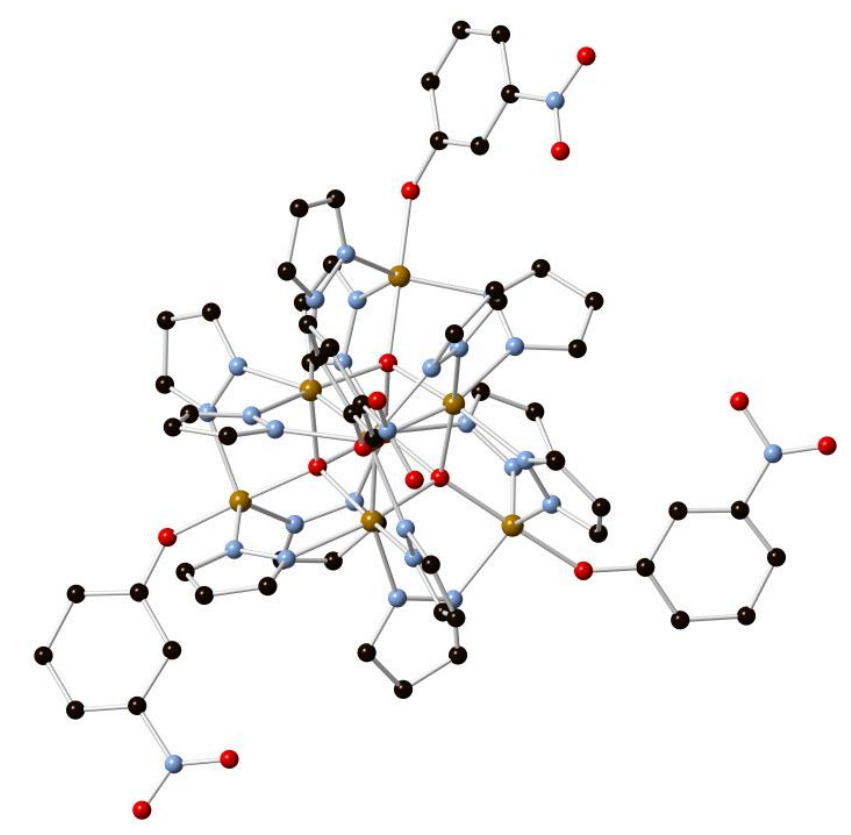

Figure 34. Ball-and-stick diagram of $\left[\mathrm{Fe}_{8}\left(\mu_{4}-\mathrm{O}\right)_{4}(\mu-\mathrm{pz})_{12}\left(3-\mathrm{NO}_{2}-\mathrm{C}_{6} \mathrm{H}_{4} \mathrm{O}\right)_{4}\right](9)$. Hydrogen atoms omitted for clarity. Color codes: gold, Fe; red, O; blue, N; black, C.

The common $\mathrm{Fe}_{8}\left(\mu_{4}-\mathrm{O}\right)_{4}(\mu-\mathrm{pz})_{12}$ core of all nine structures-the part of starting compound 1 that remains unaffected by substitution in the products $2-9$-remains essentially identical within experimental error (three standard deviation), meaning that upon substitution of the terminal chloride ligands in $\mathbf{1}$ by phenolates, no significant structural changes are observed for the main core of the complex. The interatomic angles $\mathrm{O}_{\mathrm{c}}-\mathrm{Fe}_{\mathrm{o}}-\mathrm{Cl}$ vs $\mathrm{O}_{\mathrm{c}}-\mathrm{Fe}_{\mathrm{o}}-\mathrm{O}_{\mathrm{ph}}$ are unaffected, as well. The main variation is observed in the bond lengths of the outer Fe atoms with the terminal ligand, demonstrated by the decrease in distance from $\mathrm{Fe}_{\mathrm{o}}-\mathrm{Cl} \approx 2.27 \AA$ to $\mathrm{Fe}_{\mathrm{o}}-\mathrm{O}_{\mathrm{ph}} \approx 1.85 \AA$. A comparison between the phenolate substituted compounds reveals no significant structural differences. The $\mathrm{Fe}_{\mathrm{o}}-\mathrm{O}_{\mathrm{ph}}$ bond lengths vary from $1.860 \AA$ on average for the 4-F-substituted phenol (4), to 
$1.899 \AA$ on average for $4-\mathrm{CN}(\mathbf{3})$ and $4-{ }^{\mathrm{s}} \mathrm{Bu}(\mathbf{8})$. No specific trend can be observed moving from more electron withdrawing group phenolate substituents to more electron donating ones. A trend is also not observed regarding the $\mathrm{Fe}_{\mathrm{o}}-\mathrm{O}_{\mathrm{ph}}-\mathrm{C}$ angle (where $\mathrm{C}$ is the phenolate carbon bonded to phenolate oxygen). For compounds $\mathbf{2 - 9}$, the interatomic angle is quite similar on average, from $146.2^{\circ}-149.8^{\circ}$, with the most acute and more obtuse angles observed for compound 2 (137.2 ${ }^{\circ}$ and 162.4 respectively). A detailed list of bond lengths and interatomic angles for compounds 1-9 are given in Tables 1 and 2. 
Table 1. Selected bond distances $(\AA)$ and interatomic angles $\left(^{\circ}\right)$ for $\mathbf{1}-\mathbf{5}$.

\begin{tabular}{|c|c|c|c|c|c|}
\hline & $\mathbf{1}^{a}$ & 2 & $\mathbf{3}$ & 4 & 5 \\
\hline $\mathrm{Fe}_{\mathrm{c}}-\mathrm{O}_{\mathrm{c}}$ & $2.032(6)-2.066(7)$ & $2.034(4)-2.058(4)$ & $2.033(3)-2.052(3)$ & $2.028(9)-2.043(9)$ & $2.028(2)-2.040(4)$ \\
\hline $\mathrm{Fe}_{\mathrm{c}}-\mathrm{N}$ & $2.044(9)-2.086(8)$ & $2.058(4)-2.082(5)$ & $2.056(4)-2.085(4)$ & $2.056(9)-2.081(9)$ & $2.062(3)-2.072(2)$ \\
\hline $\mathrm{Fe}_{\mathrm{o}}-\mathrm{O}_{\mathrm{c}}$ & $1.940(7)-1.960(6)$ & $1.950(3)-1.964(3)$ & $1.959(3)-1.966(3)$ & $1.961(5)-1.969(5)$ & $1.957(6)$ \\
\hline $\mathrm{Fe}_{\mathrm{o}}-\mathrm{N}$ & $2.003(9)-2.04(1)$ & $1.996(3)-2.059(3)$ & $2.012(4)-2.040(4)$ & $2.004(7)-2.044(6)$ & $2.017(8)-2.049(6)$ \\
\hline $\mathrm{Fe}_{\mathrm{o}}-\mathrm{O}_{\mathrm{ph}}$ & - & $1.862(3)-1.900(3)$ & $1.883(3)-1.927(4)$ & $1.854(5)-1.865(4)$ & $1.858(6)-1.873(4)$ \\
\hline $\mathrm{Fe}_{\mathrm{o}}-\mathrm{Cl}$ & $2.271(4)-2.274(4)$ & - & - & - & - \\
\hline $\mathrm{Fe}_{\mathrm{c}} \cdots \mathrm{Fe}_{\mathrm{c}}$ & $3.067(2)-3.091(2)$ & $3.064(5)-3.111(5)$ & $3.056(9)-3.077(9)$ & $3.028(9)-3.10(1)$ & $3.027(2)$ \\
\hline $\mathrm{Fe}_{\mathrm{o}} \cdots \mathrm{Fe}_{\mathrm{o}}$ & $5.841(3)-5.888(2)$ & $5.796(9)-5.918(9)$ & $5.842(9)-5.913(9)$ & $5.794(2)-5.950(2)$ & $5.937(2)$ \\
\hline $\mathrm{Fe}_{\mathrm{c}}-\mathrm{O}_{\mathrm{c}}-\mathrm{Fe}_{\mathrm{c}}$ & $96.5(3)-98.4(3)$ & $96.7(6)-99.3(7)$ & $96.9(2)-98.0(9)$ & $96.2(3)-99.3(6)$ & $96.1(2)-96.6(2)$ \\
\hline $\mathrm{O}_{\mathrm{c}}-\mathrm{Fe}_{\mathrm{c}}-\mathrm{O}_{\mathrm{c}}$ & $81.1(3)-82.7(3)$ & $80.0(7)-82.6(6)$ & $81.5(4)-82.4(2)$ & $82.1(1)-82.9(2)$ & $82.8(2)-82.9(2)$ \\
\hline $\mathrm{O}_{\mathrm{c}}-\mathrm{Fe}_{\mathrm{o}}-\mathrm{O}_{\mathrm{ph}}$ & - & $176.9(4)-178.8(2)$ & $178.2(9)-179.4(5)$ & $178.1(3)-179.0(2)$ & $178.2(3)-178.9(4)$ \\
\hline $\mathrm{O}_{\mathrm{c}}-\mathrm{Fe}_{\mathrm{o}}-\mathrm{Cl}$ & $176.9(2)-179.5(2)$ & - & - & - & - \\
\hline $\mathrm{Fe}_{\mathrm{o}}-\mathrm{O}_{\mathrm{ph}}-\mathrm{C}$ & - & $145.6(6)-152.5(5)$ & $137.2(3)-162.4(9)$ & $140.2(2)-158.2(8)$ & $141.7(2)-155.3(8)$ \\
\hline
\end{tabular}

${ }^{a}$ From reference 106. Subscript c denotes cubane atoms, subscript o the outer iron atoms, and subscript ph the phenolate oxygen. 
Table 2. Selected bond distances $(\AA)$ and interatomic angles $\left(^{\circ}\right)$ for $\mathbf{6}-\mathbf{9}$.

\begin{tabular}{|c|c|c|c|c|}
\hline & 6 & 7 & 8 & 9 \\
\hline $\mathrm{Fe}_{\mathrm{c}}-\mathrm{O}_{\mathrm{c}}$ & $2.021(1)-2.029(1)$ & $2.028(8)-2.045(6)$ & $2.027(9)-2.038(9)$ & $2.010(5)-2.060(6)$ \\
\hline $\mathrm{Fe}_{\mathrm{c}}-\mathrm{N}$ & $2.058(1)-2.077(1)$ & $2.059(6)-2.083(5)$ & $2.060(9)-2.080(9)$ & $2.049(7)-2.087(8)$ \\
\hline $\mathrm{Fe}_{\mathrm{o}}-\mathrm{O}_{\mathrm{c}}$ & $1.956(6)-1.961(6)$ & $1.956(6)-1.961(6)$ & $1.972(5)-1.978(5)$ & $1.947(6)-1.962(6)$ \\
\hline $\mathrm{Fe}_{\mathrm{o}}-\mathrm{N}$ & $2.030(8)-2.052(8)$ & $2.020(3)-2.059(4)$ & $2.020(7)-2.049(7)$ & $1.997(4)-2.046(4)$ \\
\hline $\mathrm{Fe}_{\mathrm{o}}-\mathrm{O}_{\mathrm{ph}}$ & $1.862(6)-1.885(6)$ & $1.872(3)-1.905(2)$ & $1.870(5)-1.926(5)$ & $1.870(3)-1.897(5)$ \\
\hline $\mathrm{Fe}_{0}-\mathrm{Cl}$ & - & - & - & - \\
\hline $\mathrm{Fe}_{\mathrm{c}} \cdots \mathrm{Fe}_{\mathrm{c}}$ & $3.025(1)$ & $3.036(3)-3.096(3)$ & $3.046(10)$ & $3.051(2)-3.096(2)$ \\
\hline $\mathrm{Fe}_{\mathrm{o}} \cdots \mathrm{Fe}_{\mathrm{o}}$ & $5.921(2)$ & $5.787(9)-5.950(9)$ & $5.92(2)$ & $5.830(3)-5.930(3)$ \\
\hline $\mathrm{Fe}_{\mathrm{c}}-\mathrm{O}_{\mathrm{c}}-\mathrm{Fe}_{\mathrm{c}}$ & $82.4(2)-96.8(2)$ & $96.3(5)-92.2(2)$ & $96.9(2)-97.2(2)$ & $97.0(3)-98.9(5)$ \\
\hline $\mathrm{O}_{\mathrm{c}}-\mathrm{Fe}_{\mathrm{c}}-\mathrm{O}_{\mathrm{c}}$ & $82.4(2)-82.6(2)$ & $80.7(2)-82.9(2)$ & $82.2(2)$ & $81.6(4)-82.6(6)$ \\
\hline $\mathrm{O}_{\mathrm{c}}-\mathrm{Fe}_{\mathrm{o}}-\mathrm{O}_{\mathrm{ph}}$ & $178.6(3)-178.9(3)$ & $178.4(2)-179.3(7)$ & $178.4(3)-178.9(2)$ & $177.0(6)-177.9(5)$ \\
\hline $\mathrm{O}_{\mathrm{c}}-\mathrm{Fe}_{\mathrm{o}}-\mathrm{Cl}$ & - & - & - & - \\
\hline $\mathrm{Fe}_{\mathrm{o}}-\mathrm{O}_{\mathrm{ph}}-\mathrm{C}$ & $140.6(2)-152.3(8)$ & $139.4(6)-156.4(3)$ & $138.9(2)-153.5(7)$ & $136.5(5)-144.2(4)$ \\
\hline
\end{tabular}


Compounds that resemble one or more sites of the $\left[\mathrm{Fe}_{8}\right]$ complexes can be used as a comparison for the structural parameters in study. Byers et al. synthesized bis(imino)pyridine iron (III) bis(aryloxide) complexes for the catalysis of the polymerization of lactide (Figure 35). ${ }^{123}$ The coordination environment of this mononuclear $\mathrm{Fe}$ (III) complex is similar to the outer $\mathrm{Fe}_{\mathrm{o}}$ sites of the $\mathrm{Fe}_{8}$. The two $\mathrm{Fe}-\mathrm{O}$ distances, 1.815 and $1.820 \AA$ are relatively shorter than the ones reported here, whereas the angles between $\mathrm{Fe}-\mathrm{O}-\mathrm{C}$ atoms which for the mononuclear species were measured $144.8^{\circ}$ and $148.7^{\circ}$ can be accounted as similar to the ones reported previously for complexes 2-9.

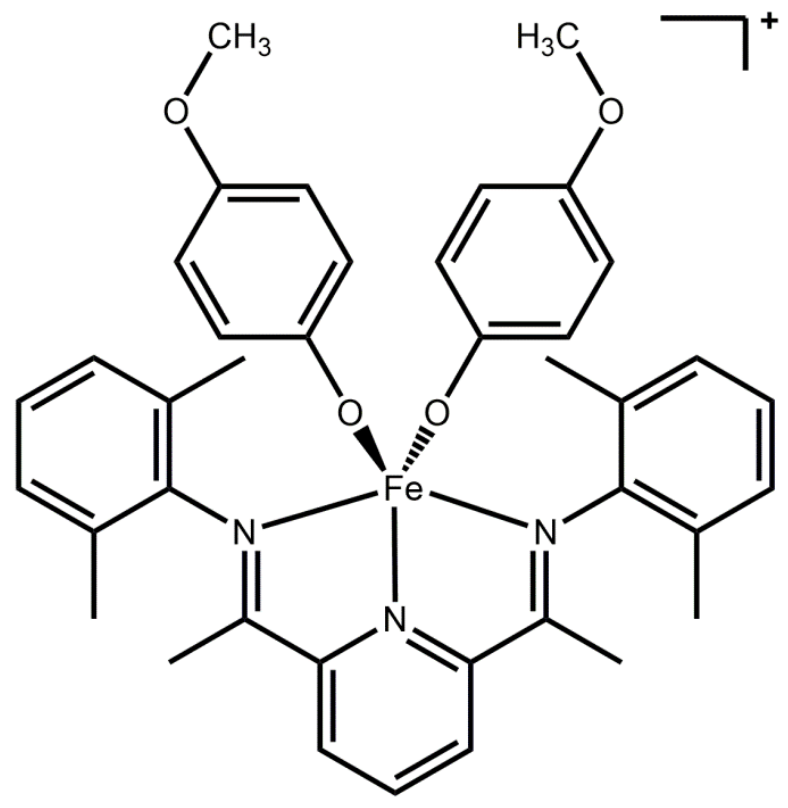

Figure 35. Bis(imino)pyridine iron(III) bis(aryloxide). 
Table 3. Structure refinement parameters for complexes $\mathbf{2}-\mathbf{5}$.

\begin{tabular}{|c|c|c|c|c|}
\hline Compound & (2) & (3) & (4) & (5) \\
\hline Empirical formula & $\mathrm{C}_{60} \mathrm{H}_{52} \mathrm{~N}_{28} \mathrm{O}_{16} \mathrm{Fe}_{8}$ & $\mathrm{C}_{64} \mathrm{H}_{52} \mathrm{~N}_{28} \mathrm{O}_{8} \mathrm{Fe}_{8}$ & $\mathrm{C}_{60} \mathrm{H}_{52} \mathrm{~N}_{24} \mathrm{O}_{8} \mathrm{Fe}_{8} \mathrm{~F}_{4}$ & $\mathrm{C}_{60} \mathrm{H}_{52} \mathrm{~N}_{24} \mathrm{O}_{8} \mathrm{Fe}_{8} \mathrm{Cl}_{4}$ \\
\hline Formula weight & 1868.09 & 1788.13 & 1760.05 & 1825.85 \\
\hline Temperature/K & 298 & 298 & 298 & 298 \\
\hline Crystal system & triclinic & triclinic & monoclinic & monoclinic \\
\hline Space group & $P-1$ & $P-1$ & $P 2_{l} / c$ & $C 2 / c$ \\
\hline $\mathbf{a} / \mathbf{A}$ & $12.838(3)$ & $13.074(6)$ & $22.506(1)$ & $24.500(2)$ \\
\hline b/Å & $14.219(3)$ & $13.093(6)$ & $25.360(1)$ & $25.150(2)$ \\
\hline $\mathbf{c} / \AA$ & $22.357(5)$ & $24.26(1)$ & $12.900(6)$ & $13.007(1)$ \\
\hline $\boldsymbol{\alpha} / /^{\circ}$ & $104.38(2)$ & $90.38(2)$ & 90 & 90 \\
\hline$\beta /{ }^{\circ}$ & $103.41(2)$ & $100.4(1)$ & $96.16(1)$ & $106.12(2)$ \\
\hline$\gamma /{ }^{\circ}$ & $93.12(2)$ & $108.9(1)$ & 90 & 90 \\
\hline Volume $/ \AA^{3}$ & $3818(1)$ & $3855.9(3)$ & $7320.3(6)$ & $7700(1)$ \\
\hline $\mathbf{Z}$ & 2 & 2 & 4 & 4 \\
\hline$\rho_{\text {cald }} / \mathrm{gcm}^{-3}$ & 1.625 & 1.540 & 1.597 & 1.575 \\
\hline $\boldsymbol{\mu} / \mathbf{m m}^{-1}$ & 1.556 & 1.530 & 1.616 & 1.667 \\
\hline Crystal size $/ \mathrm{mm}^{3}$ & $0.27 \times 0.16 \times 0.07$ & $0.28 \times 0.13 \times 0.12$ & $0.48 \times 0.15 \times 0.08$ & $0.15 \times 0.06 \times 0.03$ \\
\hline $\begin{array}{l}\text { Reflections } \\
\text { collected } / 2 \Theta \max \left({ }^{\circ}\right)\end{array}$ & $17112 / 46.512$ & $79167 / 53.628$ & $123246 / 52.888$ & $32260 / 52.836$ \\
\hline $\begin{array}{l}\text { Data/restraints/ } \\
\text { parameters }\end{array}$ & $10599 / 0 / 1009$ & 16001/0/999 & $15036 / 0 / 1157$ & $7892 / 0 / 485$ \\
\hline Goodness-of-fit on $\mathbf{F}^{2}$ & 1.014 & 1.188 & 1.014 & 1.017 \\
\hline 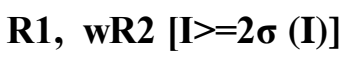 & $0.0568 / 0.1156$ & $0.0698 / 0.1053$ & $0.0364 / 0.0711$ & $0.0678 / 0.1123$ \\
\hline R1, wR2 [all data] & $0.1136 / 0.1416$ & $0.0944 / 0.1159$ & $0.0653 / 0.0800$ & $0.1431 / 0.1333$ \\
\hline
\end{tabular}


Table 4. Structure refinement parameters for complexes $6-9$.

\begin{tabular}{|c|c|c|c|c|}
\hline Compound & (6) & (7) & (8) & (9) \\
\hline Empirical formula & $\mathrm{C}_{60} \mathrm{H}_{52} \mathrm{~N}_{24} \mathrm{O}_{8} \mathrm{Fe}_{8} \mathrm{I}_{4}$ & $\mathrm{C}_{64} \mathrm{H}_{64} \mathrm{~N}_{24} \mathrm{O}_{12} \mathrm{Fe}_{8}$ & $\mathrm{C}_{76} \mathrm{H}_{88} \mathrm{~N}_{24} \mathrm{O}_{8} \mathrm{Fe}_{8}$ & $2\left(\mathrm{C}_{60} \mathrm{H}_{52} \mathrm{~N}_{28} \mathrm{O}_{16} \mathrm{Fe}_{8}\right)$ \\
\hline Formula weight & 2191.62 & 1808.19 & 1912.50 & 1910.55 \\
\hline Temperature/K & 298 & 298 & 298 & 298 \\
\hline Crystal system & monoclinic & monoclinic & monoclinic & triclinic \\
\hline Space group & $C 2 / c$ & $P 2_{1} / c$ & $C 2 / c$ & $P-1$ \\
\hline $\mathbf{a} / \mathbf{A}$ & $24.636(2)$ & $22.653(5)$ & 25.791(1) & $13.485(5)$ \\
\hline $\mathbf{b} / \mathbf{A}$ & $25.377(2)$ & $25.754(5)$ & $27.220(1)$ & $21.299(8)$ \\
\hline $\mathbf{c} / \AA$ & $13.214(7)$ & $13.285(3)$ & $13.108(6)$ & $29.39(1)$ \\
\hline $\boldsymbol{\alpha} / /^{\circ}$ & 90 & 90 & 90 & $110.85(4)$ \\
\hline$\beta /{ }^{\circ}$ & $104.68(1)$ & $96.24(2)$ & $105.53(1)$ & $99.31(4)$ \\
\hline$\gamma /{ }^{\circ}$ & 90 & 90 & 90 & $94.84(5)$ \\
\hline Volume/Å $\AA^{3}$ & 7991.4(7) & $7705(3)$ & $8866.1(7)$ & $7691(5)$ \\
\hline $\mathbf{Z}$ & 4 & 4 & 4 & 4 \\
\hline$\rho_{\text {cald }} / \mathrm{gcm}^{-3}$ & 1.822 & 1.559 & 1.433 & 1.675 \\
\hline $\boldsymbol{\mu} / \mathbf{m m}^{-1}$ & 3.018 & 1.534 & 1.334 & 1.616 \\
\hline Crystal size/mm $\mathbf{m}^{3}$ & $0.30 \times 0.16 \times 0.22$ & $0.49 \times 0.14 \times 0.03$ & $0.22 \times 0.10 \times 0.09$ & $0.23 \times 0.14 \times 0.04$ \\
\hline $\begin{array}{l}\text { Reflections } \\
\text { collected } / 2 \Theta \max \left({ }^{\circ}\right)\end{array}$ & $111629 / 54.504$ & $86509 / 54.246$ & $49921 / 54.266$ & $82516 / 52.868$ \\
\hline $\begin{array}{l}\text { Data/restraints/ } \\
\text { parameters }\end{array}$ & $8917 / 0 / 478$ & $16966 / 0 / 977$ & $9796 / 14 / 497$ & $31276 / 0 / 2057$ \\
\hline Goodness-of-fit on $\mathbf{F}^{2}$ & 1.030 & 0.982 & 1.038 & 1.049 \\
\hline 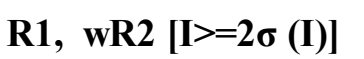 & $0.0330 / 0.0820$ & $0.0540 / 0.1362$ & $0.0491 / 0.1478$ & $0.0651 / 0.1767$ \\
\hline R1, wR2 [all data] & $0.0765 / 0.1272$ & $0.0923 / 0.1557$ & $0.0750 / 0.1687$ & $0.0968 / 0.1895$ \\
\hline
\end{tabular}




\subsection{3. ${ }^{1}$ H-NMR}

The shift and the line width in the ${ }^{1} \mathrm{H}-\mathrm{NMR}$ spectra of proton that are in proximity with paramagnetic centers such as $\mathrm{Fe}$ (III) with a spin $\mathrm{S}=5 / 2$ are significantly different than the ones observed for common organic compounds without the influence of paramagnetism. Thus the ${ }^{1} \mathrm{H}-\mathrm{NMR}$ spectra of $\left[\mathrm{Fe}_{8}\right]$ and its derivatives are paramagnetically shifted and broadened. Despite the fact that the complex's ground state is diamagnetic, in ambient temperatures a few excited states are populated, giving rise to its paramagnetism. ${ }^{106}$ The chemical environment for all twelve pyrazolate ligands is identical, thus, a single set of resonances is observed for each of them. The spectrum of the parent $\left[\mathrm{Fe}_{8}\right],(\mathbf{1})$ is shown in Figure 36.
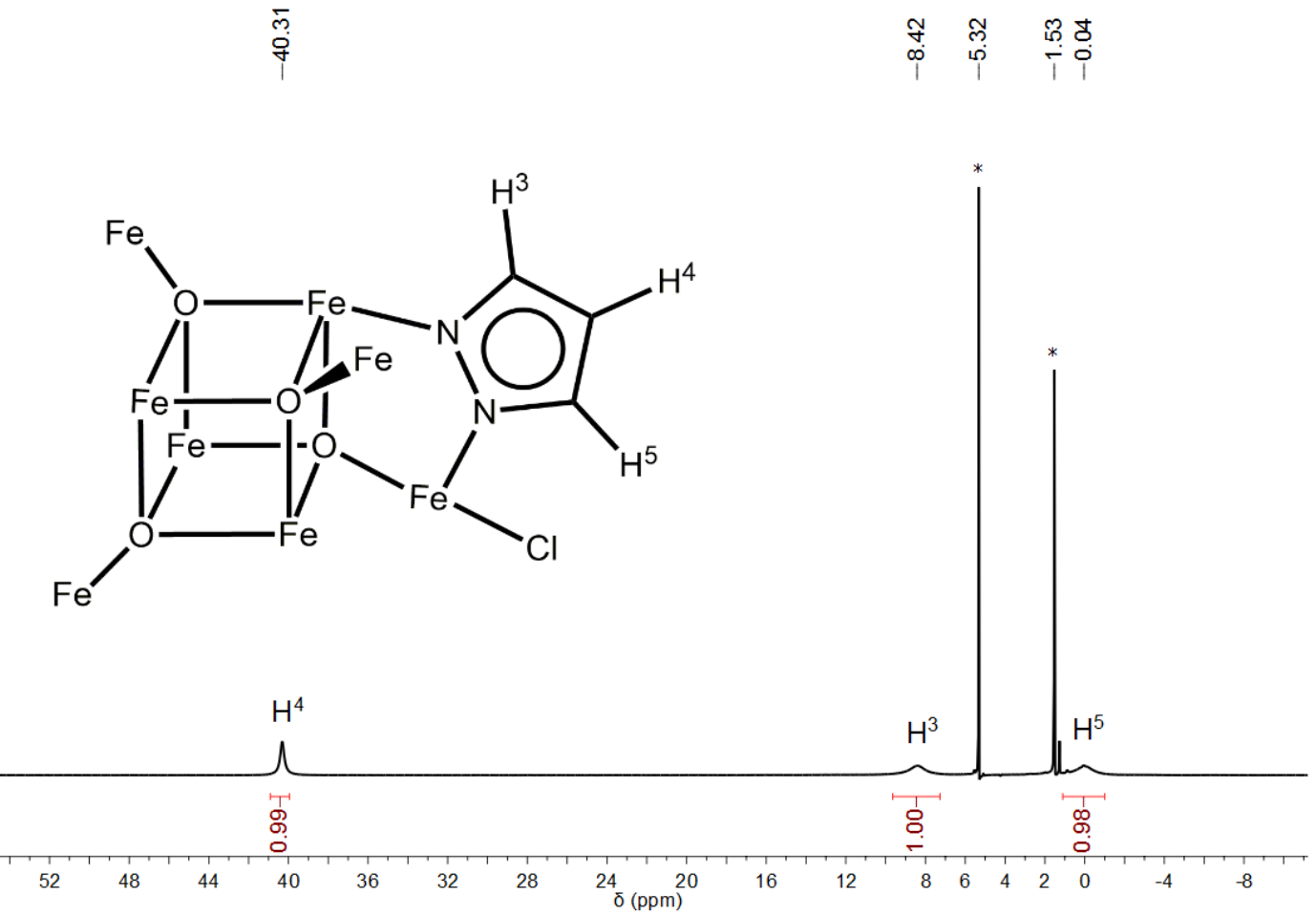

Figure 36. ${ }^{1} \mathrm{H}-\mathrm{NMR}$ of $\left[\mathrm{Fe}_{8}\left(\mu_{4}-\mathrm{O}\right)_{4}(\mu-\mathrm{pz})_{12} \mathrm{Cl}_{4}\right]$ (1) in $\mathrm{CD}_{2} \mathrm{Cl}_{2}$. Solvents denoted with asterisk. 
The proton ${ }^{4} \mathrm{H}$ is assigned to the singlet peak at $40.31 \mathrm{ppm}$, which is not present in the spectra of analogues with substituents other than $\mathrm{H}$ at this pyrazole position (e. g. - $\mathrm{Cl}$, $\mathrm{CH}_{3}$ ). Proton ${ }^{3} \mathrm{H}$, which is positioned closer to the cubane iron, $\mathrm{Fe}_{\mathrm{c}}$, is assigned to a broad singlet peak at $8.42 \mathrm{ppm}$, whereas ${ }^{5} \mathrm{H}$, closer to the outer iron, $\mathrm{Fe}_{\mathrm{o}}$, to the singlet at 0.04 ppm. The assignment for the protons on positions -3 and -5 of the pyrazolate is based on the distinct shift that ${ }^{5} \mathrm{H}$ exhibits upon substitution of the terminal $-\mathrm{Cl}$ of the $\mathrm{Fe}_{\mathrm{o}}$ atom by different ligands such as $-\mathrm{Br} .{ }^{106}$ Compounds 2-9 were all characterized by ${ }^{1} \mathrm{H}-\mathrm{NMR}$ spectroscopy. An example is given in Figure 37 for compound 4 (for all spectra see Appendix).

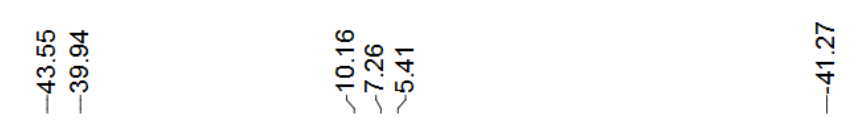

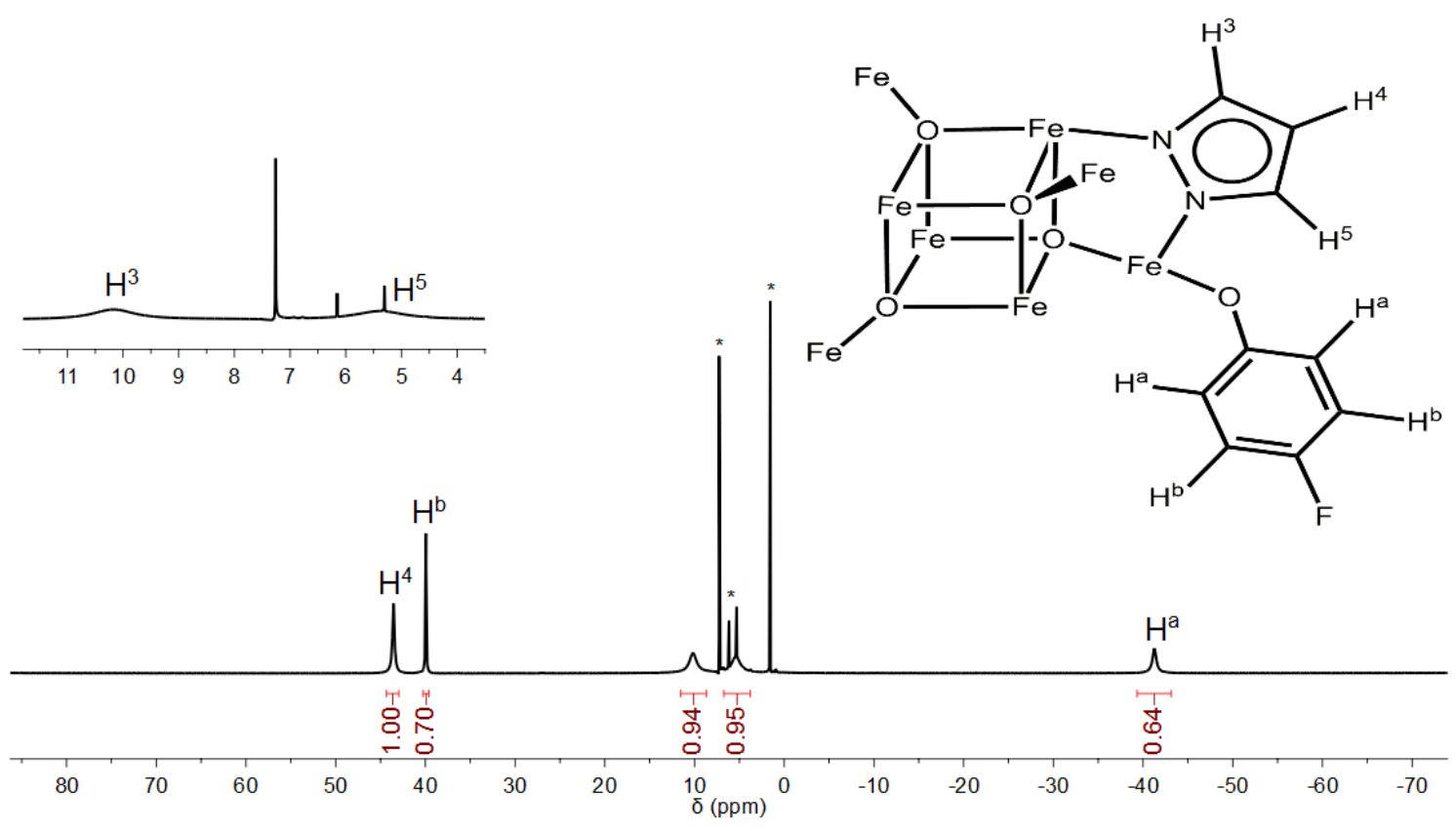

Figure 37. ${ }^{1} \mathrm{H}-\mathrm{NMR}$ of $\left[\mathrm{Fe}_{8}\left(\mu_{4}-\mathrm{O}\right)_{4}(\mu-\mathrm{pz})_{12}\left(4-\mathrm{F}-\mathrm{C}_{6} \mathrm{H}_{4} \mathrm{O}\right)_{4}\right]$ (4) in $\mathrm{CDCl}_{3}$. Solvents denoted with asterisk. 
The assignment of protons ${ }^{4} \mathrm{H},{ }^{3} \mathrm{H}$, and ${ }^{5} \mathrm{H}$ is straightforward, all of them shifting downfield upon substitution of the $-\mathrm{Cl}$ ligand of $\mathbf{1}$ by phenolate. In the case of $4-\mathrm{F}-\mathrm{PhO}$, ${ }^{4} \mathrm{H}$ is found at $43.55 \mathrm{ppm},{ }^{3} \mathrm{H}$ at $10.16 \mathrm{ppm}$ and ${ }^{5} \mathrm{H}$ at $5.41 \mathrm{ppm}$ displaying the highest shift among the three. The assignment of the phenolate protons was conducted on the basis of $\mathrm{T}_{1}$ and $\mathrm{T}_{2}{ }^{*}$ relaxation measurements (Table 5 ).

For $4, \mathrm{~T}_{1}$ and $\mathrm{T}_{2}{ }^{*}$ of ${ }^{\mathrm{a}} \mathrm{H}$ were calculated at $1.9 \mathrm{msec}$ and $1.6 \mathrm{msec}$, respectively, whereas the ones of ${ }^{b} \mathrm{H}$ were calculated at $14.7 \mathrm{msec}$ and $5.3 \mathrm{msec} .{ }^{124}$ The faster relaxation time is expected for the protons closer to the paramagnetic Fe center, thus, the -ortho ${ }^{\mathrm{a}} \mathrm{H}$ protons appear as a singlet at $-41.27 \mathrm{ppm}$, while the - meta $^{\mathrm{b}} \mathrm{H}$ ones as another singlet at 39.94 ppm. The peak area integration provides additional information regarding the location of the peaks and their chemical and magnetic equivalence. All protons in these compounds appear as singlets with no coupling. Chemical shifts for compounds 2-7 and $\mathbf{9}$ are given in Table 6 (detailed assignment for compound $\mathbf{8}$ is described in chapter III).

Table 5. $\mathrm{T}_{1}$ and $\mathrm{T}_{2}{ }^{*}$ values for ${ }^{\mathrm{a}} \mathrm{H}$ and ${ }^{\mathrm{b}} \mathrm{H}$ protons of compounds $\mathbf{2 , 4}$, and $\mathbf{7 .}$

\begin{tabular}{ccccc}
\hline Compound & $\mathrm{T}_{1}$ of ${ }^{\mathrm{a}} \mathrm{H}(\mathrm{msec})$ & $\mathrm{T}_{1}$ of ${ }^{\mathrm{b}} \mathrm{H}(\mathrm{msec})$ & $\mathrm{T}_{2}{ }^{*}$ of ${ }^{\mathrm{a}} \mathrm{H}(\mathrm{msec})$ & $\mathrm{T}_{2}{ }^{*}$ of ${ }^{\mathrm{b}} \mathrm{H}(\mathrm{msec})$ \\
\hline $\mathbf{4}$ & 1.9 & 14.7 & 1.6 & 5.3 \\
$\mathbf{2}$ & 1.8 & 16.0 & 1.4 & 5.8 \\
$\mathbf{7}$ & 1.8 & 14.0 & 1.6 & 9.1
\end{tabular}


Table 6. Chemical shifts $\delta$ (ppm) for compounds 2-7 and 9.

\begin{tabular}{cccccccc}
\hline Compound & ${ }^{3} \mathrm{H}$ & ${ }^{4} \mathrm{H}$ & ${ }^{5} \mathrm{H}$ & ${ }^{\mathrm{a}} \mathrm{H}$ & ${ }^{\mathrm{b}} \mathrm{H}$ & ${ }^{\mathrm{c}} \mathrm{H}$ & ${ }^{\mathrm{d}} \mathrm{H}$ \\
\hline $\mathbf{2}$ & 8.36 & 41.98 & 5.30 & -26.50 & 36.73 & - & - \\
$\mathbf{3}$ & 8.70 & 42.37 & 5.30 & -29.14 & 37.61 & - & - \\
$\mathbf{4}$ & 10.16 & 43.55 & 5.41 & -41.27 & 39.94 & - & - \\
$\mathbf{5}$ & 9.88 & 43.23 & 5.39 & -38.28 & 40.75 & - & - \\
$\mathbf{6}$ & 9.72 & 43.09 & 5.32 & -37.17 & 41.10 & - & - \\
$\mathbf{7}$ & 10.64 & 43.80 & 5.30 & -45.89 & 41.09 & $10.42\left(\mathrm{CH}_{3}\right)$ & - \\
$\mathbf{9}$ & 8.90 & 42.40 & 5.53 & -29.27 & 35.85 & -28.74 & -29.27
\end{tabular}

A plausible explanation about the opposite direction of the shift of the -ortho and the meta protons of the coordinated phenolates is depicted in Figure 38. The large electron spin on the Fe atom affects the local spin of the pi system of the phenyl ring, and the porbitals that point in the same direction exhibit shift towards the same direction. This interpretation can also be confirmed by the spectrum of the meta-substituted nitrophenolate, compound 9, where the para proton shifts upfield similarly to the ortho ones (see Appendix).

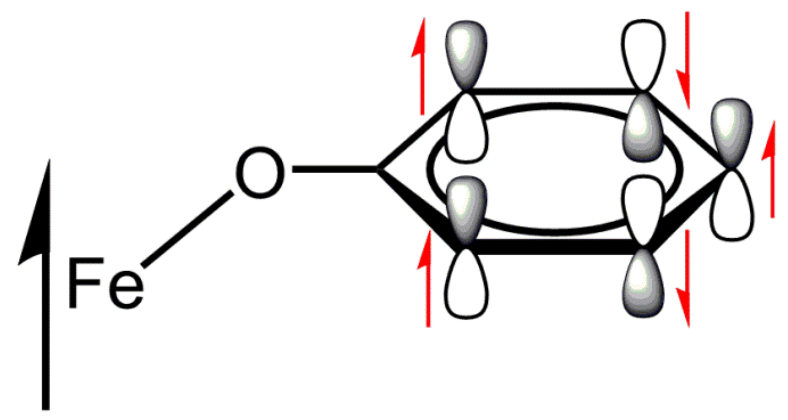

Figure 38. Spin distribution on the $\mathrm{Fe}_{\mathrm{o}}-\mathrm{OAr}$ moiety. 
An investigation of the temperature effect on the chemical shifts was also conducted with variable-temperature NMR experiments. Figures 39, 40, and 41 show the shift of the protons of compound $\mathbf{3}$ with decreasing temperature.

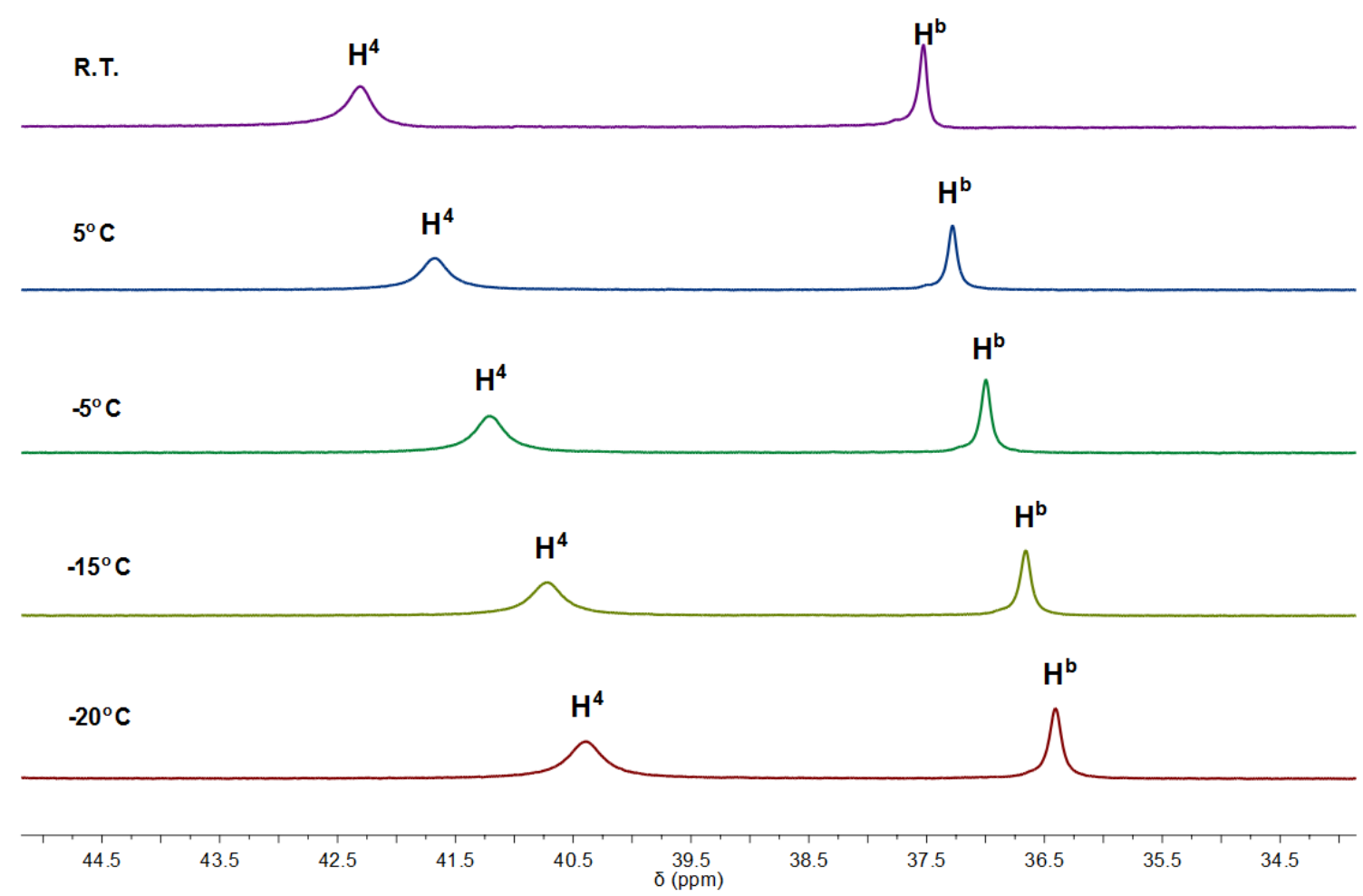

Figure 39. Chemical shift of protons ${ }^{4} \mathrm{H}$ and ${ }^{\mathrm{b}} \mathrm{H}$ of $\left[\mathrm{Fe}_{8}\left(\mu_{4}-\mathrm{O}\right)_{4}(\mu-\mathrm{pz})_{12}\left(4-\mathrm{NC}-\mathrm{C}_{6} \mathrm{H}_{4} \mathrm{O}\right)_{4}\right](3)$ with decreasing temperature. 


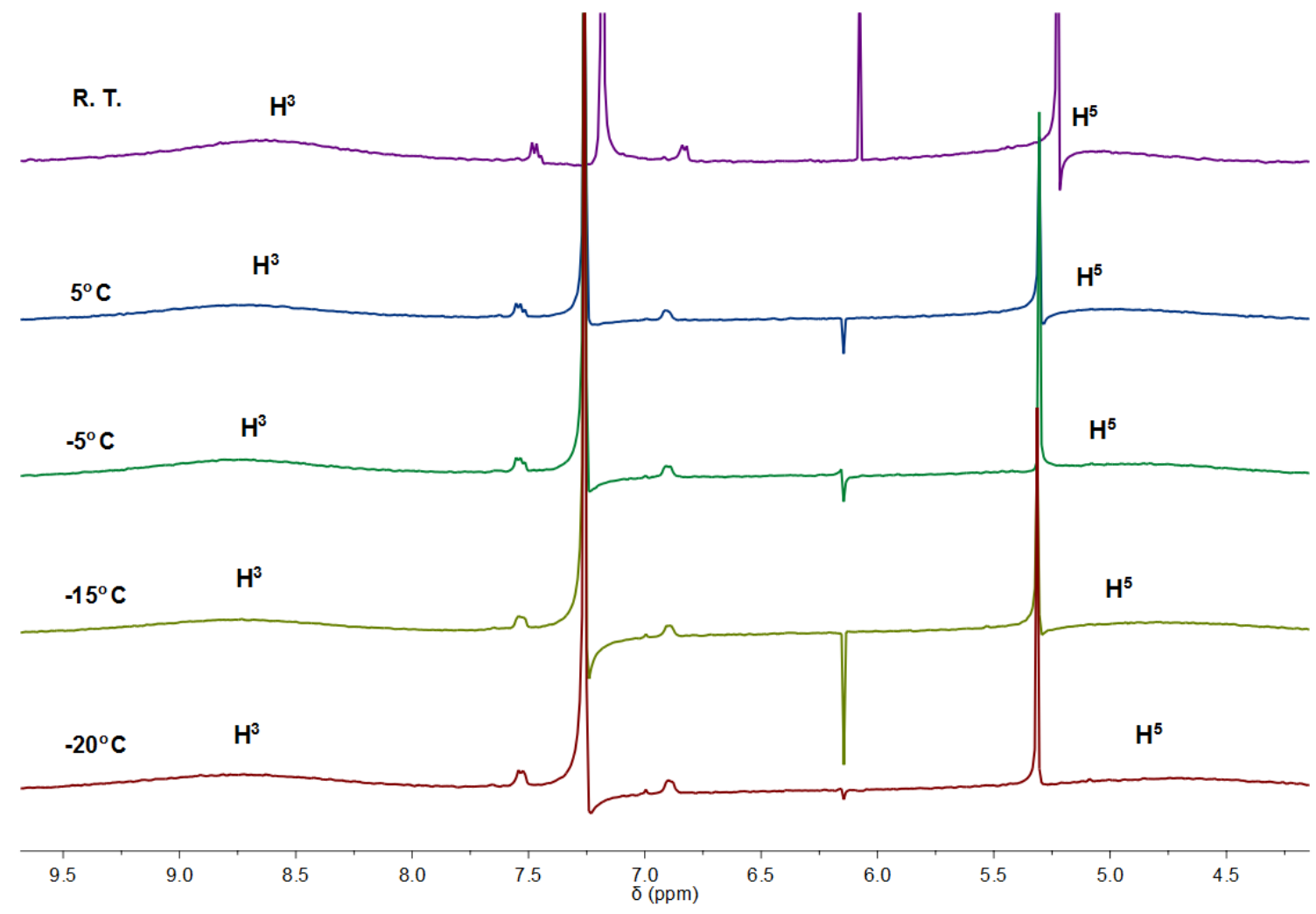

Figure 40. Chemical shift of protons ${ }^{3} \mathrm{H}$ and ${ }^{5} \mathrm{H}$ of $\left[\mathrm{Fe}_{8}\left(\mu_{4}-\mathrm{O}\right)_{4}(\mu-\mathrm{pz})_{12}\left(4-\mathrm{NC}-\mathrm{C}_{6} \mathrm{H}_{4} \mathrm{O}\right)_{4}\right](3)$ with decreasing temperature.

As shown, protons ${ }^{4} \mathrm{H},{ }^{b} \mathrm{H}$, and ${ }^{5} \mathrm{H}$ of $\mathbf{3}$ shift upfield by lowering the temperature, the effect being more prominent for the first two, whereas protons ${ }^{3} \mathrm{H}$ and ${ }^{\mathrm{a}} \mathrm{H}$ shift downfield. The magnitude of the chemical shifts is given in Table 7. The shifts observed is to be expected by the electronic structure of the cluster. The number of populated excited states decreases with decrease of the temperature. Since the ground state of the complex is diamagnetic, moving towards very low temperatures, the effect of the paramagnetism is expected to be reduced. 


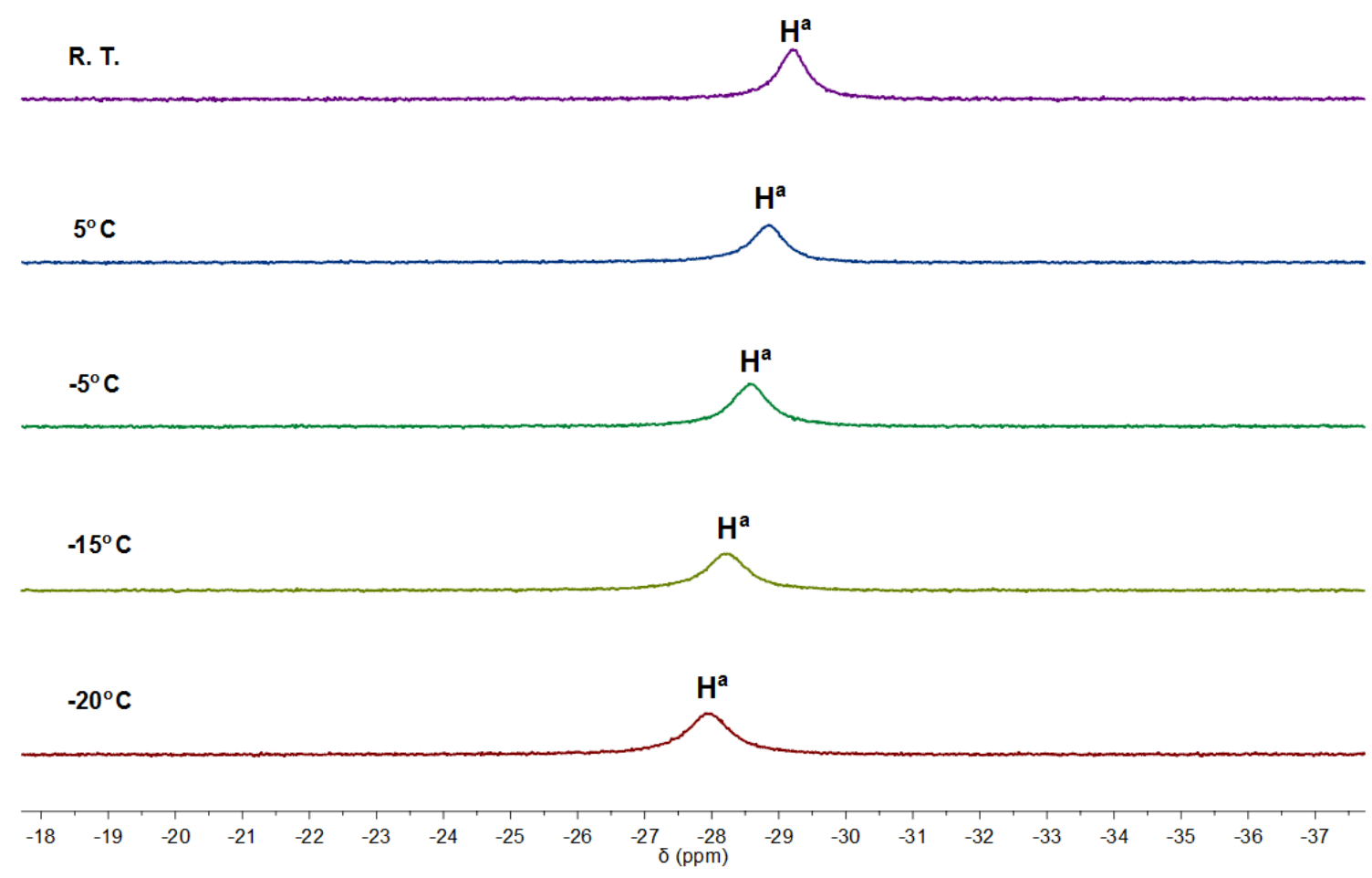

Figure 41. Chemical shift of protons ${ }^{\mathrm{a}} \mathrm{H}$ of $\left[\mathrm{Fe}_{8}\left(\mu_{4}-\mathrm{O}\right)_{4}(\mu-\mathrm{pz})_{12}\left(4-\mathrm{NC}-\mathrm{C}_{6} \mathrm{H}_{4} \mathrm{O}\right)_{4}\right]$ (3) with decreasing temperature.

Table 7. Magnitude of the chemical shifts of protons (ppm) of $\mathbf{3}$ with decreasing temperature.

\begin{tabular}{cccccc}
\hline Temperature $\left({ }^{\mathrm{o}} \mathrm{C}\right)$ & ${ }^{3} \mathrm{H}$ & ${ }^{4} \mathrm{H}$ & ${ }^{5} \mathrm{H}$ & ${ }^{\mathrm{a}} \mathrm{H}$ & ${ }^{\mathrm{b}} \mathrm{H}$ \\
\hline R. T. & 8.70 & 42.37 & 5.30 & -29.14 & 37.61 \\
5 & 8.73 & 41.67 & 5.08 & -28.81 & 37.28 \\
-5 & 8.75 & 42.21 & 4.99 & -28.56 & 36.99 \\
-15 & 8.79 & 40.72 & 4.83 & -28.22 & 36.66 \\
-20 & 8.81 & 40.39 & 4.71 & -27.90 & 36.40
\end{tabular}




\subsubsection{UV-Visible Spectroscopy}

The UV-Visible spectra of the family of $\mathrm{Fe}_{8}$ complexes are characterized by a single broad band with $\lambda \max$ at wavelengths between $350-400 \mathrm{~nm}$, attributed to ligand-to-metal charge transfer bands (LMCT) from oxygen atoms, pyrazolates, and terminal ligands. ${ }^{106}$ The substitution of terminal ligands by phenolates has a noticeable effect on the spectra, with a new broad band appearing at lower energies, which can be unequivocally assigned to the phenolate-to-metal charge transfer, plus an intramolecular $\pi-\pi *$ transition of the phenolate common to conjugate systems, between 260 and $280 \mathrm{~nm}$ (Figure 42).

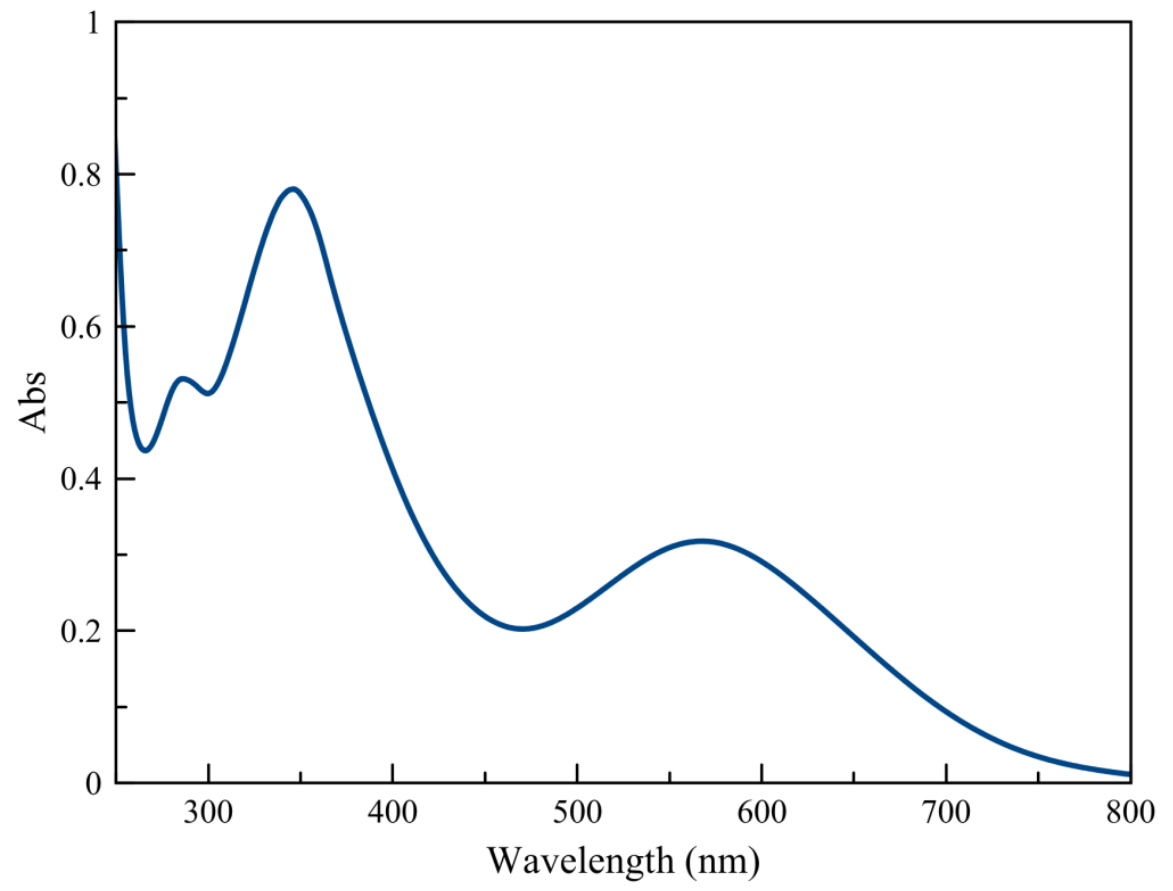

Figure 42. UV-Vis spectrum of $\left[\mathrm{Fe}_{8}\left(\mu_{4}-\mathrm{O}\right)_{4}(\mu-\mathrm{pz})_{12}\left(4-\mathrm{I}-\mathrm{C}_{6} \mathrm{H}_{4} \mathrm{O}\right)_{4}\right](\mathbf{6})$ in $\mathrm{CH}_{2} \mathrm{Cl}_{2}$. 
Evidently, the variation of the phenolate substituent group affects the position of the band attributed to the phenolate LMCT, additionally confirming its assignment. It can be affirmed that the more electron-withdrawing groups shift the maximum absorption of this band $\left(\lambda \max _{1}\right)$ to higher energy (lower wavelength), and, in contrast, electron-donating groups shift the $\lambda \max _{1}$ to lower energy (higher wavelength). The bands at around $350 \mathrm{~nm}$ attributed to the rest of the LMCT of the complex remain essentially unaffected. The wavelengths of the maximum absorption of the two different LMCT bands for compounds 2-9 are given in Table 8.

Table 8. LMCT bands maxima of compounds 2-9.

\begin{tabular}{|c|c|c|}
\hline Compound & $\begin{array}{c}\lambda \max _{1} \\
(\mathrm{~nm})\end{array}$ & $\begin{array}{c}\lambda \max _{2} \\
(\mathrm{~nm})\end{array}$ \\
\hline $2\left(4-\mathrm{NO}_{2}\right)$ & 528 & 353 \\
\hline $3(4-\mathrm{CN})$ & 533 & 351 \\
\hline $4(4-F)$ & 558 & 344 \\
\hline $5(4-\mathrm{Cl})$ & 560 & 345 \\
\hline $6(4-I)$ & 568 & 346 \\
\hline $7\left(4-\mathrm{CH}_{3} \mathrm{O}\right)$ & 619 & 345 \\
\hline $8\left(4--^{5} B u\right)$ & 586 & 347 \\
\hline $9\left(3-\mathrm{NO}_{2}\right)$ & 518 & 345 \\
\hline
\end{tabular}




\subsection{5. ${ }^{57}$ Fe Mössbauer}

Mössbauer spectroscopy is a solid-state technique that provides useful information about the oxidation states and coordination environment around metal centers. Numerical values extracted from a Mössbauer spectrum are the isomer shift $\delta\left(\mathrm{mms}^{-1}\right)$, which describes the coulombic interaction between the nucleus and the electrons, giving information about the oxidation state of the metal, electronegativity of the ligands, character of bonds and spin state (high spin/low spin), and the quadruple splitting $\Delta \mathrm{E}_{\mathrm{Q}}$ $\left(\mathrm{mms}^{-1}\right)$, which additionally informs about the character of bonds and spin state, but mainly about the molecular symmetry. ${ }^{125}$

The ${ }^{57} \mathrm{Fe}$ Mössbauer spectra of $\left[\mathrm{Fe}_{8}\right]$ and derivatives have been thoroughly studied. ${ }^{126}$ The terminal-Cl-substituted clusters present a similar pattern with two doublets, one for the cubane six-coordinate Fe sites and one for the five-coordinate outer Fe sites (Figure 43)

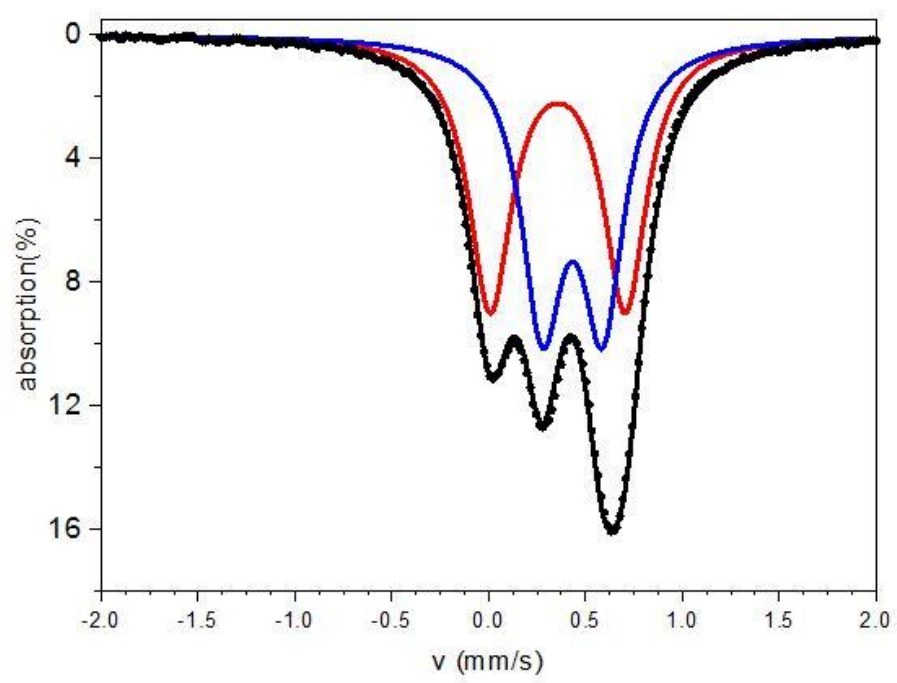

Figure 43. ${ }^{57} \mathrm{Fe}$ Mössbauer of $\left[\mathrm{Fe}_{8}\left(\mu_{4}-\mathrm{O}\right)_{4}(\mu-4-\mathrm{Ph}-\mathrm{pz})_{12} \mathrm{Cl}_{4}\right]$ at $80 \mathrm{~K}\left(\mathrm{Fe}_{\mathrm{c}}\right.$ blue trace, $\mathrm{Fe}_{\mathrm{o}}$ red trace). 
Upon substitution of the terminal $-\mathrm{Cl}$ ligand with phenolates the major change on the spectrum is observed for the quadruple splitting of the outer doublet as expected by the change in the coordination environment of the outer Fe atoms (Figure 44).

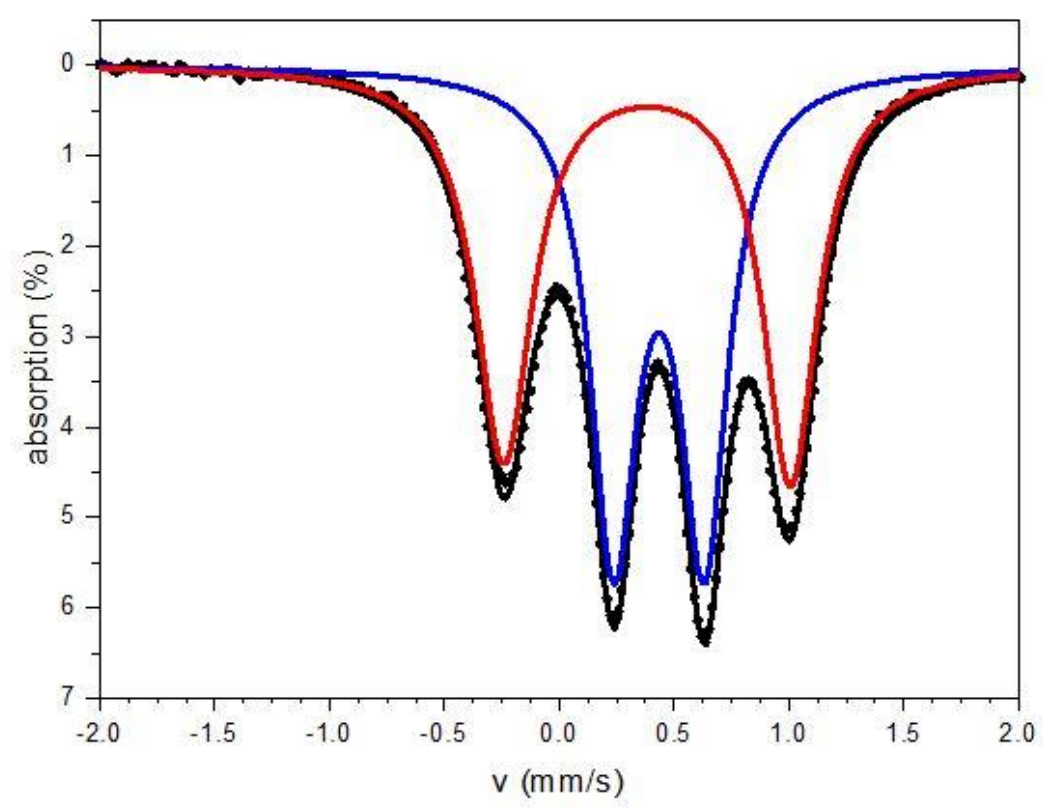

Figure 44. ${ }^{57} \mathrm{Fe}$ Mössbauer of $\left[\mathrm{Fe}_{8}\left(\mu_{4}-\mathrm{O}\right)_{4}(\mu \text {-pz })_{12}\left(4-\mathrm{I}-\mathrm{C}_{6} \mathrm{H}_{4} \mathrm{O}\right)_{4}\right](6)$ at $80 \mathrm{~K}\left(\mathrm{Fe}_{\mathrm{c}}\right.$ blue trace, $\mathrm{Fe}_{\mathrm{o}}$ red trace).

The substitution of terminal - $\mathrm{Cl}$ to phenolates has little to no effect on the isomer shift $\delta$ values of both the $\mathrm{Fe}_{\mathrm{c}}$ and the $\mathrm{Fe}_{\mathrm{o}}$ sites. For $\left[\mathrm{Fe}_{8}\right](\mathbf{1})$ the reported values are $0.44 \mathrm{~mm} \cdot \mathrm{s}^{-1}$ and $0.36 \mathrm{~mm} \cdot \mathrm{s}^{-1}$, respectively (recorded at $4.2 \mathrm{~K}$ ). ${ }^{106} \mathrm{~A}$ small increase is observed on the $\Delta \mathrm{E}_{\mathrm{Q}}$ of the $\mathrm{Fe}_{\mathrm{c}}\left(0.32 \mathrm{~mm} \cdot \mathrm{s}^{-1}\right.$ on average for $-\mathrm{Cl}$-substituted to $0.37 \mathrm{~mm} \cdot \mathrm{s}^{-1}$ for the phenolate ones), whereas the larger increase is observed for the $\Delta \mathrm{E}_{\mathrm{Q}}$ of the $\mathrm{Fe}_{\mathrm{o}}$ that range from $0.65 \mathrm{~mm} \cdot \mathrm{s}^{-1}$ on average for the former and $1.20 \mathrm{~mm} \cdot \mathrm{s}^{-1}$ for the latter. In addition, the $\Delta \mathrm{E}_{\mathrm{Q}}$ of the $\mathrm{Fe}_{\mathrm{o}}$ observed for the phenolate-substituted compounds described here are smaller than 
two oxo-bridged polymeric analogues of the $\left[\mathrm{Fe}_{8}\right]$ reported earlier by our group (1.87 $\mathrm{mm} \cdot \mathrm{s}^{-1}$ for $4-\mathrm{H}-\mathrm{pz} \mathrm{Fe}_{8}$ and $1.85 \mathrm{~mm} \cdot \mathrm{s}^{-1}$ for $\left.\left.4-\mathrm{CH}_{3}-\mathrm{pz} \mathrm{Fe}\right)_{8}\right){ }^{127}$ Values for compounds 2-9 are summarized in Table 9. (For the rest of the spectra see Appendix).

Table 9. ${ }^{57}$ Fe Mössbauer parameters of compounds 2 - 9.

\begin{tabular}{|c|c|c|c|c|c|}
\hline Compound & Sites & $\delta\left(\mathrm{mm} \cdot \mathrm{s}^{-1}\right)$ & $\Delta \mathrm{E}_{\mathrm{Q}}\left(\mathrm{mm} \cdot \mathrm{s}^{-1}\right)$ & $\Gamma\left(\mathrm{mm} \cdot \mathrm{s}^{-1}\right)$ & Assignment \\
\hline \multirow[t]{2}{*}{2} & Site I $\left(\mathrm{Fe}_{\mathrm{c}}\right)$ & 0.44 & 0.39 & 0.31 & Cubane \\
\hline & Site II $\left(\mathrm{Fe}_{\mathrm{o}}\right)$ & 0.38 & 1.08 & 0.34 & Outer \\
\hline \multirow[t]{2}{*}{3} & Site $\mathrm{I}\left(\mathrm{Fe}_{\mathrm{c}}\right)$ & 0.44 & 0.36 & 0.30 & Cubane \\
\hline & Site II $\left(\mathrm{Fe}_{\mathrm{o}}\right)$ & 0.32 & 1.08 & 0.33 & Outer \\
\hline \multirow[t]{2}{*}{4} & Site I $\left(\mathrm{Fe}_{\mathrm{c}}\right)$ & 0.44 & 0.38 & 0.25 & Cubane \\
\hline & Site II $\left(\mathrm{Fe}_{\mathrm{o}}\right)$ & 0.39 & 1.23 & 0.28 & Outer \\
\hline \multirow[t]{2}{*}{5} & Site I $\left(\mathrm{Fe}_{\mathrm{c}}\right)$ & 0.43 & 0.39 & 0.29 & Cubane \\
\hline & Site II $\left(\mathrm{Fe}_{\mathrm{o}}\right)$ & 0.38 & 1.28 & 0.32 & Outer \\
\hline \multirow[t]{2}{*}{6} & Site I $\left(\mathrm{Fe}_{\mathrm{c}}\right)$ & 0.44 & 0.40 & 0.25 & Cubane \\
\hline & Site II $\left(\mathrm{Fe}_{\mathrm{o}}\right)$ & 0.39 & 1.26 & 0.30 & Outer \\
\hline \multirow[t]{2}{*}{7} & Site $\mathrm{I}\left(\mathrm{Fe}_{\mathrm{c}}\right)$ & 0.43 & 0.37 & 0.24 & Cubane \\
\hline & Site II $\left(\mathrm{Fe}_{\mathrm{o}}\right)$ & 0.40 & 1.40 & 0.28 & Outer \\
\hline \multirow[t]{2}{*}{8} & Site I $\left(\mathrm{Fe}_{\mathrm{c}}\right)$ & 0.44 & 0.36 & 0.26 & Cubane \\
\hline & Site II $\left(\mathrm{Fe}_{\mathrm{o}}\right)$ & 0.40 & 1.37 & 0.30 & Outer \\
\hline \multirow[t]{2}{*}{9} & Site I $\left(\mathrm{Fe}_{\mathrm{c}}\right)$ & 0.43 & 0.35 & 0.25 & Cubane \\
\hline & Site II $\left(\mathrm{Fe}_{\mathrm{o}}\right)$ & 0.37 & 1.22 & 0.27 & Outer \\
\hline
\end{tabular}


The electronic properties of the phenolate-substituents have a direct effect on the $\Delta \mathrm{E}_{\mathrm{Q}}$ of $\mathrm{Fe}_{\mathrm{o}}$ with the more electron-withdrawing ones decreasing it and the more electrondonating ones increasing it.

\subsubsection{Electrochemistry}

Cyclic voltammetry (CV) and differential pulse voltammetry (DPV) experiments were conducted to assess the electrochemical properties of the complexes. The rich electrochemistry already studied for the parent $\left[\mathrm{Fe}_{8}\right]$ and derivatives ${ }^{106}$ (see for example Figure 27), is also present to the same or lesser extent in the phenolate analogues. The CV and DPV of 2 presented on the same diagram are depicted in Figure 45.

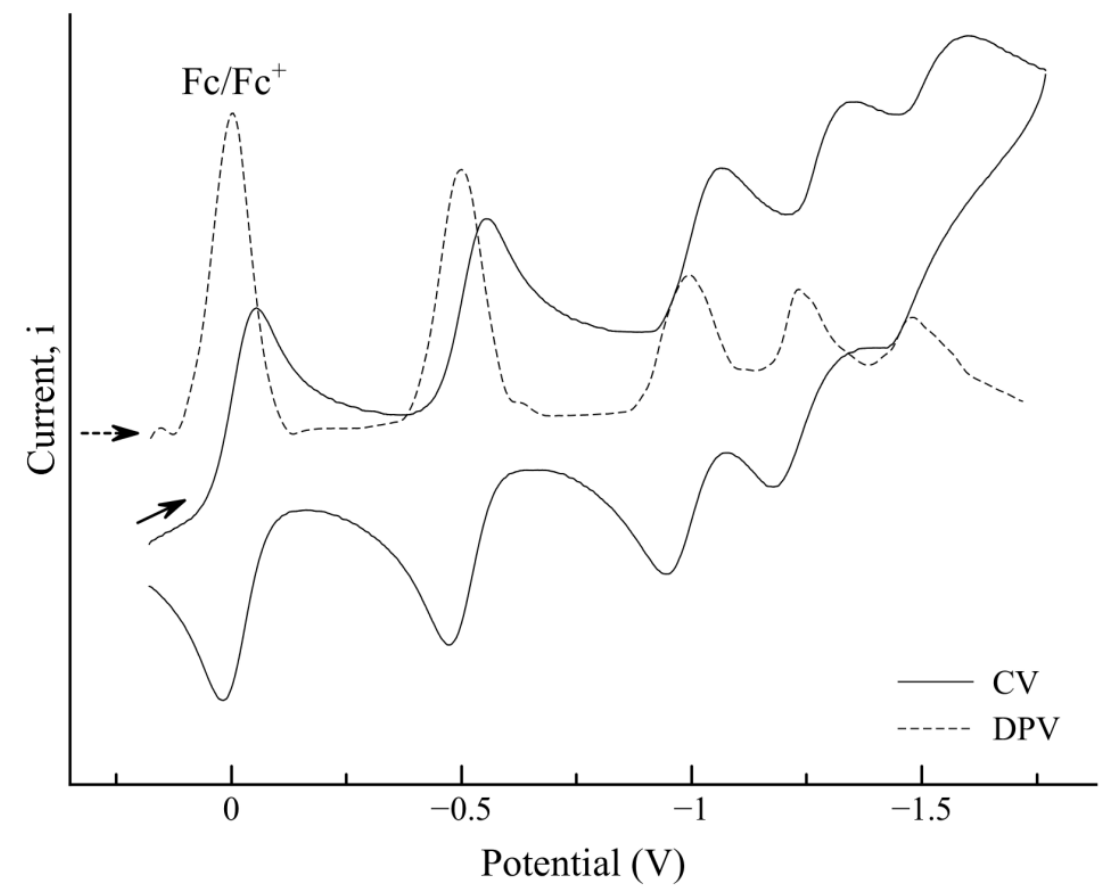

Figure 45. Cyclic voltammogram (solid line) and differential pulse voltammogram (dashed line) of $\left[\mathrm{Fe}_{8}\left(\mu_{4}-\mathrm{O}\right)_{4}(\mu-\mathrm{pz})_{12}\left(4-\mathrm{NO}_{2}-\mathrm{C}_{6} \mathrm{H}_{4} \mathrm{O}\right)_{4}\right]$ (2) in $0.5 \mathrm{M} \mathrm{Bu}_{4} \mathrm{NPF}_{6} / \mathrm{CH}_{2} \mathrm{Cl}_{2}$, vs $\mathrm{Fc}^{+} / \mathrm{Fc}$. 
Table 10. Redox potentials $\left(\mathrm{E}_{1 / 2}\right.$ in $\left.\mathrm{V}\right)$ and separation $(\Delta \mathrm{V})$ between consecutive redox processes of compounds 2-9.

\begin{tabular}{|c|c|c|c|c|}
\hline Compound & $\mathrm{E}_{1 / 2}(1)$ & $\mathrm{E}_{1 / 2}(2) / \Delta_{1-2}$ & $\mathrm{E}_{1 / 2}(3) / \Delta_{2-3}$ & $E_{1 / 2}(4) / \Delta_{3-4}$ \\
\hline 1 & -0.43 & $-0.78 / 0.35$ & $-1.07 / 0.29$ & $-1.38 / 0.31$ \\
\hline $2\left(4-\mathrm{NO}_{2}\right)$ & -0.50 & $-0.99 / 0.49$ & $-1.23 / 0.24$ & $-1.48 / 0.25$ \\
\hline $3(4-C N)$ & -0.54 & $-1.08 / 0.54$ & - & - \\
\hline $4(4-F)$ & -0.71 & $-1.26 / 0.55$ & - & - \\
\hline 5 (4-Cl) & -0.66 & $-1.21 / 0.55$ & - & - \\
\hline $6(4-I)$ & -0.65 & $-1.18 / 0.53$ & - & - \\
\hline $7\left(4-\mathrm{CH}_{3} \mathrm{O}\right)$ & -0.73 & $-1.26 / 0.53$ & - & - \\
\hline $8\left(4--^{s} \mathbf{B u}\right)$ & -0.74 & $-1.28 / 0.54$ & - & - \\
\hline $9\left(3-\mathrm{NO}_{2}\right)$ & -0.58 & $-1.13 / 0.55$ & $-1.51 / 0.38$ & - \\
\hline
\end{tabular}

In close analogy with the parent $\left[\mathrm{Fe}_{8}\right]$ complex, compound $\mathbf{2}$ exhibits three fully reversible reductions and one quasi-reversible reduction. Two fully reversible processes can be observed for the rest of the compounds with a third one being present in the spectrum of 9 (Table 10). Two features can be readily observed comparing the $\mathrm{E}_{1 / 2}$ values of the chloro-substituted compounds and the phenolate-substituted ones. The first is that they shift towards more negative potentials (cathodical shift), meaning that they become harder to reduce. The second is their increasing separation, in particular between $\mathrm{E}_{1 / 2}(1)$ and $E_{1 / 2}(2)$, which for the former ones is of the range of $0.30 \mathrm{~V}$, but for the latter increases to approximately $0.50 \mathrm{~V}$. A larger separation between the waves could allow for more facile isolation of the reduced species upon chemical reduction. As for the other spectroscopic studies, a correlation between the phenolate-substituent and the redox 
potential values is presented. Electron-donating groups tend to shift $E_{1 / 2}(1)$ and $E_{1 / 2}(2)$ to more negative potentials with a deviation observed for the fluoro-phenolate compound 4.

\subsection{Conclusions}

A series of octanuclear iron-oxo-pyrazolates where synthesized by substitution of the terminal chloride ligands of the parent $\mathrm{Fe}_{8}$ complex with phenolates and characterized with a variety of techniques to better understand the structural and spectroscopic features of these compounds. The effect of the phenolatate substituents was assessed and found to be significant, especially to the variation of values obtained from experiments such as ${ }^{1} \mathrm{H}$ NMR, UV-Visible, ${ }^{57} \mathrm{Fe}$ Mössbauer, and electrochemistry, demonstrating that by tuning of the chemical composition and structure of these unique complexes, a level of control of their properties can be achieved. These results can additionally be utilized as fingerprints for analogous compounds encountered either in nature or in synthetic forms. 


\subsection{Experimental section}

\subsubsection{Materials}

Reagents were purchased from Aldrich and Fisher Scientific and used as received. Solvents were purified and distilled prior use by conventional techniques. ${ }^{128}$ The anhydrous Fe (III) salts were stored in a glove box compartment under argon.

\subsubsection{Instrumentation}

UV-Vis, IR, and ${ }^{1} \mathrm{H}-\mathrm{NMR}$ spectra were obtained with a Cary 50000 Series UV-Vis-NIR spectrophotometer, an Agilent 600 Series FTIR, and a Bruker AVANCE $400 \mathrm{MHz}$ spectrometer, respectively. Electrochemical experiments were carried out with a BAS CV $50 \mathrm{~W}$ voltammetric analyzer in $0.5 \mathrm{M} \mathrm{Bu}_{4} \mathrm{NPF}_{6} / \mathrm{CH}_{2} \mathrm{Cl}_{2}$ using a non-aqueous $\mathrm{Ag} / \mathrm{AgNO}_{3}$ reference electrode for which the ferrocene/ferricenium couple occurs at $2.00 \mathrm{~V}, \mathrm{Pt}$ auxiliary electrode, and glassy carbon and/or Pt working electrode. The ${ }^{57} \mathrm{Fe}-\mathrm{Mössbauer}$ measurements were recorded on a constant acceleration conventional spectrometer with a

${ }^{57}$ Co (Rh matrix) source. Variable-temperature spectra were obtained by using Oxford cryostats, operating at $4.2-300 \mathrm{~K}$. Isomer shift values $(\delta)$ are quoted relative to iron foil at $293 \mathrm{~K}$. Analysis of the experimental spectra were performed with the WMOSS software (SEE Co, Edina, Minnesota). Elemental analyses were performed by Galbraith Laboratories, Knoxville, TN.

\subsubsection{X-ray Crystallography}

Crystals of the complexes 2-7 and $\mathbf{9}$ were obtained by recrystallization of dichloromethane/hexane solutions. In cases of 2-6 a suitable crystal for each complex was selected and mounted on a Bruker D8 Quest diffractometer equipped with PHOTON 
100 detector, while in cases of $\mathbf{7}$ and $\mathbf{9}$ a suitable single crystal from each samples was selected and mounted on a Bruker SMART APEX II diffractometer equipped with CCD detector, both operating at $\mathrm{T}=298 \mathrm{~K}$. Data were collected with $\omega$ scan technique using graphite monochromated Mo-K $\alpha$ radiation $(\lambda=0.71073 \AA)$. The total number of runs and images for data collection was based on strategy calculation from the program APEX3 (Bruker). ${ }^{129}$ Cell parameters were retrieved using the SAINT (Bruker) software ${ }^{130}$ and refined using SAINT (Bruker) on 10599 independent reflections for 2, 16001 for 3, 15036 for $\mathbf{4}, 7894$ for $\mathbf{5}, 8917$ for $\mathbf{6}, 16964$ for $\mathbf{7}$, and 31262 for $\mathbf{9}$. Data reduction was performed using the SAINT (Bruker) software, which corrects for Lorentz and polarization effects. The final completeness is $96.5 \%$ for $\mathbf{2}, 96.9 \%$ for $\mathbf{3}, 99.7 \%$ for $\mathbf{4}$, 99.6\% for 5, $99.7 \%$ for $\mathbf{6}, 99.7 \%$ for $\mathbf{7}$, and $98.7 \%$ for $\mathbf{9}$. Multi-scan absorption corrections were performed on all data sets using SADABS 2016/2. ${ }^{131}$ The structures for complexes $\mathbf{2}, 3$ and 9 were solved in space group $P-1$ (No. 2), for complexes 4 and 7 in $P 2_{l} / c$ (No. 14) and for complexes 5 and $\mathbf{6}$ in $C 2 / c$ (No. 15) by intrinsic phasing method using the ShelXT ${ }^{132}$ structure solution program and refined by full matrix least square procedure on F2 using version 2016/6 of ShelXL. ${ }^{133}$ The non-hydrogen atoms were refined anisotropically in all cases. Hydrogen atom positions were calculated geometrically and refined using the riding model. To alleviate the complications related to solvent accessible voids within the extended lattice in cases of $\mathbf{3}, \mathbf{5}, \mathbf{7}$ and $\mathbf{9}$, SQUEEZE operation (included in the PLATON program) was performed with the raw data set and the structure was refined form the data obtained upon SQUEEZE operation. ${ }^{134}$ In case of complex $\mathbf{3}$, one of the phenol fragments (with C58A as pivotal C atom) revealed a two-fold orientation disorder, which was modeled, and the anisotropic 
displacement parameters of two pairs of atoms were constrained to be equal. In case of complex 4, the $\mathrm{F}$ atoms on the para position of the phenol rings exhibited two-fold disorder, which was modeled using PART refinement. All calculations and molecular graphics were preformed using SHELXTL 2016, and Olex2. ${ }^{135}$

\subsubsection{Synthesis}

$\left[\mathbf{F e}_{\mathbf{8}}\left(\boldsymbol{\mu}_{\mathbf{4}}-\mathbf{O}\right)_{\mathbf{4}}(\boldsymbol{\mu}-\mathbf{p z})_{\mathbf{1 2}} \mathbf{C l}_{\mathbf{4}}\right](\mathbf{1})$ was prepared by a literature method. ${ }^{106}$

$\left[\mathrm{Fe}_{\mathbf{8}}\left(\boldsymbol{\mu}_{\mathbf{4}}-\mathbf{O}\right)_{\mathbf{4}}(\boldsymbol{\mu}-\mathbf{p z})_{\mathbf{1 2}}\left(\mathbf{4}-\mathrm{NO}_{\mathbf{2}}-\mathbf{C}_{\mathbf{6}} \mathbf{H}_{\mathbf{4}} \mathbf{O}\right)_{\mathbf{4}}\right] \mathbf{( 2 )}$. A flask was charged with $50 \mathrm{mg}, 0.034 \mathrm{mmol}$, of $\left[\mathrm{Fe}_{8}\left(\mu_{4}-\mathrm{O}\right)_{4}(\mu-\mathrm{pz})_{12} \mathrm{Cl}_{4}\right](\mathbf{1})$, and were dissolved in $10 \mathrm{~mL} \mathrm{CH}_{2} \mathrm{Cl}_{2}$ at room temperature. A 20-fold excess (95 mg, $0.68 \mathrm{mmol}$ ), of 4-nitrophenol and triethylamine (96 $\mu \mathrm{l}, 0.68$ mmol),were added in the solution resulting in a color change from dark red to dark maroon within minutes. The reaction flask was sealed and kept stirring for $3 \mathrm{~h}$. In the resulting solution $10 \mathrm{~mL} n$-hexane were added, and the mixture was left stirring for 30 min. The reaction was filtered through celite, and X-ray quality crystals were obtained by slow evaporation of the $\mathrm{CH}_{2} \mathrm{Cl}_{2}$ /hexane mixture. The crystals were washed with $\mathrm{MeOH}$ to remove excess of phenol, $\mathrm{Et}_{3} \mathrm{~N}$, and $\mathrm{Et}_{3} \mathrm{NH}^{+} \mathrm{Cl}^{-}$and dried under vacuum. Yield: $45 \%$. Anal. Calcd for $\mathrm{C}_{60} \mathrm{H}_{52} \mathrm{Fe}_{8} \mathrm{~N}_{28} \mathrm{O}_{16} \cdot \mathrm{CH}_{2} \mathrm{Cl}_{2} \cdot \mathrm{H}_{2} \mathrm{O}$ : C, 37.17; H, 2.86; N, 19.90. Found: C, 37.66; H, 2.89; N, 19.79. IR (CsI disk): 1582(vs), 1490(s), 1418(m), 1364(s), 1300(vs, NO stretch), 1269(m), 1167(s), 1110(m), 1045(vs), 963(w), 873(m), 849(m), 764(s), 669(s), 617(m), 555(w), 482(vs, br $\left.\mathrm{Fe}_{\mathrm{c}}-\mathrm{O}\right)$, 351(s), 306(m). UV-Vis $\left(\mathrm{CH}_{2} \mathrm{Cl}_{2}\right): \lambda_{\max 1}$, $18939 \mathrm{~cm}^{-1},(528 \mathrm{~nm}), \lambda_{\max 2}, 28328 \mathrm{~cm}^{-1},(353 \mathrm{~nm}) .{ }^{1} \mathrm{H}-\mathrm{NMR}\left(\delta, \mathrm{ppm}, \mathrm{CDCl}_{3}\right): 41.2(\mathrm{~s}$, $\left.12 \mathrm{H},{ }^{4} \mathrm{H}\right), 8.3\left(\mathrm{~s}, 12 \mathrm{H},{ }^{3} \mathrm{H}\right), 5.3\left(\mathrm{~s}, 12 \mathrm{H},{ }^{5} \mathrm{H}\right), 36.7\left(\mathrm{~s}, 8 \mathrm{H},{ }^{\mathrm{b}} \mathrm{H}\right),-26.5\left(\mathrm{~s}, 8 \mathrm{H},{ }^{\mathrm{a}} \mathrm{H}\right)$. 
$\left[\mathrm{Fe}_{8}\left(\mu_{4}-\mathrm{O}\right)_{4}(\mu-\mathrm{pz})_{12}\left(4-\mathrm{NC}-\mathrm{C}_{6} \mathrm{H}_{4} \mathrm{O}\right)_{4}\right](3)$. Complex 3 was synthesized in a similar fashion to 2. Yield: $35 \%$. Anal. Calcd for $\mathrm{C}_{64} \mathrm{H}_{52} \mathrm{Fe}_{8} \mathrm{~N}_{28} \mathrm{O}_{8} \cdot \mathrm{CH}_{2} \mathrm{Cl}_{2}$ : 42.51, 2.91, $21.35 \mathrm{C}, 41.68$; H, 2.91; N, 20.94. Found: C, 41.84; H, 2.95; N, 21.33. IR (CsI disk): 2218(m, C-N nitrile), 1592(s), 1496(vs), 1417(m), 1364(m), 1308(vs), 1269(m), 1167(s), 1102(w), 1045(vs), 963(w), 868(m), 840(m), 763(s), 617(m), 549(m), 480(vs, br Fe $\left.\mathrm{c}^{-} \mathrm{O}\right), 353(\mathrm{~m})$, 304(m). UV-Vis $\left(\mathrm{CH}_{2} \mathrm{Cl}_{2}\right): \lambda_{\max 1}, 18762 \mathrm{~cm}^{-1},(533 \mathrm{~nm}), \lambda_{\max 2}, 28490 \mathrm{~cm}^{-1},(351 \mathrm{~nm}) .{ }^{1} \mathrm{H}-$ $\operatorname{NMR}\left(\delta\right.$, ppm, $\left.\mathrm{CDCl}_{3}\right): 42.3\left(\mathrm{~s}, 12 \mathrm{H},{ }^{4} \mathrm{H}\right), 8.7\left(\mathrm{~s}, 12 \mathrm{H},{ }^{3} \mathrm{H}\right), 5.3\left(\mathrm{~s}, 12 \mathrm{H},{ }^{5} \mathrm{H}\right), 37.6(\mathrm{~s}, 8$ $\left.\mathrm{H},{ }^{\mathrm{b}} \mathrm{H}\right),-29.1\left(\mathrm{~s}, 8 \mathrm{H},{ }^{\mathrm{a}} \mathrm{H}\right)$.

$\left[\mathrm{Fe}_{8}\left(\boldsymbol{\mu}_{4}-\mathrm{O}\right)_{4}(\mu-\mathrm{pz})_{12}\left(4-\mathrm{F}-\mathrm{C}_{6} \mathrm{H}_{4} \mathrm{O}\right)_{4}\right]$ (4). Complex 4 was synthesized in a similar fashion to 2. Yield: 70\%. Anal. Calcd for $\mathrm{C}_{60} \mathrm{H}_{52} \mathrm{~F}_{4} \mathrm{Fe}_{8} \mathrm{~N}_{24} \mathrm{O}_{8}$ : C, 40.95; H, 2.98; N, 19.1. Found: C, 41.59; H, 2.98; N, 18.98. IR (CsI disk): 1493(vs), 1417(m), 1364(s), 1289(s), 1270(s), 1209(s), 1169(s), 1146(m), 1086(m), 1046(vs), 963(m), 916(w), 878(m), 831(s), 786(s), 762(s), 618(m), 553(m), 485(vs, br Fe $\left.\mathrm{Fe}_{\mathrm{c}}-\mathrm{O}\right), 378(\mathrm{~m}), 349(\mathrm{~s}), 326(\mathrm{~m}), 305(\mathrm{~m}) . \mathrm{UV}-\mathrm{Vis}$ $\left(\mathrm{CH}_{2} \mathrm{Cl}_{2}\right): \lambda_{\max 1}, 17921 \mathrm{~cm}^{-1},(558 \mathrm{~nm}), \lambda_{\max 2}, 29070 \mathrm{~cm}^{-1},(344 \mathrm{~nm}) .{ }^{1} \mathrm{H}-\mathrm{NMR}(\delta, \mathrm{ppm}$, $\left.\mathrm{CDCl}_{3}\right): 43.5\left(\mathrm{~s}, 12 \mathrm{H},{ }^{4} \mathrm{H}\right), 10.2\left(\mathrm{~s}, 12 \mathrm{H},{ }^{3} \mathrm{H}\right), 5.4\left(\mathrm{~s}, 12 \mathrm{H},{ }^{5} \mathrm{H}\right), 39.9\left(\mathrm{~s}, 8 \mathrm{H},{ }^{\mathrm{b}} \mathrm{H}\right),-41.3$ (s, $\left.8 \mathrm{H},{ }^{\mathrm{a}} \mathrm{H}\right)$.

$\left[\mathrm{Fe}_{8}\left(\mu_{4}-\mathrm{O}\right)_{4}(\mu-\mathrm{pz})_{12}\left(4-\mathrm{Cl}-\mathrm{C}_{6} \mathrm{H}_{4} \mathrm{O}\right)_{4}\right](5)$. Complex 5 was synthesized in a similar fashion to 2. Yield: 55\%. Anal. Calcd for $\mathrm{C}_{60} \mathrm{H}_{52} \mathrm{Cl}_{4} \mathrm{Fe}_{8} \mathrm{~N}_{24} \mathrm{O}_{8}$ : C, 39.47; $\mathrm{H}, 2.87 ; \mathrm{N}, 18.41$. Found: C, 39.56; H, 2.97; N, 17.96. IR (CsI disk): 1581(m), 1481(s), 1435(m), 1417(m), 1288(s), 1269(s), 1168(s), 1087(m), 1045(vs), 1002(w), 963(m), 916(w), 870(m), 828(s), 763(s), 688(s), 618(m), 552(w), 482(vs, br $\left.\mathrm{Fe}_{\mathrm{c}}-\mathrm{O}\right)$, 351(s), 320(m), 306(s). UV-Vis $\left(\mathrm{CH}_{2} \mathrm{Cl}_{2}\right): \lambda_{\max 1}, 17857 \mathrm{~cm}^{-1},(560 \mathrm{~nm}), \lambda_{\max 2}, 28985 \mathrm{~cm}^{-1},(345 \mathrm{~nm}) .{ }^{1} \mathrm{H}-\mathrm{NMR}(\delta, \mathrm{ppm}$, 
$\left.\mathrm{CDCl}_{3}\right): 43.2\left(\mathrm{~s}, 12 \mathrm{H},{ }^{4} \mathrm{H}\right), 9.9\left(\mathrm{~s}, 12 \mathrm{H},{ }^{3} \mathrm{H}\right), 5.3\left(\mathrm{~s}, 12 \mathrm{H},{ }^{5} \mathrm{H}\right), 40.7\left(\mathrm{~s}, 8 \mathrm{H},{ }^{\mathrm{b}} \mathrm{H}\right),-38.3(\mathrm{~s}$, $\left.8 \mathrm{H},{ }^{a} \mathrm{H}\right)$.

$\left[\mathrm{Fe}_{8}\left(\mu_{4}-\mathrm{O}\right)_{4}(\mu-\mathrm{pz})_{12}\left(4-\mathrm{I}-\mathrm{C}_{6} \mathrm{H}_{4} \mathrm{O}\right)_{4}\right](6)$. Complex 6 was synthesized in a similar fashion to 2. Yield: $80 \%$. Anal. Calcd for $\mathrm{C}_{60} \mathrm{H}_{52} \mathrm{I}_{4} \mathrm{Fe}_{8} \mathrm{~N}_{24} \mathrm{O}_{8}: \mathrm{C}, 32.88 ; \mathrm{H}, 2.39 ; \mathrm{N}, 15.34$. Found: $\mathrm{C}$, 32.87; H, 2.42; N, 14.97. IR (CsI disk): 1569(m), 1490(m), 1476(vs), 1417(m), 1288(s), 1268(m), 1168(s), 1147(m), 1045(vs), 995(w), 962(w), 866(m), 823(m), 762(s), 648(m), 617(m), 551(w), 482(vs, br $\left.\mathrm{Fe}_{\mathrm{c}}-\mathrm{O}\right), 375(\mathrm{~m}), 349(\mathrm{~m}), 303(\mathrm{w})$. UV-Vis $\left(\mathrm{CH}_{2} \mathrm{Cl}_{2}\right): \lambda_{\max 1}$, $17606 \mathrm{~cm}^{-1},(568 \mathrm{~nm}), \lambda_{\max 2}, 28902 \mathrm{~cm}^{-1},(346 \mathrm{~nm}) .{ }^{1} \mathrm{H}-\mathrm{NMR}\left(\delta, \mathrm{ppm}, \mathrm{CDCl}_{3}\right): 43.1(\mathrm{~s}$, $\left.12 \mathrm{H},{ }^{4} \mathrm{H}\right), 9.7\left(\mathrm{~s}, 12 \mathrm{H},{ }^{3} \mathrm{H}\right), 5.3\left(\mathrm{~s}, 12 \mathrm{H},{ }^{5} \mathrm{H}\right), 41.1\left(\mathrm{~s}, 8 \mathrm{H},{ }^{\mathrm{b}} \mathrm{H}\right),-37.2\left(\mathrm{~s}, 8 \mathrm{H},{ }^{\mathrm{a}} \mathrm{H}\right)$.

$\left[\mathrm{Fe}_{8}\left(\mu_{4}-\mathrm{O}\right)_{4}(\mu-\mathrm{pz})_{12}\left(4-\mathrm{CH}_{3} \mathrm{O}-\mathrm{C}_{6} \mathrm{H}_{4} \mathrm{O}\right)_{4}\right]$ (7). Complex 7 was synthesized in a similar fashion to 2. Yield: 80\%. Anal. Calcd for $\mathrm{C}_{64} \mathrm{H}_{64} \mathrm{Fe}_{8} \mathrm{~N}_{24} \mathrm{O}_{12}: \mathrm{C}, 42.51 ; \mathrm{H}, 3.57 ; \mathrm{N}, 18.59$. Found: C, 42.46; H, 3.78; N, 18.37. IR (CsI disk): 1598(w), 1495(vs), 1465(w), 1439(w), 1417(m), 1364(s), 1268(vs), 1234(vs), 1169(s), 1098(w), 1045(vs), 962(w), 916(w), 875(m), 828(m), 764(s), 619(m), 548(w), 483(vs, br Fe $\left.\mathrm{c}^{-} \mathrm{O}\right), 348(\mathrm{~s}), 330(\mathrm{w}), 304(\mathrm{~m}) . \mathrm{UV}-$ Vis $\left(\mathrm{CH}_{2} \mathrm{Cl}_{2}\right): \lambda_{\max 1}, 16155 \mathrm{~cm}^{-1},(619 \mathrm{~nm}), \lambda_{\max 2}, 28985 \mathrm{~cm}^{-1},(345 \mathrm{~nm}) .{ }^{1} \mathrm{H}-\mathrm{NMR}(\delta$, ppm, $\left.\mathrm{CDCl}_{3}\right): 43.8\left(\mathrm{~s}, 12 \mathrm{H},{ }^{4} \mathrm{H}\right), 10.6\left(\mathrm{~s}, 12 \mathrm{H},{ }^{3} \mathrm{H}\right), 5.3\left(\mathrm{~s}, 12 \mathrm{H},{ }^{5} \mathrm{H}\right), 41.1\left(\mathrm{~s}, 8 \mathrm{H},{ }^{\mathrm{b}} \mathrm{H}\right),-$ $45.9\left(\mathrm{~s}, 8 \mathrm{H},{ }^{\mathrm{a}} \mathrm{H}\right), 10.4\left(\mathrm{~s}, 12 \mathrm{H},{ }^{\mathrm{c}} \mathrm{CH}_{3}\right)$.

$\left[\mathrm{Fe}_{8}\left(\mu_{4}-\mathrm{O}\right)_{4}(\mu-\mathrm{pz})_{12}\left(4^{\mathrm{s}}{ }^{\mathrm{B}} \mathrm{Bu}-\mathrm{C}_{6} \mathrm{H}_{4} \mathrm{O}\right)_{4}\right](8)$. See chapter III.

$\left[\mathrm{Fe}_{8}\left(\mu_{4}-\mathrm{O}\right)_{4}(\mu-\mathrm{pz})_{12}\left(3-\mathrm{NO}_{2}-\mathrm{C}_{6} \mathrm{H}_{4} \mathrm{O}\right)_{4}\right]$ (9). Complex 9 was synthesized in a similar fashion to 2. Yield: 70\%. Anal. Calcd for $\mathrm{C}_{60} \mathrm{H}_{52} \mathrm{Fe}_{8} \mathrm{~N}_{28} \mathrm{O}_{16}: \mathrm{C}, 38.58 ; \mathrm{H}, 2.81 ; \mathrm{N}, 20.99$. Found: C, 38.58; H, 2.70; N, 20.60. IR (CsI disk): 1608(w), 1560(w), 1524(s), 1491(m), 
1473(m), 1436(m), 1363(s), 1308(s, N-O stretch), 1286(s), 1269(s), 1168(s), 1075(w), 1045(vs), 996(w), 871(w), 826(s), 763(s), 739(m), 675(m), 617(m), 556(w), 482(vs, br $\left.\mathrm{Fe}_{\mathrm{c}}-\mathrm{O}\right), 352(\mathrm{~s}), 306(\mathrm{~m}) . \mathrm{UV}-\mathrm{Vis}\left(\mathrm{CH}_{2} \mathrm{Cl}_{2}\right): \lambda_{\max 1}, 19305 \mathrm{~cm}^{-1},(518 \mathrm{~nm}), \lambda_{\max 2}, 28985 \mathrm{~cm}^{-}$ ${ }^{1},(345 \mathrm{~nm}) .{ }^{1} \mathrm{H}-\mathrm{NMR}\left(\delta, \mathrm{ppm}, \mathrm{CDCl}_{3}\right): 42.4\left(\mathrm{~s}, 12 \mathrm{H},{ }^{4} \mathrm{H}\right), 8.9\left(\mathrm{~s}, 12 \mathrm{H},{ }^{3} \mathrm{H}\right), 5.5(\mathrm{~s}, 12 \mathrm{H}$, $\left.{ }^{5} \mathrm{H}\right), 35.8\left(\mathrm{~s}, 4 \mathrm{H},{ }^{\mathrm{b}} \mathrm{H}\right),-29.3\left(\mathrm{~s}, 4 \mathrm{H},{ }^{\mathrm{a}} \mathrm{H}\right),-29.3\left(\mathrm{~s}, 4 \mathrm{H},{ }^{\mathrm{d}} \mathrm{H}\right)-28.7\left(\mathrm{~s}, 4 \mathrm{H},{ }^{\mathrm{c}} \mathrm{H}\right)$. 


\section{Chapter III: Resolution of $\mathrm{Fe}_{8}$ via diastereomer formation with chiral phenols}

\section{Introduction}

Utilization of chiral phenols for the formation of diastereomers was proven to be the most promising method for the resolution of the $\mathrm{Fe}_{8}$ complex. The use of the racemic mixture of the phenol would yield a high number of the possible diastereomers that can be formed by the combination of the $P / M \mathrm{Fe}_{8}$ complex enantiomers and $R / S$ phenol enantiomers, since the substitution of terminal chloride ligands by four phenolates can give rise to combinations such as $P(R, R, R, R), P(R, R, R, S), P(R, R, S, S), M(R, R, R, R), M(R, R$, $R, S$ ) etc., rendering their separation a challenging task. However, a potential preference

of each of the complex's enantiomers for a specific enantiomer of the phenol would significantly decrease this number facilitating their isolation. Herein, we demonstrate how this preference exists and results in the resolution of one of the $\mathrm{Fe}_{8}$ derivatives upon crystallization.

\subsection{Results and discussion}

\subsubsection{Synthesis}

Three $\mathrm{Fe}_{8}$ derivatives were used, $\left[\mathrm{Fe}_{8}\left(\mu_{4}-\mathrm{O}\right)_{4}(\mu-\mathrm{pz})_{12} \mathrm{Cl}_{4}\right]$ (1), $\left[\mathrm{Fe}_{8}\left(\mu_{4}-\mathrm{O}\right)_{4}\left(\mu-4-\mathrm{CH}_{3}-\right.\right.$ pz $\left.{ }_{12} \mathrm{Cl}_{4}\right](\mathbf{1 0})$ and $\left[\mathrm{Fe}_{8}\left(\mu_{4}-\mathrm{O}\right)_{4}(\mu-4-\mathrm{Cl}-\mathrm{pz})_{12} \mathrm{Cl}_{4}\right]$ (11) and reacted with $4-{ }^{\mathrm{s}} \mathrm{Bu}-$ phenol and base in a similar fashion to the compounds bearing achiral phenols, yielding compounds $\left[\mathrm{Fe}_{8}\left(\mu_{4}-\mathrm{O}\right)_{4}(\mu-\mathrm{pz})_{12}\left(r a c-4-{ }^{\mathrm{s}} \mathrm{Bu}-\mathrm{C}_{6} \mathrm{H}_{4} \mathrm{O}\right)_{4}\right] \quad(\mathbf{8}), \quad\left[\mathrm{Fe}_{8}\left(\mu_{4}-\mathrm{O}\right)_{4}\left(\mu-4-\mathrm{CH}_{3}-\mathrm{pz}\right)_{12}\left(r a c-4-{ }^{\mathrm{s}} \mathrm{Bu}-\right.\right.$ $\left.\left.\mathrm{C}_{6} \mathrm{H}_{4} \mathrm{O}\right)_{4}\right](\mathbf{1 2})$, and $\left[\mathrm{Fe}_{8}\left(\mu_{4}-\mathrm{O}\right)_{4}(\mu-4-\mathrm{Cl}-\mathrm{pz})_{12}\left(r a c-4-{ }^{\mathrm{s}} \mathrm{Bu}-\mathrm{C}_{6} \mathrm{H}_{4} \mathrm{O}\right)_{4}\right](\mathbf{1 3})$. 


\subsubsection{X-ray crystallography}

Compound $\mathbf{8}$ crystallizes in the monoclinic centrosymmetric $C 2 / c$ space group with half molecule per asymmetric unit and half $\mathrm{CH}_{2} \mathrm{Cl}_{2}$ solvent. The molecule resides on a $C_{2}$ axis, thus the other half is generated by this symmetry element. The crystal structure confirms the replacement of all four chloride ligands by 4-sec-butylphenolates without other significant change in the structure (Figure 46). The crystallization of 8 in a centrosymmetric space group indicates its racemate nature, implying that this $\mathrm{Fe}_{8}$ derivative does not resolve upon crystallization. However, the configuration of the $4{ }^{\mathrm{s}} \mathrm{Bu}-$ phenolate ligands, all four of which are $S$-, indicates that there is selectivity of the cluster to one of the two enantiomers of the phenolate. There are four molecules in the unit cell; two pairs of enantiomers, the symmetry element relating each to the other being an inversion center. The characteristic $\mathrm{Fe}-\mathrm{O}$ bond lengths of the $\mathrm{Fe}_{4} \mathrm{O}_{4}$ cubane range from

2.027(3) to 2.038(3) $\AA$, whereas the $\mathrm{Fe}_{\mathrm{c}}-\mathrm{O}-\mathrm{Fe}_{\mathrm{c}}$ and $\mathrm{O}_{\mathrm{c}}-\mathrm{Fe}_{\mathrm{c}}-\mathrm{O}_{\mathrm{c}}$ angles vary from 96.9(1) ${ }^{\mathrm{o}}$ to $97.2(1)^{\circ}$ and from $82.2(1)^{\circ}$ to $82.3(1)^{\circ}$, respectively. Selected bond lengths and angles for $\mathbf{8}$ are summarized in Table 11. 


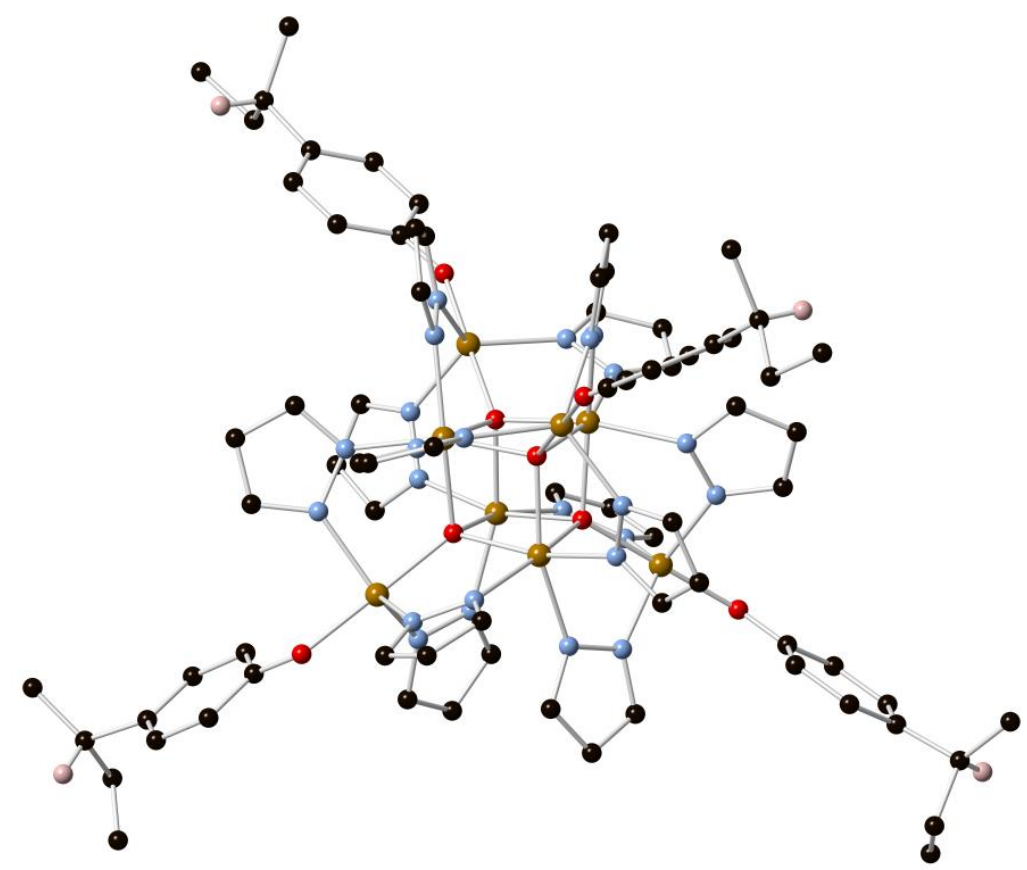

Figure 46. Ball-and-stick diagram of $\left[\mathrm{Fe}_{8}\left(\mu_{4}-\mathrm{O}\right)_{4}(\mu-\mathrm{pz})_{12}\left(r a c-4-{ }^{\mathrm{s}} \mathrm{Bu}-\mathrm{C}_{6} \mathrm{H}_{4} \mathrm{O}\right)_{4}\right](\mathbf{8})$ : Gold, $\mathrm{Fe}$; red, O; blue, N; black, C. Only hydrogen atoms on the stereocenters are shown.

Similarly 12 (Figure 47) crystallizes in the centrosymmetric $C 2 / c$ space group with half a molecule per asymmetric unit and resides on a $C_{2}$ axis. However the configuration of one of the $4-{ }^{\mathrm{s}} \mathrm{Bu}$-phenolate ligands is obscured by crystallographic disorder, indicating partial occupancy of this position by either the $S$ - or the $R$-enantiomer. Selected bonds and angles for $\mathbf{1 2}$ are summarized in Table 11. 


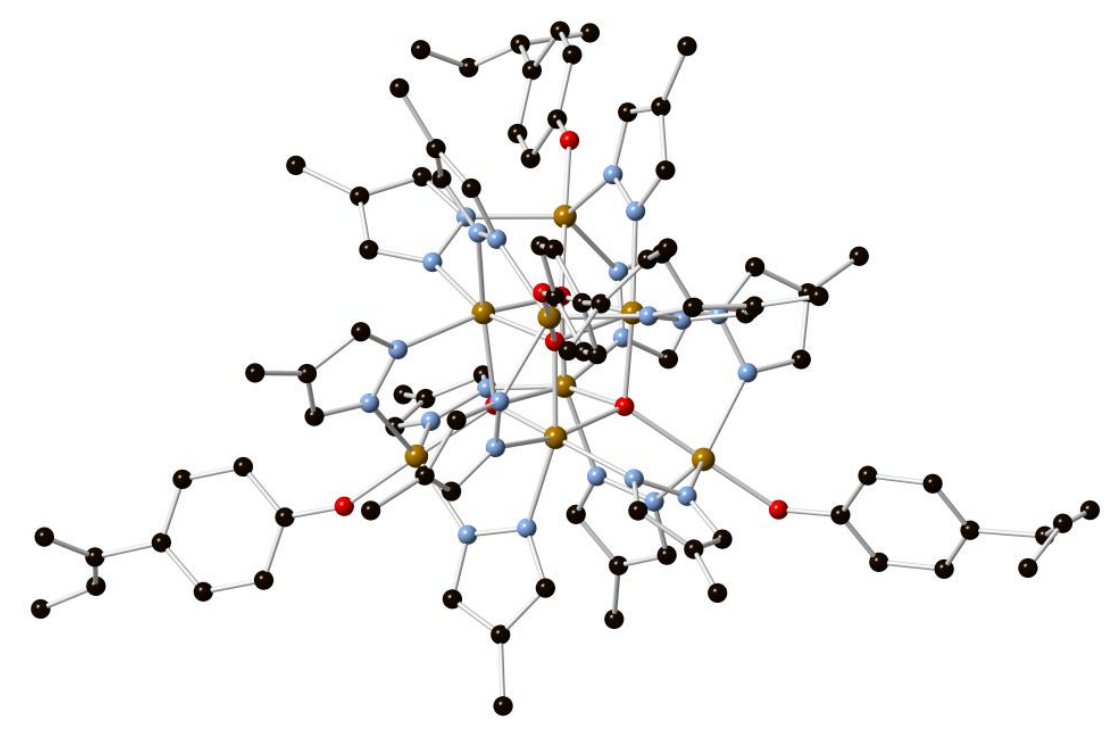

Figure 47. Ball-and-stick diagram of $\left[\mathrm{Fe}_{8}\left(\mu_{4}-\mathrm{O}\right)_{4}\left(\mu-4-\mathrm{CH}_{3}-\mathrm{pz}\right)_{12}\left(\mathrm{rac}-4-{ }^{\mathrm{s}} \mathrm{Bu}_{-} \mathrm{C}_{6} \mathrm{H}_{4} \mathrm{O}\right)_{4}\right]$ (12): Gold, Fe; red, O; blue, N; black, C. Hydrogen atoms omitted for clarity.

In contrast to 8 and $\mathbf{1 2}$, compound $\mathbf{1 3}$ crystallizes in the chiral non-centrosymmetric $P 2{ }_{1} 3$ space group with $Z=4$; the molecule occupies a general position with one third molecule per asymmetric unit. One $4-{ }^{\mathrm{s}} \mathrm{Bu}$-phenolate ligand is positioned on the threefold symmetry axis $\left(C_{3}\right)$ with crystallographically imposed symmetry; thus, its absolute configuration is obscured by the crystallographic disorder. Nevertheless, this is irrelevant to the fact that the $P$ and $M\left[\mathrm{Fe}_{8}\right]$ enantiomers crystallized separately. There are several possible diastereomers that can be formed with the racemic ligand, the number of which can be reduced to four if all peripheral positions are occupied by ligands with the same configuration (i.e., all $R$ or all $S$ would yield $P(S), P(R), M(S)$, and $M(R)$ ). X-ray analysis showed two different types of crystal structures, $13 \mathbf{a}$ and $\mathbf{1 3 b}$, that correspond to the enantiomers $\boldsymbol{P}(R)$ and $\boldsymbol{M}(S)$ with Flack parameters -0.006(4) and -0.003(5), respectively. 
The $\boldsymbol{P}(R)$ and $\boldsymbol{M}(S)$ compounds crystallized with different interstitial solvent content.

Selected bond lengths and angles for $\mathbf{1 3 a}$ and $\mathbf{1 3 b}$ are summarized in Table 11.
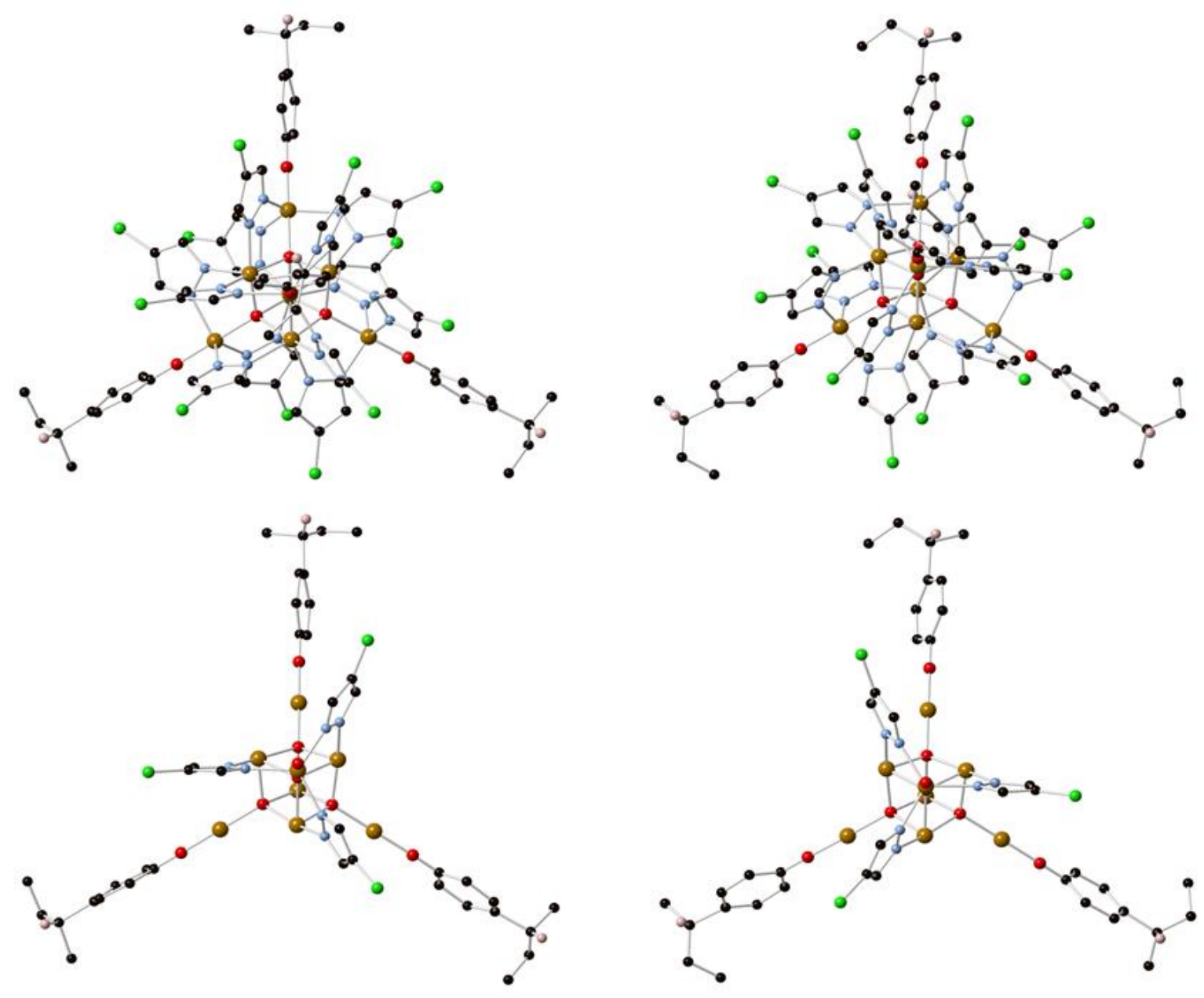

Figure 48. Ball-and-stick diagrams of $\mathbf{1 3 a}(P / R$ enantiomer,up and left), and $\mathbf{1 3 b}(M / S$ enantiomer, up and right). View parallel to one of the $C_{3}$ axes of 13a (down and left), and 13b (down and right). Three of the twelve pyrazolates and three of the four phenolates are shown: Gold, Fe; red, O; blue, N; green, Cl; black, C. Only hydrogen atoms on the stereocenters are shown. 
Table 11. Selected bond lengths $(\AA)$ and interatomic angles $\left(^{\circ}\right)$ for compounds $\mathbf{8 , 1 2}, \mathbf{1 3 a}$ and 13b.

\begin{tabular}{lllll}
\hline & \multicolumn{1}{c}{$\mathbf{8}$} & \multicolumn{1}{c}{12} & \multicolumn{1}{c}{$13 \mathrm{a}$} & \multicolumn{1}{c}{$13 \mathbf{b}$} \\
\hline $\mathrm{Fe}_{\mathrm{o}}-\mathrm{O}_{\mathrm{c}}$ & $1.971(2)-1.979(3)$ & $1.970(3)-1.971(3)$ & $1.987(4)-1.994(4)$ & $1.985(7)-1.991(7)$ \\
$\mathrm{Fe}_{\mathrm{c}}-\mathrm{O}_{\mathrm{c}}$ & $2.027(3)-2.038(3)$ & $2.022(3)-2.039(3)$ & $2.024(4)-2.036(4)$ & $2.017(7)-2.030(7)$ \\
$\mathrm{Fe}_{\mathrm{c}}-\mathrm{N}$ & $2.060(3)-2.080(3)$ & $2.055(3)-2.078(4)$ & $2.080(5)-2.089(7)$ & $2.070(9)-2.076(9)$ \\
$\mathrm{Fe}_{\mathrm{o}}-\mathrm{N}$ & $2.020(4)-2.049(3)$ & $2.016(4)-2.030(3)$ & $2.024(8)-2.038(7)$ & $2.011(9)-2.036(9)$ \\
$\mathrm{Fe}_{\mathrm{o}}-\mathrm{O}_{\mathrm{ph}}$ & $1.869(4)-1.926(3)$ & $1.853(3)-1.874(3)$ & $1.820(7)-1.824(5)$ & $1.817(9)-1.819(9)$ \\
$\mathrm{Fe}_{\mathrm{c}} \cdots \mathrm{Fe}_{\mathrm{c}}$ & $3.045(2)-3.090(3)$ & $3.046(2)-3.056(2)$ & $3.055(1)$ & $3.049(2)$ \\
$\mathrm{Fe}_{\mathrm{o}} \cdots \mathrm{Fe}_{\mathrm{o}}$ & $5.814(8)-5.943(9)$ & $5.8764(3)-5.8793(3)$ & $5.930(1)$ & $5.915(2)$ \\
$\mathrm{O}_{\mathrm{c}}-\mathrm{Fe}_{\mathrm{o}}-\mathrm{O}_{\mathrm{ph}}$ & $178.4(1)-178.9(1)$ & $178.3(1)-179.2(1)$ & $179.1(2)-180.0(2)$ & $179.1(4)-180.0(4)$ \\
$\mathrm{O}_{\mathrm{c}}-\mathrm{Fe}_{\mathrm{c}}-\mathrm{O}_{\mathrm{c}}$ & $82.2(1)-82.3(1)$ & $81.8(1)-81.9(1)$ & $82.2(2)-82.3(2)$ & $81.3(4)-82.3(3)$ \\
$\mathrm{Fe}_{\mathrm{c}}-\mathrm{O}-\mathrm{Fe}$ & $96.9(1)-97.2(1)$ & $97.7(1)-97.9(1)$ & $97.33(2)-97.6(2)$ & $97.3(3)-97.9(3)$ \\
$\mathrm{N}_{\mathrm{c}} \mathrm{Fe}_{\mathrm{o}}-\mathrm{N}$ & $116.1(2)-125.2(2)$ & $116.3(2)-124.9(1)$ & $119.27(8)-121.6(3)$ & $119.2(1)-122.0(4)$ \\
$\mathrm{Fe}_{\mathrm{o}}-\mathrm{O}_{\mathrm{ph}}-\mathrm{C}$ & $139.0(3)-153.5(3)$ & $141.6(4)-154.9(4)$ & $169.8(9)-175.1(8)$ & $174.9(1)-180.0(3)$
\end{tabular}


Table 12. Structure refinement parameters for complexes $\mathbf{8 , 1 2}, \mathbf{1 3 a}$, and $\mathbf{1 3 b}$.

\begin{tabular}{|c|c|c|c|c|}
\hline Compound & (8) & (12) & (13a) & $(13 b)$ \\
\hline Empirical formula & $\mathrm{C}_{76} \mathrm{H}_{88} \mathrm{Fe}_{8} \mathrm{~N}_{24} \mathrm{O}_{8}$ & $\mathrm{C}_{88} \mathrm{H}_{96} \mathrm{~N}_{24} \mathrm{O}_{8} \mathrm{Fe}_{8}$ & $\mathrm{C}_{76} \mathrm{H}_{76} \mathrm{Cl}_{12} \mathrm{Fe}_{8} \mathrm{~N}_{24} \mathrm{O}_{8}$ & $\mathrm{C}_{76} \mathrm{H}_{76} \mathrm{Cl}_{12} \mathrm{Fe}_{8} \mathrm{~N}_{24} \mathrm{O}_{8}$ \\
\hline Formula weight & 1912.50 & 2064.68 & 2325.83 & 2325.83 \\
\hline Temperature/K & 298 & 300 & 298 & 298 \\
\hline Crystal system & monoclinic & monoclinic & cubic & cubic \\
\hline Space group & $C 2 / c$ & $C 2 / c$ & $P 2{ }_{1} 3$ & $P 2{ }_{1} 3$ \\
\hline $\mathbf{a} / \mathbf{A}$ & 25.791(1) & $13.074(6)$ & $21.861(2)$ & 21.797(2) \\
\hline b/Å & $27.220(1)$ & $13.093(6)$ & $21.861(2)$ & 21.797(2) \\
\hline c/Å & $13.1084(6)$ & $24.262(12)$ & $21.861(2)$ & 21.797(2) \\
\hline $\boldsymbol{\alpha} /{ }^{\circ}$ & 90 & 90 & 90 & 90 \\
\hline$\beta /{ }^{\circ}$ & $105.534(1)$ & $104.686(2)$ & 90 & 90 \\
\hline$\gamma /{ }^{\circ}$ & 90 & $108.9(1)$ & 90 & 90 \\
\hline Volume $/ \AA^{3}$ & $8866.1(7)$ & 11471(1) & $10447(3)$ & $10356(2)$ \\
\hline $\mathbf{Z}$ & 4 & 4 & 4 & 4 \\
\hline$\rho_{\text {cald }} / \mathrm{gcm}^{-3}$ & 1.433 & 1.195 & 1.479 & 1.492 \\
\hline$\mu / \mathbf{m m}^{-1}$ & 1.334 & 1.036 & 1.444 & 1.456 \\
\hline Crystal size $/ \mathrm{mm}^{3}$ & $0.22 \times 0.09 \times 0.08$ & $0.75 \times 0.29 \times 0.15$ & $0.28 \times 0.25 \times 0.03$ & $0.18 \times 0.15 \times 0.07$ \\
\hline $\begin{array}{l}\text { Reflections } \\
\text { collected } / 2 \Theta \max \left({ }^{\circ}\right)\end{array}$ & $49921 / 54.26$ & $67482 / 52.94$ & $118781 / 54.64$ & $184558 / 49.40$ \\
\hline $\begin{array}{l}\text { Data/restraints/ } \\
\text { parameters }\end{array}$ & $9796 / 14 / 497$ & $11820 / 11 / 596$ & $7843 / 148 / 403$ & $5892 / 181 / 385$ \\
\hline Goodness-of-fit on $\mathbf{F}^{2}$ & 1.027 & 1.099 & 1.067 & 1.148 \\
\hline 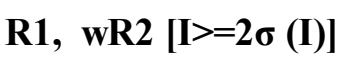 & $0.049 / 0.1465$ & $0.061 / 0.1793$ & $0.049 / 0.1260$ & $0.058 / 0.1508$ \\
\hline R1, wR2 [all data] & $0.076 / 0.1686$ & $0.091 / 0.2053$ & $0.066 / 0.1458$ & $0.077 / 0.1782$ \\
\hline Flack & - & - & $-0.006(4)$ & $-0.003(5)$ \\
\hline
\end{tabular}




\subsubsection{UV-Vis}

The UV-Vis spectra of compounds $\mathbf{8 , 1 2}$, and $\mathbf{1 3}$ display the same features as the ones with achiral phenolates discussed in Chapter II. Two LMCT bands are present for all complexes together with a band attributed to the intramolecular $\pi-\pi *$ transition of the phenolate. For 8 (Figure 49) these bands are located at 583 and 344 nm (LMCT bands), and $281 \mathrm{~nm}\left(\pi-\pi^{*}\right.$ transition) and accordingly, for 12, at 564, 349, and $281 \mathrm{~nm}$ (Figure 50), and for $\mathbf{1 3}$ at 643, 353, and $278 \mathrm{~nm}$, respectively (Figure 51).

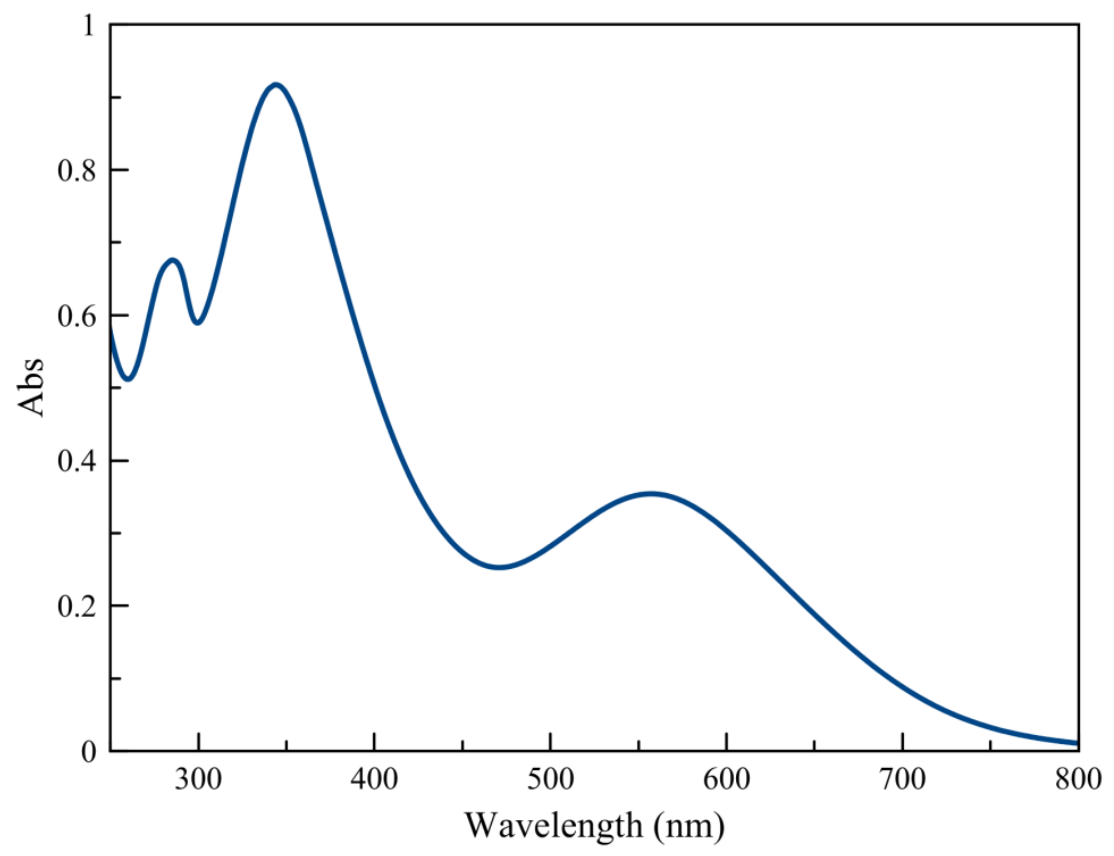

Figure 49. UV-Vis spectrum of $\left[\mathrm{Fe}_{8}\left(\mu_{4}-\mathrm{O}\right)_{4}(\mu-\mathrm{pz})_{12}\left(4-{ }^{\mathrm{s}} \mathrm{Bu}-\mathrm{C}_{6} \mathrm{H}_{4} \mathrm{O}\right)_{4}\right],(\mathbf{8})$, recorded at 295 $\mathrm{K}$ in $\mathrm{CH}_{2} \mathrm{Cl}_{2}$. 


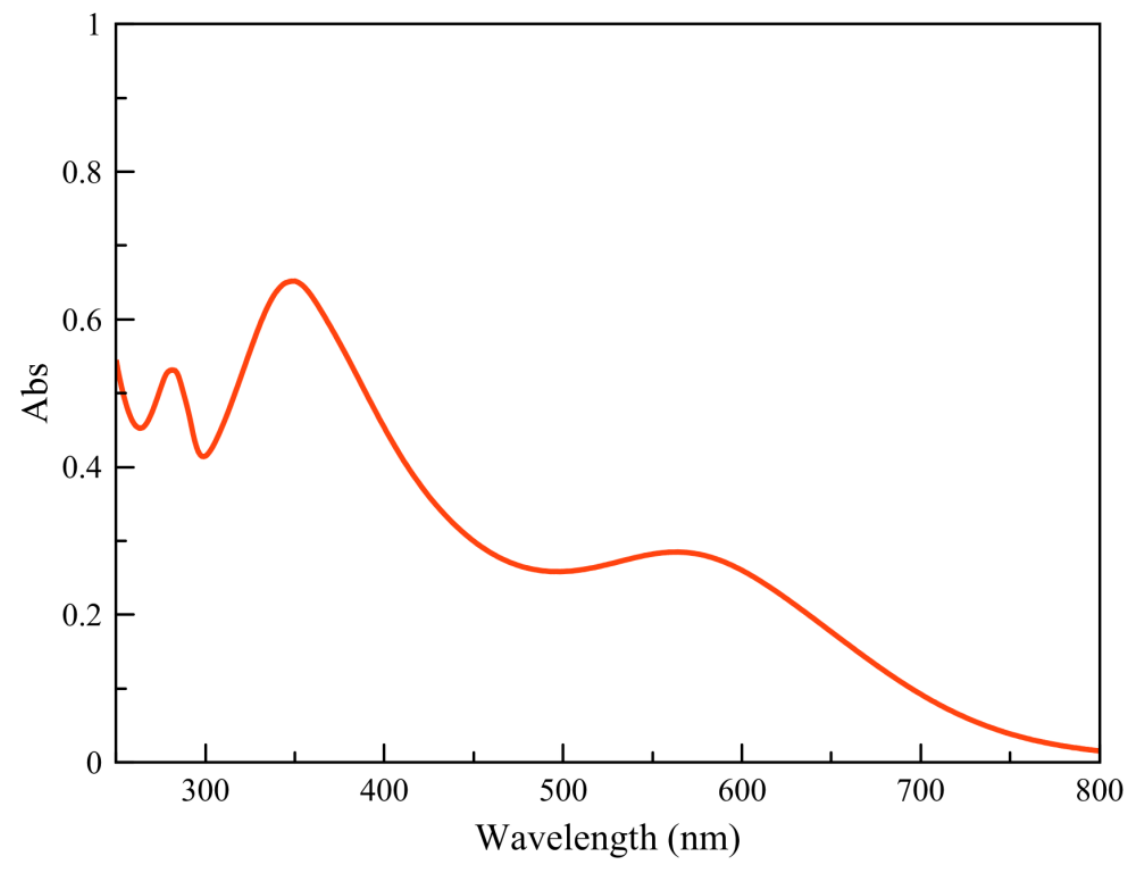

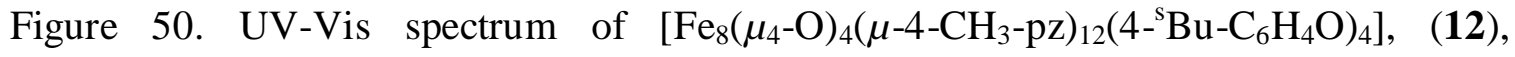
recorded at $295 \mathrm{~K}$ in $\mathrm{CH}_{2} \mathrm{Cl}_{2}$.

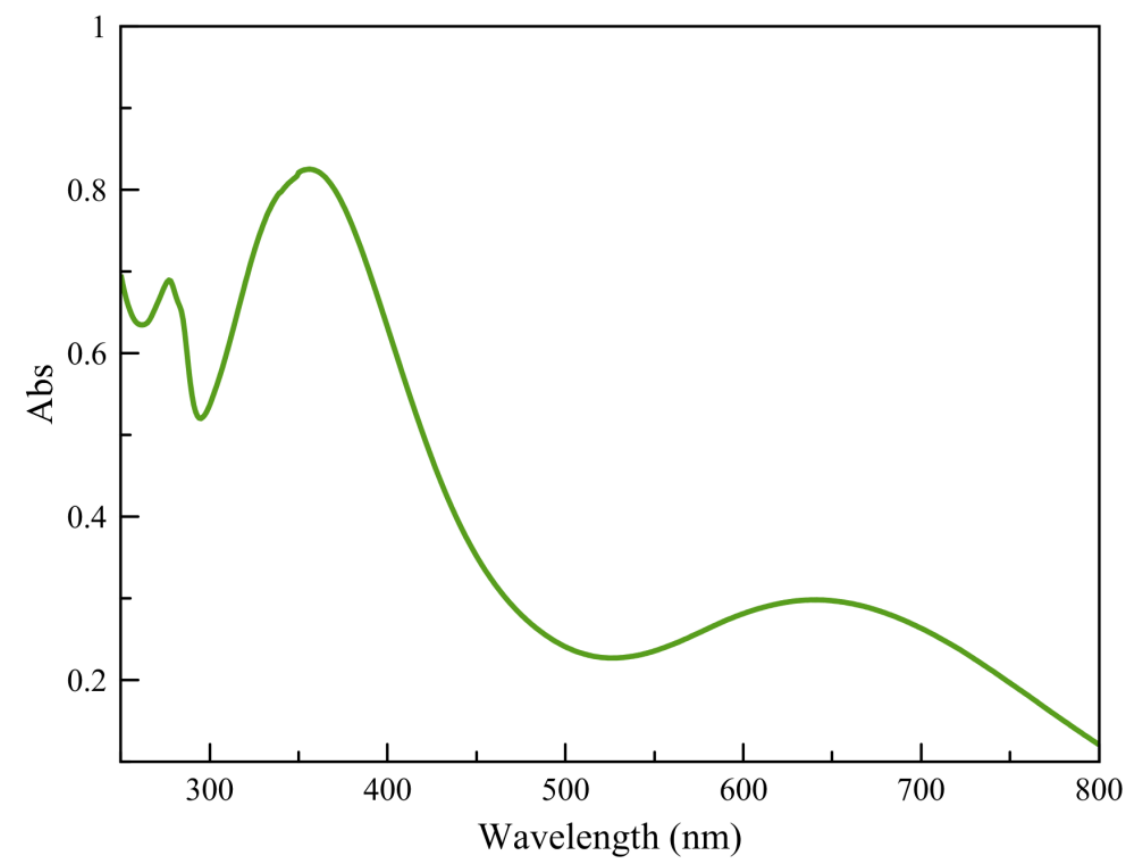

Figure 51. UV-Vis spectrum of $\left[\mathrm{Fe}_{8}\left(\mu_{4}-\mathrm{O}\right)_{4}(\mu-4-\mathrm{Cl}-\mathrm{pz})_{12}\left(4-{ }^{\mathrm{s}} \mathrm{Bu}-\mathrm{C}_{6} \mathrm{H}_{4} \mathrm{O}\right)_{4}\right],(13)$, recorded at $295 \mathrm{~K}$ in $\mathrm{CH}_{2} \mathrm{Cl}_{2}$. 


\subsection{4. ${ }^{1} \mathrm{H}-\mathrm{NMR}$}

The assignment of the ${ }^{1} \mathrm{H}-\mathrm{NMR}$ spectra of $\mathbf{8 , 1 2}$, and $\mathbf{1 3}$ was based on the methodology followed for the assignment of the compounds with achiral terminal phenolate ligands. The spectrum of $\mathbf{8}$ (Figure 52) shows one set of resonances for the twelve pyrazolate ligands. The pyrazolate protons shift downfield, compared to the parent chloroterminated compound. The chemical shifts of protons ${ }^{3} \mathrm{H},{ }^{4} \mathrm{H}$, and ${ }^{5} \mathrm{H}$ are $\delta\left({ }^{3} \mathrm{H}\right)=10.7$ ppm, $\delta\left({ }^{4} \mathrm{H}\right)=43.8 \mathrm{ppm}$, and $\delta\left({ }^{5} \mathrm{H}\right)=5.2 \mathrm{ppm}$, respectively. The -ortho protons of the phenolate ligand, ${ }^{\mathrm{a}} \mathrm{H}$, in closest distance from the $\mathrm{Fe}_{\mathrm{c}}$, appear as a broad singlet at $\delta\left({ }^{\mathrm{a}} \mathrm{H}\right)=$ $-43.7 \mathrm{ppm}$, whereas the - meta $^{\mathrm{b}} \mathrm{H}$ ones at $\delta\left({ }^{\mathrm{b}} \mathrm{H}\right)=44.0 \mathrm{ppm}$ overlapping with ${ }^{4} \mathrm{H}$.

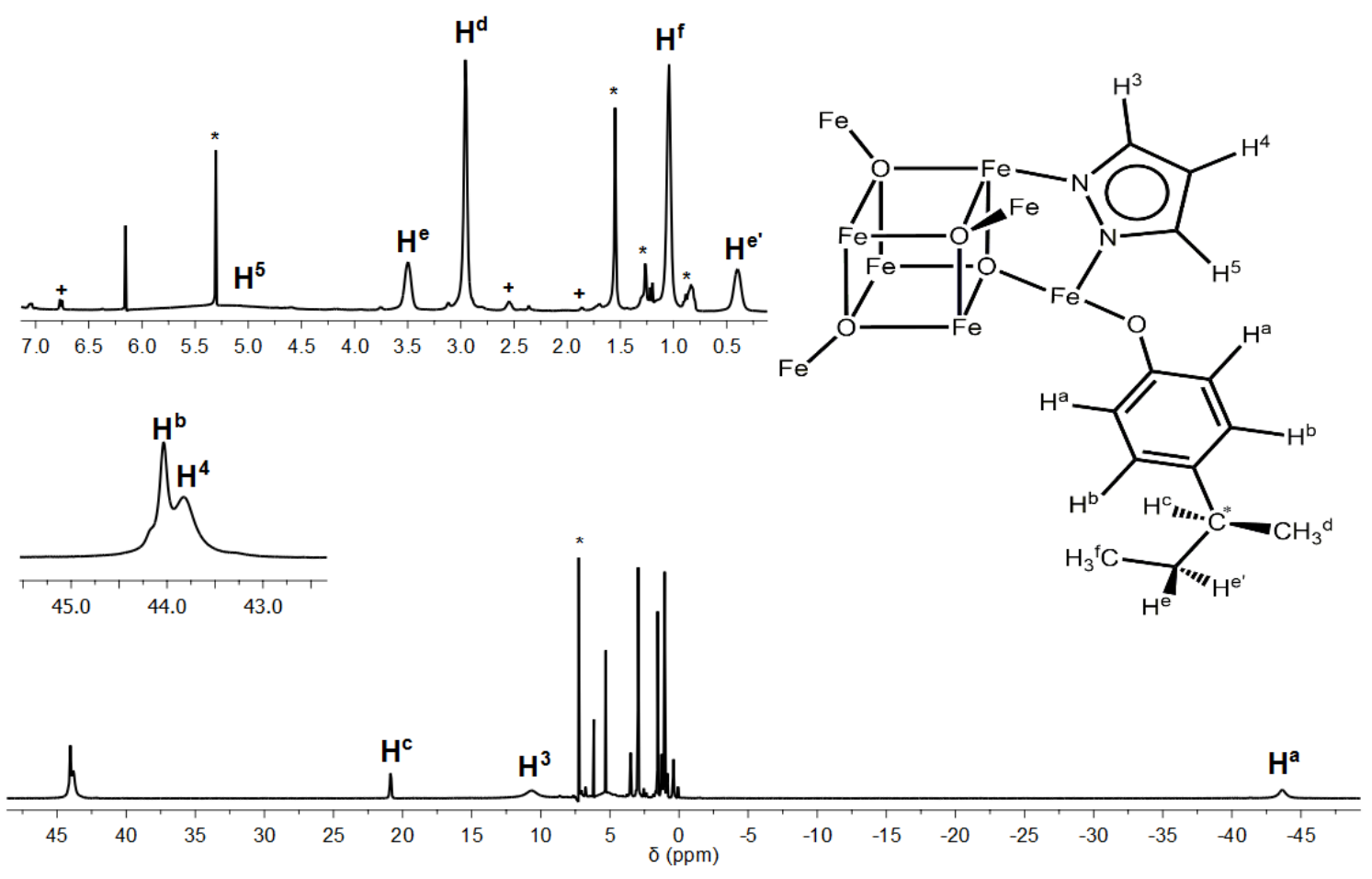

Figure 52. ${ }^{1} \mathrm{H}-\mathrm{NMR}$ spectrum of $\mathbf{8}, 400 \mathrm{MHz}, \mathrm{CDCl}_{3}$. Solvents denoted with asterisk, phenol impurities with cross. 
The chemical shift of the proton attached to the chiral carbon of the sec-butyl group is $\delta\left({ }^{\mathrm{c}} \mathrm{H}\right)=20.9 \mathrm{ppm}$. The diastereotopic ${ }^{\mathrm{e}} \mathrm{H}$ and ${ }^{\mathrm{e}}{ }^{\prime} \mathrm{H}$ give two singlets at $\delta=3.5 \mathrm{ppm}$ and $\delta=$ 0.4 ppm, and ${ }^{\mathrm{d}} \mathrm{H}$ and ${ }^{\mathrm{f}} \mathrm{H}$ two singlets at $\delta\left({ }^{\mathrm{d}} \mathrm{H}\right)=3.0$ and $\delta\left({ }^{\mathrm{f}} \mathrm{H}\right)=1.1 \mathrm{ppm}$, respectively. Assignment of the spectra of compounds 12 (Figure 53) and 13 (Figure 54) was conducted in a similar fashion. For 12 the shifts of protons ${ }^{3} \mathrm{H},{ }^{4} \mathrm{H}\left(\mathrm{CH}_{3}\right)$, and ${ }^{5} \mathrm{H}$ are $\delta\left({ }^{3} \mathrm{H}\right)=8.8 \mathrm{ppm}, \delta\left({ }^{4} \mathrm{H}\right)=24.8 \mathrm{ppm}$, and $\delta\left({ }^{5} \mathrm{H}\right)=6.9$ ppm, respectively. The - ortho protons ${ }^{\mathrm{a}} \mathrm{H}$, appear at $\delta\left({ }^{\mathrm{a}} \mathrm{H}\right)=-36.1 \mathrm{ppm}$, the - meta ${ }^{\mathrm{b}} \mathrm{H}$ at $\delta\left({ }^{\mathrm{b}} \mathrm{H}\right)=39.5 \mathrm{ppm}$, the proton on the chiral carbon ${ }^{\mathrm{c}} \mathrm{H}$ at $\delta\left({ }^{\mathrm{c}} \mathrm{H}\right)=17.6 \mathrm{ppm}$, the diastereotopic ${ }^{\mathrm{e}} \mathrm{H}$ and ${ }^{\mathrm{e}} \mathrm{H}$ at $\delta=3.3 \mathrm{ppm}$ and $\delta=0.5$ ppm, while ${ }^{\mathrm{d}} \mathrm{H}$ and ${ }^{\mathrm{f}} \mathrm{H}$ at $\delta\left({ }^{\mathrm{d}} \mathrm{H}\right)=2.7$ and $\delta\left({ }^{\mathrm{f}} \mathrm{H}\right)=1.0$ ppm, respectively.

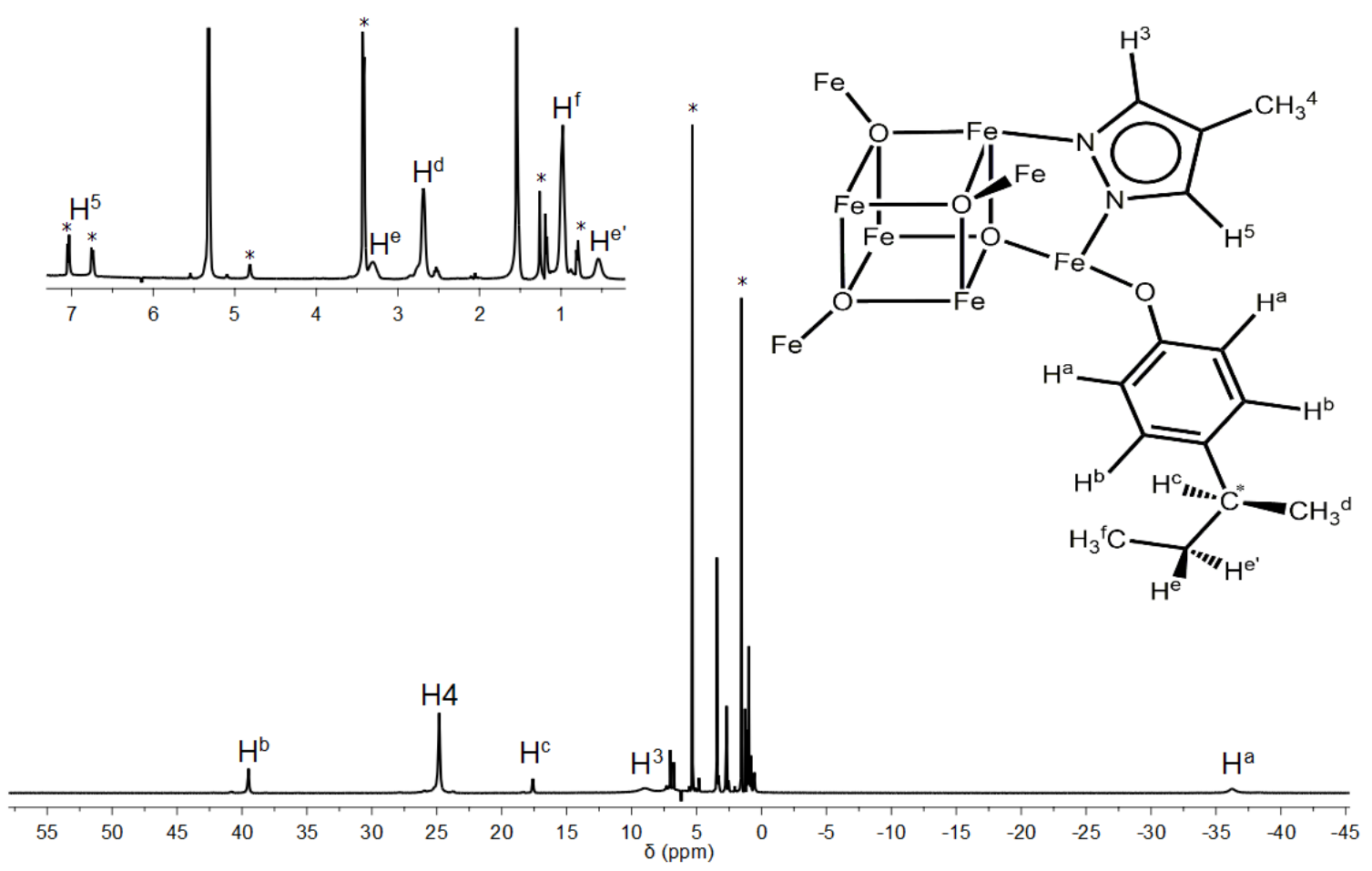

Figure 53. ${ }^{1} \mathrm{H}-\mathrm{NMR}$ spectrum of $\mathbf{1 2}, 400 \mathrm{MHz}, \mathrm{CD}_{2} \mathrm{Cl}_{2}$. Solvents denoted with asterisk. 
Accordingly for 13 , protons ${ }^{3} \mathrm{H}$ and ${ }^{5} \mathrm{H}$ shift at $\delta\left({ }^{3} \mathrm{H}\right)=15.8 \mathrm{ppm}$ and $\delta\left({ }^{5} \mathrm{H}\right)=10.9 \mathrm{ppm}$, respectively. The -ortho protons ${ }^{\mathrm{a}} \mathrm{H}$, appear at $\delta\left({ }^{\mathrm{a}} \mathrm{H}\right)=-58.1 \mathrm{ppm}$, the - meta ${ }^{\mathrm{b}} \mathrm{H}$ at $\delta\left({ }^{\mathrm{b}} \mathrm{H}\right)=$ $51.5 \mathrm{ppm}$, the proton on the chiral carbon ${ }^{\mathrm{c}} \mathrm{H}$ at $\delta\left({ }^{\mathrm{c}} \mathrm{H}\right)=26.8 \mathrm{ppm}$, the diastereotopic ${ }^{\mathrm{e}} \mathrm{H}$ and ${ }^{\mathrm{e}^{\prime}} \mathrm{H}$ at $\delta=4.2$ ppm and $\delta=0.04$ ppm, while ${ }^{\mathrm{d}} \mathrm{H}$ and ${ }^{\mathrm{f}} \mathrm{H}$ at $\delta\left({ }^{\mathrm{d}} \mathrm{H}\right)=3.7$ and $\delta\left({ }^{\mathrm{f}} \mathrm{H}\right)=1.1$ ppm. A summary of the chemical shifts of protons for compounds $\mathbf{8}, \mathbf{1 2}$, and $\mathbf{1 3}$ is given in Table 13.

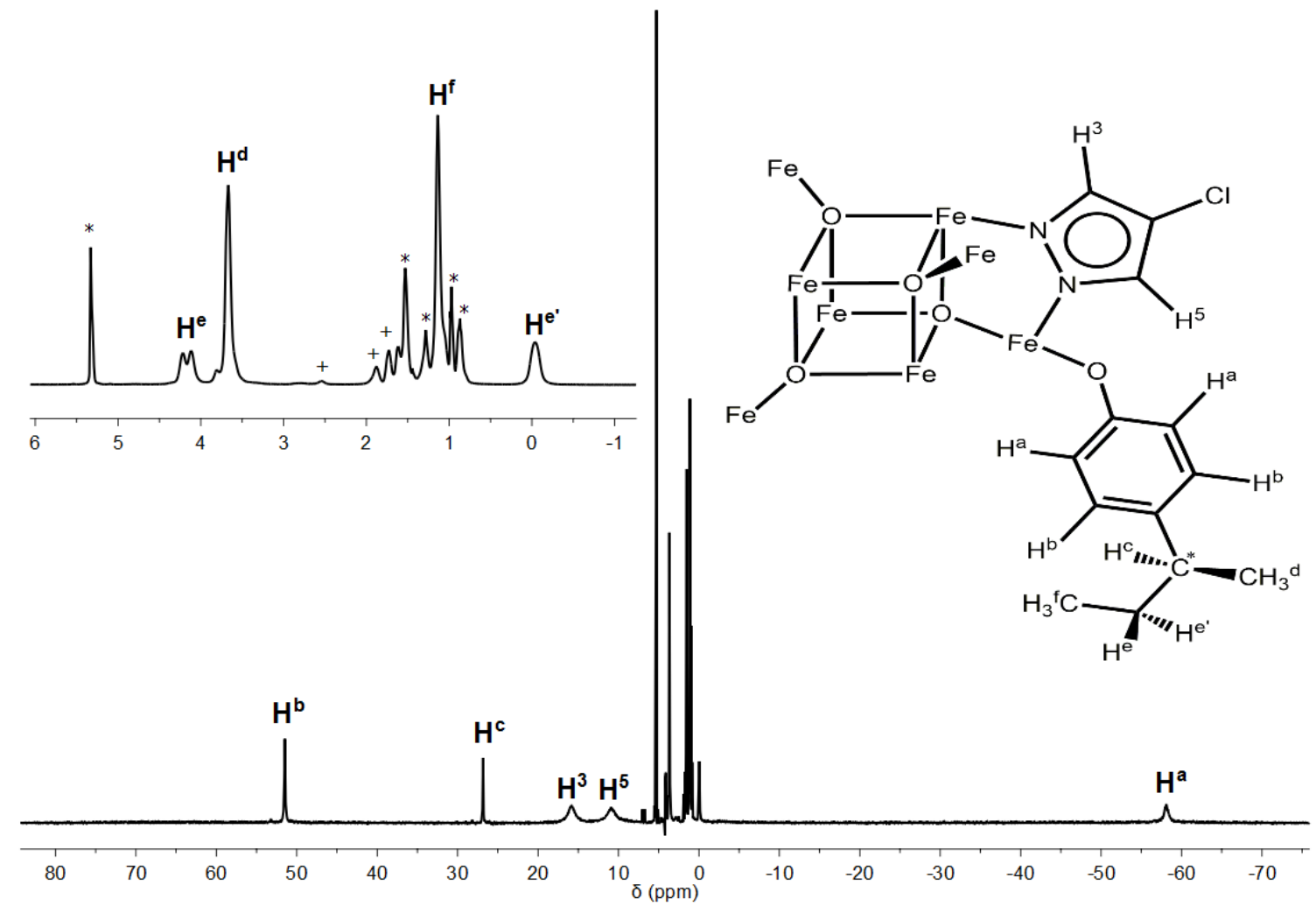

Figure 54. ${ }^{1} \mathrm{H}-\mathrm{NMR}$ spectrum of $13,400 \mathrm{MHz}, \mathrm{CDCl}_{3}$. Solvents denoted with asterisk, phenol impurities with cross. 
Table 13. Chemical shifts $\delta$ (ppm) for compounds 8,12 and $\mathbf{1 3}$.

\begin{tabular}{ccccccccccc}
\hline Comp & ${ }^{3} \mathrm{H}$ & ${ }^{4} \mathrm{H}$ & ${ }^{5} \mathrm{H}$ & ${ }^{\mathrm{a}} \mathrm{H}$ & ${ }^{\mathrm{b}} \mathrm{H}$ & ${ }^{\mathrm{c}} \mathrm{H}$ & ${ }^{\mathrm{d}} \mathrm{H}$ & ${ }^{\mathrm{e}} \mathrm{H}$ & ${ }^{\mathrm{e}} \mathrm{H}$ & ${ }^{\mathrm{f}} \mathrm{H}$ \\
\hline $\mathbf{8}$ & 10.7 & 43.8 & 5.2 & -43.7 & 44.0 & 20.9 & 3.0 & 3.5 & 0.4 & 1.1 \\
$\mathbf{1 2}$ & 8.8 & 24.9 & 6.9 & -36.1 & 39.5 & 17.6 & 2.7 & 3.3 & 0.5 & 1.0 \\
$\mathbf{1 3}$ & 15.8 & - & 10.9 & -58.1 & 51.5 & 26.8 & 3.7 & 4.2 & 1.1 & 0.04
\end{tabular}

\subsubsection{Circular Dichroism}

The resolution was performed by circular dichroism spectroscopy on the single crystals of the compounds that crystallized in non-centrosymmetric space groups, 13a and $\mathbf{1 3 b}$. $\mathrm{CD}$ experiments conducted on solutions of single crystals exhibit two mirror image spectra, confirming their enantiomeric relationship (Figure 55). The CD spectrum of the $\boldsymbol{M}(S)$ diastereomer, $\mathbf{1 3 b}$, displays positive Cotton effect with three maxima/minima at $\lambda_{\max }=326,380$, and $462 \mathrm{~nm}$, assigned to LMCT bands of the complex, and a $\lambda_{\max }$ at 270 $\mathrm{nm}$ assigned to the intramolecular $\pi-\pi *$ transition of the phenolate ligands. Accordingly, the $\boldsymbol{P}(R)$ isomer, 13a, displays negative Cotton effect, being a mirror image of that of the $\boldsymbol{M}(S)$. A comparison between the CD and the UV-Vis spectrum of $\mathbf{1 3}$ reveals that the UV-Vis band at $643 \mathrm{~nm}$, attributed to the phenolate-to-iron charge transfer, does not give rise to a $\mathrm{CD}$ signal, as the electric transition dipole of the O-to-Fe transition lies in the mirror plane relating the $P$ and $M$ enantiomeric forms. 


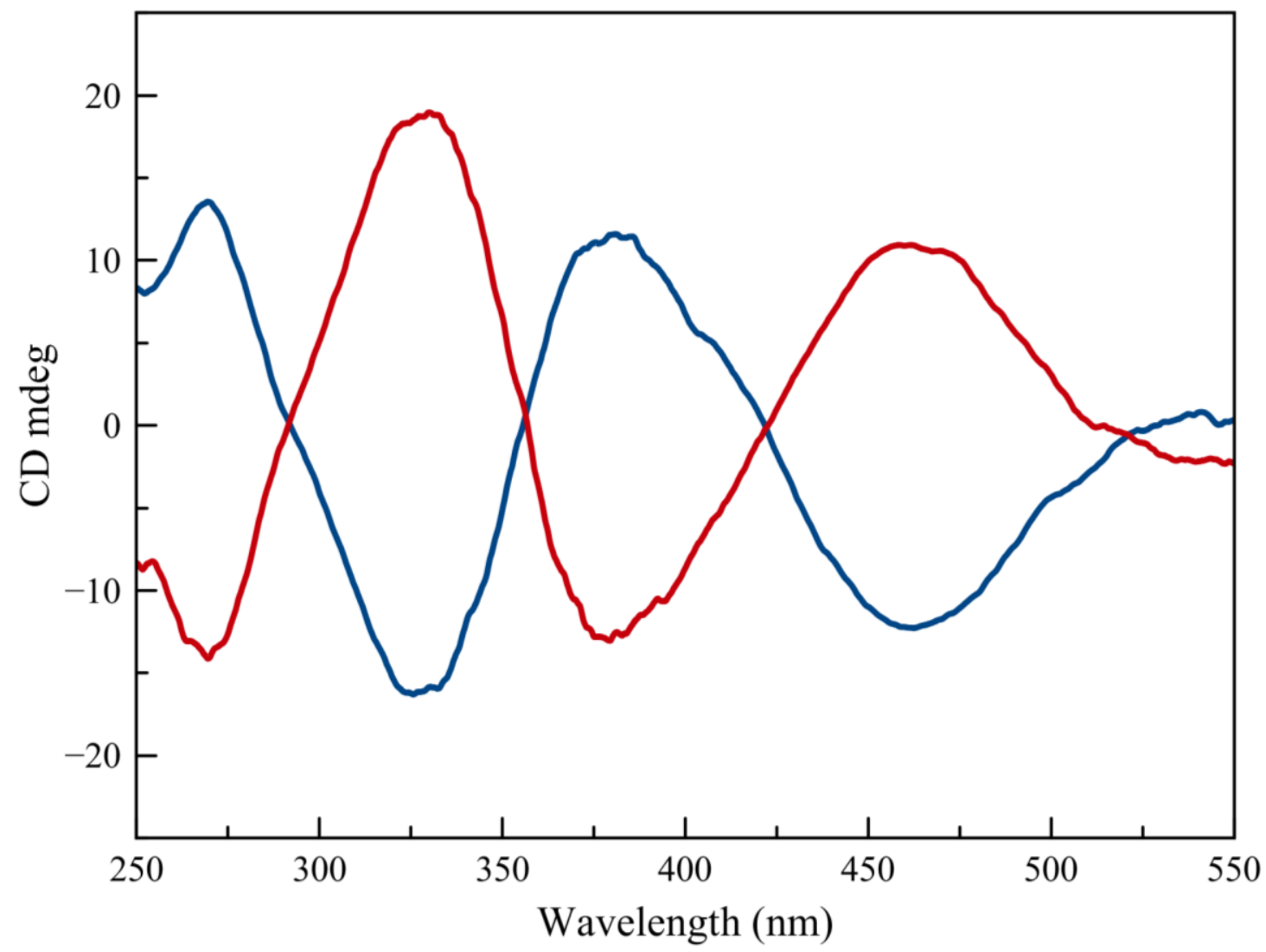

Figure 55. CD spectra of $\boldsymbol{M}(S)$ (red) and $\boldsymbol{P}(R)$ (blue) diastereomers of $\left[\mathrm{Fe}_{8}\left(\mu_{4}-\mathrm{O}\right)_{4}(\mu-4-\right.$ $\left.\mathrm{Cl}-\mathrm{pz})_{12}\left(4-{ }^{\mathrm{s}} \mathrm{Bu}-\mathrm{C}_{6} \mathrm{H}_{4} \mathrm{O}\right)_{4}\right]\left(\mathbf{1 3 b}\right.$ and 13a) in $\mathrm{CH}_{2} \mathrm{Cl}_{2}$ at $295 \mathrm{~K}$.

The CD spectra of the above solutions were recorded again after a period of a month; No changes were observed, indicating that no racemization takes place. Furthermore, the CD spectra were recorded again after addition of an excess of a $0.06 \mathrm{M}$ solution of $\mathrm{HCl}$ to substitute the phenolates and reintroduce the terminal chloride ligands (Figure 56), showing that the parent compound, $\left[\mathrm{Fe}_{8}\left(\mu_{4}-\mathrm{O}\right)_{4}(\mu-4-\mathrm{Cl}-\mathrm{pz})_{12} \mathrm{Cl}_{4}\right]$ (11), is also configurationally stable. The $\boldsymbol{M}$ and $\boldsymbol{P}$ enantiomers display positive and negative Cotton effects, respectively, with $\lambda_{\max }$ at 327,362 , and $476 \mathrm{~nm}$, while the opposite bands at 289 $\mathrm{nm}$ are attributed to free $S$ - and $R$-phenol. 


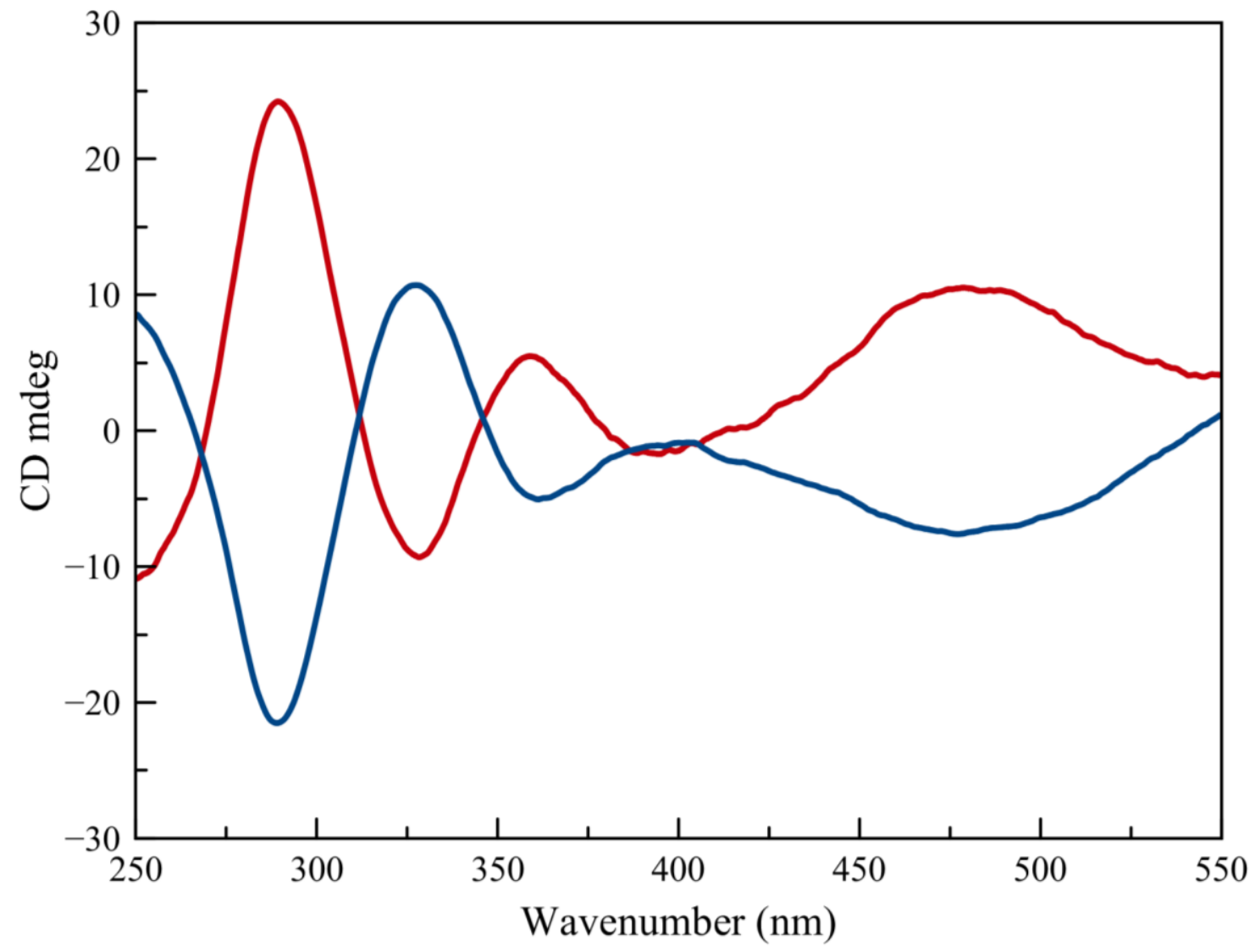

Figure 56. CD spectra of $\boldsymbol{M}$ (red) and $\boldsymbol{P}$ (blue) enantiomers of $\left[\mathrm{Fe}_{8}\left(\mu_{4}-\mathrm{O}\right)_{4}(\mu-4-\mathrm{Cl}-\right.$ pz) $\left.{ }_{12} \mathrm{Cl}_{4}\right]$, (11), in $\mathrm{CH}_{2} \mathrm{Cl}_{2}$ at $295 \mathrm{~K}$.

To confirm the presence of only the $\left[\mathrm{Fe}_{8}\left(\mu_{4}-\mathrm{O}\right)_{4}(\mu-4-\mathrm{Cl}-\mathrm{pz})_{12} \mathrm{Cl}_{4}\right]$ and free phenol, the UV-Vis spectrum of the above solution (Figure 57) was recorded and compared to the UV-Vis of $\left[\mathrm{Fe}_{8}\left(\mu_{4}-\mathrm{O}\right)_{4}(\mu-4-\mathrm{Cl}-\mathrm{pz})_{12} \mathrm{Cl}_{4}\right]$ (Figure 58) and of 4-sec-butylphenol. Figure 57 shows that the spectrum after the addition of $\mathrm{HCl}$ matches the one of pure $\left[\mathrm{Fe}_{8}\left(\mu_{4}-\mathrm{O}\right)_{4}(\mu-\right.$ 4-Cl-pz ${ }_{12} \mathrm{Cl}_{4}$ ] plus two features at 284 and $277 \mathrm{~nm}$. Subtraction of the two spectra gives rise to the one shown in Figure 59 which is an exact match to the free 4-sec-butylphenol spectrum. 


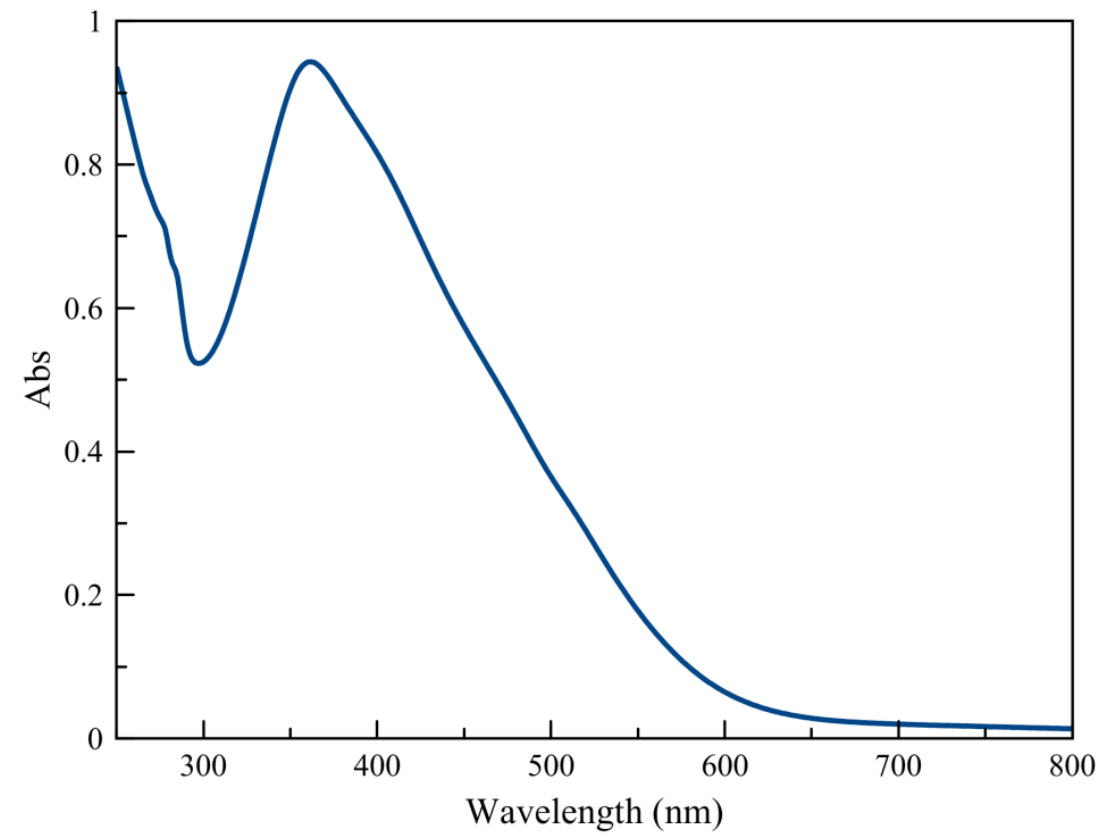

Figure 57. UV-vis spectrum of a solution of 13 after addition of $\mathrm{HCl} 0.06 \mathrm{M}$ recorded at $295 \mathrm{~K}$ in $\mathrm{CH}_{2} \mathrm{Cl}_{2}$.

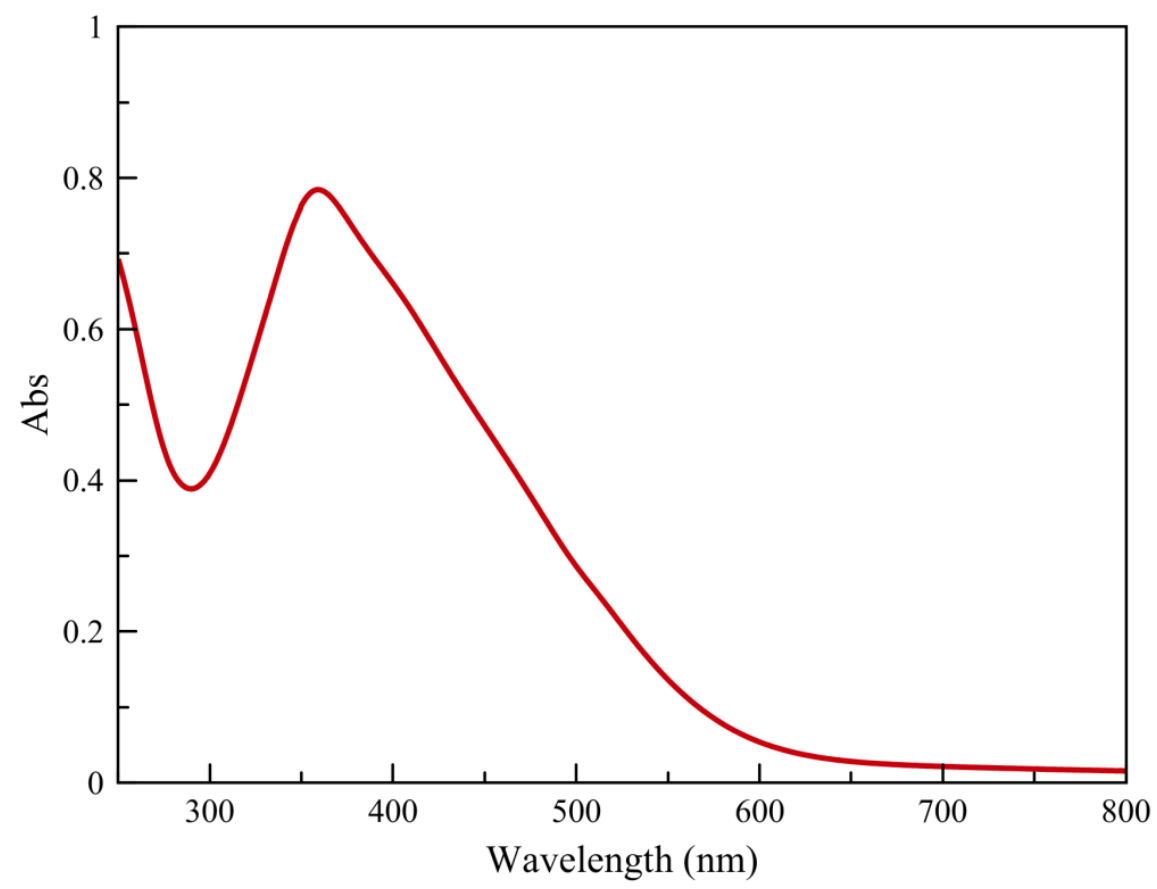

Figure 58. UV-vis spectrum of $\left[\mathrm{Fe}_{8}\left(\mu_{4}-\mathrm{O}\right)_{4}(\mu-4-\mathrm{Cl}-\mathrm{pz})_{12} \mathrm{Cl}_{4}\right](\mathbf{1 1})$, recorded at $295 \mathrm{~K}$ in $\mathrm{CH}_{2} \mathrm{Cl}_{2}$. 


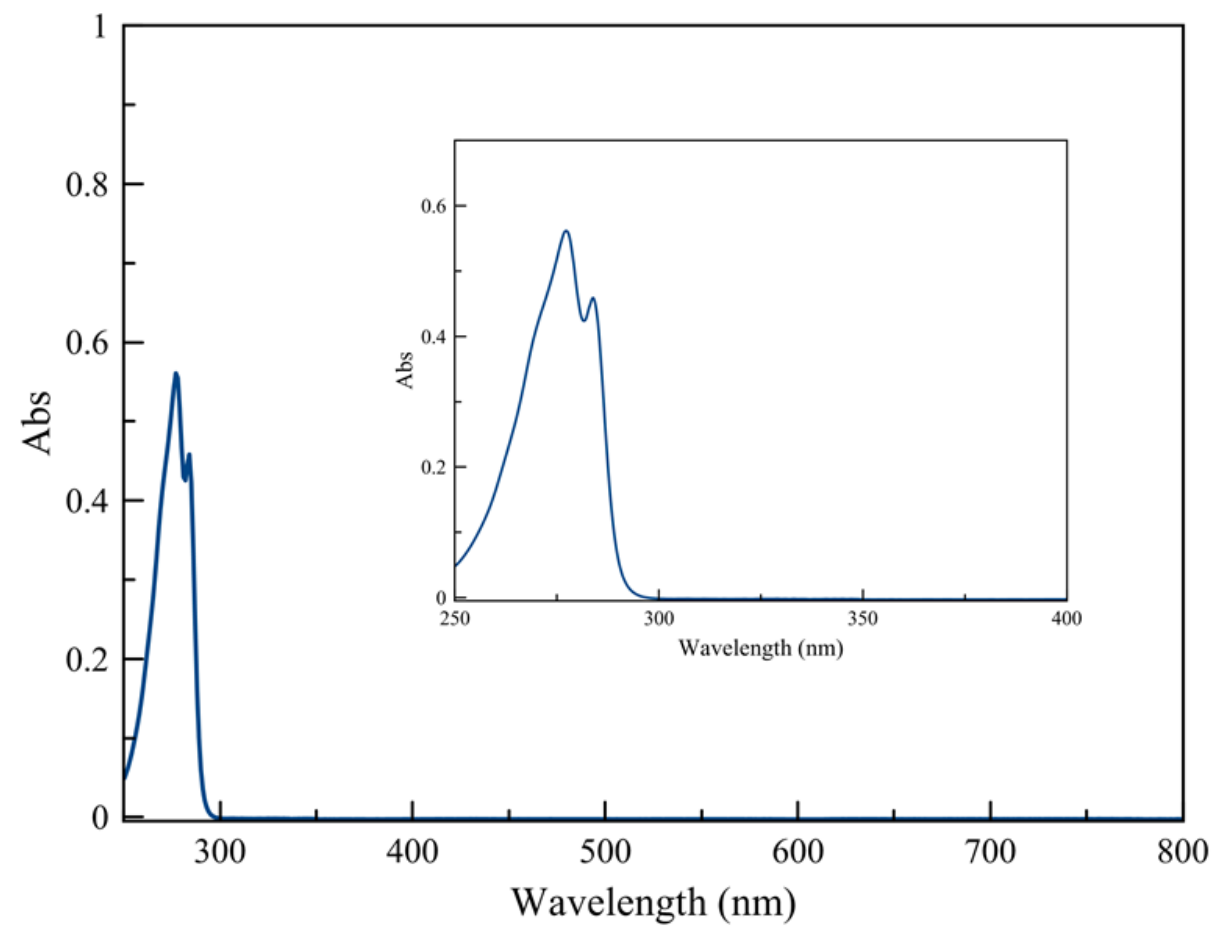

Figure 59. Subtraction of the UV-Vis spectra depicted on Figure 56 and Figure 57. The resulting graph matches the $\mathrm{UV}-\mathrm{Vis}$ spectrum of $4-{ }^{\mathrm{s}} \mathrm{Bu}-\mathrm{C}_{6} \mathrm{H}_{4} \mathrm{OH}$ recorded in $\mathrm{CH}_{2} \mathrm{Cl}_{2}$.

\subsection{Conclusions}

In summary, the racemic $(P, M)$ chloro-terminated cluster, $\left[\mathrm{Fe}_{8}\left(\mu_{4}-\mathrm{O}\right)_{4}(\mu-4-\mathrm{Cl}-\mathrm{pz})_{12} \mathrm{Cl}_{4}\right]$, prepared from $\mathrm{FeCl}_{3}$ and 4-Cl-pz, was converted to its 4-sec-butylphenolate derivative, rac- $\left[\mathrm{Fe}_{8}\left(\mu_{4}-\mathrm{O}\right)_{4}(\mu-4-\mathrm{Cl}-\mathrm{pz})_{12}\left(4-{ }^{\mathrm{s}} \mathrm{Bu}-\mathrm{C}_{6} \mathrm{H}_{4} \mathrm{O}\right)_{4}\right]$, via a metathetical reaction with also racemic $(R, S)$ 4-sec-butylphenol. The racemic octanuclear complex consists of the $P / R$ and $M / S$ enantiomers, which were resolved spontaneously upon crystallization. The choice of 4-R-pz ligand is critical; cluster-ligand recognition takes place for both pyrazolates studied here, however spontaneous resolution occurs only with the 4-Cl derivative. 


\subsection{Experimental section}

\subsubsection{Materials}

See section 2.3.1

\subsubsection{Instrumentation}

UV-Vis, IR, and ${ }^{1} \mathrm{H}-\mathrm{NMR}$ spectra were obtained with a Cary 50000 Series UV-Vis-NIR spectrophotometer, an Agilent 600 Series FTIR, and a Bruker AVANCE $400 \mathrm{MHz}$ spectrometer, respectively. Circular Dichroism spectra were recorded on a JASCO J-815 CD spectropolarimeter (1 nm bandwidth, scanning speed $200 \mathrm{~nm} / \mathrm{min}, 2 \mathrm{~mm}$ path length). Elemental analyses were performed by Galbraith Laboratories, Inc.

\subsubsection{X-ray Crystallography}

X-ray diffraction data from crystals 8, 12, 13a and 13b mounted atop glass fibers, collected on a Bruker D8 Quest diffractometer equipped with PHOTON 100 detector, operating at $\mathrm{T}=298 \mathrm{~K}$. Data were collected with shutterless $\omega$ scan technique using graphite monochromated Mo-K $\alpha$ radiation $(\lambda=0.71073 \AA)$. The total number of runs and images for data collection was based on strategy calculation from the program APEX3. ${ }^{129}$ Resolution of $\theta \geq 25^{\circ}$ was achieved. Cell parameters were retrieved using the SAINT software and refined using SAINT on 9796 independent reflections for $\mathbf{8}, 11820$ for $\mathbf{1 2}$, 7843 for $\mathbf{1 3 a}$, and 5892 for $\mathbf{1 3 b}$. $^{130}$ Data reduction was performed using the SAINT software, which corrects for Lorentz and polarization effects. The final completeness is 99.7\% for $\mathbf{1 2}, 99.8 \%$ for $\mathbf{8}$ and 13a, and $99.9 \%$ for $\mathbf{1 3 b}$. Multi-scan absorption corrections were performed on all data sets using $S A D A B S$ 2016/2. ${ }^{131}$ The minimum and maximum transmissions for $\mathbf{8}$ are 0.753 and 0.898 , for $\mathbf{1 2}$ are 0.704 and 0.853 , for $\mathbf{1 3 a}$ are 0.589 and 
0.746, and for $\mathbf{1 3 b}$ are 0.668 and 0.745 . The structures for complexes $\mathbf{1 3 a}$ and $\mathbf{1 3 b}$ were solved in a chiral space group $P 2{ }_{1} 3$ (No. 198) and in case of complexes $\mathbf{8}$ and $\mathbf{1 2}$ in $C 2 / c$ (No. 15) by intrinsic phasing using the ShelXT ${ }^{132}$ structure solution program and refined by full matrix least square procedure on $\mathrm{F}^{2}$ using version $2016 / 6$ of ShelXL. ${ }^{133}$ The nonhydrogen atoms were refined anisotropically in all cases. Hydrogen atom positions were calculated geometrically and refined using the riding model. To alleviate the complications related to solvent accessible voids within the extended lattice in all cases, SQUEEZE operation (included in the PLATON program) was performed with the raw data set and the structure was refined form the data obtained upon SQUEEZE operation. $^{134}$

The relatively large thermal ellipsoids (associated with large thermal motion) of certain $\mathrm{C}$ atoms of the sec-butyl groups are restrained with Enhanced Rigid Bond Restrain. The application of this restrain enabled to achieve similar displacement parameters $\left(\mathrm{U}_{\mathrm{ij}}\right)$ to emulate rigid body motion. In few cases two adjacent atoms were also constrained to have equivalent atomic displacement parameters. In case of 13a and 13b, one of the phenyl groups resides on a 3-fold axis and found to be severely disordered. This phenyl ring resides in three symmetry equivalent positions. Initially six $\mathrm{C}$ atoms of this phenyl ring are located from the difference map and appropriate AFIX constraint was applied to fit these atoms to a regular hexagon with default C-C distance of $1.39 \AA$. In case of $\mathbf{1 3 a}$ and 13b the site occupancy factor (sof) are refined in slightly different ways. In case of 13b, the pivotal $\mathrm{C}$ atoms of this phenyl ring $(\mathrm{C} 23)$ are found to be on the same axis as the $\mathrm{Fe} 4$ and $\mathrm{O} 4$ atoms $\left(\mathrm{C} 23-\mathrm{O} 4-\mathrm{Fe} 4\right.$ angle is $\left.180^{\circ}\right)$. This $\mathrm{C}$ atom $(\mathrm{C} 23)$ is on a special 
position and refined with a sof of 0.166 and is shared by three symmetry equivalent phenyl rings. The other $\mathrm{C}$ atoms ( $\mathrm{C} 24$ to $\mathrm{C} 28$ ) of this constrained phenyl ring was refined with sof of 0.333. However, in case of 13a, the pivotal C atom (C23) is not on the same axis as $\mathrm{O} 4$ and $\mathrm{Fe} 4\left(\mathrm{C} 23-\mathrm{O} 4-\mathrm{Fe} 4\right.$ angle is $\left.169.84^{\circ}\right)$. Thus, in this case all the six $\mathrm{C}$ atoms of the constrained phenyl ring (C23-C28) are refined with sof of 0.333 . In both cases the pivotal $\mathrm{C}$ atoms ( $\mathrm{C} 23$ which is bonded to the $\mathrm{O} 4$ atom) has been located unambiguously from the difference map and has not been constrained or restrained with the $\mathrm{O} 4$ atom. PART -1 was applied to $\mathrm{C} 23$ to $\mathrm{C} 28$, to avert the symmetry equivalent atoms to bind to one another. PART -1 has also been applied on the $\mathrm{C}$ atoms of the sec-butyl fragment connected with this phenyl ring for the same reason. Appropriate restrain has also been applied as to impart $\mathrm{U}_{\mathrm{ij}}$ values of the $\mathrm{C}$ atoms of this phenyl rings (C23-C28) to refine as approximately isotropic with the standard uncertainty. Few distances between the two bonded C atoms of the sec-butyl fragment have been restrained with DFIX command to possess reasonable bond distance with standard uncertainty. All calculations and molecular graphics were preformed using either SHELXTL 2016 or Olex2 programs. ${ }^{135}$ 


\subsubsection{Synthesis}

$\left[\mathrm{Fe}_{8}\left(\mu_{4}-\mathrm{O}\right)_{4}\left(\mu-4-\mathrm{CH}_{3}-\mathrm{pz}\right)_{12} \mathrm{Cl}_{4}\right](10)$ and $\left[\mathrm{Fe}_{8}\left(\mu_{4}-\mathrm{O}\right)_{4}(\mu-4-\mathrm{Cl}-\mathrm{pz})_{12} \mathrm{Cl}_{4}\right](11)$ were prepared by a literature method. ${ }^{106}$

$\left[\mathrm{Fe}_{\mathbf{8}}\left(\boldsymbol{\mu}_{\mathbf{4}}-\mathbf{O}\right)_{\mathbf{4}}(\boldsymbol{\mu}-\mathbf{p z})_{\mathbf{1 2}}\left(\mathbf{4}^{\mathrm{s}}{ }^{\mathrm{B}} \mathbf{B u}-\mathbf{C}_{\mathbf{6}} \mathbf{H}_{\mathbf{4}} \mathrm{O}\right)_{\mathbf{4}}\right] \quad(\mathbf{8}) .0 .086 \mathrm{~g} \quad(0.059 \mathrm{mmol})$ of $\quad\left[\mathrm{Fe}_{8}\left(\mu_{4}-\mathrm{O}\right)_{4}(\mu-\right.$ pz) ${ }_{12} \mathrm{Cl}_{4}$ ], were dissolved in $10 \mathrm{~mL} \mathrm{CH}_{2} \mathrm{Cl}_{2}$ forming a dark red solution in which $0.177 \mathrm{~g}$, $(1.18 \mathrm{mmol})$ of rac-4-sec-butylphenol, and $168 \mu \mathrm{L}(1.18 \mathrm{mmol})$ of $\mathrm{Et}_{3} \mathrm{~N}(0.044 \mathrm{~g}, 0.44$ mmol) were added resulting in a color change from dark red to dark blue. The solution was stirred for $3 \mathrm{~h}$, filtered and layered with hexane. X-ray quality crystals as blue needles were obtained by slow evaporation of the $\mathrm{CH}_{2} \mathrm{Cl}_{2} /$ hexane solution. (Yield: $71 \mathrm{mg}$;

$67.7 \%)$ Anal. Calc. for $\left[\mathrm{Fe}_{8}\left(\mu_{4}-\mathrm{O}\right)_{4}(\mu-\mathrm{pz})_{12}\left(4-{ }^{\mathrm{s}} \mathrm{Bu}-\mathrm{C}_{6} \mathrm{H}_{4} \mathrm{O}\right)_{4}\right] \cdot 0.5 \mathrm{CH}_{2} \mathrm{Cl}_{2}$ $\left(\mathrm{C}_{77} \mathrm{H}_{89} \mathrm{ClFe}_{8} \mathrm{~N}_{24} \mathrm{O}_{8}\right): \mathrm{C}, 47.16 ; \mathrm{H}, 4.57 ; \mathrm{N}, 17.14$. Found: $\mathrm{C}, 47.13 ; \mathrm{H}, 4.58 ; \mathrm{N}, 17.09$. FTIR (CsI disk, $\mathrm{cm}^{-1}$ ): 2961(w), 2926(m), 2872(m), 1598(w), 1499(s), 1417(m), 1365(s), 1271(vs), 1170(s), 1147(w), 1046(vs), 962(w), 876(m), 832(m), 762(s), 720(w), 618(m), 551(w), 482(vs, br $\left.\mathrm{Fe}_{\mathrm{c}}-\mathrm{O}\right), 346(\mathrm{~m}), 304(\mathrm{~m})$. UV-Vis $\left(\mathrm{CH}_{2} \mathrm{Cl}_{2}, \mathrm{~nm}\right): 281,344$ and 583. ${ }^{1} \mathrm{H}-\mathrm{NMR}\left(\mathrm{CDCl}_{3}, 400 \mathrm{MHz}, \mathrm{ppm},\right): 10.7$ (s, $\left.12 \mathrm{H},{ }^{3} \mathrm{H}\right), 5.2\left(\mathrm{~s}, 12 \mathrm{H},{ }^{5} \mathrm{H}\right), 43.8(\mathrm{~s}, 12 \mathrm{H}$, $\left.{ }^{4} \mathrm{H}\right),-43.7\left(\mathrm{~s}, 8 \mathrm{H},{ }^{\mathrm{a}} \mathrm{H}\right), 44.0\left(\mathrm{~s}, 8 \mathrm{H},{ }^{\mathrm{b}} \mathrm{H}\right), 20.9\left(\mathrm{~s}, 4 \mathrm{H},{ }^{\mathrm{c}} \mathrm{H}\right), 3.0\left(\mathrm{~s}, 12 \mathrm{H},{ }^{\mathrm{d}} \mathrm{H}\right), 3.5(\mathrm{~s}, 4 \mathrm{H}$, $\left.{ }^{\mathrm{e}} \mathrm{H}\right), 0.4\left(\mathrm{~s}, 4 \mathrm{H},{ }^{\mathrm{e}} \mathrm{H}\right), 1.1\left(\mathrm{~s}, 12 \mathrm{H},{ }^{\mathrm{f}} \mathrm{H}\right)$. 
$\left[\mathrm{Fe}_{8}\left(\mu_{4}-\mathrm{O}\right)_{4}\left(\mu-4-\mathrm{CH}_{3}-\mathrm{pz}\right)_{12}\left(4-{ }^{\mathrm{s}} \mathrm{Bu}-\mathrm{C}_{6} \mathrm{H}_{4} \mathrm{O}\right)_{4}\right]$ (12). Compound 12 was synthesized in a similar fashion to 8. (Yield: $20 \%)$ Anal. Calc. for $\mathrm{Fe}_{8}\left(\mu \mu_{4}-\mathrm{O}\right)_{4}\left(\mu-4-\mathrm{CH}_{3}-\mathrm{pz}\right)_{12}\left(4{ }^{\mathrm{s}} \mathrm{Bu}-\right.$ $\left.\mathrm{C}_{6} \mathrm{H}_{4} \mathrm{O}\right)_{4} \cdot \mathrm{C}_{6} \mathrm{H}_{14}\left(\mathrm{C}_{88} \mathrm{H}_{112} \mathrm{Fe}_{8} \mathrm{~N}_{24} \mathrm{O}_{8}\right): \mathrm{C}, 50.80 ; \mathrm{H}, 5.43 ; \mathrm{N}, 16.16$. Found: C, 51.06; H, 5.46; N, 16.09\%. FTIR (CsI disk, $\left.\mathrm{cm}^{-1}\right)$ : 2959(m), 2927(m), 2872(m), 1499(s), 1457(w), 1387(m), 1357(m), 1313(s), 1286(s), 1166(s), 1056(vs), 1009(m), 873(w), 843(m), 718(w), 673(m), 619(m), 551(w), 482(vs, br Fe $\left.\mathrm{c}^{-} \mathrm{O}\right)$, 381(w), 328(m), 280(w). UV-Vis $\left(\mathrm{CH}_{2} \mathrm{Cl}_{2}, \mathrm{~nm}\right): 281,349$ and 564. ${ }^{1} \mathrm{H}-\mathrm{NMR}\left(\mathrm{CD}_{2} \mathrm{Cl}_{2}, 400 \mathrm{MHz}, \mathrm{ppm},\right): 8.8\left(\mathrm{~s}, 12 \mathrm{H},{ }^{3} \mathrm{H}\right)$, $24.9\left(\mathrm{~s}, 12 \mathrm{H},{ }^{4} \mathrm{H}\right), 6.9\left(\mathrm{~s}, 12 \mathrm{H},{ }^{5} \mathrm{H}\right),-36.1\left(\mathrm{~s}, 8 \mathrm{H},{ }^{\mathrm{a}} \mathrm{H}\right), 39.5\left(\mathrm{~s}, 8 \mathrm{H},{ }^{\mathrm{b}} \mathrm{H}\right), 17.6\left(\mathrm{~s}, 4 \mathrm{H},{ }^{\mathrm{c}} \mathrm{H}\right)$, $2.7\left(\mathrm{~s}, 12 \mathrm{H},{ }^{\mathrm{d}} \mathrm{H}\right), 3.3\left(\mathrm{~s}, 4 \mathrm{H},{ }^{\mathrm{e}} \mathrm{H}\right), 0.5\left(\mathrm{~s}, 4 \mathrm{H},{ }^{\mathrm{e}} \mathrm{H}\right), 1.0\left(\mathrm{~s}, 12 \mathrm{H},{ }^{\mathrm{f}} \mathrm{H}\right)$.

$\left[\mathrm{Fe}_{8}\left(\mu_{4}-\mathrm{O}\right)_{4}(\mu-4-\mathrm{Cl}-\mathrm{pz})_{12}\left(4-{ }^{\mathrm{s}} \mathrm{Bu}-\mathrm{C}_{6} \mathrm{H}_{4} \mathrm{O}\right)_{4}\right]$ (13). Compound 13 was synthesized in a similar fashion to 8. (Yield: $30 \%)$ Anal. Calc. for $\mathrm{Fe}_{8}\left(\mu_{4}-\mathrm{O}\right)_{4}(\mu-4-\mathrm{Cl}-\mathrm{pz})_{12}\left(4-{ }^{\mathrm{s}} \mathrm{Bu}-\right.$ $\left.\mathrm{C}_{6} \mathrm{H}_{4} \mathrm{O}\right)_{4} \cdot \mathrm{C}_{6} \mathrm{H}_{14}\left(\mathrm{C}_{82} \mathrm{H}_{90} \mathrm{Cl}_{12} \mathrm{Fe}_{8} \mathrm{~N}_{24} \mathrm{O}_{8}\right): \mathrm{C}, 40.83 ; \mathrm{H}, 3.76 ; \mathrm{N}, 13.94$. Found: $\mathrm{C}, 40.86 ; \mathrm{H}$, 3.79; N, 14.03\%. FTIR (CsI disk, $\left.\mathrm{cm}^{-1}\right):$ 2961(w), 2927(m), 2872(m), 1497(m), 1384(m), 1356(m), 1299(vs), 1270(w), 1191(m), 1151(m), 1042(vs), 992(w), 967(m), 883(w), 846(m), 830(m), 610(s), 526(w), 479(vs, br Fe $\left.\mathrm{c}_{\mathrm{c}} \mathrm{-O}\right), 397(\mathrm{w}), 377(\mathrm{w}), 356(\mathrm{w}), 325(\mathrm{w})$, 303(m). UV-Vis $\left(\mathrm{CH}_{2} \mathrm{Cl}_{2}, \mathrm{~nm}\right): 278,353$ and 643. ${ }^{1} \mathrm{H}-\mathrm{NMR}\left(\mathrm{CDCl}_{3}, 400 \mathrm{MHz}, \mathrm{ppm},\right)$ : $15.8\left(\mathrm{~s}, 12 \mathrm{H},{ }^{3} \mathrm{H}\right), 10.9\left(\mathrm{~s}, 12 \mathrm{H},{ }^{5} \mathrm{H}\right),-58.1\left(\mathrm{~s}, 8 \mathrm{H},{ }^{\mathrm{a}} \mathrm{H}\right), 51.5\left(\mathrm{~s}, 8 \mathrm{H},{ }^{\mathrm{b}} \mathrm{H}\right), 26.8(\mathrm{~s}, 4 \mathrm{H}$, $\left.{ }^{\mathrm{c}} \mathrm{H}\right), 3.7\left(\mathrm{~s}, 12 \mathrm{H},{ }^{\mathrm{d}} \mathrm{H}\right), 4.2$ and $4.1\left(\mathrm{~s}\right.$ and s, $\left.4 \mathrm{H},{ }^{\mathrm{e}} \mathrm{H}\right), 0.04\left(\mathrm{~s}, 4 \mathrm{H},{ }^{\mathrm{e}} \mathrm{H}\right), 1.1\left(\mathrm{~s}, 12 \mathrm{H},{ }^{\mathrm{f}} \mathrm{H}\right)$. 


\section{Overall conclusions and future work}

The enantiomeric resolution of racemic octanuclear iron-oxo-pyrazolate complexes with formula $\left[\mathrm{Fe}_{8}\left(\mu_{4}-\mathrm{O}\right)_{4}(\mu-4-\mathrm{R}-\mathrm{pz})_{12} \mathrm{Cl}_{4}\right]\left(\mathrm{R}=\mathrm{H}, \mathrm{CH}_{3}, \mathrm{Cl}\right)$ was attempted via diastereomer formation by substitution of the terminal chloride ligands with rac-4-sec-butylphenolate. Enantiomeric recognition between the $P$ and $M$ enantiomers of the metal cluster and $\mathrm{R}$ and $\mathrm{S}$ of the phenolate ligand was observed for all complex derivatives. However, only the cluster containing the 4-Cl-pz bridging ligand was spontaneously resolved by crystallization. This can be attributed to the difference in the crystal packing between the compounds. Nevertheless, this was the first example of such a non-biological system to demonstrate this level of recognition. Full structural and spectroscopic characterization was performed for all products bearing the chiral phenolate ligand, as well as for a series of compounds with achiral mono-substituted phenolates. The spectroscopic data and, in addition, electrochemical and ${ }^{57} \mathrm{Fe}$ Mössbauer data reveal some interesting trends related to the nature and the position of the phenolate substituent, for example the increase of $E_{1 / 2}$ values with increase of the electron donating ability of the substituent, or the increase of the quadruple splitting $\Delta \mathrm{E}_{\mathrm{Q}}$ with increase of the electron donating ability of the substituent. Extensive interpretation of these trends, using computational analysis, between chemical properties of phenol substituted octanuclear iron complexes with inherent properties of the phenolate ligands (ei. pKa, Hammett parameter, $\sigma$ ) has the potential to open the window for the design of new complexes based on their desired properties. Catalytic studies of the enantiopure compounds resulting from the resolution is another future task since development of $\mathrm{Fe}$ (III) based catalysts resistant to racemizationFe for enantioselective synthesis is of high significance to the field. 
References

(1) Gal, J. Louis Pasteur, Language, and Molecular Chirality. I. Background and Dissymmetry. Chirality 2010, 23 (1), 1-16.

(2) Werner, A. Über Mehrkernige Metallammoniake. Justus Liebigs Ann. Chem. 1910, 375 (1), 1-144.

(3) Setsune, J. I.; Tsukajima, A.; Okazaki, N.; Lintuluoto, J. M.; Lintuluoto, M. Enantioselective Induction of Helical Chirality in Cyclooctapyrroles by MetalComplex Formation. Angew. Chem. Int. Ed. 2009, 48 (4), 771-775.

(4) Liu, C. M.; Zhang, D. Q.; Zhu, D. Ben. A Chiral Screw Propeller-like Scalene Triangle Manganese(III) Cluster. Dalton Trans. 2010, 39 (7), 1781-1785.

(5) Saalfrank, R. W.; Schmidt, C.; Maid, H.; Hampel, F.; Bauer, W.; Scheurer, A. Enantiomerically Pure Copper(II) Cubanes [Cu4L2(OMe)4] from Chiral Bis-1,3Diketones H2L through Diastereoselective Self-Assembly. Angew. Chem. Int. Ed. 2005, 45 (2), 315-318.

(6) Reddy, V. D. Synthesis, Characterization, and Reactivity of a Novel Ruthenium Carbonyl Cluster Containing Tri-O-Benzyl-d-Glucal as a Chiral Carbohydrate Ligand. J. Organomet. Chem. 2006, 691 (1-2), 27-34.

(7) Rizzo, P.; Montefusco, T.; Guerra, G. Chiral Optical Films Based on Achiral Chromophore Guests. J. Am. Chem. Soc. 2011, 133 (25), 9872-9877.

(8) Liu, T.; Liu, Y.; Xuan, W.; Cui, Y. Chiral Nanoscale Metal-Organic Tetrahedral Cages: Diastereo-Selective Self-Assembly and Enantioselective Separation. Angew. Chem. Int. Ed. 2010, 49 (24), 4121-4124.

(9) Chorazy, S.; Reczyński, M.; Podgajny, R.; Nogaś, W.; Buda, S.; Rams, M.; Nitek, W.; Nowicka, B.; Mlynarski, J.; Ohkoshi, S. I.; et al. Implementation of Chirality into High-Spin Ferromagnetic Co(II)9W(V)6 and Ni(II)9W(V)6 Cyanido-Bridged Clusters. Cryst. Growth Des. 2015, 15 (8), 3573-3581.

(10) Novitchi, G.; Vela, S.; Pilet, G.; Train, C.; Robert, V. Twisting Induces Ferromagnetism in Homometallic Clusters. Dalton Trans. 2017, 46 (34), 1115411158.

(11) Wang, Y.; Huang, H.; Zhang, Q.; Zhang, P. Chirality in Metal-Based Anticancer Agents. Dalton Trans. 2018, 47 (12), 4017-4026.

(12) Izake, E. L. Chiral Discrimination and Enantioselective Analysis of Drugs: An Overview. J. Pharm. Sci. 2007, 96 (7), 1659-1676. 
(13) Kou, X.; Shao, Q.; Ye, C.; Yang, G.; Zhang, W. Asymmetric Aza-Wacker-Type Cyclization of N-Ts Hydrazine-Tethered Tetrasubstituted Olefins: Synthesis of Pyrazolines Bearing One Quaternary or Two Vicinal Stereocenters. J. Am. Chem. Soc. 2018, 140 (24), 7587-7597.

(14) Wang, M.-X.; Lin, S.-J. Practical and Convenient Enzymatic Synthesis of Enantiopure $\alpha$-Amino Acids and Amides. J. Org. Chem. 2002, 67 (18), 65426545.

(15) Tong, X.-L.; Hu, T.-L.; Zhao, J.-P.; Wang, Y.-K.; Zhang, H.; Bu, X.-H. Chiral Magnetic Metal-Organic Frameworks of Mn(II) with Achiral Tetrazolate-Based Ligands by Spontaneous Resolution. Chem. Commun. 2010, 46 (45), 8543.

(16) Song, Y.; Zhang, G.; Qin, X.; Gao, Y.; Ding, S.; Wang, Y.; Du, C.; Liu, Z. Chiral [NaMnIIMnIII3] and [Na2MnII2MnIII6] Clusters Constructed by Chiral Multidentate Schiff-Base Ligands: Synthesis, Structures, CD Spectra and Magnetic Properties. Dalton Trans. 2014, 43 (10), 3880-3887.

(17) Fan, L.-L.; Guo, F.-S.; Yun, L.; Lin, Z.-J.; Herchel, R.; Leng, J.-D.; Ou, Y.-C.; Tong, M. Chiral Transition Metal Clusters from Two Enantiomeric Schiff Base Ligands. Synthesis, Structures, CD Spectra and Magnetic Properties. Dalton Trans. 2010, 39 (7), 1771-1780.

(18) Yao, R. X.; Cui, X.; Wang, J.; Zhang, X. M. A Homochiral Magnet Based on D3 Symmetric [(NaO3)Co3] Clusters: From Spontaneous Resolution to Absolute Chiral Induction. Chem. Commun. 2015, 51 (24), 5108-5111.

(19) Ma, X. F.; Tian, J. L.; Gu, W.; Gao, S.; Yan, S. P.; Liao, D. Z. Synthesis, Structure and Magnetic Properties of One Chiral Heptanuclear Fe Cluster: \{Fe[(FeL)2(M2$\mathrm{OH})] 3(\mathrm{M} 2-\mathrm{OH}) 6\} \cdot 13 \mathrm{H} 2 \mathrm{O}$. Inorg. Chem. Commun. 2008, 11 (3), 256-259.

(20) Yeom, J.; Santos, U. S.; Chekini, M.; Cha, M.; De Moura, A. F.; Kotov, N. A. Chiromagnetic Nanoparticles and Gels. Science. 2018, 359 (6373), 309-314.

(21) Wen, H.-R.; Tang, Y.-Z.; Liu, C.-M.; Chen, J.-L.; Yu, C.-L. One-Dimensional Homochiral Cyano-Bridged Heterometallic Chain Coordination Polymers with Metamagnetic or Ferroelectric Properties. Inorg. Chem. 2009, 48 (21), 1017710185.

(22) Rota Martir, D.; Escudero, D.; Jacquemin, D.; Cordes, D.; Slawin, A.; Fruchtl, H.; Warriner, S.; Zysman-Colman, E. Homochiral Emissive $\Lambda 8$ - and $\Delta 8$-[Ir8Pd4]16+ Supramolecular Cages. Chem. Eur. J. 2017, 1-10.

(23) Qiu, Y.; Chen, P.; Guo, P.; Li, Y.; Liu, M. Supramolecular Chiroptical Switches Based on Achiral Molecules. Adv. Mater. 2008, 20 (15), 2908-2913. 
(24) Tranter, G. E.; Le Pevelen, D. D. Chiroptical Spectroscopy and the Validation of Crystal Structure Stereochemical Assignments. Tetrahedron Asymmetry 2017, 28 (10), 1192-1198.

(25) Escuer, A.; Mayans, J.; Font-Bardia, M.; Górecki, M.; Di Bari, L. Syntheses, Structures, and Chiroptical and Magnetic Properties of Chiral Clusters Built from Schiff Bases: A Novel [MnIIMnIII6NaI2] Core. Dalton Trans. 2017, 46 (20), 6514-6517.

(26) Williams, A. Opportunities for Chiral Agrochemicals. Pestic. Sci. 2018, 46 (1), $3-$ 9.

(27) Iwata, Y. T.; Inoue, H.; Kuwayama, K.; Kanamori, T.; Tsujikawa, K.; Miyaguchi, H.; Kishi, T. Forensic Application of Chiral Separation of Amphetamine-Type Stimulants to Impurity Analysis of Seized Methamphetamine by Capillary Electrophoresis. Forensic Sci. Int. 2006, 161 (2), 92-96.

(28) Cherney, A. H.; Kadunce, N. T.; Reisman, S. E. Enantioselective and Enantiospecific Transition-Metal-Catalyzed Cross-Coupling Reactions of Organometallic Reagents to Construct C-C Bonds. Chem. Rev. 2015, 115 (17), 9587-9652.

(29) Kobayashi, S.; Araki, M.; Hachiya, I. A Chiral Scandium Catalyst for Enantioselective Diels-Alder Reactions. J. Org. Chem. 1994, 59 (14), 3758-3759.

(30) Bauer, E. B. Chiral-at-Metal Complexes and Their Catalytic Applications in Organic Synthesis. Chem. Soc. Rev. 2012, 41 (8), 3153-3167.

(31) Noyori, R. Chiral Metal Complexes as Discriminating Molecular Catalysts. Science. 1990, 248 (4960), 1194-1199.

(32) Saint-Denis, T. G.; Zhu, R.-Y.; Chen, G.; Wu, Q.-F.; Yu, J.-Q. Enantioselective C(Sp3)-H Bond Activation by Chiral Transition Metal Catalysts. Science. 2018, 359 (6377).

(33) Gong, L.; Lin, Z.; Harms, K.; Meggers, E. Isomerization-Induced Asymmetric Coordination Chemistry: From Auxiliary Control to Asymmetric Catalysis. Angew. Chem. Int. Ed. 2010, 49 (43), 7955-7957.

(34) Lewis, K. G.; Ghosh, S. K.; Bhuvanesh, N.; Gladysz, J. A. Cobalt(III) Werner Complexes with 1,2-Diphenylethylenediamine Ligands: Readily Available, Inexpensive, and Modular Chiral Hydrogen Bond Donor Catalysts for Enantioselective Organic Synthesis. ACS Cent. Sci. 2015, 1 (1), 50-56.

(35) Andreiadis, E. S.; Vitale, M. R.; Mézailles, N.; Le Goff, X.; Le Floch, P.; Toullec, P. Y.; Michelet, V. Chiral Undecagold Clusters: Synthesis, Characterization and Investigation in Catalysis. Dalton Trans. 2010, 39 (44), 10608-10616. 
(36) Iovan, D. A.; Wilding, M. J. T.; Baek, Y.; Hennessy, E. T.; Betley, T. A. Diastereoselective C-H Bond Amination for Disubstituted Pyrrolidines. Angew. Chem. Int. Ed. 2017, 56 (49), 15599-15602.

(37) Friedfeld, M. R.; Zhong, H.; Ruck, R. T.; Shevlin, M.; Chirik, P. J. CobaltCatalyzed Asymmetric Hydrogenation of Enamides Enabled by Single-Electron Reduction. Science. 2018, 360 (6391), 888-893.

(38) Bruce, P. Y. Organic Chemistry (6th Ed.); Prentice Hall, 2011; pp 209-210.

(39) Gingras, M.; Félix, G.; Peresutti, R. One Hundred Years of Helicene Chemistry. Part 2: Stereoselective Syntheses and Chiral Separations of Carbohelicenes. Chem. Soc. Rev. 2013, 42 (3), 1007-1050.

(40) Berova, N.; Bari, L. Di; Pescitelli, G. Application of Electronic Circular Dichroism in Configurational and Conformational Analysis of Organic Compounds. Chem. Soc. Rev. 2007, 36 (6), 914-931.

(41) Ziegler, M.; von Zelewsky, A. Charge-Transfer Excited State Properties of Chiral Transition Metal Coordination Compounds Studied by Chiroptical Spectroscopy. Coord. Chem. Rev. 1998, 177 (1), 257-300.

(42) Schies, C.; Alemayehu, A. B.; Vazquez-Lima, H.; Thomas, K. E.; Bruhn, T.; Bringmann, G.; Ghosh, A. Metallocorroles as Inherently Chiral Chromophores: Resolution and Electronic Circular Dichroism Spectroscopy of a Tungsten Biscorrole. Chem. Commun. 2017, 53 (45), 6121-6124.

(43) Telfer, S. G.; McLean, T. M.; Waterland, M. R. Exciton Coupling in Coordination Compounds. Dalton Trans. 2011, 40 (13), 3097-3108.

(44) Freedman, T. B.; Cao, X.; Dukor, R. K.; Nafie, L. A. Absolute Configuration Determination of Chiral Molecules in the Solution State Using Vibrational Circular Dichroism. Chirality 2003, 15 (9), 743-758.

(45) Jähnigen, S.; Scherrer, A.; Vuilleumier, R.; Sebastiani, D. Chiral Crystal Packing Induces Enhancement of Vibrational Circular Dichroism. Angew. Chem. Int. Ed. 2018, 13344-13348.

(46) Flack, H. D.; Bernardinelli, G. Absolute Structure and Absolute Configuration. Acta Crystallogr. A 1999, 55 (5), 908-915.

(47) Bijvoet, J. M.; Peerdeman, A. F.; van Bommel, A. J. Determination of the Absolute Configuration of Optically Active Compounds by Means of X-Rays. Nature 1951, 168, 271.

(48) Kang, X.; Cheley, S.; Guan, X.; Bayley, H. Stochastic Detection of Enantiomers. J. Am. Chem. Soc. 2006, 128 (33), 10684-10685. 
(49) Noyori, R.; Takaya, H. BINAP: An Efficient Chiral Element for Asymmetric Catalysis. Acc. Chem. Res. 1990, 23 (10), 345-350.

(50) Vineyard, B. D.; Knowles, W. S.; Sabacky, M. J.; Bachman, G. L.; Weinkauff, D. J. Asymmetric Hydrogenation. Rhodium Chiral Bisphosphine Catalyst. J. Am. Chem. Soc. 1977, 99 (18), 5946-5952.

(51) Knowles, W. S. Asymmetric Hydrogenations (Nobel Lecture). Angew. Chem. Int. Ed. 2002, 41 (12), 1998-2007.

(52) Collet, A.; Brienne, M. J.; Jacques, J. Optical Resolution by Direct Crystallization of Enantiomer Mixtures. Chem. Rev. 1980, 80 (3), 215-230.

(53) Pérez-García, L.; Amabilino, D. B. Spontaneous Resolution under Supramolecular Control. Chem. Soc. Rev. 2002, 31 (6), 342-356.

(54) Zhang, J.; Chen, S.; Wu, T.; Feng, P.; Bu, X. Homochiral Crystallization of Microporous Framework Materials from Achiral Precursors by Chiral Catalysis. $J$. Am. Chem. Soc. 2008, 130 (39), 12882-12883.

(55) Okamoto, Y.; Ikai, T. Chiral HPLC for Efficient Resolution of Enantiomers. Chem. Soc. Rev. 2008, 37 (12), 2593-2608.

(56) Ward, T. J.; Hamburg, D.-M. Chiral Separations. Anal. Chem. 2004, 76 (16), 4635-4644.

(57) Lacour, J.; Moraleda, D. Chiral Anion-Mediated Asymmetric Ion Pairing Chemistry. Chem. Commun. 2009, No. 46, 7073-7089.

(58) Howson, S. E.; Allan, L. E. N.; Chmel, N. P.; Clarkson, G. J.; van Gorkum, R.; Scott, P. Self-Assembling Optically Pure Fe(A-B)3 Chelates. Chem. Commun. 2009, No. 13, 1727.

(59) Banerjee-Ghosh, K.; Dor, O. Ben; Tassinari, F.; Capua, E.; Yochelis, S.; Capua, A.; Yang, S. H.; Parkin, S. S. P.; Sarkar, S.; Kronik, L.; et al. Separation of Enantiomers by Their Enantiospecific Interaction with Achiral Magnetic Substrates. Science. 2018, 360 (6395), 1331-1334.

(60) Fogassy, E.; Nógrádi, M.; Kozma, D.; Egri, G.; Pálovics, E.; Kiss, V. Optical Resolution Methods. Org. Biomol. Chem. 2006, 4 (16), 3011-3030.

(61) Lorenz, H.; Seidel-Morgenstern, A. Processes to Separate Enantiomers. Angew. Chem. Int. Ed. 2014, 53 (5), 1218-1250.

(62) Knof, U.; Von Zelewsky, A. Predetermined Chirality at Metal Centers. Angew. Chem. Int. Ed. 1999, 38 (3), 302-322.

(63) Crassous, J. Transfer of Chirality from Ligands to Metal Centers: Recent Examples. Chem. Commun. 2012, 48 (56), 7022-7024. 
(64) Gong, L.; Mulcahy, S. P.; Harms, K.; Meggers, E. Chiral-Auxiliary-Mediated Asymmetric Synthesis of Tris-Heteroleptic Ruthenium Polypyridyl Complexes. $J$. Am. Chem. Soc. 2009, 131 (28), 9602-9603.

(65) Warr, R. J.; Willis, A. C.; Wild, S. B. Inorganic Asymmetric Synthesis: Asymmetric Synthesis of a Two-Bladed Propeller, Octahedral Metal Complex. Inorg. Chem. 2006, 45 (21), 8618-8627.

(66) Hamann, C.; von Zelewsky, A.; Neels, A.; Stoeckli-Evans, H.; Zelewsky, A. Von; Stoeckli-Evans, H. Diastereoselective Synthesis of Coordination Compounds: A Chiral Tripodal Ligand Based on Bipyridine Units and Its Ruthenium(II) and Iron(II) Complexes. Dalton Trans. 2004, No. 3, 402-406.

(67) Mamula, O.; Von Zelewsky, A. Supramolecular Coordination Compounds with Chiral Pyridine and Polypyridine Ligands Derived from Terpenes. Coord. Chem. Rev. 2003, 242 (1-2), 87-95.

(68) Mamula, O.; Bark, T.; Quinodoz, B.; Stoeckli-Evans, H.; von Zelewsky, A. SelfAssembly of $\mathrm{Ag}(\mathrm{I})$ Helicates with New Enantiopure 5,6-Chiragen Type Ligands. Inorg. Chim. Acta 2018, 475, 200-206.

(69) Chamayou, A.-C.; Lüdeke, S.; Brecht, V.; Freedman, T. B.; Nafie, L. A.; Janiak, C. Chirality and Diastereoselection of $\Delta / \Lambda$-Configured Tetrahedral Zinc Complexes through Enantiopure Schiff Base Complexes: Combined Vibrational Circular Dichroism, Density Functional Theory, 1H NMR, and X-Ray Structural Studies. Inorg. Chem. 2011, 50 (22), 11363-11374.

(70) Humbert, N.; Mazet, C. The Diastereoselective Synthesis of Octahedral Cationic Iridium Hydride Complexes with a Stereogenic Metal Centre. Chem. Commun. 2016, 52 (70), 10629-10631.

(71) Zheng, Z.; Cao, Y.; Chong, Q.; Han, Z.; Ding, J.; Luo, C.; Wang, Z.; Zhu, D.; Zhou, Q. L.; Ding, K. Chiral Cyclohexyl-Fused Spirobiindanes: Practical Synthesis, Ligand Development, and Asymmetric Catalysis. J. Am. Chem. Soc. 2018, 140 (32), 10374-10381.

(72) Yin, J.; Yin, T. T.; Gao, C.; Wang, B. W.; Zhu, Y. Y.; Wu, Z. Q.; Gao, S. A Pair of Enantiopure Cubane-Type CuII4O4 Clusters: Synthesis, Structure, Chirality and Magnetism. Eur. J. Inorg. Chem. 2014, 2014 (31), 5385-5390.

(73) He, X.; Wang, Y.; Jiang, H.; Zhao, L. Structurally Well-Defined Sigmoidal Gold Clusters: Probing the Correlation between Metal Atom Arrangement and Chiroptical Response. J. Am. Chem. Soc. 2016, 138 (17), 5634-5643.

(74) Escuer, A.; Mayans, J.; Font-Bardia, M.; Di Bari, L.; Gorecki, M. Chiral [MnIIMnIII3M'] (M' = NaI, CaII, MnII) and [MnIIMnIII6NaI2] Clusters Built from an Enantiomerically Pure Schiff Base: Synthetic, Chiroptical and Magnetic Properties. Chem. Eur. J. 2018, 1-14. 
(75) Zhang, Z. M.; Li, Y. G.; Yao, S.; Wang, E. B.; Wang, Y. H.; Clérac, R. Enantiomerically Pure Chiral \{Fe28\} Wheels. Angew. Chem. Int. Ed. 2009, 48 (9), 1581-1584.

(76) Ikai, T.; Okamoto, Y. Structure Control of Polysaccharide Derivatives for Efficient Separation of Enantiomers by Chromatography. Chem. Rev. 2009, 109 (11), 60776101.

(77) Pirkle, W. H.; Pochapsky, T. C. Considerations of Chiral Recognition Relevant to the Liquid Chromatography Separation of Enantiomers. Chem. Rev. 1989, 89 (2), 347-362.

(78) Zhao, C. F.; Cann, N. M. Molecular Dynamics Study of Chiral Recognition for the Whelk-O1 Chiral Stationary Phase. Anal. Chem. 2008, 80 (7), 2426-2438.

(79) Kubota, T.; Yamamoto, C.; Okamoto, Y. Tris(Cyclohexylcarbamate)s of Cellulose and Amylose as Potential Chiral Stationary Phases for High-Performance Liquid Chromatography and Thin-Layer Chromatography. J. Am. Chem. Soc. 2000, 122 (17), 4056-4059.

(80) Zhu, X.; Cai, Y.; Zhang, W.; Chen, L.; Li, Y. Direct Resolution of Novel Tetrahedral Metal Clusters on a Cellulose Tris-(3,5-Dimethylphenylcarbamate) Chiral Stationary Phase by High-Performance Liquid Chromatography. J. Sep. Sci. 2003, 26 (12-13), 1207-1210.

(81) Zhu, X.; Cai, Y.; Zhang, W.; Chen, L.; Li, Y. Enantioseparation of Novel Chiral Heterometal Tetrahedral Clusters by High-Performance Liquid Chromatography. J. Chromatogr. A 2003, 1002, 231-236.

(82) Bian, Z. G.; Zhang, W. Q.; Guan, H. X.; Yin, Y. Q.; Li, Q. S.; Sun, J. Synthesis, Reaction and Enantiomeric Resolution of Chiral Clusters Containing SRuNiM (M = Mo, W) Core. J. Organomet. Chem. 2002, 664 (1-2), 201-207.

(83) Kerckhoffs, J. M. C. A.; Peberdy, J. C.; Meistermann, I.; Childs, L. J.; Isaac, C. J.; Pearmund, C. R.; Reudegger, V.; Khalid, S.; Alcock, N. W.; Hannon, M. J.; et al. Enantiomeric Resolution of Supramolecular Helicates with Different Surface Topographies. Dalton Trans. 2007, No. 7, 734-742.

(84) Dolamic, I.; Knoppe, S.; Dass, A.; Bürgi, T. First Enantioseparation and Circular Dichroism Spectra of Au38 Clusters Protected by Achiral Ligands. Nat. Commun. 2012, 3, 798-803.

(85) Pidcock, E. Achiral Molecules in Non-Centrosymmetric Space Groups. Chem. Commun. 2005, No. 27, 3457-3459. 
(86) Lo, W.; Huang, S.; Zheng, S. L.; Holm, R. H. Cubane-Type Fe4S4clusters with Chiral Thiolate Ligation: Formation by Ligand Substitution, Detection of Intermediates by $1 \mathrm{H}$ NMR, and Solid State Structures Including Spontaneous Resolution upon Crystallization. Inorg. Chem. 2011, 50 (21), 11082-11090.

(87) Krämer, R.; Lehn, J.; De Cian, A.; Fischer, J. Self Assembly, Structure, and Spontaneous Resolution of a Trinuclear Triple Helix from an Oligobipyridine Ligand and NiII Ions. Angew. Chem. Int. Ed. 1993, 32 (5), 703-706.

(88) Muzioł, T. M.; Wrzeszcz, G. Spontaneous Resolution of Heterometallic Complex: Cis-[Co(NH3)4(H2O)2][Fe(Ox)3]·2H2O - A Rare Example for Labile Iron(III) Complex. Polyhedron 2016, 109, 138-146.

(89) Gil-Hernández, B.; Höppe, H. A.; Vieth, J. K.; Sanchiz, J.; Janiak, C. Spontaneous Resolution upon Crystallization of Chiral La(III) and Gd(III) MOFs from Achiral Dihydroxymalonate. Chem. Commun. 2010, 46 (43), 8270-8272.

(90) Bonnet, S.; Li, J.; Siegler, M. A.; von Chrzanowski, L. S.; Spek, A. L.; van Koten, G.; Klein Gebbink, R. J. M. Synthesis and Resolution of Planar-Chiral Ruthenium-Palladium Complexes with ECE' Pincer Ligands. Chem. Eur. J. 2009, 15 (14), 3340-3343.

(91) Herse, C.; Bas, D.; Krebs, F. C.; Bürgi, T.; Weber, J.; Wesolowski, T.; Laursen, B. W.; Lacour, J. A Highly Configurationally Stable [4]Heterohelicenium Cation. Angew. Chem. Int. Ed. 2003, 42 (27), 3162-3166.

(92) Auffrant, A.; Barbieri, A.; Barigelletti, F.; Lacour, J.; Mobian, P.; Collin, J.-P.; Sauvage, J.-P.; Ventura, B. Bimetallic Iridium(III) Complexes Consisting of $\operatorname{Ir}(\mathrm{Ppy}) 2$ Units (Ppy = 2-Phenylpyridine) and Two Laterally Connected N-N Chelates as Bridge: Synthesis, Separation, and Photophysical Properties. Inorg. Chem. 2007, 46 (17), 6911-6919.

(93) Mimassi, L.; Guyard-Duhayon, C.; Rager, M. N.; Amouri, H. Chiral Recognition and Resolution of the Enantiomers of Supramolecular Triangular Hosts: Synthesis, Circular Dichroism, NMR, and x-Ray Molecular Structure of [Li-(R,R,R)$\{\mathrm{Cp} * \mathrm{Rh}$ (5-Chloro-2,3-Dioxopyridine) $\} 3][\Delta$-Trisphat]. Inorg. Chem. 2004, 43 (21), 6644-6649.

(94) Yeh, R. M.; Raymond, K. N. Supramolecular Asymmetric Induction in Dinuclear Triple-Stranded Helicates. Inorg. Chem. 2006, 45 (3), 1130-1139.

(95) Terpin, A. J.; Ziegler, M.; Johnson, D. W.; Raymond, K. N. Resolution and Kinetic Stability of a Chiral Supramolecular Assembly Made of Labile Components. Angew. Chem. Int. Ed. 2001, 40 (1), 157-160.

(96) Davis, A. V.; Fiedler, D.; Ziegler, M.; Terpin, A.; Raymond, K. N. Resolution of Chiral, Tetrahedral M4L6 Metal-Ligand Hosts. J. Am. Chem. Soc. 2007, 129 (49), 15354-15363. 
(97) Srinivasan, A.; Cortijo, M.; Bulicanu, V.; Naim, A.; Clérac, R.; Sainctavit, P.; Rogalev, A.; Wilhelm, F.; Rosa, P.; Hillard, E. A. Enantiomeric Resolution and XRay Optical Activity of a Tricobalt Extended Metal Atom Chain. Chem. Sci. 2018, 9 (5), 1136-1143.

(98) Knoppe, S.; Wong, O. A.; Malola, S.; Häkkinen, H.; Bürgi, T.; Verbiest, T.; Ackerson, C. J. Chiral Phase Transfer and Enantioenrichment of ThiolateProtected Au102 Clusters. J. Am. Chem. Soc. 2014, 136 (11), 4129-4132.

(99) Jadzinsky, P. D.; Calero, G.; Ackerson, C. J.; Bushnell, D. A.; Kornberg, R. D. Structure of a Thiol Monolayer-Protected Gold Nanoparticle at 1.1 A Resolution. Science. 2007, 318 (5849), 430-433.

(100) Carmona, M.; Rodríguez, R.; Méndez, I.; Passarelli, V.; Lahoz, F. J.; GarcíaOrduña, P.; Carmona, D. Stereospecific Control of the Metal-Centred Chirality of Rhodium(III) and Iridium(III) Complexes Bearing Tetradentate CNN'P Ligands. Dalton Trans. 2017, 46 (22), 7332-7350.

(101) Carmona, M.; Rodríguez, R.; Passarelli, V.; Lahoz, F. J.; García-Orduna, P.; Carmona, D. Metal as Source of Chirality in Octahedral Complexes with Tripodal Tetradentate Ligands. J. Am. Chem. Soc. 2018, 140 (3), 912-915.

(102) Zhang, L.; Meggers, E. Stereogenic-Only-at-Metal Asymmetric Catalysts. Chem. Asian J. 2017, 12 (18), 2335-2342.

(103) Hu, Y.; Shaw, A. P.; Guan, H.; Norton, J. R.; Sattler, W.; Rong, Y. Synthesis and Resolution of Chiral Ruthenium Complexes Containing the 1-Me-3-PhCp Ligand. Organometallics 2016, 35 (1), 39-46.

(104) Raptis, R. G.; Georgakaki, I. P.; Hockless, D. C. R. A Fe(III)/Oxo Cubane Contained in an Octanuclear Complex of T Symmetry That Is Stable over Five Oxidation States. Angew. Chem. Int. Ed. 1999, 38 (11), 1632-1634.

(105) Castilla, A. M.; Ramsay, W. J.; Nitschke, J. R. Stereochemistry in Subcomponent Self-Assembly. Acc. Chem. Res. 2014, 47 (7), 2063-2073.

(106) Baran, P.; Boča, R.; Chakraborty, I.; Giapintzakis, J.; Herchel, R.; Huang, Q.; McGrady, J. E.; Raptis, R. G.; Sanakis, Y.; Simopoulos, A. Synthesis, Characterization, and Study of Octanuclear Iron-Oxo Clusters Containing a Redox-Active Fe4O4-Cubane Core. Inorg. Chem. 2008, 47 (2), 645-655.

(107) Das, S.; Chakraborty, I.; Skachkov, D.; Ahmadi, M.; Ishikawa, Y.; Baran, P.; Raptis, R. G. Water-Soluble Derivatives of Octanuclear Iron-Oxido-Pyrazolato Complexes - An Experimental and Computational Study. Eur. J. Inorg. Chem. 2012, 8 (23), 3704-3711.

(108) Bauer, I.; Knölker, H.-J.; Knoelker, H.-J. Iron Catalysis in Organic Synthesis. Chem. Rev. 2015, 115 (9), 3170-3387. 
(109) Fürstner, A. Iron Catalysis in Organic Synthesis: A Critical Assessment of What It Takes to Make This Base Metal a Multitasking Champion. ACS Cent. Sci. 2016, 2 (11), 778-789.

(110) Liu, J.; Hu, L.; Wang, L.; Chen, H.; Deng, L. An Iron(II) Ylide Complex as a Masked Open-Shell Iron Alkylidene Species in Its Alkylidene-Transfer Reactions with Alkenes. J. Am. Chem. Soc. 2017, 139 (10), 3876-3888.

(111) Jiang, X.; Zhang, J.; Ma, S. Iron Catalysis for Room-Temperature Aerobic Oxidation of Alcohols to Carboxylic Acids. J. Am. Chem. Soc. 2016, 138 (27), 8344-8347.

(112) Egorova, K. S.; Ananikov, V. P. Which Metals Are Green for Catalysis? Comparison of the Toxicities of $\mathrm{Ni}, \mathrm{Cu}, \mathrm{Fe}, \mathrm{Pd}, \mathrm{Pt}, \mathrm{Rh}$, and Au Salts. Angew. Chem. Int. Ed. 2016, 55 (40), 12150-12162.

(113) Gopalaiah, K. Chiral Iron Catalysts for Asymmetric Synthesis. Chem. Rev. 2013, 113 (1951), 3248-3296.

(114) Bigler, R.; Mezzetti, A. Highly Enantioselective Transfer Hydrogenation of Polar Double Bonds by Macrocyclic Iron(II)/(NH)2P2Catalysts. Org. Process Res. Dev. 2016, 20 (2), 253-261.

(115) Loup, J.; Zell, D.; Oliveira, J. C. A.; Keil, H.; Stalke, D.; Ackermann, L. Asymmetric Iron-Catalyzed C-H Alkylation Enabled by Remote Ligand MetaSubstitution. Angew. Chem. Int. Ed. 2017, 56 (45), 14197-14201.

(116) Jalba, A.; Regnier, N.; Ollevier, T. Enantioselective Aromatic Sulfide Oxidation and Tandem Kinetic Resolution Using Aqueous H2O2 and Chiral IronBis(Oxazolinyl)Bipyridine Catalysts. Eur. J. Org. Chem. 2017, 2017 (12), 16281637.

(117) Li, M.; Carreras, V.; Jalba, A.; Ollevier, T. Asymmetric Diels-Alder Reaction of $\alpha, \beta$-Unsaturated Oxazolidin-2-One Derivatives Catalyzed by a Chiral Fe(III)Bipyridine Diol Complex. Org. Lett. 2018, 20 (4), 995-998.

(118) Zang, C.; Liu, Y.; Xu, Z.-J.; Tse, C.-W.; Guan, X.; Wei, J.; Huang, J.-S.; Che, C.M. Highly Enantioselective Iron-Catalyzed Cis-Dihydroxylation of Alkenes with Hydrogen Peroxide Oxidant via an FeIII-OOH Reactive Intermediate. Angew. Chem. Int. Ed. 2016, 55 (35), 10253-10257.

(119) Zima, A. M.; Lyakin, O. Y.; Ottenbacher, R. V.; Bryliakov, K. P.; Talsi, E. P. IronCatalyzed Enantioselective Epoxidations with Various Oxidants: Evidence for Different Active Species and Epoxidation Mechanisms. ACS Catal. 2017, 7 (1), 60-69. 
(120) Piontek, A.; Bisz, E.; Szostak, M. Iron-Catalyzed Cross-Couplings in the Synthesis of Pharmaceuticals: In Pursuit of Sustainability. Angew. Chem. Int. Ed. 2018, $11116-11128$.

(121) Schwizer, F.; Okamoto, Y.; Heinisch, T.; Gu, Y.; Pellizzoni, M. M.; Lebrun, V.; Reuter, R.; Köhler, V.; Lewis, J. C.; Ward, T. R. Artificial Metalloenzymes: Reaction Scope and Optimization Strategies. Chem. Rev. 2018, 118 (1), 142-231.

(122) Liptak, M. D.; Gross, K. C.; Seybold, P. G.; Feldgus, S.; Shields, G. C. Absolute p $K_{\mathrm{a}}$ Determinations for Substituted Phenols. J. Am. Chem. Soc. 2002, 124 (22), 6421-6427.

(123) Biernesser, A. B.; Li, B.; Byers, J. A. Redox-Controlled Polymerization of Lactide Catalyzed by Bis(Imino)Pyridine Iron Bis(Alkoxide) Complexes. J. Am. Chem. Soc. 2013, 135 (44), 16553-16560.

(124) Gonzalez-Nieves, K. Efforts towards the Resolution of Racemic Octaferric Pyrazolato Complexes into M/P Enantiomers(Doctoral Dissertation), University of Puerto Rico, Rio Piedras, 2013.

(125) Wertheim, G. K. Mössbauer Effect: Principles and Applications; Academic Press: New York, 1964.

(126) Zueva, E. M.; Sameera, W. M. C.; Piñero, D. M.; Chakraborty, I.; Devlin, E.; Baran, P.; Lebruskova, K.; Sanakis, Y.; McGrady, J. E.; Raptis, R. G. Experimental and Theoretical Mössbauer Study of an Extended Family of [Fe8( $\mu$ 4-O)4( $\mu-4-\mathrm{R}-\mathrm{Pz}) 12 \mathrm{X} 4]$ Clusters. Inorg. Chem. 2011, 50 (3), 1021-1029.

(127) Cao, X. Y.; Hubbard, J. W.; Guerrero-Medina, J.; Hernández-Maldonado, A. J.; Mathivathanan, L.; Rinaldi, C.; Sanakis, Y.; Raptis, R. G. Spin-Glass Behavior of a Hierarchically-Organized, Hybrid Microporous Material, Based on an Extended Framework of Octanuclear Iron-Oxo Units. Dalton Trans. 2015, 44 (7), 33993409.

(128) Perrin, D. Armarego, F, Perrin, R. Purification of Laboratoty Chemicals, 2nd ed.; Pergamon Press: New York, 1987.

(129) Bruker APEX 3. Bruker AXS Inc.: Madison, Wisconsin, USA 2014.

(130) Bruker SAINT. Bruker AXS Inc.: Madison, Wisconsin, USA 2012.

(131) Bruker SADABS. Bruker AXS Inc.: Madison, Wisconsin, USA 2016.

(132) Sheldrick, G. M. SHELXT - Integrated Space-Group and Crystal-Structure Determination. Acta Cryst. A71 2015, 3-8.

(133) Sheldrick, G. M. Crystal Structure Refinement with SHELXL. Acta Cryst. C71 2015, 3-8. 
(134) Spek, A. L. PLATON SQUEEZE. Acta Crystallogr. Sect. C 2015, 9.

(135) Dolomanov, O. V.; Bourhis, L. J.; Gildea, R. J.; Howard, J. A. K.; Puschmann, H. OLEX2: A Complete Structure Solution, Refinement and Analysis Program. $J$. Appl. Cryst. 2009, 42, 339-341. 
Appendix

\section{${ }^{1}$ H-NMR Spectroscopy}
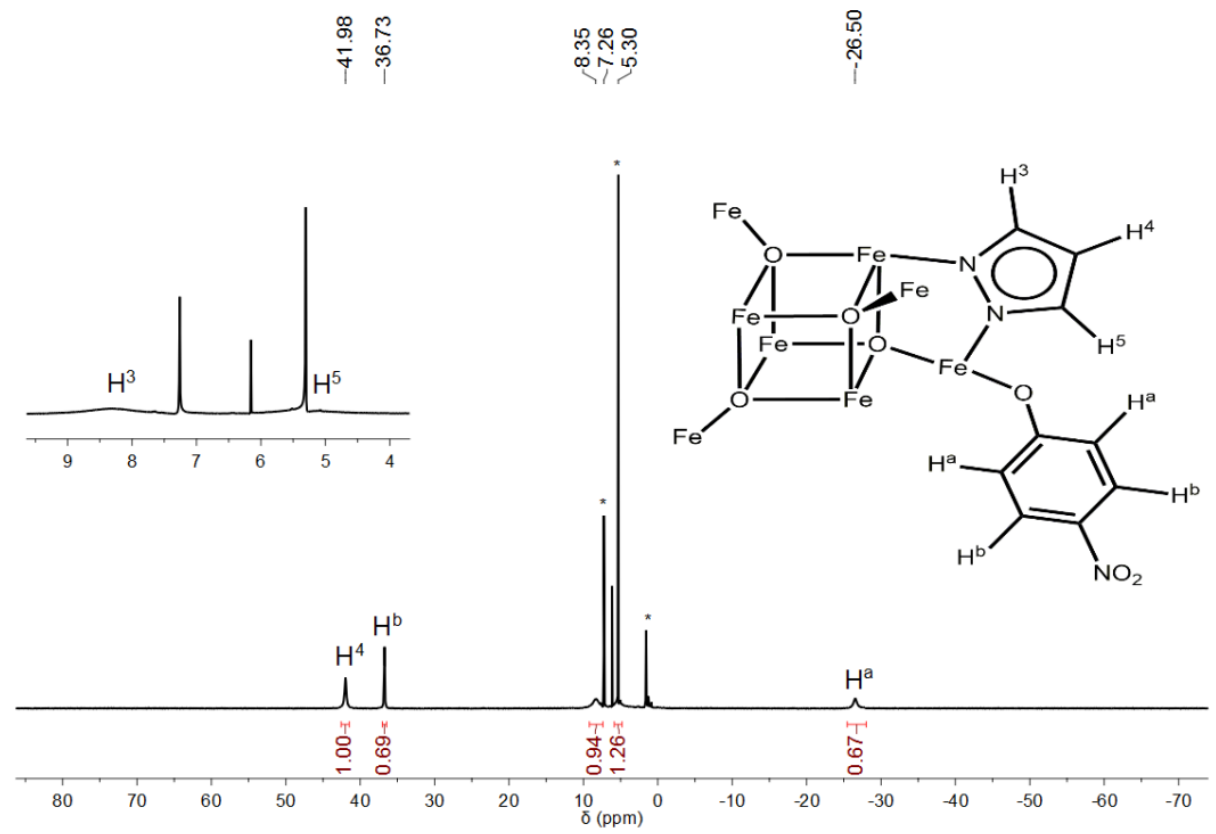

Figure 1. ${ }^{1} \mathrm{H}-\mathrm{NMR}\left[\mathrm{Fe}_{8}\left(\mu_{4}-\mathrm{O}\right)_{4}(\mu-\mathrm{pz})_{12}\left(4-\mathrm{NO}_{2}-\mathrm{C}_{6} \mathrm{H}_{4} \mathrm{O}\right)_{4}\right]$ (2).
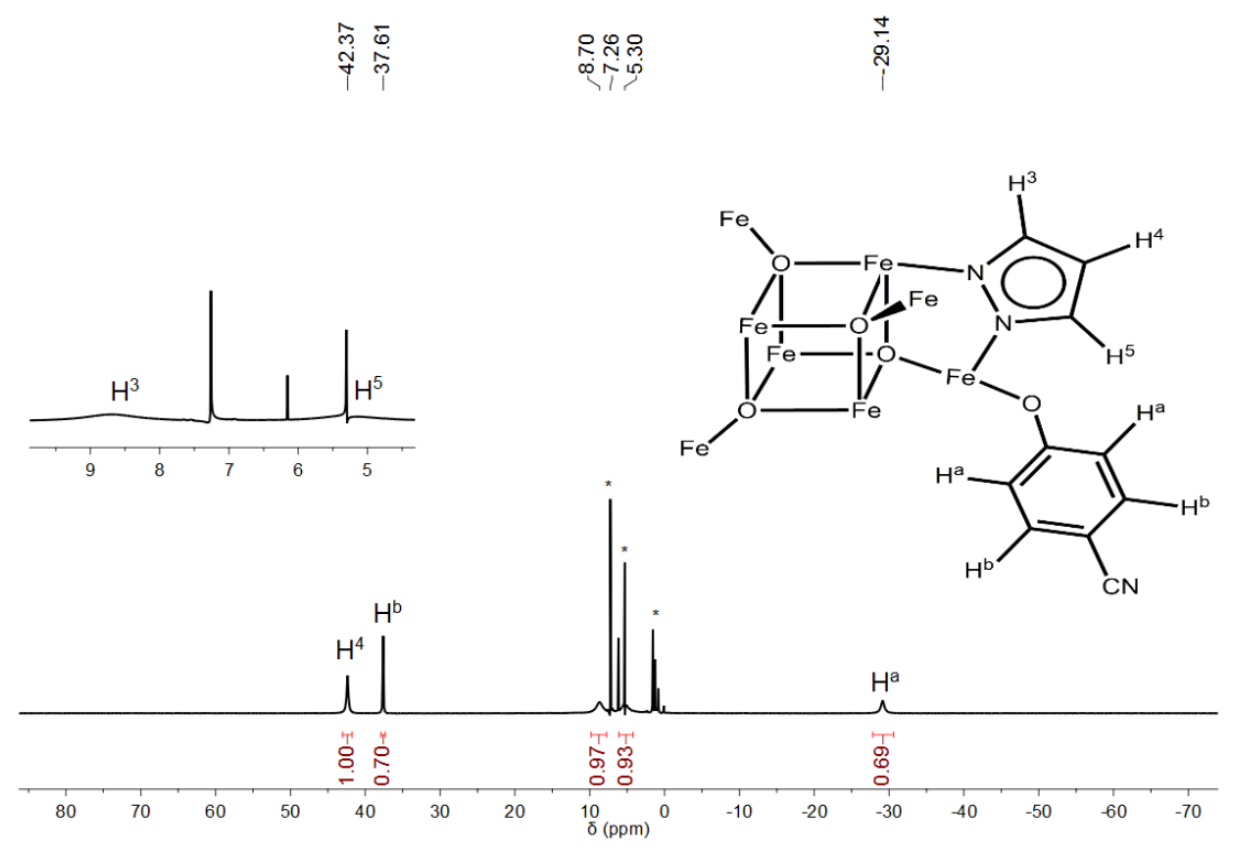

Figure 2. ${ }^{1} \mathrm{H}-\mathrm{NMR}$ of $\left[\mathrm{Fe}_{8}\left(\mu_{4}-\mathrm{O}\right)_{4}(\mu-\mathrm{pz})_{12}\left(4-\mathrm{CN}-\mathrm{C}_{6} \mathrm{H}_{4} \mathrm{O}\right)_{4}\right](3)$. 


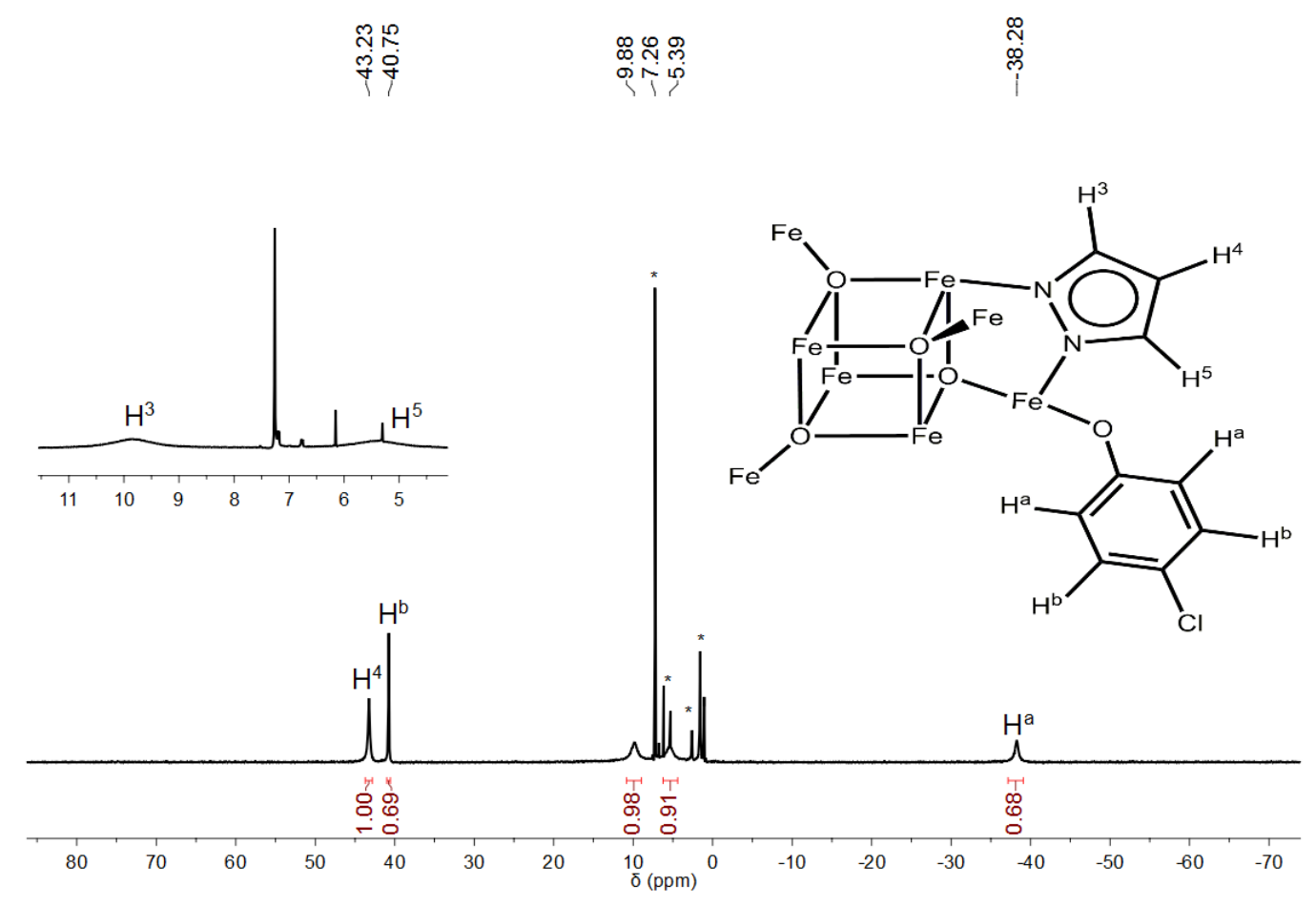

Figure 3. ${ }^{1} \mathrm{H}-\mathrm{NMR}$ of $\left[\mathrm{Fe}_{8}\left(\mu_{4}-\mathrm{O}\right)_{4}(\mu-\mathrm{pz})_{12}\left(4-\mathrm{Cl}-\mathrm{C}_{6} \mathrm{H}_{4} \mathrm{O}\right)_{4}\right](\mathbf{5})$.

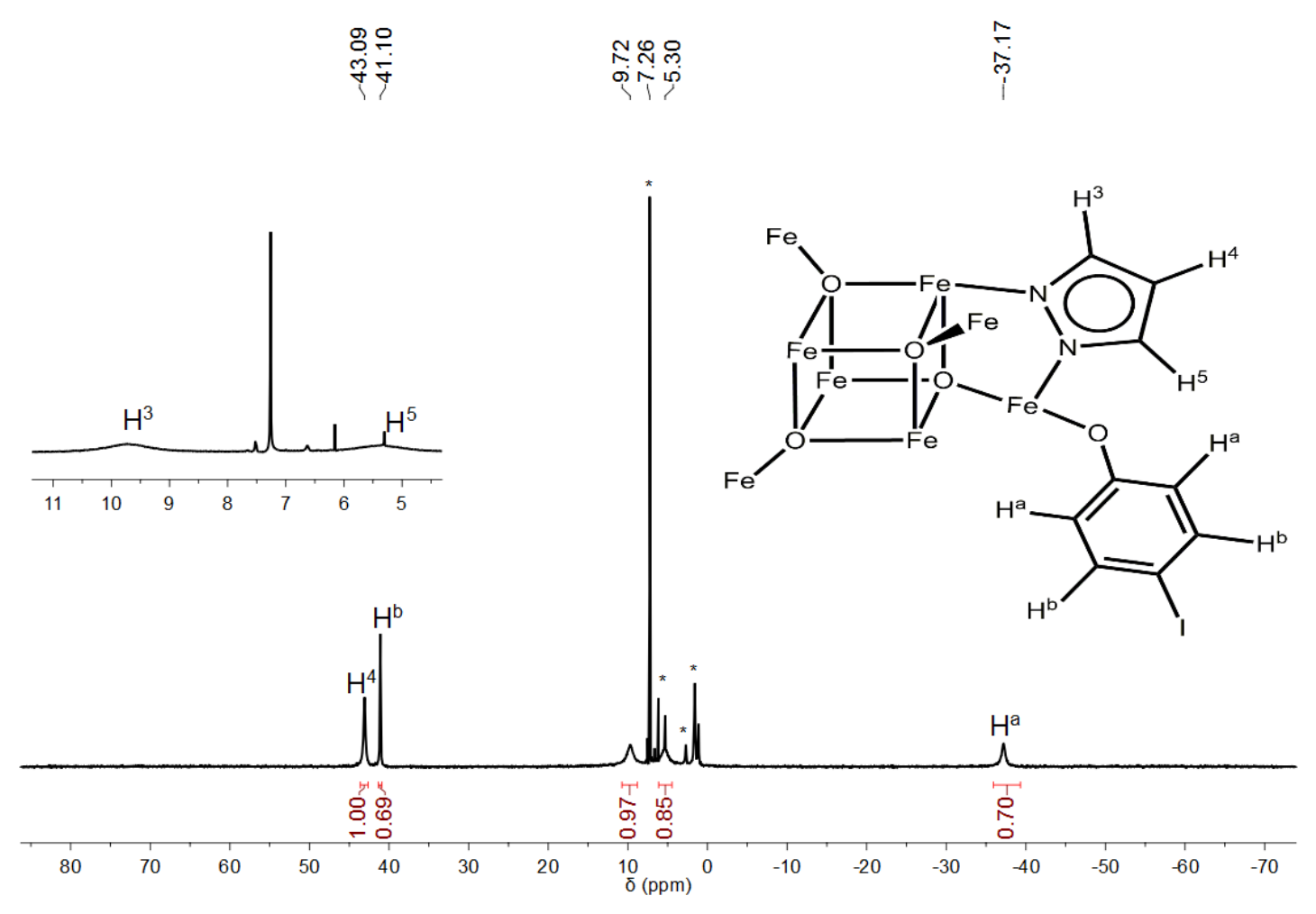

Figure 4. ${ }^{1} \mathrm{H}-\mathrm{NMR}$ of $\left[\mathrm{Fe}_{8}\left(\mu_{4}-\mathrm{O}\right)_{4}(\mu-\mathrm{pz})_{12}\left(4-\mathrm{I}-\mathrm{C}_{6} \mathrm{H}_{4} \mathrm{O}\right)_{4}\right](6)$. 


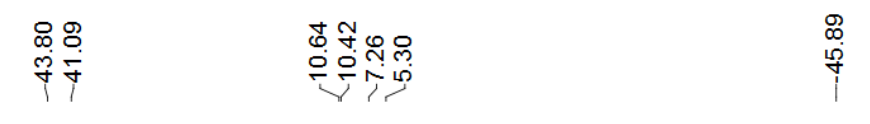
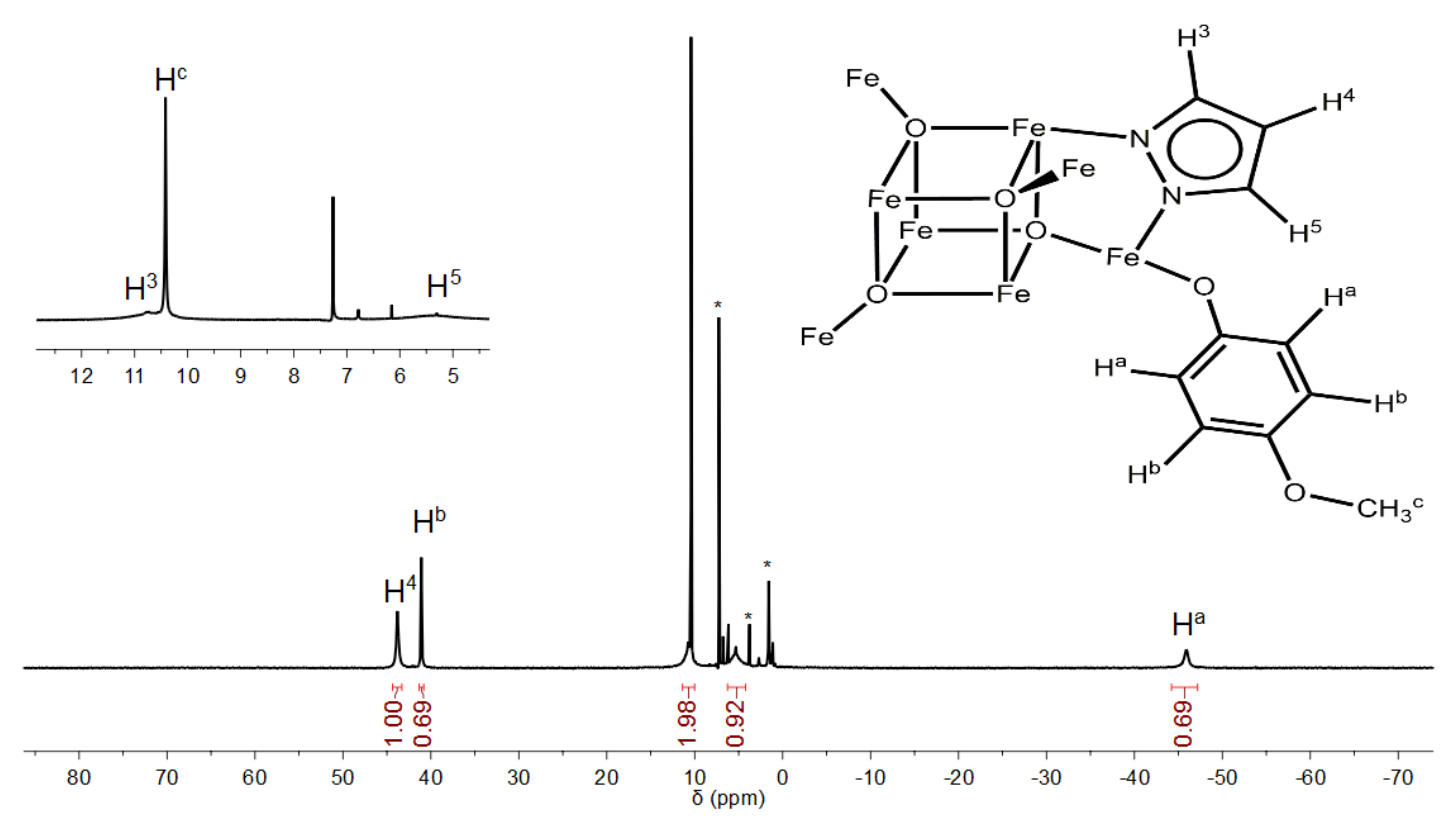

Figure 5. ${ }^{1} \mathrm{H}-\mathrm{NMR}$ of $\left[\mathrm{Fe}_{8}\left(\mu_{4}-\mathrm{O}\right)_{4}(\mu-\mathrm{pz})_{12}\left(4-\mathrm{CH}_{3} \mathrm{O}-\mathrm{C}_{6} \mathrm{H}_{4} \mathrm{O}\right)_{4}\right](7)$.
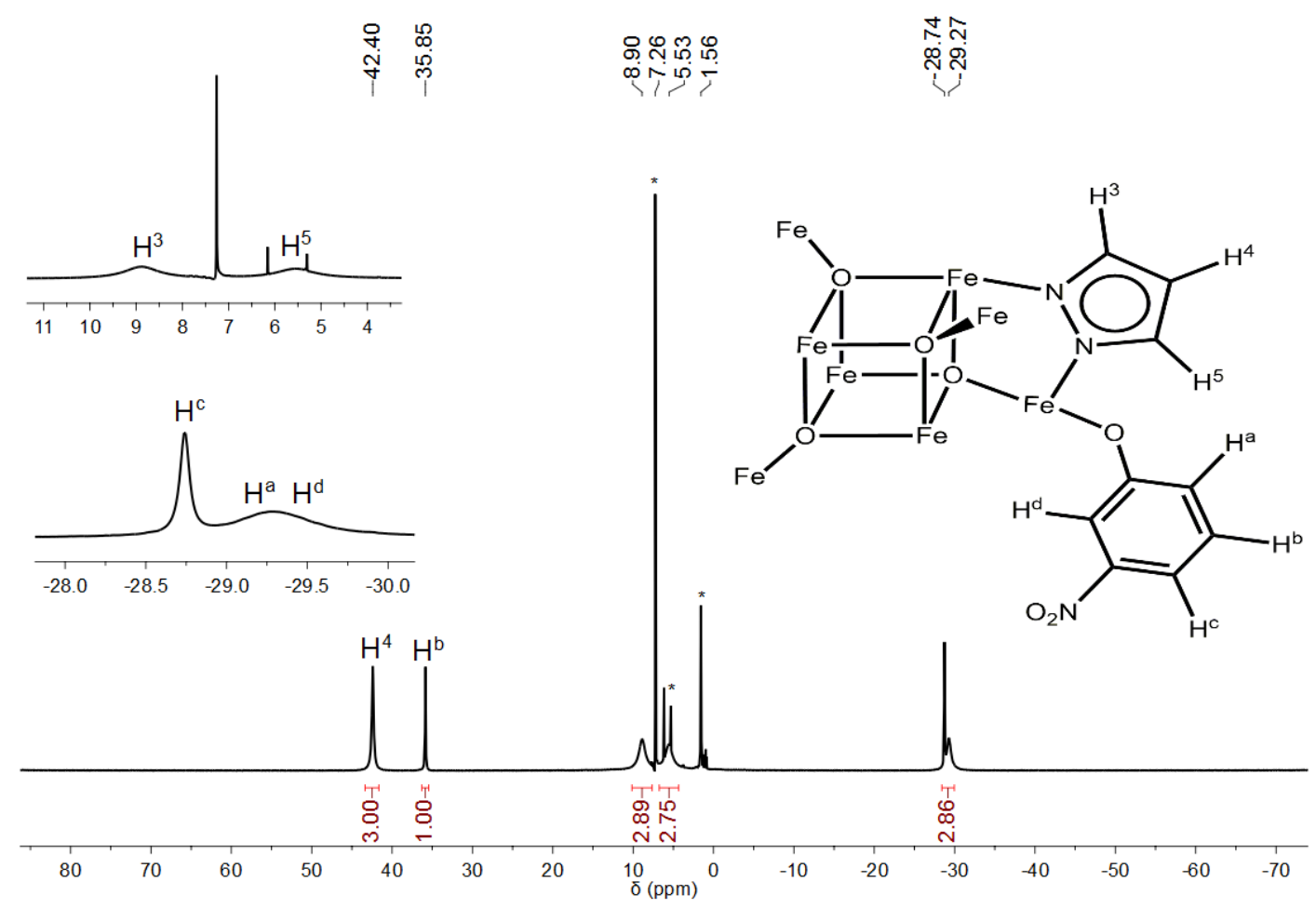

Figure 6. ${ }^{1} \mathrm{H}-\mathrm{NMR}$ of $\left[\mathrm{Fe}_{8}\left(\mu_{4}-\mathrm{O}\right)_{4}(\mu-\mathrm{pz})_{12}\left(3-\mathrm{NO}_{2}-\mathrm{C}_{6} \mathrm{H}_{4} \mathrm{O}\right)_{4}\right](\mathbf{9})$. 


\section{UV-Vis-Spectroscopy}

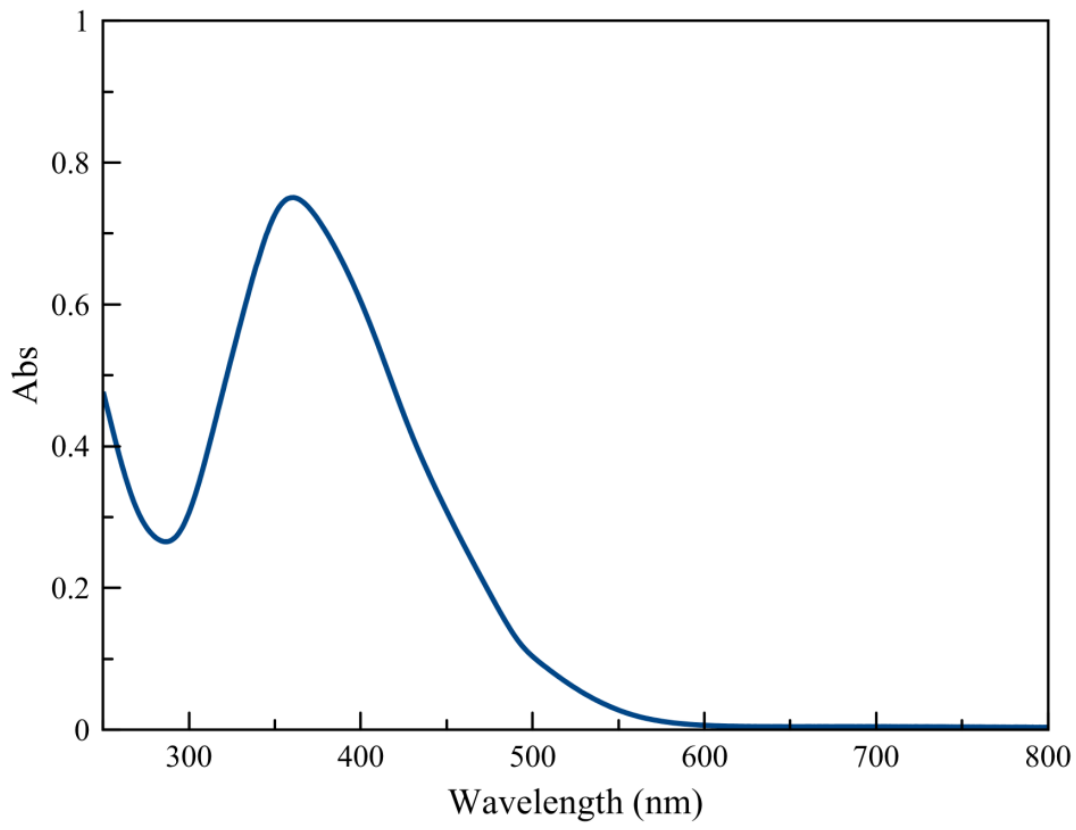

Figure 7. UV-vis of $\left[\mathrm{Fe}_{8}\left(\mu_{4}-\mathrm{O}\right)_{4}(\mu-\mathrm{pz})_{12} \mathrm{Cl}_{4}\right](\mathbf{1})$.

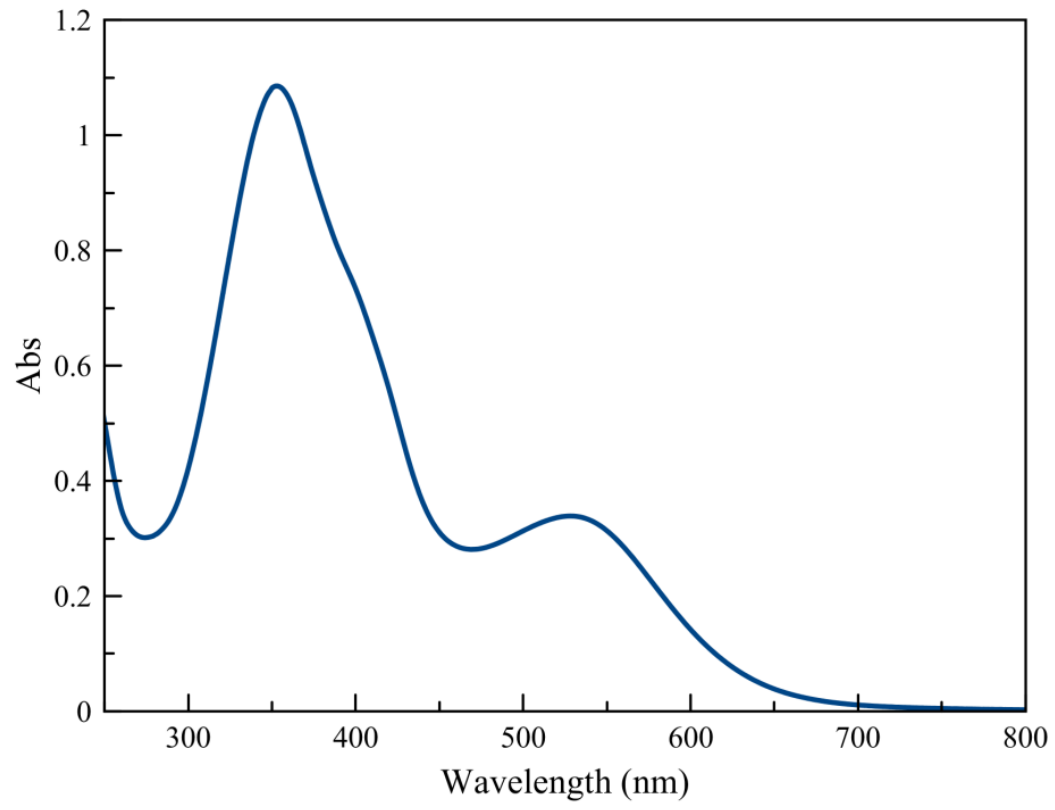

Figure 8. UV-vis of $\left[\mathrm{Fe}_{8}\left(\mu_{4}-\mathrm{O}\right)_{4}(\mu-\mathrm{pz})_{12}\left(4-\mathrm{NO}_{2}-\mathrm{C}_{6} \mathrm{H}_{4} \mathrm{O}\right)_{4}\right](2)$. 


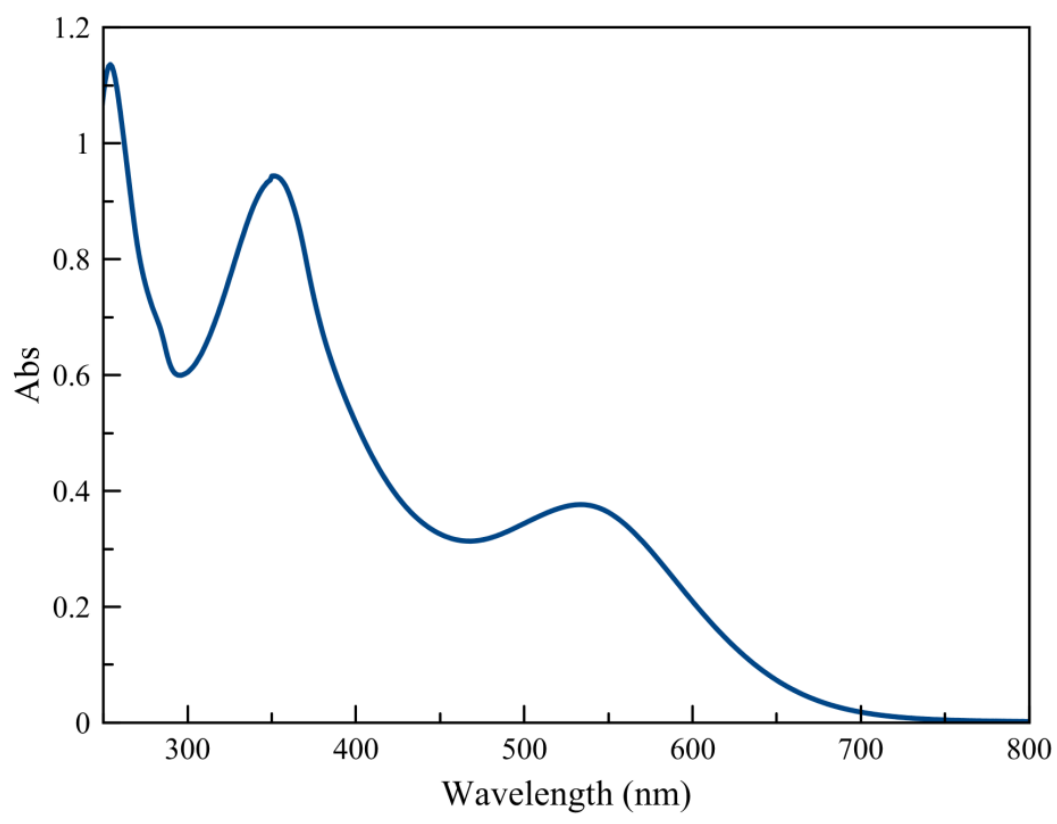

Figure 9. UV-vis of $\left[\mathrm{Fe}_{8}\left(\mu_{4}-\mathrm{O}\right)_{4}(\mu-\mathrm{pz})_{12}\left(4-\mathrm{CN}-\mathrm{C}_{6} \mathrm{H}_{4} \mathrm{O}\right)_{4}\right](3)$.

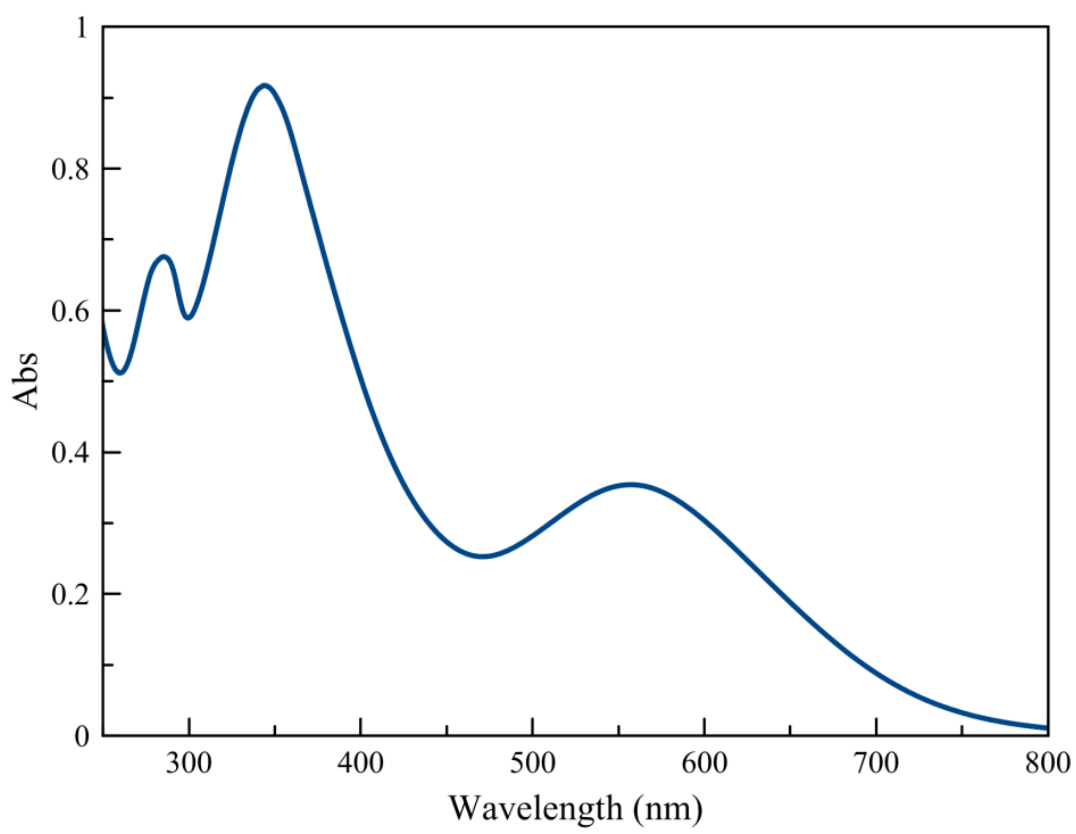

Figure 10. UV-vis of $\left[\mathrm{Fe}_{8}\left(\mu_{4}-\mathrm{O}\right)_{4}(\mu-\mathrm{pz})_{12}\left(4-\mathrm{F}-\mathrm{C}_{6} \mathrm{H}_{4} \mathrm{O}\right)_{4}\right](4)$. 


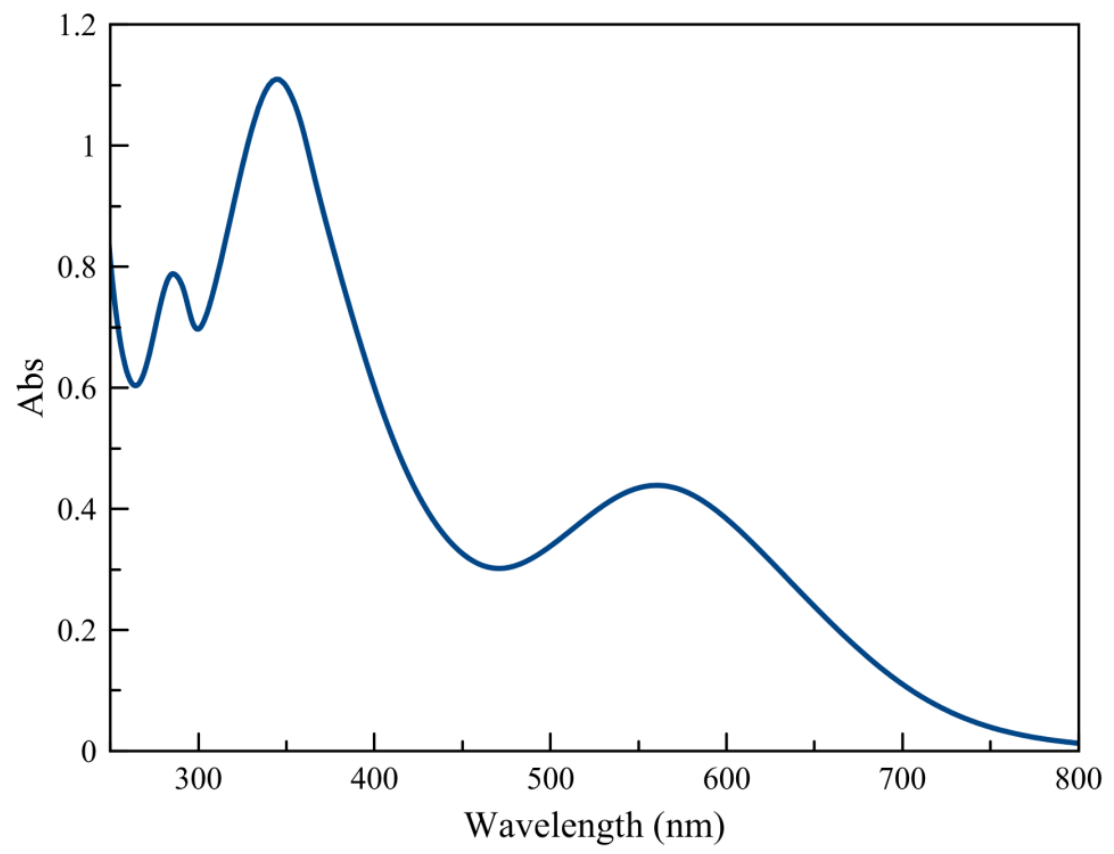

Figure 11. UV-vis of $\left[\mathrm{Fe}_{8}\left(\mu_{4}-\mathrm{O}\right)_{4}(\mu-\mathrm{pz})_{12}\left(4-\mathrm{Cl}-\mathrm{C}_{6} \mathrm{H}_{4} \mathrm{O}\right)_{4}\right](5)$.

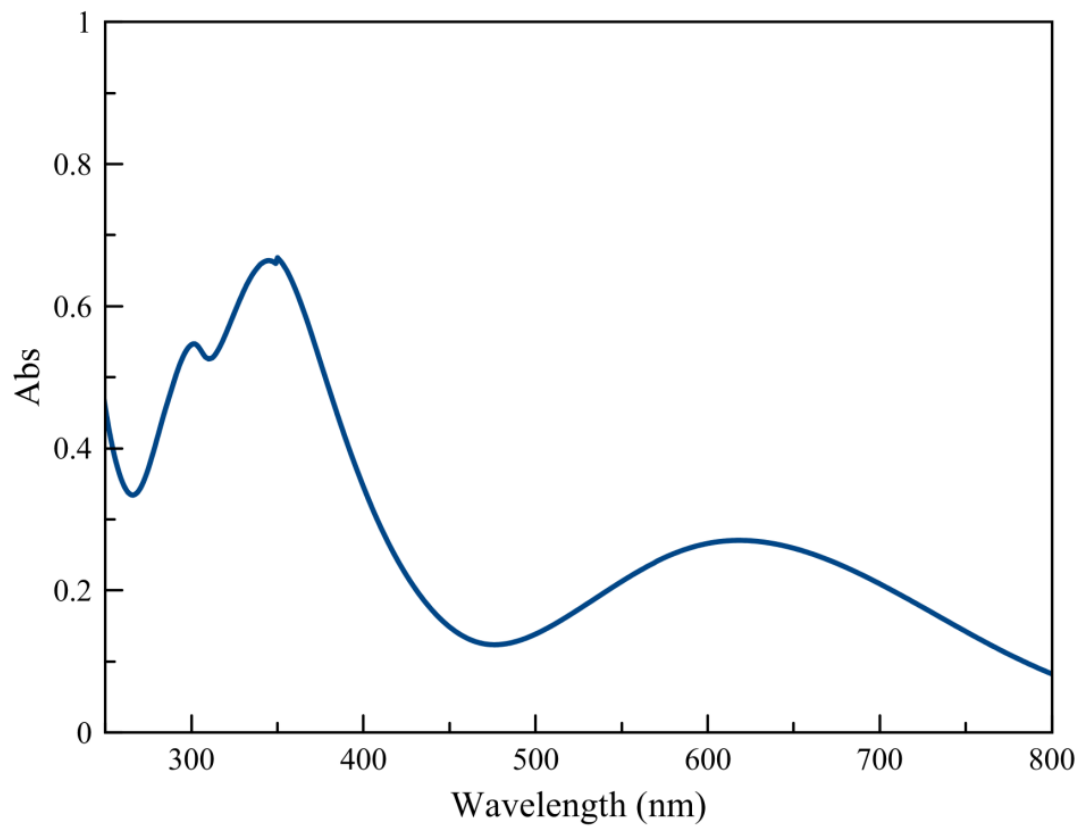

Figure 12. UV-vis of $\left[\mathrm{Fe}_{8}\left(\mu_{4}-\mathrm{O}\right)_{4}(\mu-\mathrm{pz})_{12}\left(4-\mathrm{CH}_{3} \mathrm{O}-\mathrm{C}_{6} \mathrm{H}_{4} \mathrm{O}\right)_{4}\right](7)$. 


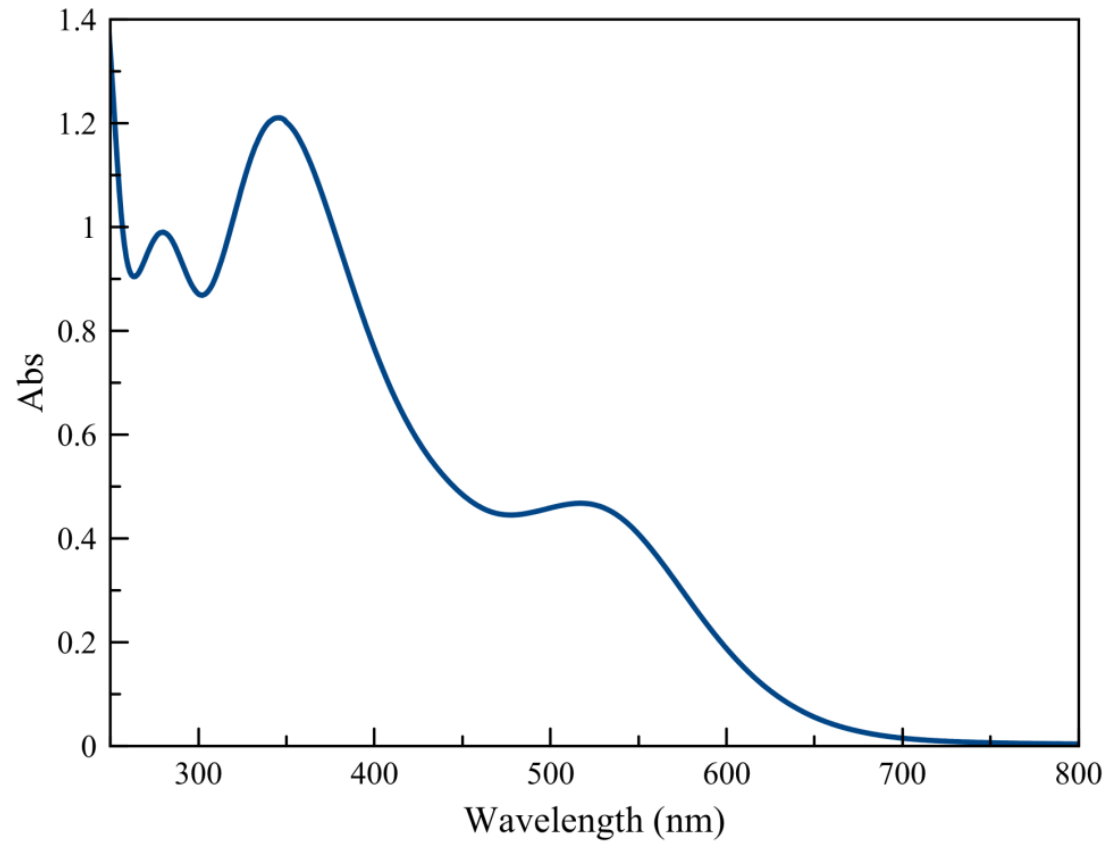

Figure 12. UV-vis of $\left[\mathrm{Fe}_{8}\left(\mu_{4}-\mathrm{O}\right)_{4}(\mu-\mathrm{pz})_{12}\left(3-\mathrm{NO}_{2}-\mathrm{C}_{6} \mathrm{H}_{4} \mathrm{O}\right)_{4}\right](\mathbf{9})$. 
${ }^{57}$ Fe Mössbauer Spectroscopy

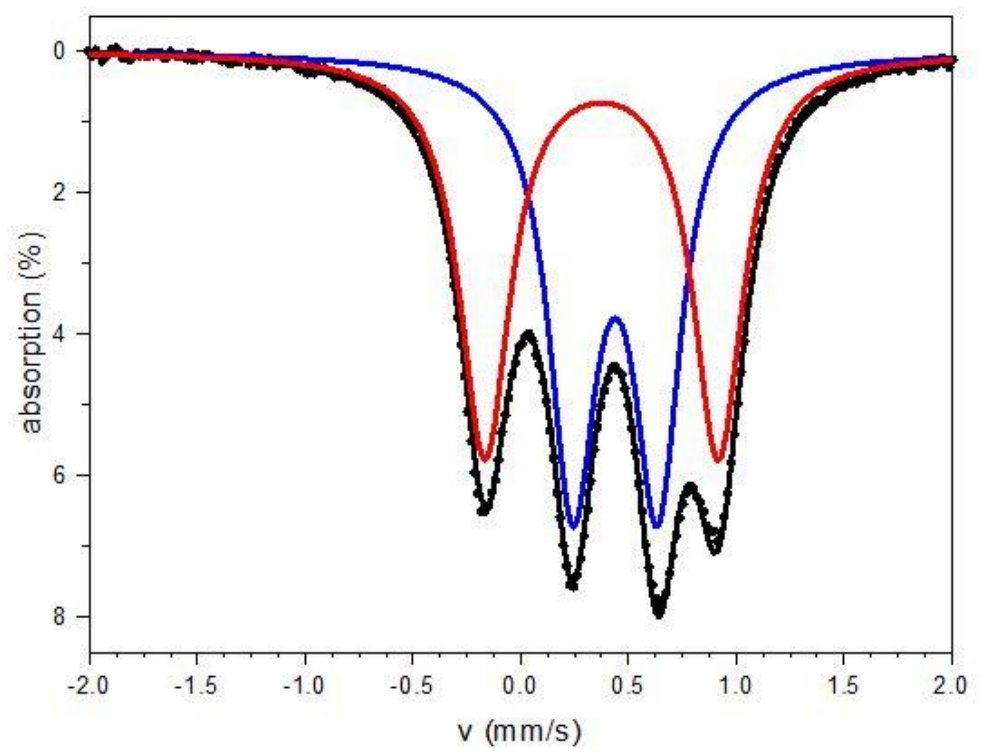

Figure 13. ${ }^{57} \mathrm{Fe}$ Mössbauer of $\left[\mathrm{Fe}_{8}\left(\mu_{4}-\mathrm{O}\right)_{4}(\mu-\mathrm{pz})_{12}\left(4-\mathrm{NO}_{2}-\mathrm{C}_{6} \mathrm{H}_{4} \mathrm{O}\right)_{4}\right]$ (2).

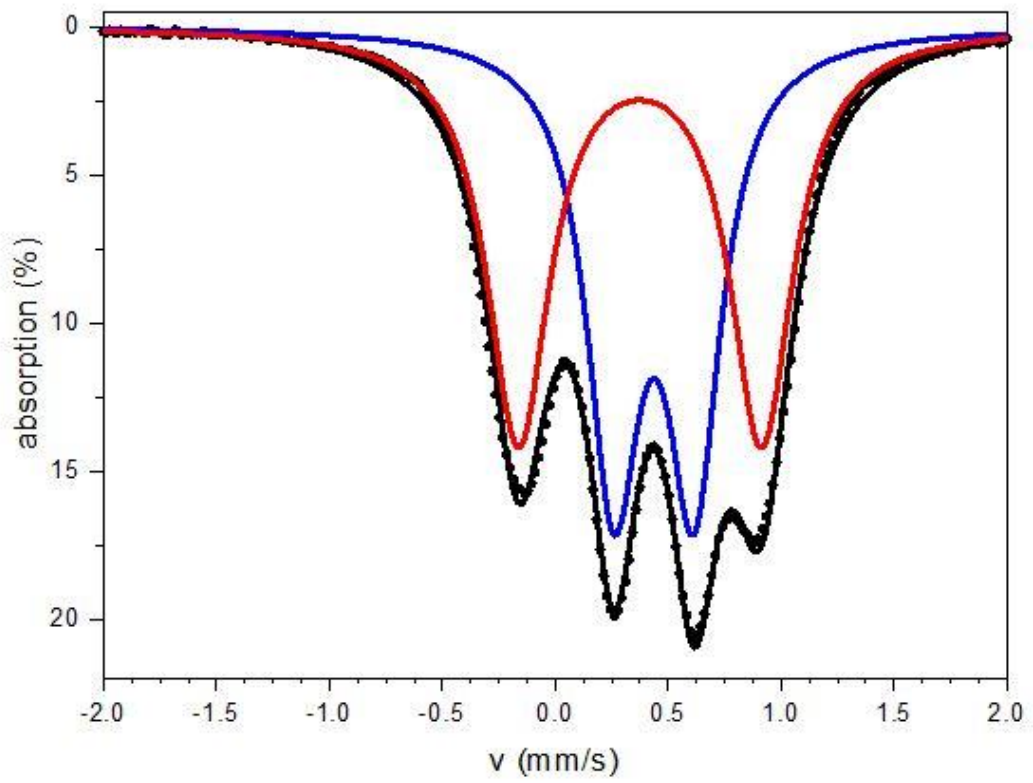

Figure 14. ${ }^{57} \mathrm{Fe}$ Mössbauer of $\left[\mathrm{Fe}_{8}\left(\mu_{4}-\mathrm{O}\right)_{4}(\mu-\mathrm{pz})_{12}\left(4-\mathrm{CN}-\mathrm{C}_{6} \mathrm{H}_{4} \mathrm{O}\right)_{4}\right](3)$. 


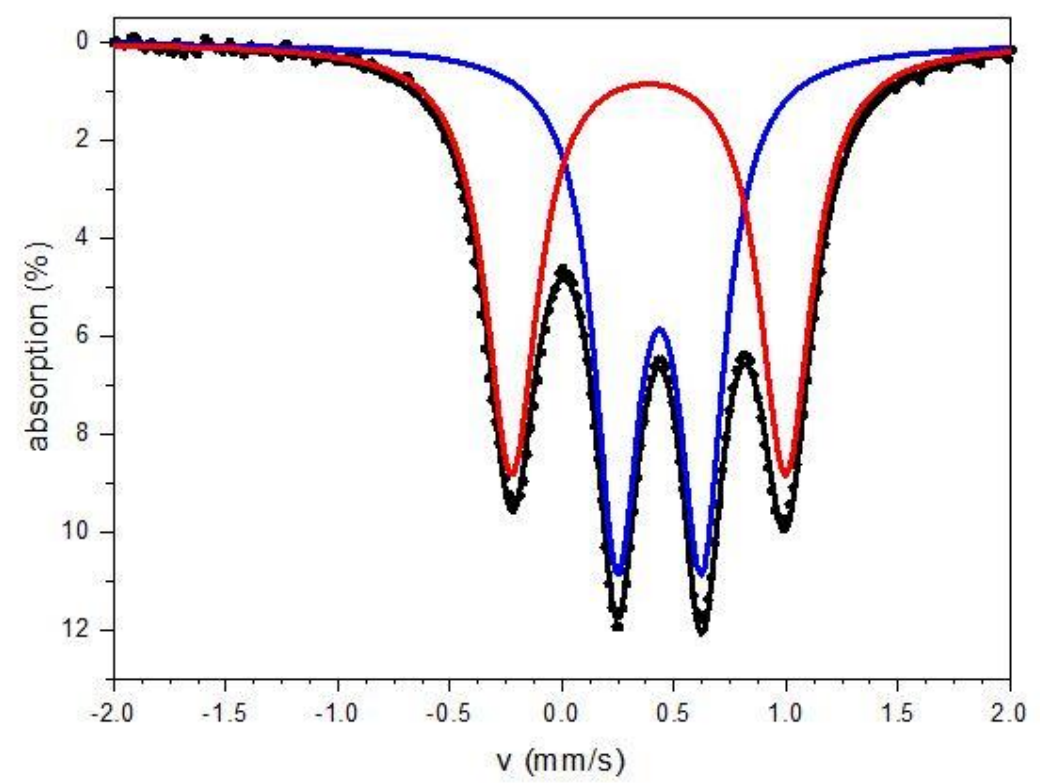

Figure 15. ${ }^{57} \mathrm{Fe}$ Mössbauer of $\left[\mathrm{Fe}_{8}\left(\mu_{4}-\mathrm{O}\right)_{4}(\mu-\mathrm{pz})_{12}\left(4-\mathrm{F}-\mathrm{C}_{6} \mathrm{H}_{4} \mathrm{O}\right)_{4}\right](4)$.

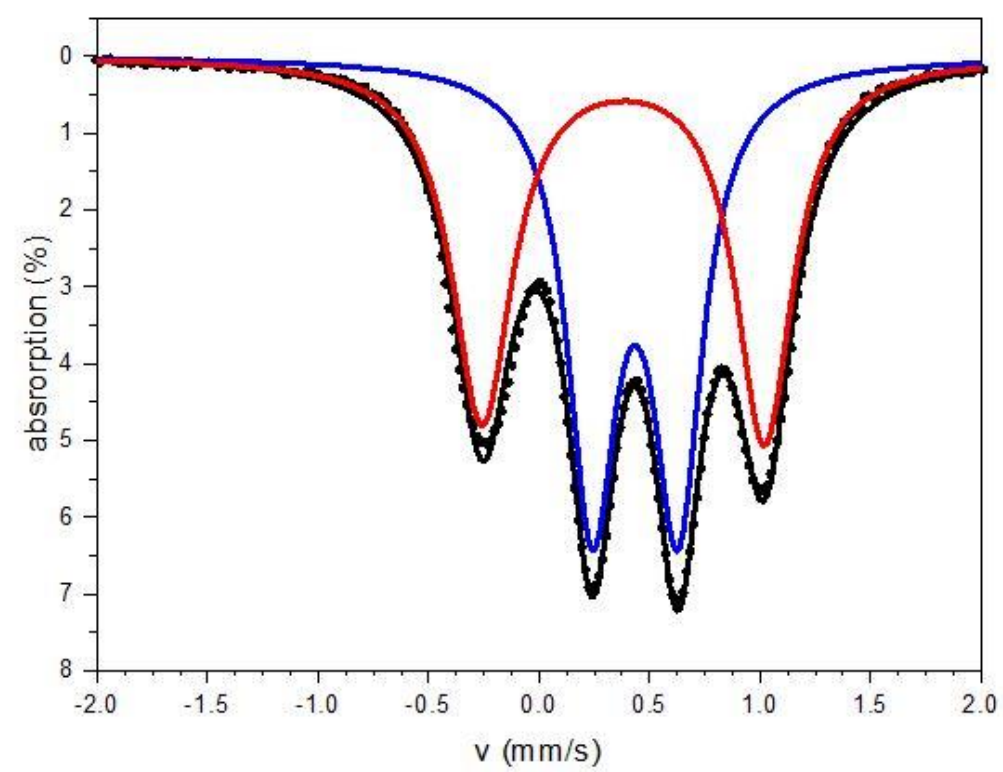

Figure 16. ${ }^{57} \mathrm{Fe}$ Mössbauer of $\left[\mathrm{Fe}_{8}\left(\mu_{4}-\mathrm{O}\right)_{4}(\mu-\mathrm{pz})_{12}\left(4-\mathrm{Cl}-\mathrm{C}_{6} \mathrm{H}_{4} \mathrm{O}\right)_{4}\right](5)$. 


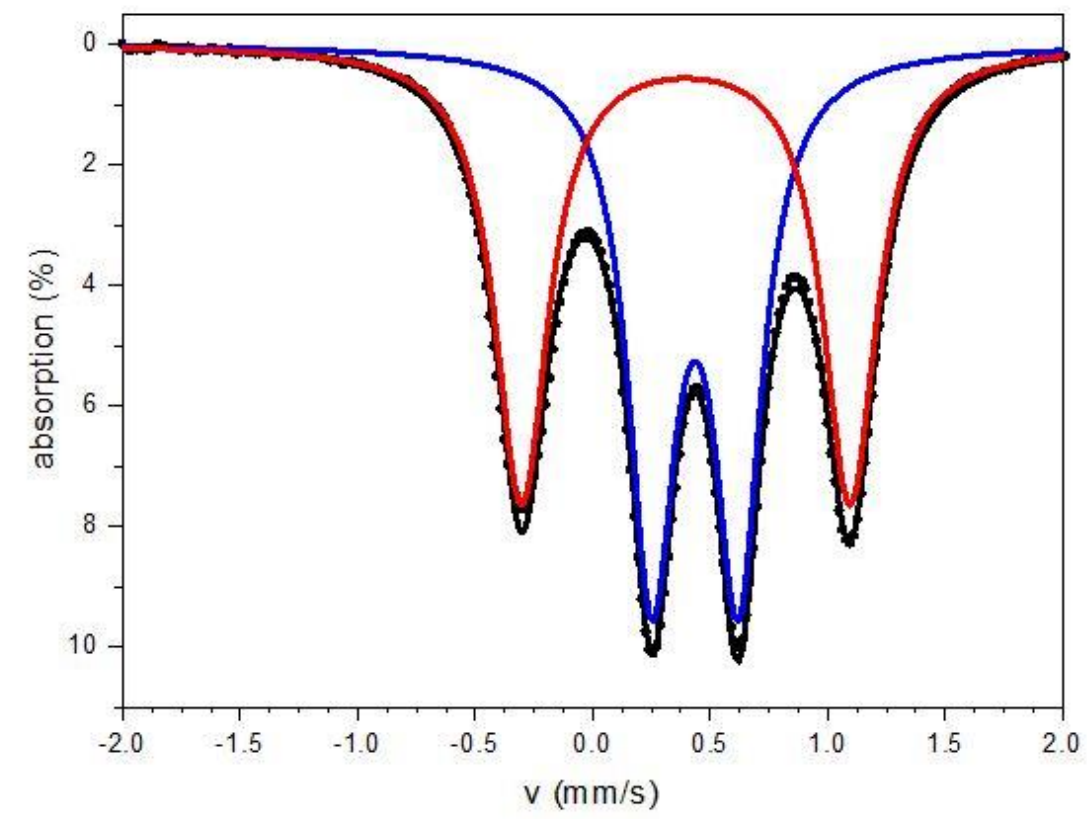

Figure 17. ${ }^{57} \mathrm{Fe}$ Mössbauer of $\left[\mathrm{Fe}_{8}\left(\mu_{4}-\mathrm{O}\right)_{4}(\mu-\mathrm{pz})_{12}\left(4-\mathrm{CH}_{3} \mathrm{O}-\mathrm{C}_{6} \mathrm{H}_{4} \mathrm{O}\right)_{4}\right](7)$.

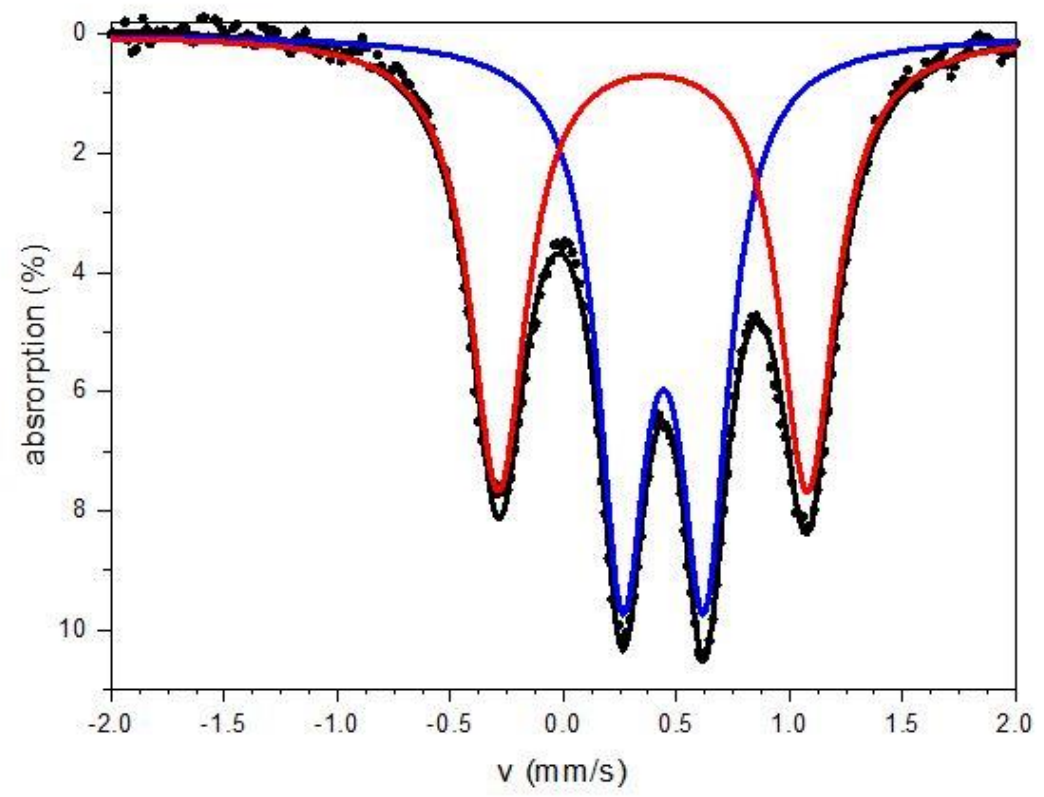

Figure 18. ${ }^{57} \mathrm{Fe}$ Mössbauer of $\left[\mathrm{Fe}_{8}\left(\mu_{4}-\mathrm{O}\right)_{4}(\mu-\mathrm{pz})_{12}\left(4-{ }^{\mathrm{s}} \mathrm{Bu}-\mathrm{C}_{6} \mathrm{H}_{4} \mathrm{O}\right)_{4}\right](\mathbf{8})$. 


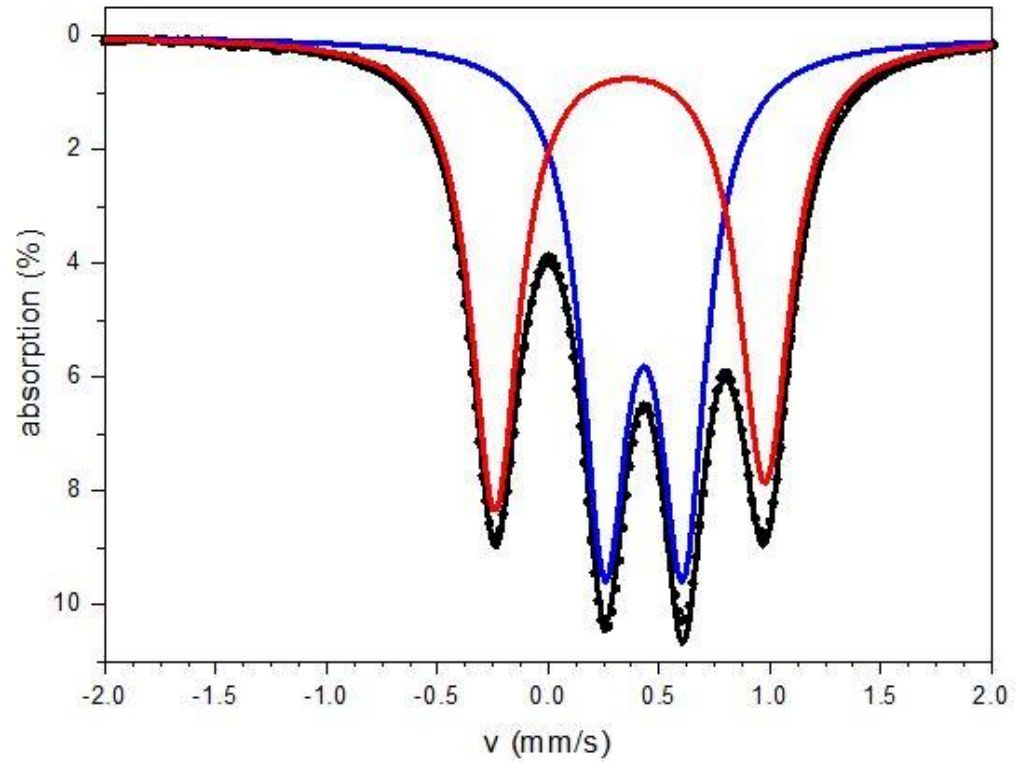

Figure 19. ${ }^{57} \mathrm{Fe}$ Mössbauer of $\left[\mathrm{Fe}_{8}\left(\mu_{4}-\mathrm{O}\right)_{4}(\mu-\mathrm{pz})_{12}\left(3-\mathrm{NO}_{2}-\mathrm{C}_{6} \mathrm{H}_{4} \mathrm{O}\right)_{4}\right](\mathbf{9})$. 
Electrochemistry (Cyclic Voltammetry - Differential Pulse Voltammetry)

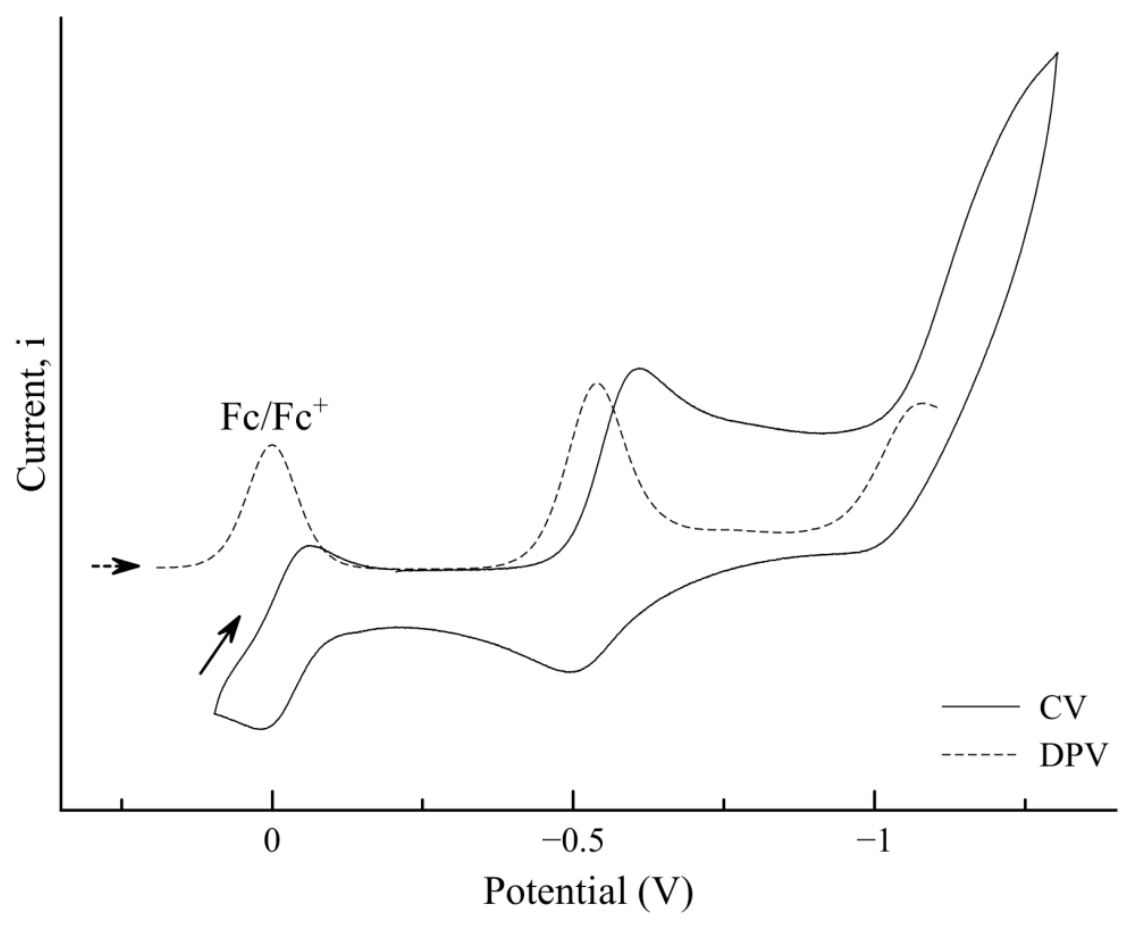

Figure 20. CV-DPV of $\left[\mathrm{Fe}_{8}\left(\mu_{4}-\mathrm{O}\right)_{4}(\mu-\mathrm{pz})_{12}\left(4-\mathrm{CN}-\mathrm{C}_{6} \mathrm{H}_{4} \mathrm{O}\right)_{4}\right](\mathbf{3})$.

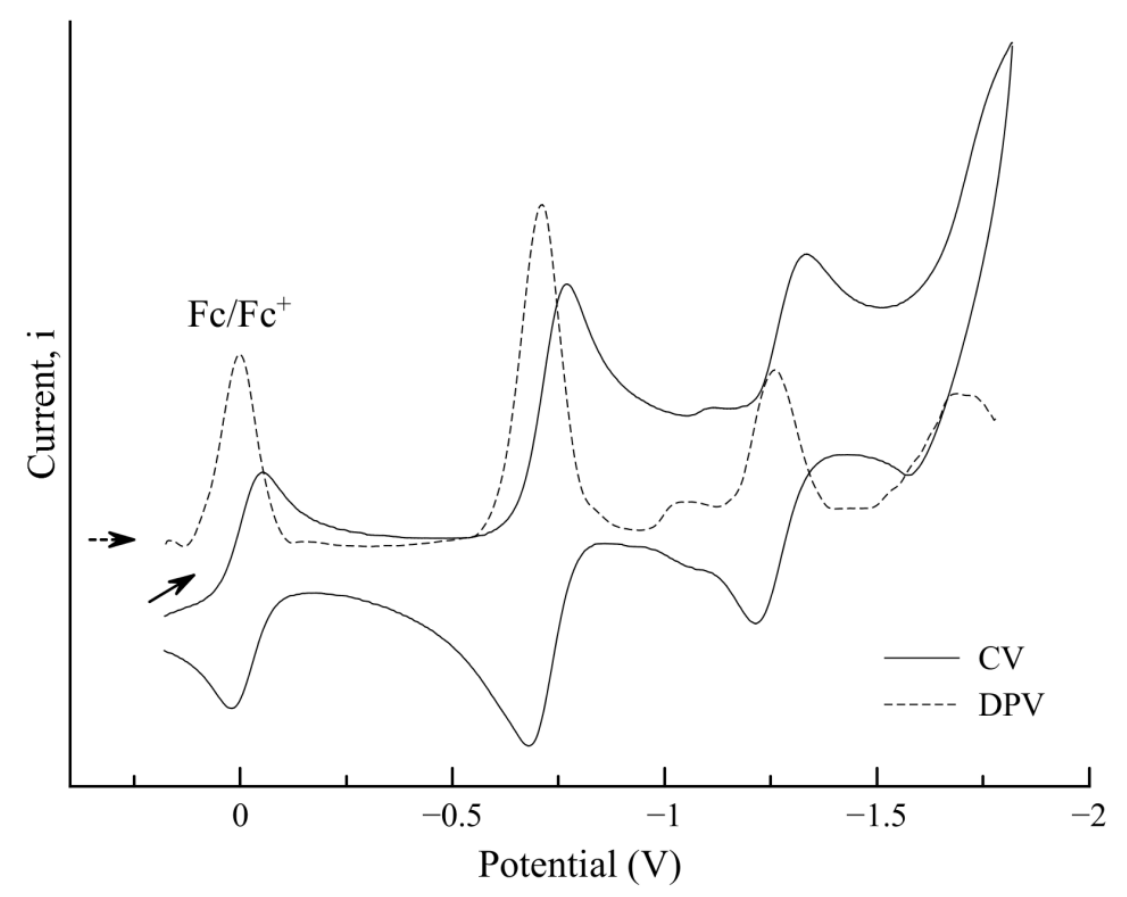

Figure 21. CV-DPV of $\left[\mathrm{Fe}_{8}\left(\mu_{4}-\mathrm{O}\right)_{4}(\mu-\mathrm{pz})_{12}\left(4-\mathrm{F}-\mathrm{C}_{6} \mathrm{H}_{4} \mathrm{O}\right)_{4}\right](4)$. 


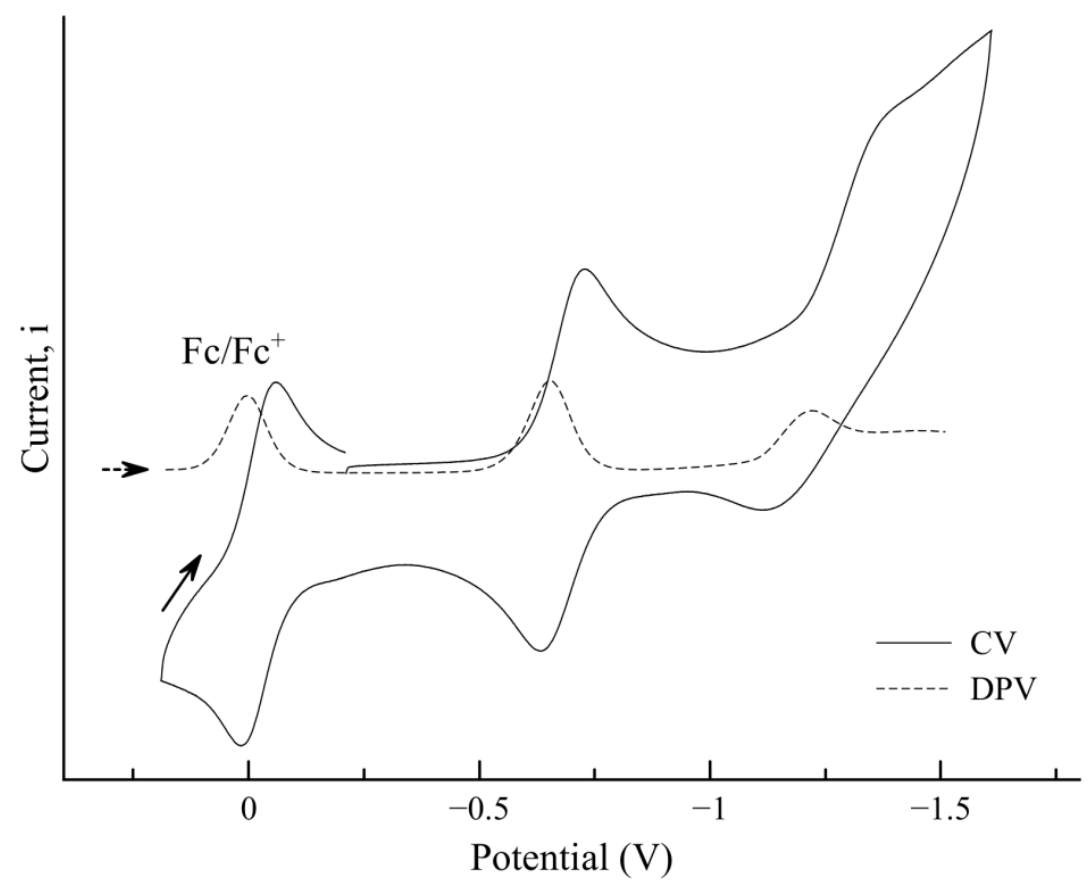

Figure 22. CV-DPV of $\left[\mathrm{Fe}_{8}\left(\mu_{4}-\mathrm{O}\right)_{4}(\mu-\mathrm{pz})_{12}\left(4-\mathrm{Cl}-\mathrm{C}_{6} \mathrm{H}_{4} \mathrm{O}\right)_{4}\right](5)$.

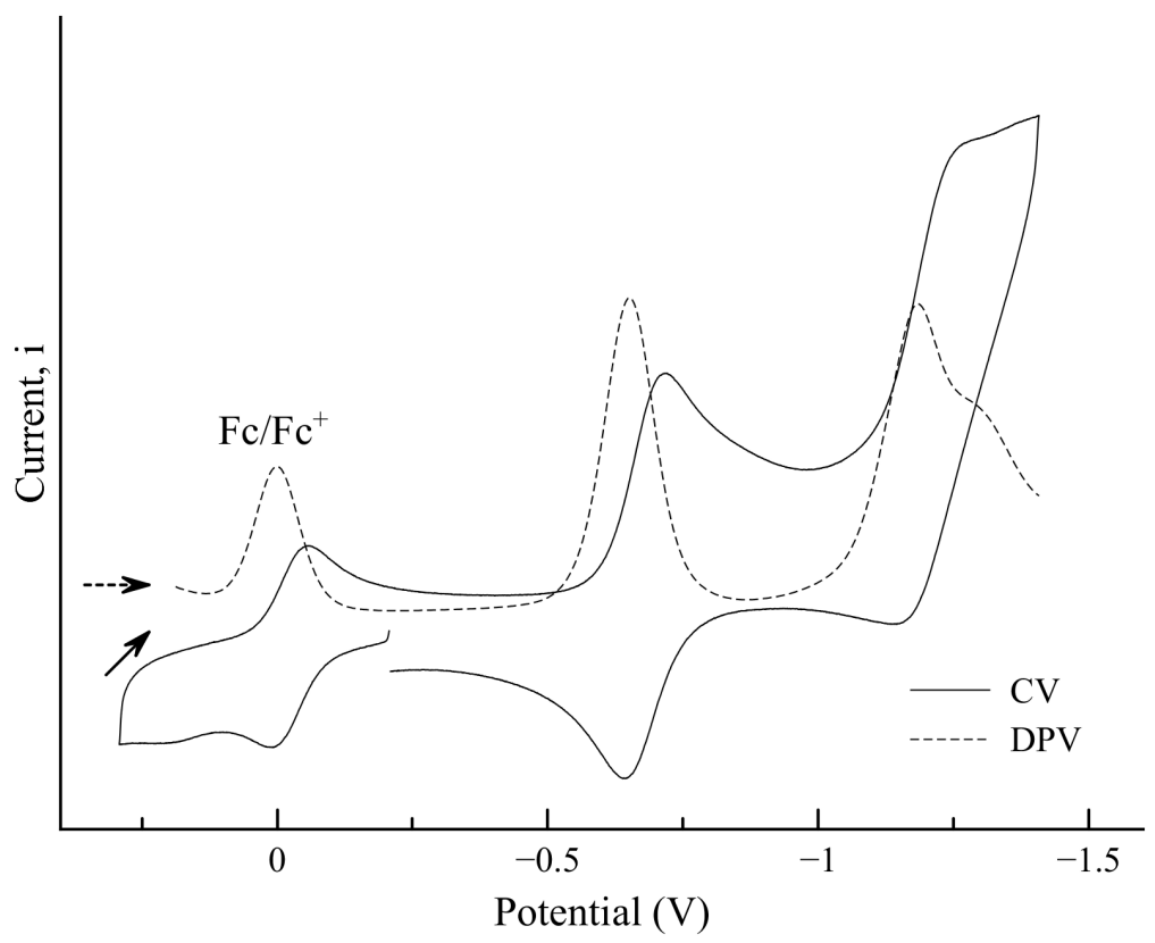

Figure 23. CV-DPV of $\left[\mathrm{Fe}_{8}\left(\mu_{4}-\mathrm{O}\right)_{4}(\mu-\mathrm{pz})_{12}\left(4-\mathrm{I}-\mathrm{C}_{6} \mathrm{H}_{4} \mathrm{O}\right)_{4}\right](\mathbf{6})$. 


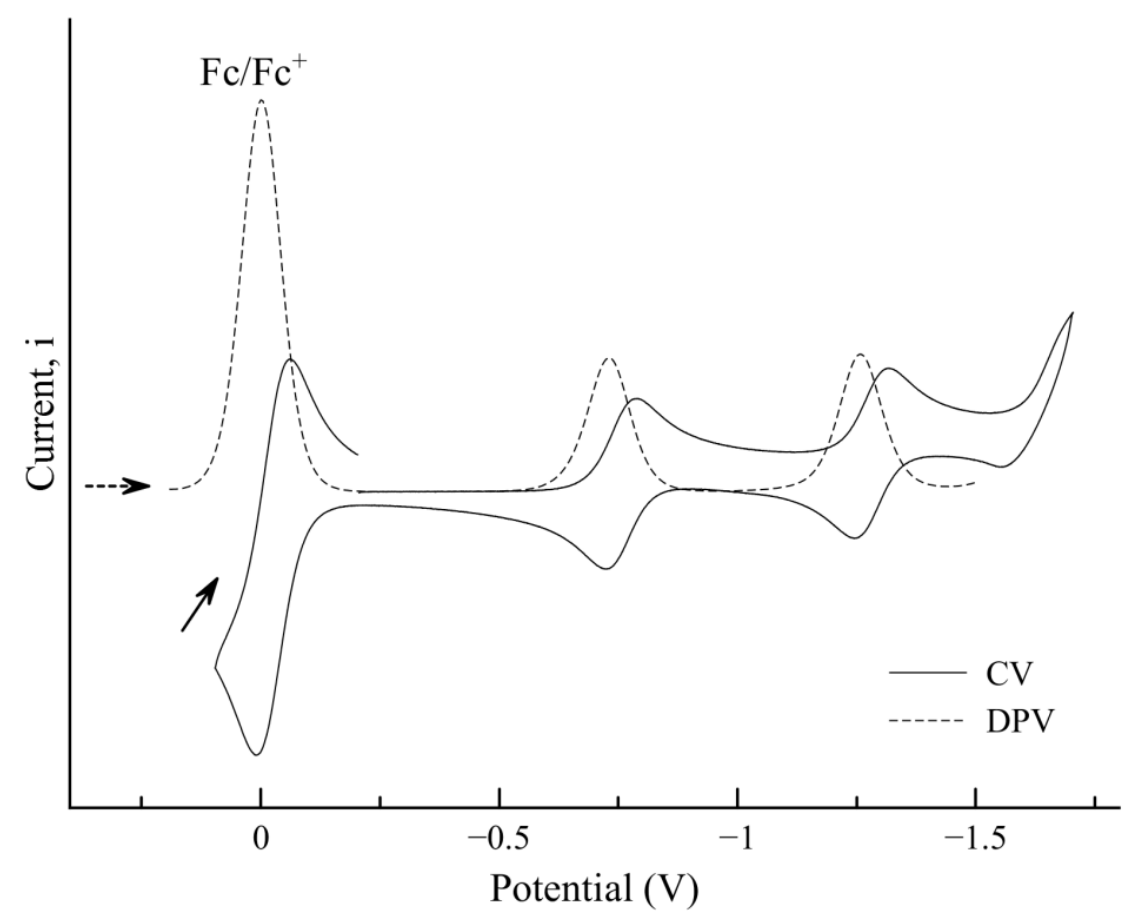

Figure 24. CV-DPV of $\left[\mathrm{Fe}_{8}\left(\mu_{4}-\mathrm{O}\right)_{4}(\mu-\mathrm{pz})_{12}\left(4-\mathrm{CH}_{3} \mathrm{O}-\mathrm{C}_{6} \mathrm{H}_{4} \mathrm{O}\right)_{4}\right](7)$.

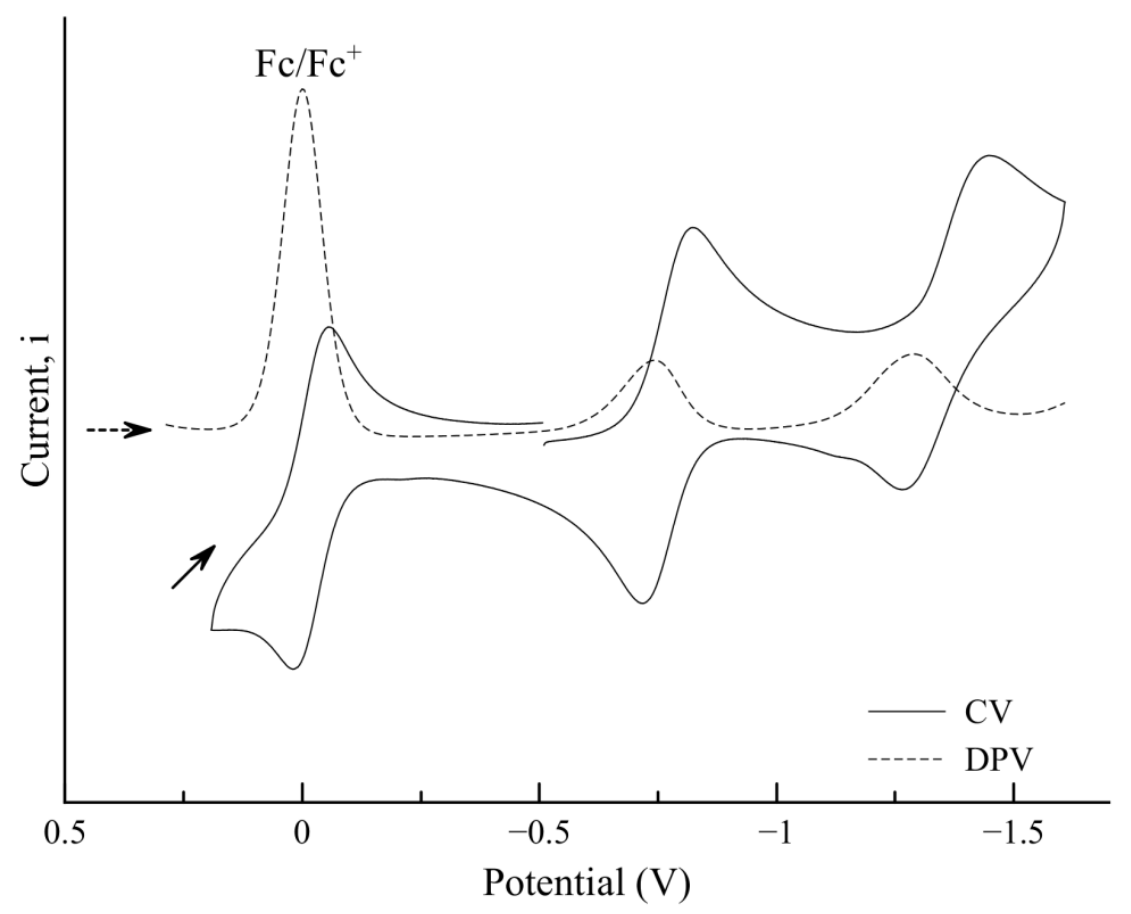

Figure 25. CV-DPV of $\left[\mathrm{Fe}_{8}\left(\mu_{4}-\mathrm{O}\right)_{4}(\mu-\mathrm{pz})_{12}\left(4-{ }^{\mathrm{s}} \mathrm{Bu}-\mathrm{C}_{6} \mathrm{H}_{4} \mathrm{O}\right)_{4}\right](\mathbf{8})$. 


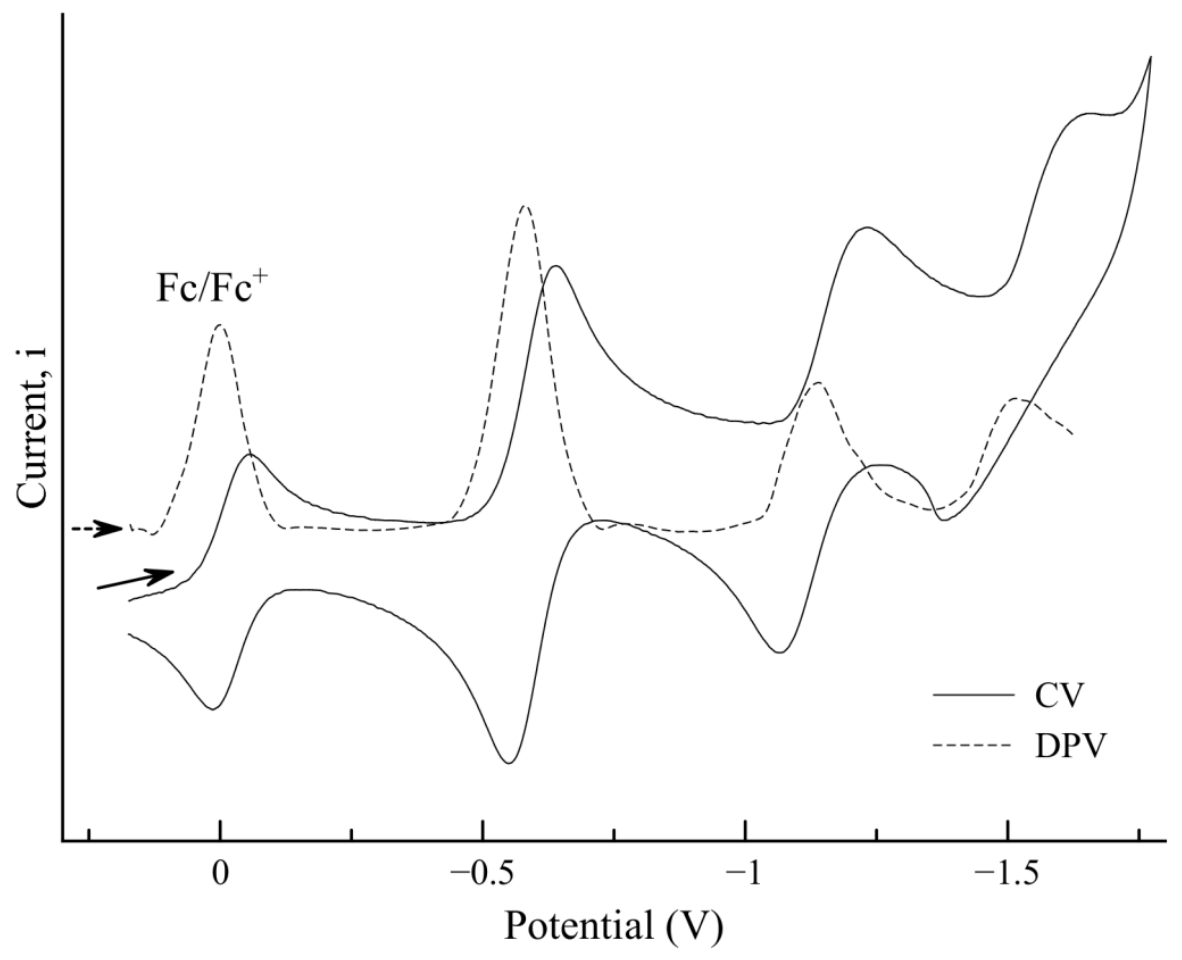

Figure 26. CV-DPV of $\left[\mathrm{Fe}_{8}\left(\mu_{4}-\mathrm{O}\right)_{4}(\mu-\mathrm{pz})_{12}\left(3-\mathrm{NO}_{2}-\mathrm{C}_{6} \mathrm{H}_{4} \mathrm{O}\right)_{4}\right](\mathbf{9})$. 


\section{MID-FAR-IR Spectroscopy}

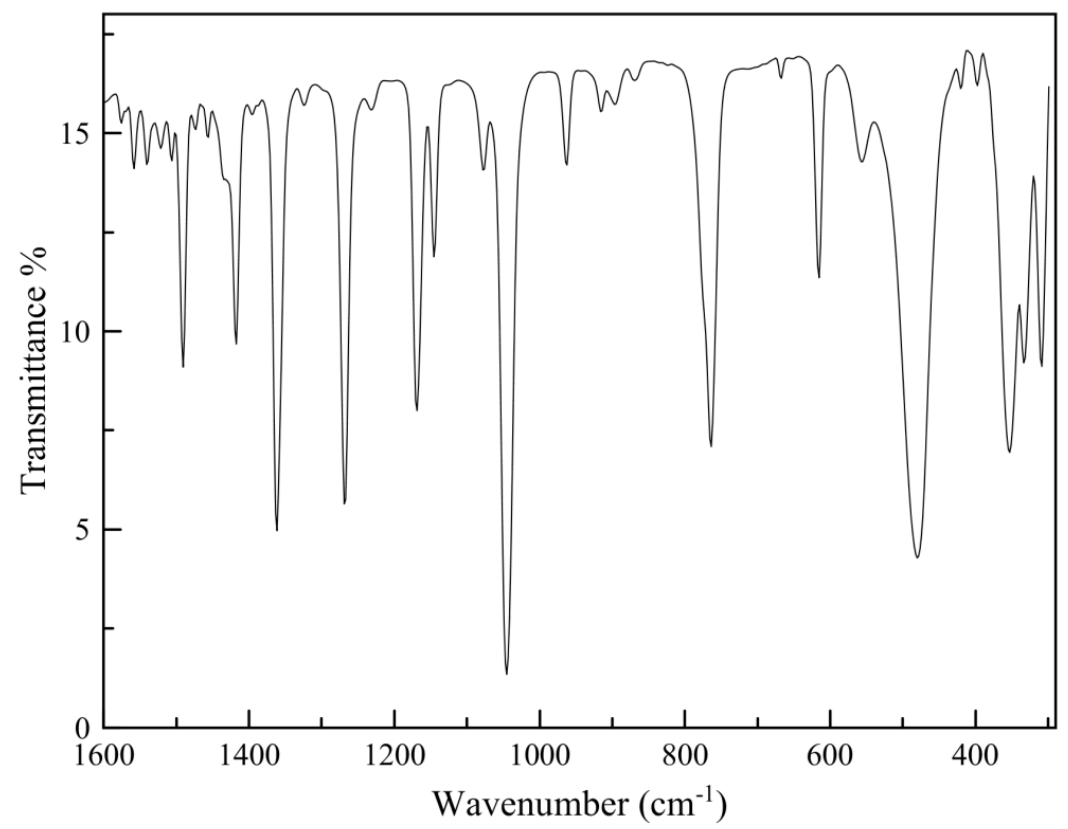

Figure 27. MID-FAR-IR of $\left[\mathrm{Fe}_{8}\left(\mu_{4}-\mathrm{O}\right)_{4}(\mu-\mathrm{pz})_{12} \mathrm{Cl}_{4}\right](\mathbf{1})$.

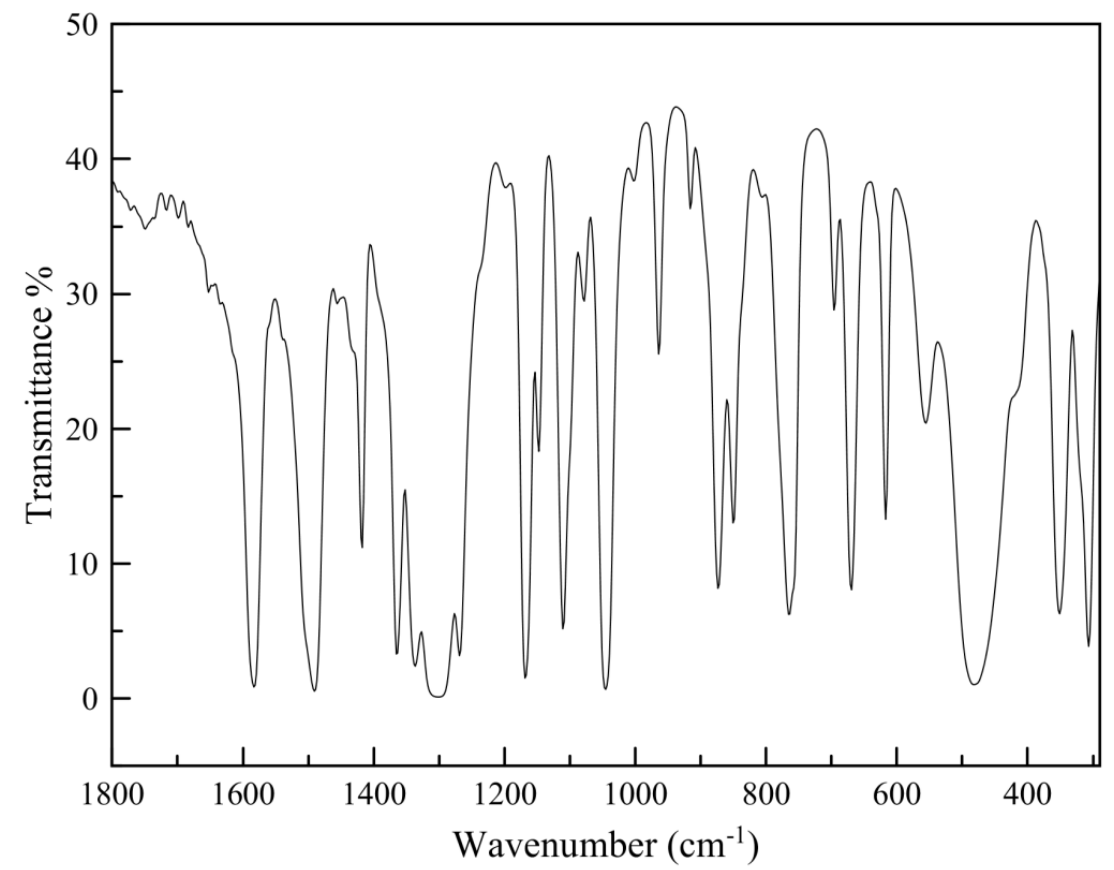

Figure 28. MID-FAR-IR of $\left[\mathrm{Fe}_{8}\left(\mu_{4}-\mathrm{O}\right)_{4}(\mu-\mathrm{pz})_{12}\left(4-\mathrm{NO}_{2}-\mathrm{C}_{6} \mathrm{H}_{4} \mathrm{O}\right)_{4}\right](\mathbf{2})$. 


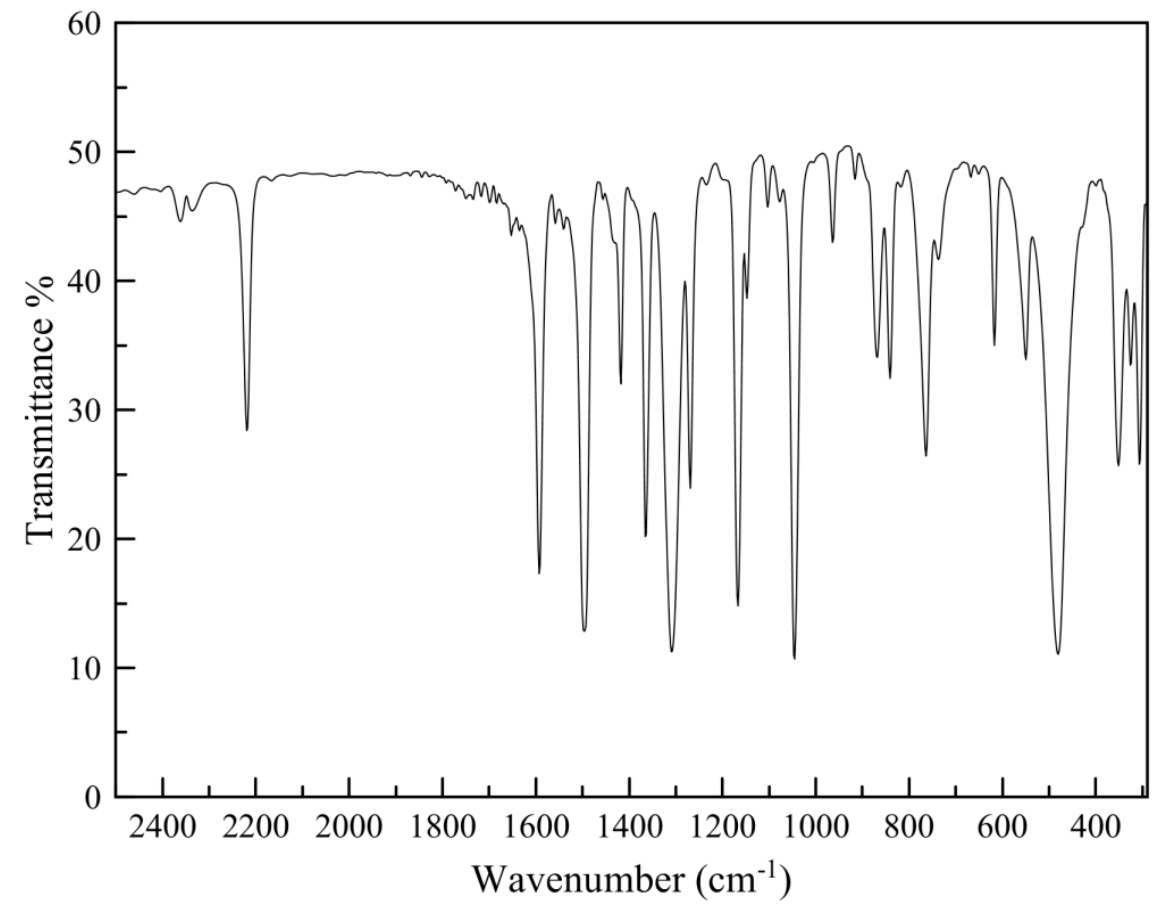

Figure 29. MID-FAR-IR of $\left[\mathrm{Fe}_{8}\left(\mu_{4}-\mathrm{O}\right)_{4}(\mu-\mathrm{pz})_{12}\left(4-\mathrm{CN}-\mathrm{C}_{6} \mathrm{H}_{4} \mathrm{O}\right)_{4}\right](3)$.

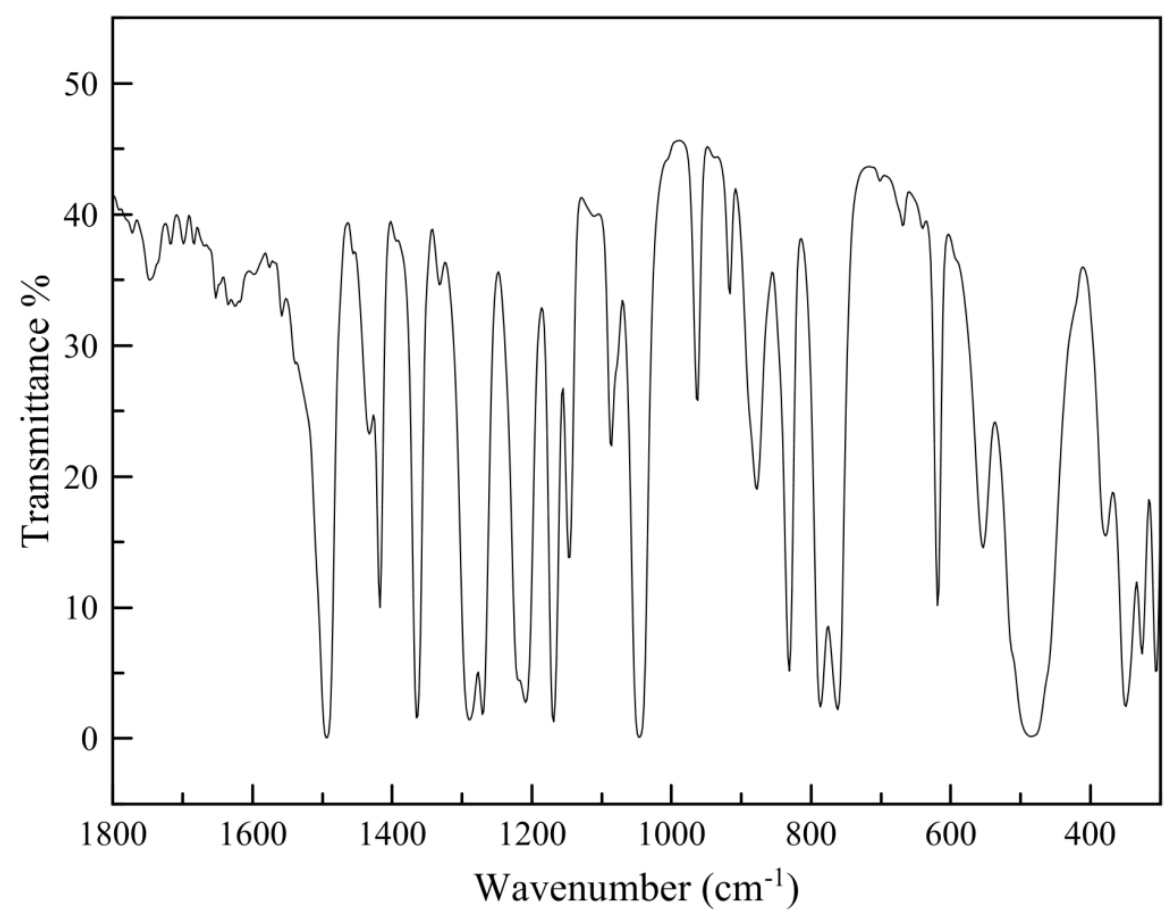

Figure 30. MID-FAR-IR of $\left[\mathrm{Fe}_{8}\left(\mu_{4}-\mathrm{O}\right)_{4}(\mu-\mathrm{pz})_{12}\left(4-\mathrm{F}-\mathrm{C}_{6} \mathrm{H}_{4} \mathrm{O}\right)_{4}\right](4)$. 


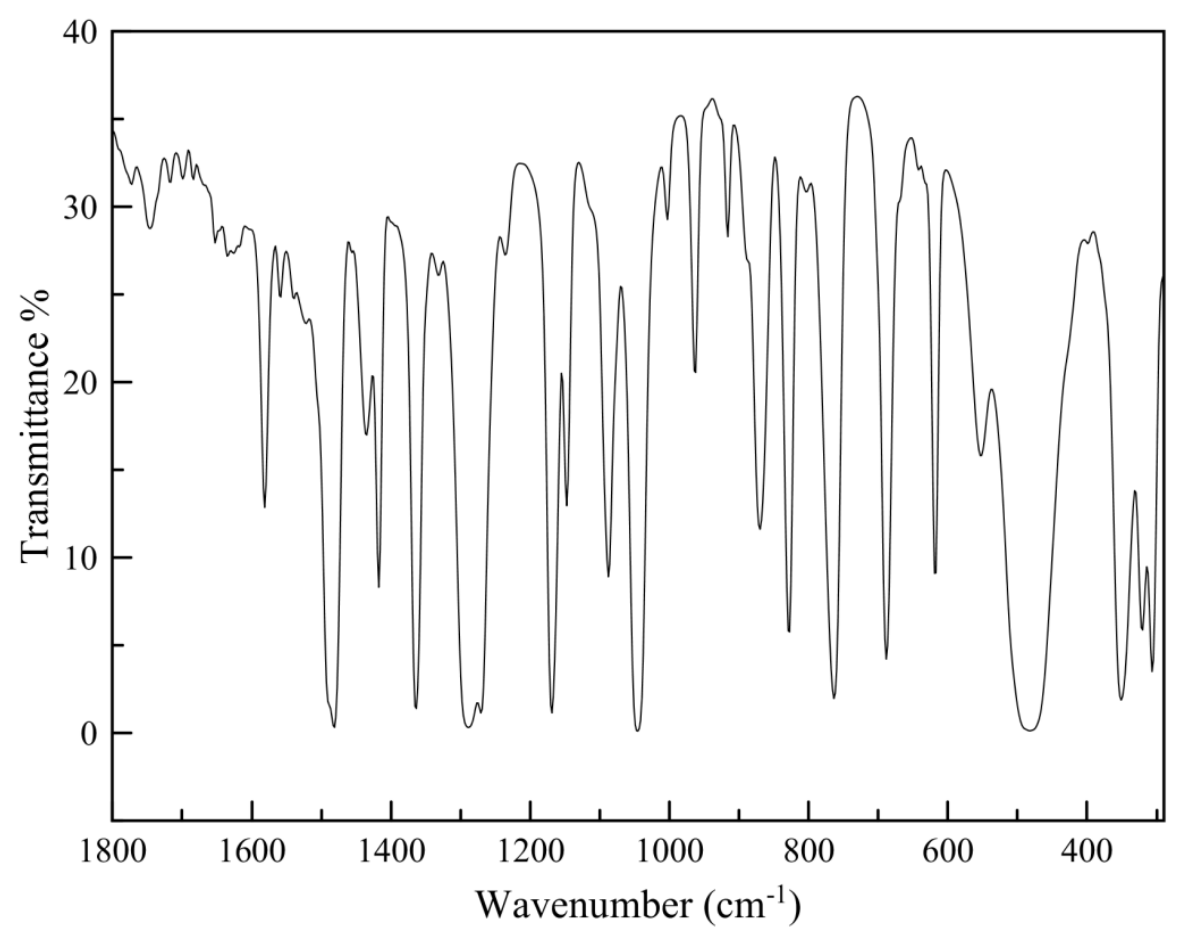

Figure 31. MID-FAR-IR of $\left[\mathrm{Fe}_{8}\left(\mu_{4}-\mathrm{O}\right)_{4}(\mu-\mathrm{pz})_{12}\left(4-\mathrm{Cl}-\mathrm{C}_{6} \mathrm{H}_{4} \mathrm{O}\right)_{4}\right](5)$.

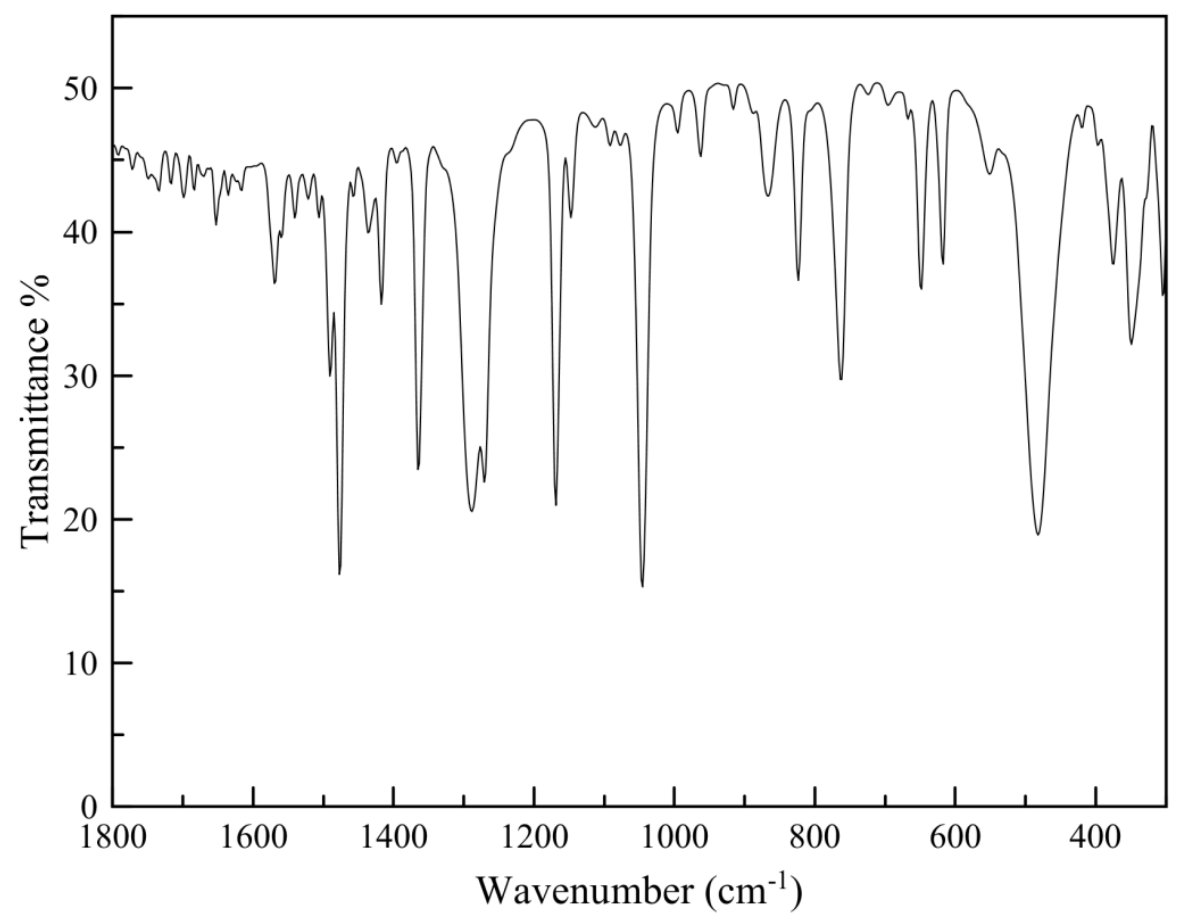

Figure 32. MID-FAR-IR of $\left[\mathrm{Fe}_{8}\left(\mu_{4}-\mathrm{O}\right)_{4}(\mu-\mathrm{pz})_{12}\left(4-\mathrm{I}-\mathrm{C}_{6} \mathrm{H}_{4} \mathrm{O}\right)_{4}\right](6)$. 


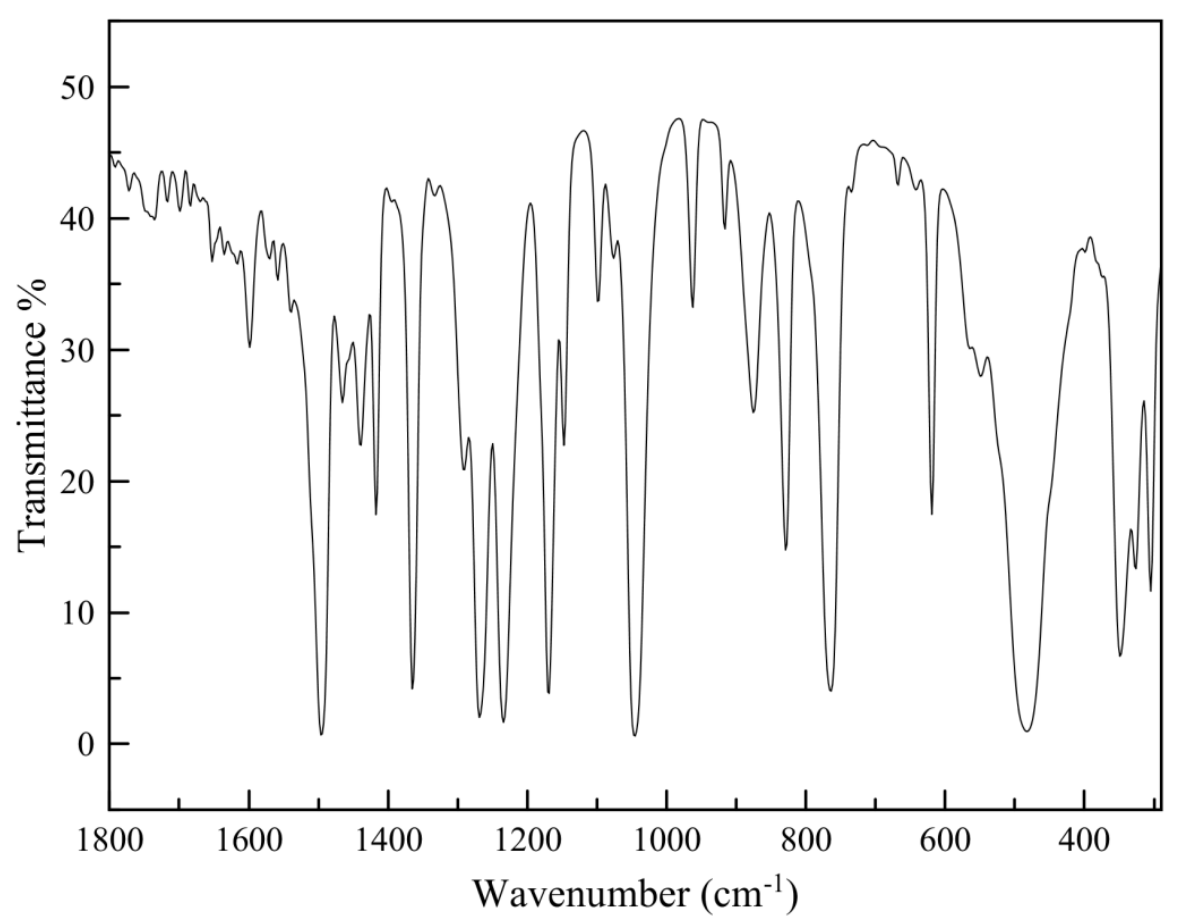

Figure 33. MID-FAR-IR of $\left[\mathrm{Fe}_{8}\left(\mu_{4}-\mathrm{O}\right)_{4}(\mu-\mathrm{pz})_{12}\left(4-\mathrm{CH}_{3} \mathrm{O}-\mathrm{C}_{6} \mathrm{H}_{4} \mathrm{O}\right)_{4}\right](7)$.

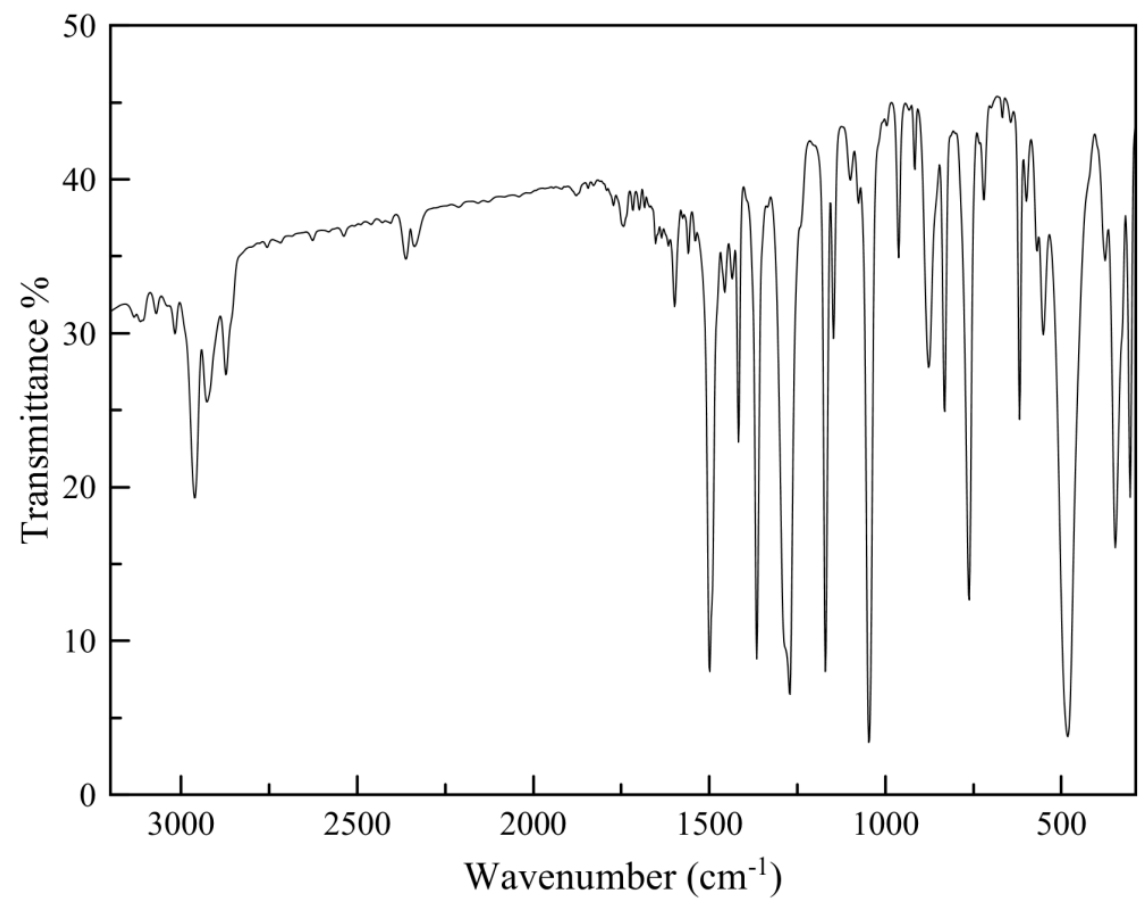

Figure 34. MID-FAR-IR of $\left[\mathrm{Fe}_{8}\left(\mu_{4}-\mathrm{O}\right)_{4}(\mu-\mathrm{pz})_{12}\left(4-{ }^{\mathrm{s}} \mathrm{Bu}-\mathrm{C}_{6} \mathrm{H}_{4} \mathrm{O}\right)_{4}\right](\mathbf{8})$. 


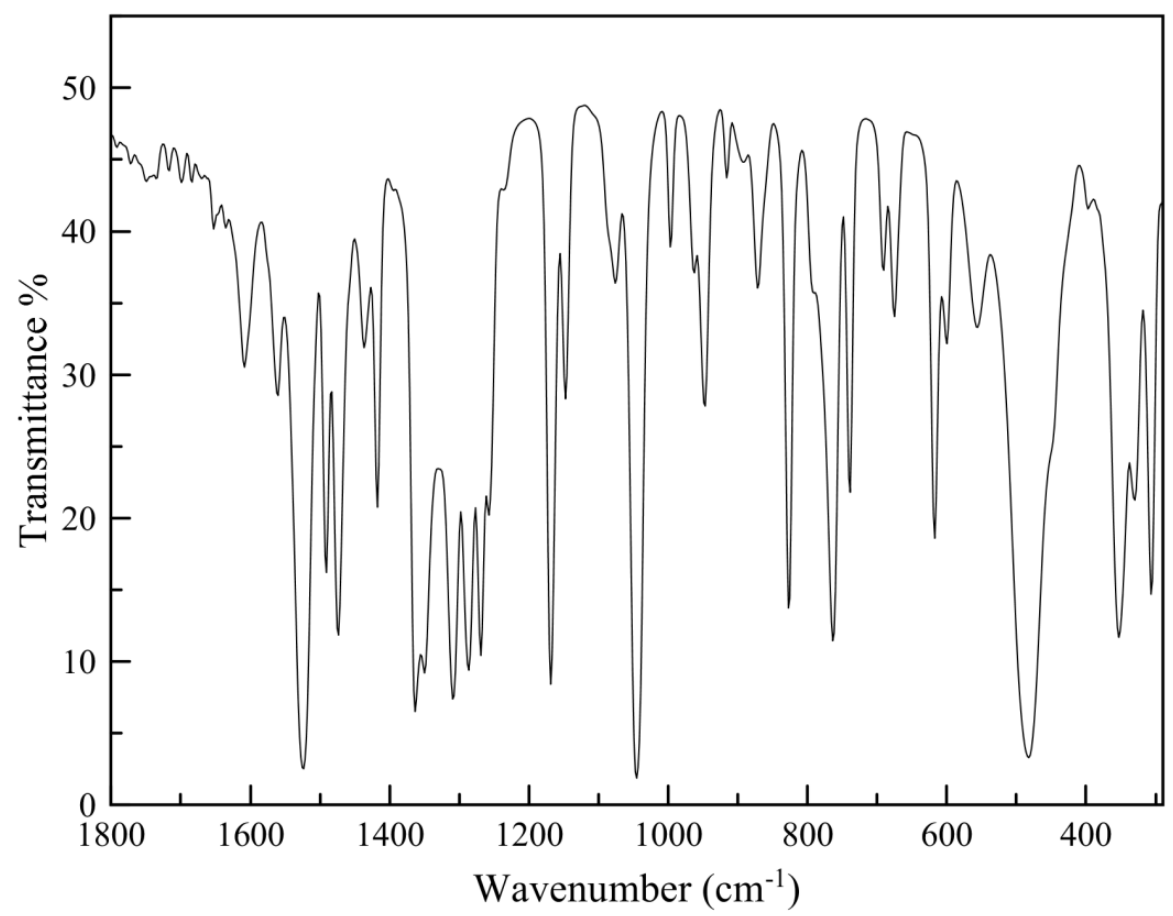

Figure 35. MID-FAR-IR of $\left[\mathrm{Fe}_{8}\left(\mu_{4}-\mathrm{O}\right)_{4}(\mu-\mathrm{pz})_{12}\left(3-\mathrm{NO}_{2}-\mathrm{C}_{6} \mathrm{H}_{4} \mathrm{O}\right)_{4}\right](9)$.

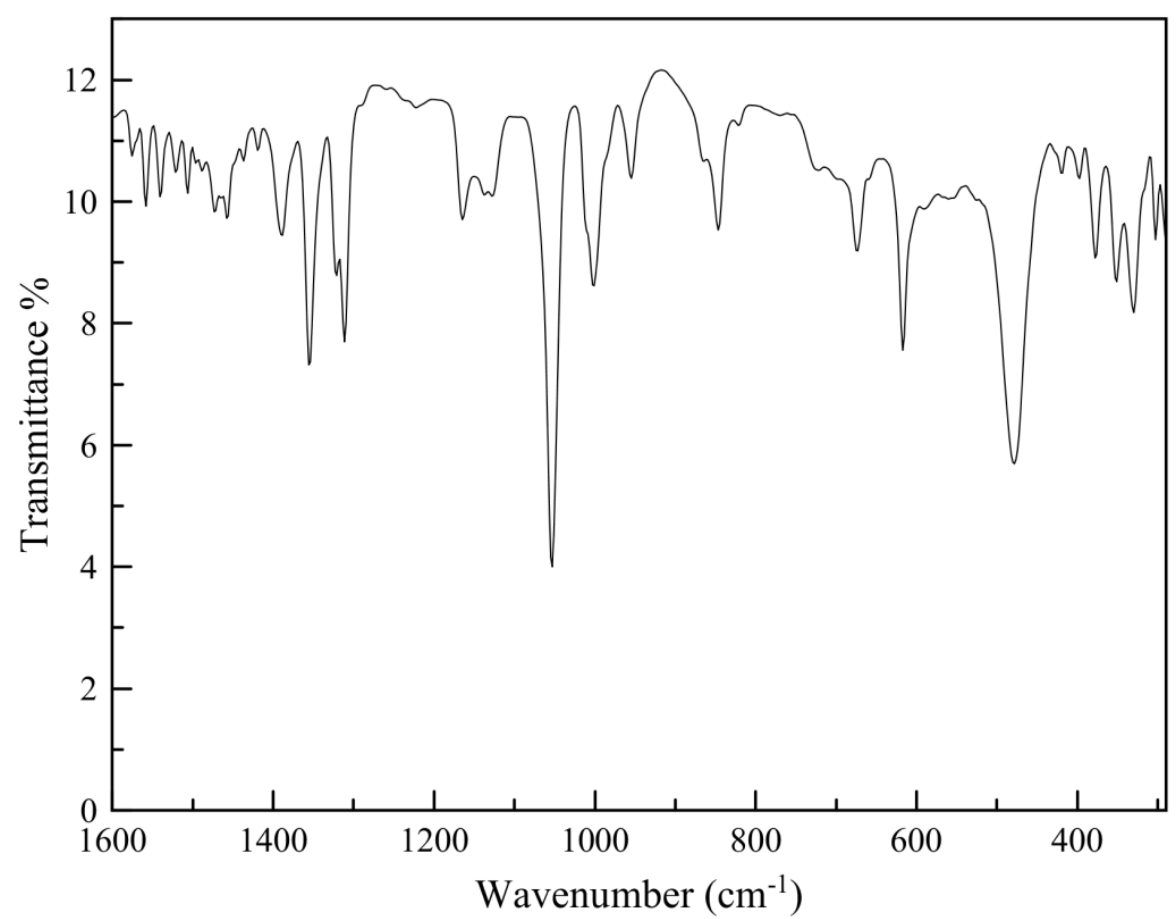

Figure 36. MID-FAR-IR of $\left[\mathrm{Fe}_{8}\left(\mu_{4}-\mathrm{O}\right)_{4}\left(\mu-4-\mathrm{CH}_{3}-\mathrm{pz}\right)_{12} \mathrm{Cl}_{4}\right](\mathbf{1 0})$. 


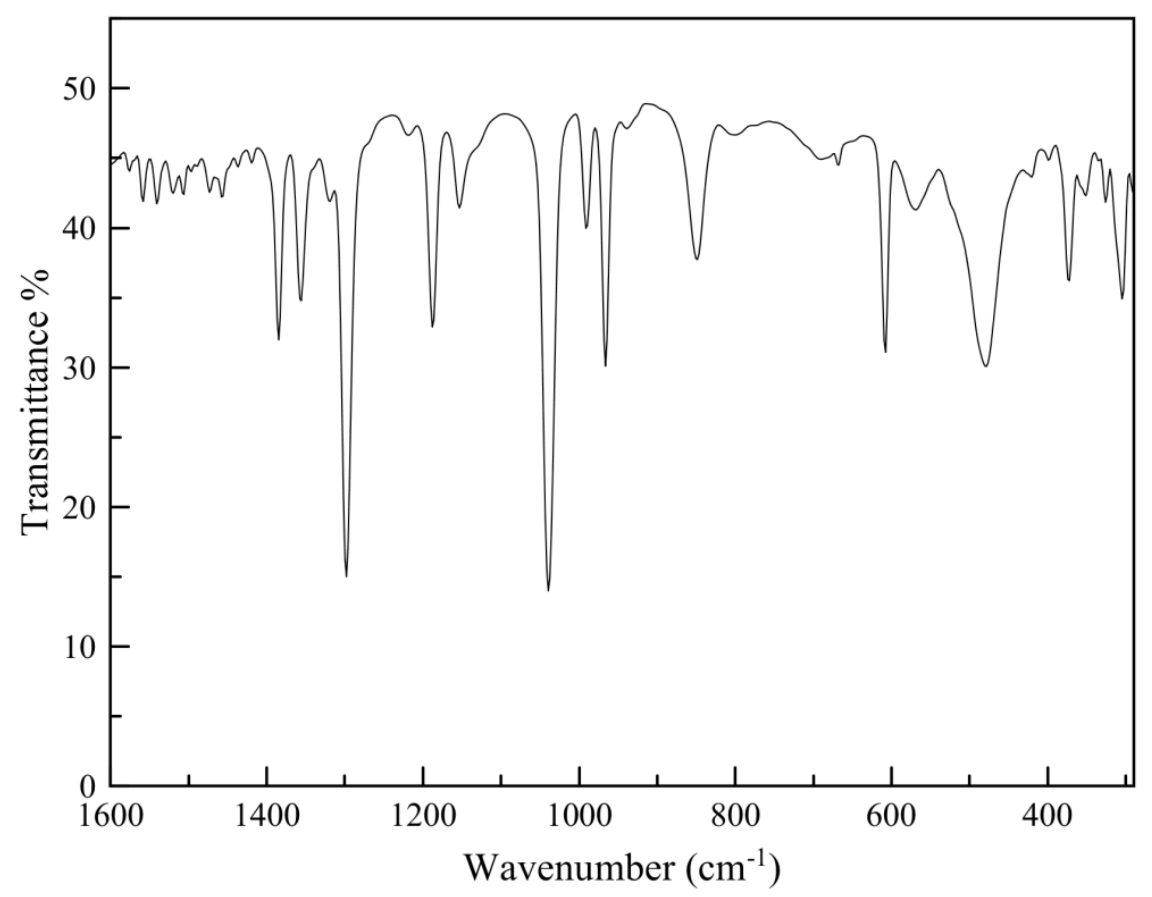

Figure 37. MID-FAR-IR of $\left[\mathrm{Fe}_{8}\left(\mu_{4}-\mathrm{O}\right)_{4}(\mu-4-\mathrm{Cl}-\mathrm{pz})_{12} \mathrm{Cl}_{4}\right](\mathbf{1 1})$.

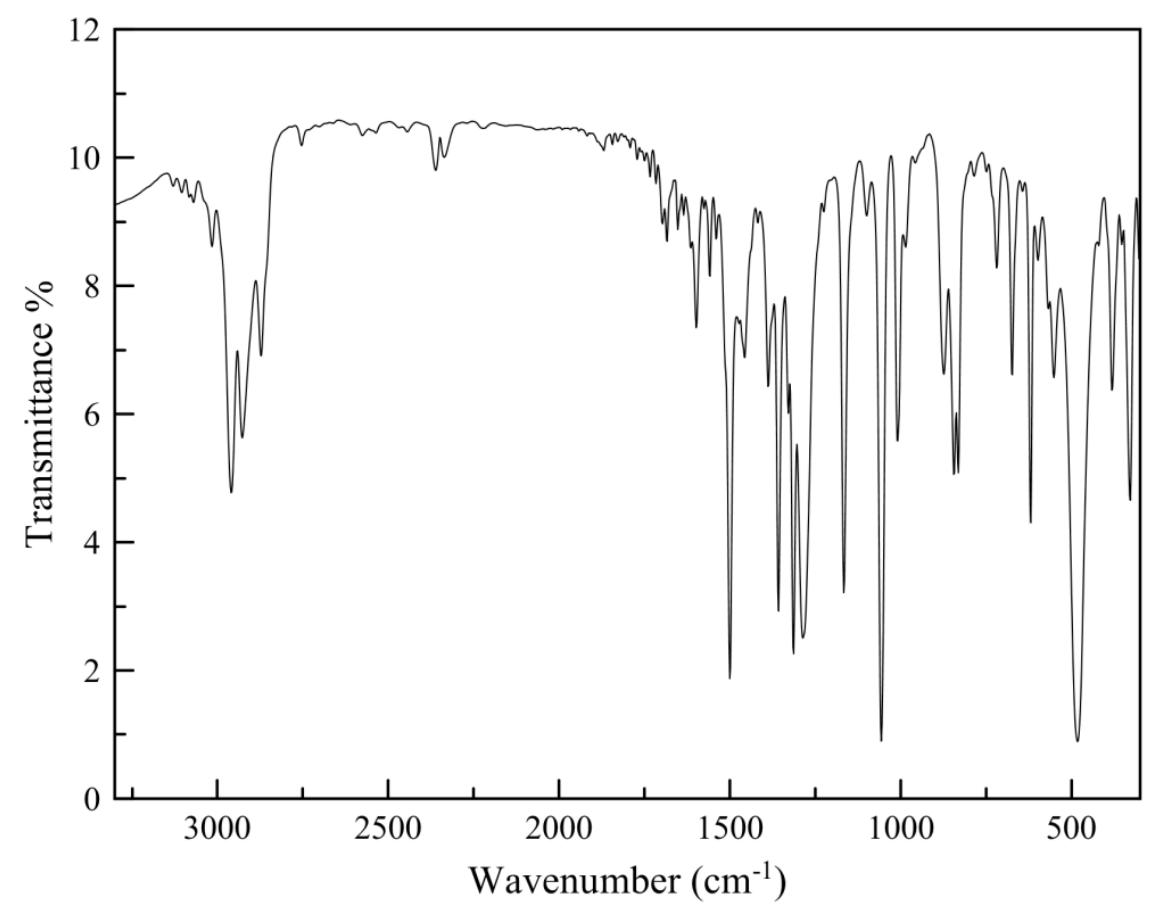

Figure 38. MID-FAR-IR of $\left[\mathrm{Fe}_{8}\left(\mu_{4}-\mathrm{O}\right)_{4}\left(\mu-4-\mathrm{CH}_{3}-\mathrm{pz}\right)_{12}\left(4-{ }^{\mathrm{s}} \mathrm{Bu}-\mathrm{C}_{6} \mathrm{H}_{4} \mathrm{O}\right)_{4}\right]$ (12). 


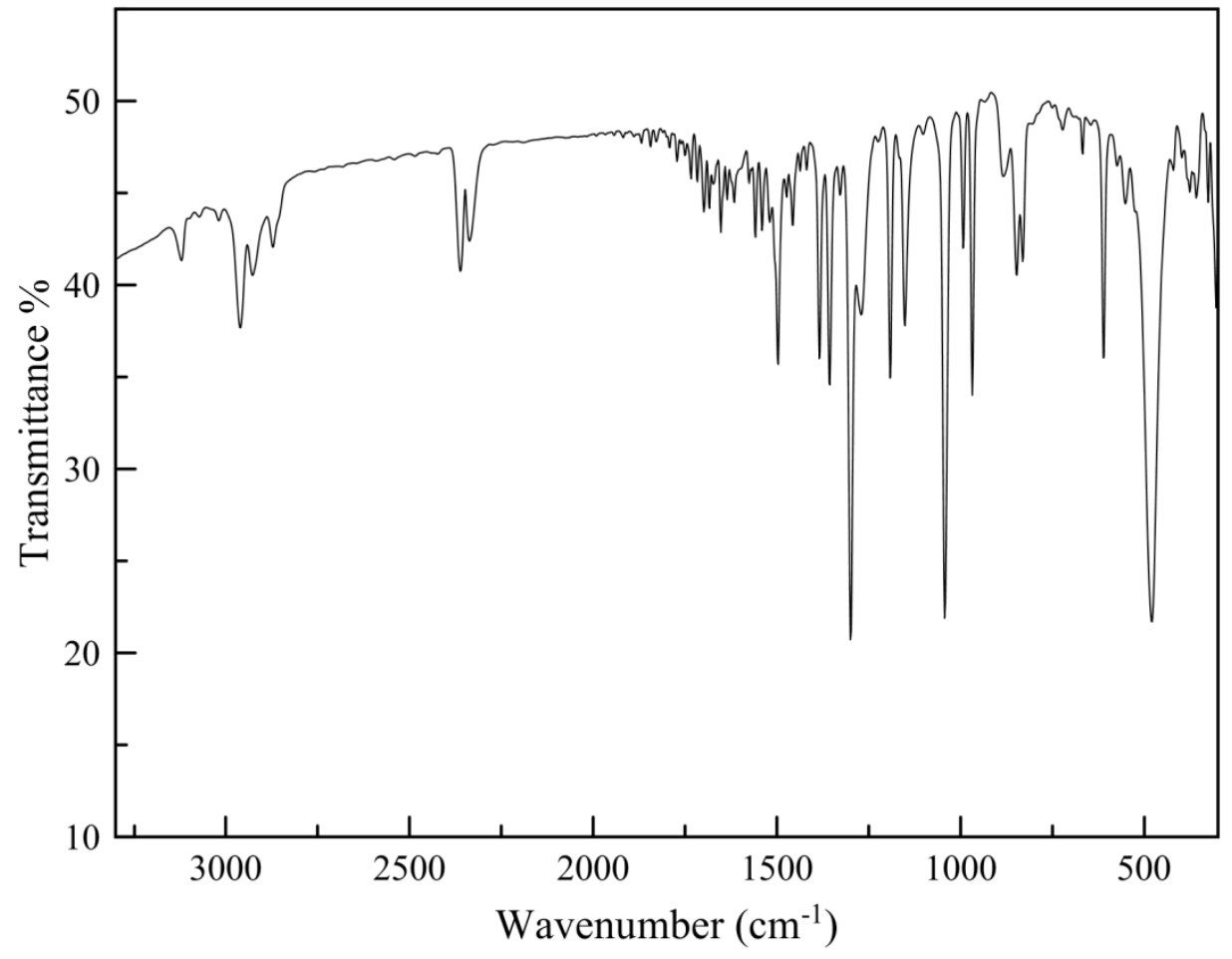

Figure 39. MID-FAR-IR of $\left[\mathrm{Fe}_{8}\left(\mu_{4}-\mathrm{O}\right)_{4}(\mu-4-\mathrm{Cl}-\mathrm{pz})_{12}\left(4-{ }^{\mathrm{s}} \mathrm{Bu}-\mathrm{C}_{6} \mathrm{H}_{4} \mathrm{O}\right)_{4}\right](\mathbf{1 3})$. 


\section{Permissions for reprint of publications}

\section{Chemical communications}

Order detail ID: 71856587

Order License Id: 4553241452888

ISSN : 1364-548X

Publication Type: e-Journal

Volume:

Issue:

Start page:

Publisher:

Author/Editor:
ROYAL SOCIETY OF CHEMISTRY Royal Society of Chemistry (Great Britain)

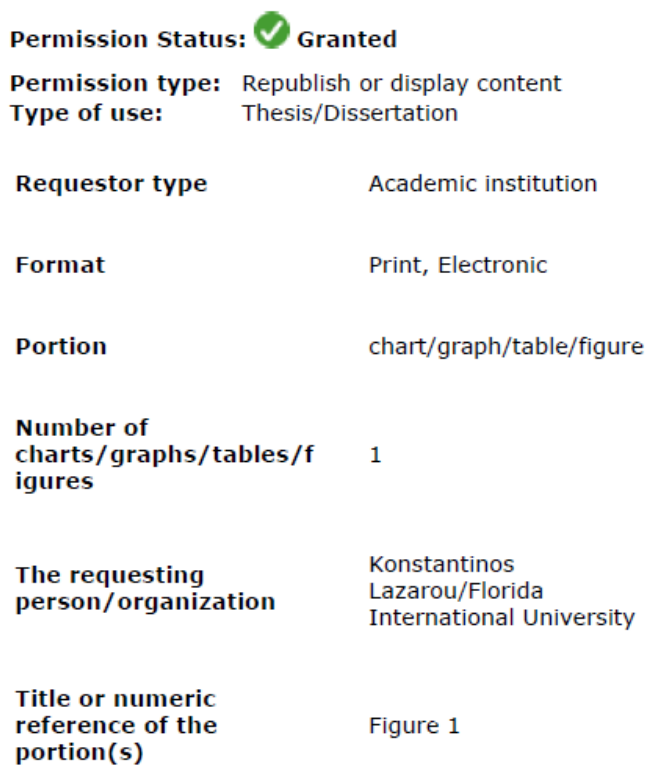

Permission Status: $\nabla_{\text {Granted }}$

Permission type: Republish or display content

Requestor typ

portion(s)

Konstantinos

Lazarou/Florida

International University

Figure 1 


\section{Copyright \\ Clearance \\ Center

ACS Publications Title:

Most Trusted. Most Cited. Most Read. Sigmoidal Gold Clusters: Probing the Correlation between Metal Atom Arrangement and Chiroptical Response

Author: Xin He, Yuechao Wang, Hong Jiang, et al

Publication: Journal of the American Chemical Society

Publisher: American Chemical Society

Date: May 1, 2016

Copyright (9) 2016, American Chemical Society

\section{PERMISSION/LICENSE IS GRANTED FOR YOUR ORDER AT NO CHARGE}

This type of permission/license, instead of the standard Terms \& Conditions, is sent to you because no fee is being charged for your order. Please note the following:

- Permission is granted for your request in both print and electronic formats, and translations.

- If figures and/or tables were requested, they may be adapted or used in part.

- Please print this page for your records and send a copy of it to your publisher/graduate school.

- Appropriate credit for the requested material should be given as follows: "Reprinted (adapted) with permission from (COMPLETE REFERENCE CITATION). Copyright (YEAR) American Chemical Society." Insert appropriate information in place of the capitalized words.

- One-time permission is granted only for the use specified in your request. No additional uses are granted (such as derivative works or other editions). For any other uses, please submit a new request. 
ACSPublications Title:

Most Trusted. Most Cited. Most Read.
Chiral Phase Transfer and Enantioenrichment of ThiolateProtected Au102 Clusters Author: Stefan Knoppe, O. Andrea Wong, Sami Malola, et al

Publication: Journal of the American Chemical Society

Publisher: American Chemical Society

Date: $\quad$ Mar 1, 2014

Copyright (e) 2014, American Chemical Society

\begin{tabular}{|l|}
\multicolumn{1}{|c|}{ LOGIN } \\
If you're a copyright.com \\
user, you can login to \\
RightsLink using your \\
copyright.com credentials. \\
Already a RightsLink user or \\
want to learn more?
\end{tabular}

want to learn more?

\section{PERMISSION/LICENSE IS GRANTED FOR YOUR ORDER AT NO CHARGE}

This type of permission/license, instead of the standard Terms \& Conditions, is sent to you because no fee is being charged for your order. Please note the following:

- Permission is granted for your request in both print and electronic formats, and translations.

- If figures and/or tables were requested, they may be adapted or used in part.

- Please print this page for your records and send a copy of it to your publisher/graduate school.

- Appropriate credit for the requested material should be given as follows: "Reprinted (adapted) with permission from (COMPLETE REFERENCE CITATION). Copyright (YEAR) American Chemical Society." Insert appropriate information in place of the capitalized words.

- One-time permission is granted only for the use specified in your request. No additional uses are granted (such as derivative works or other editions). For any other uses, please submit a new request. 
ACS Publications Title:

Most Trusted Most Cited Most Read.

\section{(a) \\ Author:}

Synthesis, Characterization, and Study of Octanuclear Iron-Oxo Clusters Containing a RedoxActive Fe404-Cubane Core Peter Baran, Roman Boča, Indranil Chakraborty, et al

Publication: Inorganic Chemistry

Publisher: American Chemical Society

Date: Jan 1, 2008

Copyright (s) 2008, American Chemical Society

If you're a copyright.com

user, you can login to

RightsLink using your

copyright.com credentials.

Already a RightsLink user or
want to learn more?

PERMISSION/LICENSE IS GRANTED FOR YOUR ORDER AT NO CHARGE

This type of permission/license, instead of the standard Terms \& Conditions, is sent to you because no fee is being charged for your order. Please note the following:

- Permission is granted for your request in both print and electronic formats, and translations.

- If figures and/or tables were requested, they may be adapted or used in part.

- Please print this page for your records and send a copy of it to your publisher/graduate school.

- Appropriate credit for the requested material should be given as follows: "Reprinted (adapted) with permission from (COMPLETE REFERENCE CITATION). Copyright (YEAR) American Chemical Society." Insert appropriate information in place of the capitalized words.

- One-time permission is granted only for the use specified in your request. No additional uses are granted (such as derivative works or other editions). For any other uses, please submit a new request. 
VITA

KONSTANTINOS LAZAROU

$\begin{array}{ll} & \text { Born, Naousa, Greece } \\ 2008 & \begin{array}{l}\text { Bachelor in Chemistry } \\ \text { University of Ioannina } \\ \text { Ioannina, Greece }\end{array} \\ & \begin{array}{l}\text { Master of Science - Bioinorganic Chemistry } \\ \text { University of Ioannina } \\ \text { Ioannina, Greece }\end{array} \\ & \begin{array}{l}\text { Graduate teaching assistant } \\ \text { Florida International University } \\ \text { Miami, FL }\end{array} \\ & \begin{array}{l}\text { Doctoral Candidate } \\ \text { Florida International University } \\ \text { Miami, FL }\end{array}\end{array}$

Oral presentations and publications

- Konstantinos Lazarou, Karilys Gonzalez-Nieves, Raphaels Raptis. "Resolution of the racemic octanuclear iron-oxo-pyrazolate to its $M$ and $P$ enantiomers". $257^{\text {th }}$ ACS National Meeting and Exposition, Orlando, FL, March $31^{\text {st }}-$ April $4^{\text {th }}, 2019$.

- Konstantinos Lazarou, Karilys Gonzalez-Nieves, Raphaels Raptis. "Resolution of the racemic octanuclear iron-oxo-pyrazolate to its $M$ and $P$ enantiomers". $93^{\text {rd }}$ Florida Annual Meeting and Exposition (FAME 2018), Florida Local Section of the ACS(FLACS), Tampa, FL, USA, May $3^{\text {rd }}-5^{\text {th }}, 2018$ 